\title{
Seeing Like a Neoliberal State? \\ Authoritarian High Modernism, Commercialization and \\ Governmentality in Rwanda's Agricultural Reform
}

\section{by}

Christopher Huggins

A thesis submitted to the Faculty of Graduate and Postdoctoral Affairs in partial fulfillment of the requirements for the degree of

Doctor of Philosophy

in

Geography with Specialization in Political Economy

Carleton University

Ottawa, Ontario

(C) 2013, Christopher Huggins 


\section{Abstract}

Rwanda's contemporary agricultural reform fits the criteria in James C. Scott's book, Seeing Like a State for an authoritarian high modernist project, as it involves the ambitious administrative re-ordering of nature and society according to transformative state simplifications, significant coercion, and marginalization of smallholder farmer preferences and indigenous knowledge. However, with its heterogeneous networks of state and non-state actors and processes of commercialization, the reform differs from the monolithic state projects in Scott (1998). Rwandan state policies have been described as 'liberalizing' and 'neoliberal'.

The dissertation examines whether increased involvement of commercial non-state actors in agricultural reform in Rwanda has an effect on processes of spatial and institutional homogenisation and coercion. I also investigate the ways in which discourses and practices of (neo)liberalism in the agricultural sector intersect with state efforts to mould ideas of citizenship, development, and governance.

Based on fieldwork in two districts of Rwanda in 2011 and 2013, and with reference to Foucauldian and Marxian concepts, I contend that although the government of Rwanda has incorporated neo-liberal policy tools into its administrative structures, this does not necessarily result in 'liberalization'. Increased involvement of non-state actors can reinforce processes of spatial and institutional homogenisation and coercion, such as imposition of obligatory land use consolidation and government-approved commercial 
crops. The introduction of private profit-making mechanisms into state-directed systems characterised by coercion have provided material incentives for state and non-state actors to continue to use coercive measures to increase sales (of fertiliser, for example).

The dissertation shows that the Rwandan state aims to create a new kind of Rwandan citizen, an entrepreneurial 'modern farmer' compliant with state policies, and fully integrated into commercial commodity-chains. Entrepreneurship, subjection to restrictive government policies, and patriotism are discursively intertwined, despite the tensions and contradictions this involves. These relationships are especially explicit in some geo-spatial contexts which represent 'spaces of governance' with particular characteristics. I also identify an emerging subject-type that incorporates elements of the state's ideal development subject and farmer notions of resistance. By significantly extending Scott's framework, the dissertation gives it new relevance to analysis of complex and heterogeneous authoritarian projects involving commercialization. 


\section{Acknowledgements}

This research was financially supported by a Departmental scholarship from the Department of Geography and Environmental Studies (DGES) at Carleton University, an Ontario Graduate Scholarship, a Philip E. Uren Fellowship and an Ina Hutchinson Award. Versions of the chapters were presented at various conferences, with financial assistance from the DGES travel bursary and the Indian Ocean World MCRI at McGill University. I also received a small grant from the Land Deal Politics Initiative. I am very grateful for all these sources of support.

The research was conducted with the permission of the Rwandan government, under research permits MINEDUC 802/12.00/2011, MINEDUC/S\&T/0026/2011, and MINEDUC/S\&T/0026/2013. I would like to thank the Rwandan Ministry of Education's Directorate of Science, Technology and Research for processing the research permit applications, as well as several local government officials and civil servants for their willingness to answer my questions (they remain anonymous in accordance with ethics protocols for the research).

I would like to thank all of the participants in this research for generously sharing their time and perspectives. The research would not have been possible without the excellent and dedicated work of the research assistants, particularly the primary field researcher 
who must remain anonymous. May the furrow you hoe always bring fruit, even when the climate is harsh.

My PhD co-supervisors Blair Rutherford and Simon Dalby have been extremely supportive and responsive, even in the midst of institutional changes. Committee member Marie-Eve Desrosiers consistently offered excellent advice in a very timely manner. Thank you all.

Most of all I would like to thank my family, including Christine and Sudha for providing childcare and a place to work in peace, Siddhu and Safia for their flexibility and patience when their dad and mum were so busy, and especially Sheila for her daily moral, intellectual, and logistical support, which allowed the dissertation to be written. Sheila, I hope your current academic journey is even more fulfilling than mine.

This dissertation is dedicated to all the people of Rwanda, particularly those in rural areas who work hard every day to navigate the risks and opportunities of the changing agricultural landscape; and to the memory of the late Alison Des Forges, a great academic and a wonderful human being. 


\section{Contents}

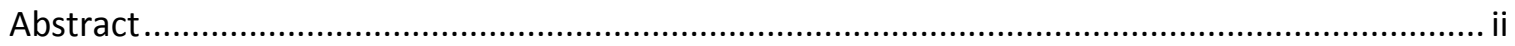

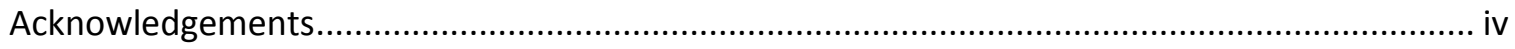

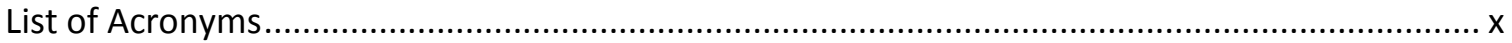

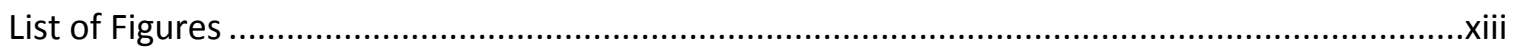

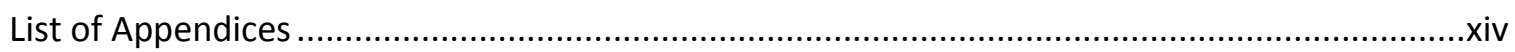

Chapter One: Introduction and Research Questions.............................................................. 1

Post-Genocide Rwanda and Authoritarian High Modernism ................................................. 1

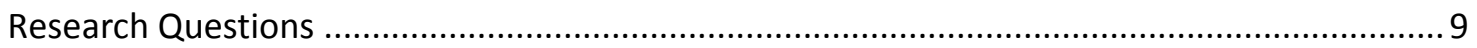

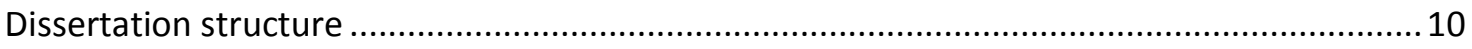

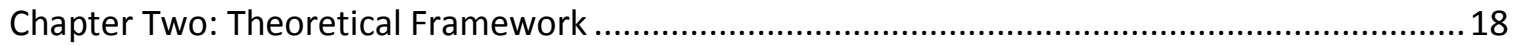

The Authoritarian High Modernism Theoretical Framework: its Strengths and Limitations .... 20

The 'Authoritarian High Modernism' model and the Fallacy of the Monolithic State ..............22

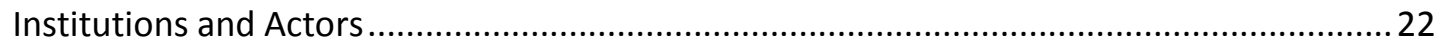

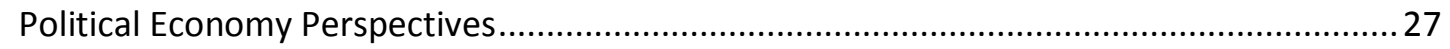

Forms of Power: Discipline, Sovereignty and Governmentality ........................................... 40

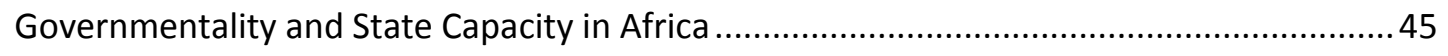

Governmentality and Neoliberalism in Africa................................................................... 49

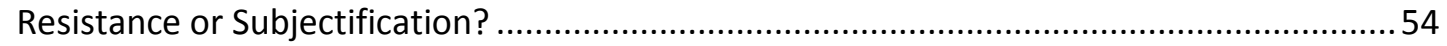

Geographical Context and 'Spaces of Governance' ............................................................. 57

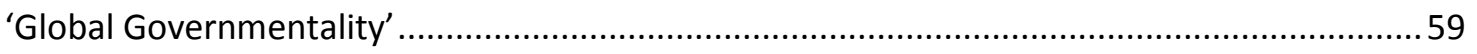

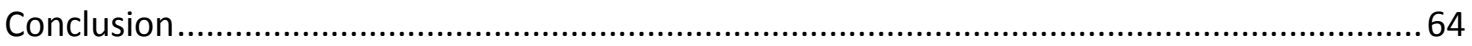

Chapter Three: An Overview of the Political Economy of Agricultural Reform in Rwanda ...........69

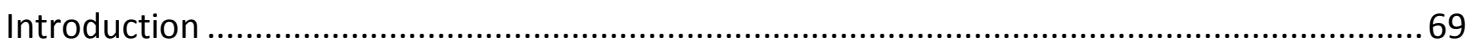

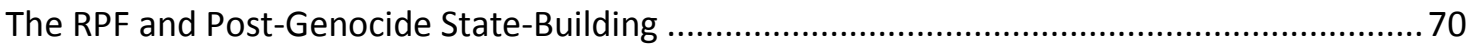

Internal Drivers of Change in the Rwandan Agricultural Sector ............................................. 78

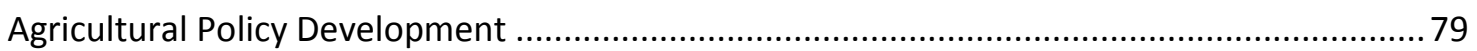

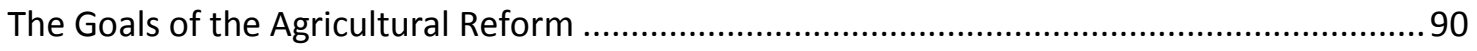

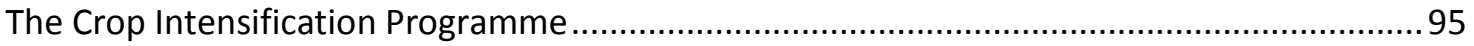

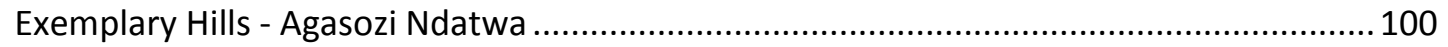

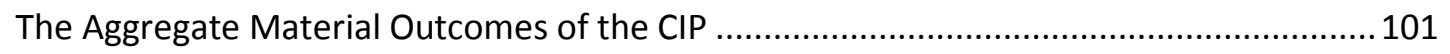




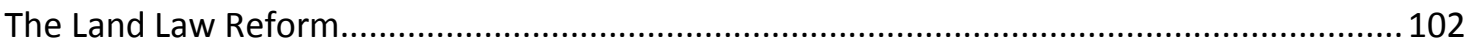

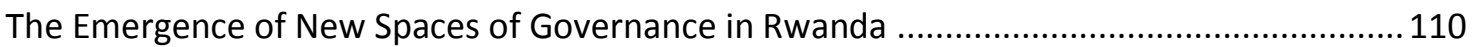

Domestic and Foreign Corporate Investment in the Agricultural Sector ............................... 114

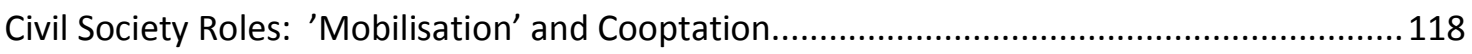

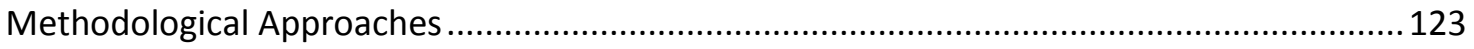

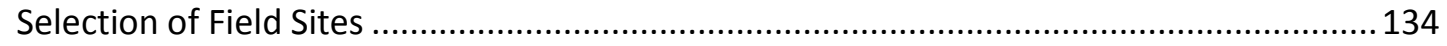

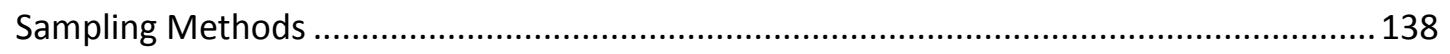

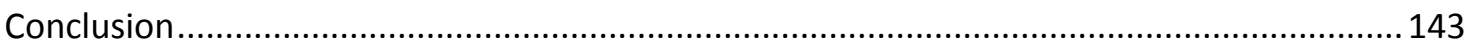

Chapter Four: Rwanda's Modernist Agricultural Reform in an International Context................ 148

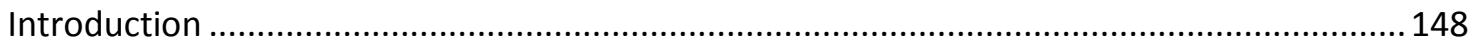

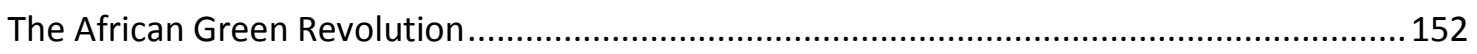

Rwanda's Engagement in International Governmental Networks ........................................ 156

The Agricultural Reform in Rwanda and International Governmentality.............................. 157

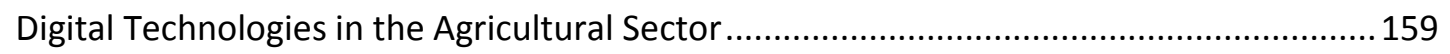

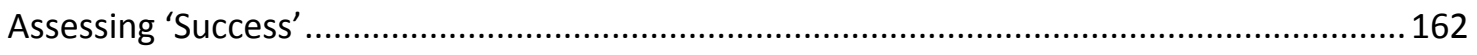

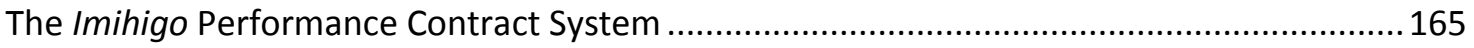

The Government of Rwanda and International Governmentality....................................... 171

Donor-government Coordination Mechanisms within Rwanda ........................................ 174

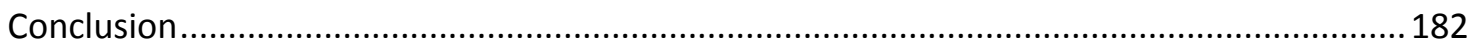

Chapter Five: Systems of Governmentality and Discipline in Rwanda ..................................... 186

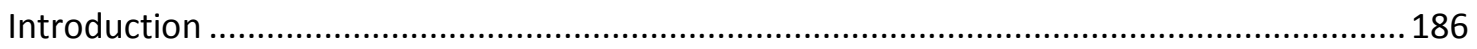

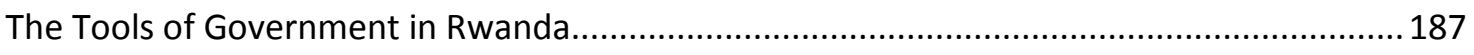

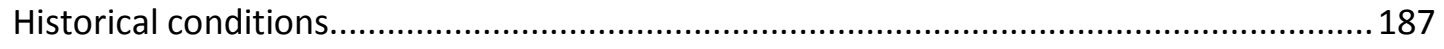

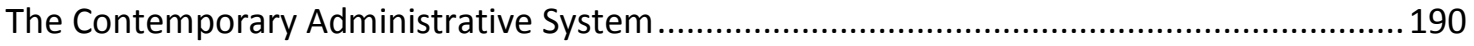

'Eradicating Genocide Ideology' and 'Promoting National Unity and Reconciliation' in Rwanda

Creating an Ideal Farmer: Governmentality in the Agricultural Sector ...................................208

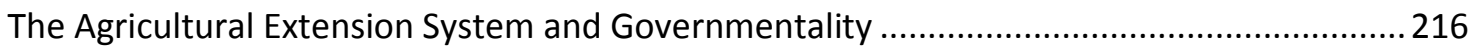

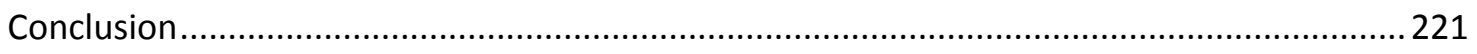

Chapter Six: Agricultural Cooperatives in Musanze District .................................................... 224

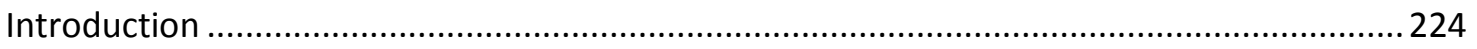

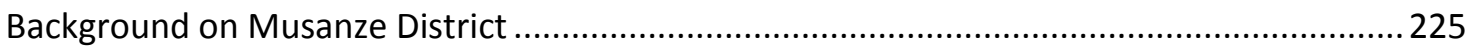


Implementation of the National Agricultural Policy in Musanze District ...............................226

The Diverse Nature of Cooperatives in Musanze District .......................................................... 230

Case Study: A 'Policy Entrepreneur', Conflict, and Primitive Accumulation in an Agricultural Cooperative

State Discourse and Private Initiative: Founding the Cooperative .....................................233

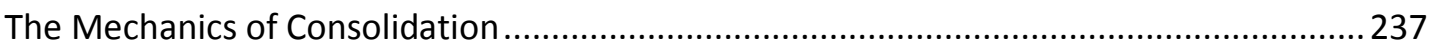

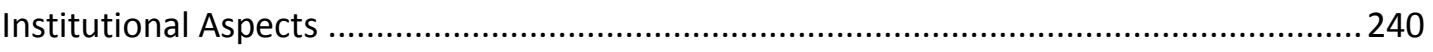

Primitive Accumulation: Purchase of Land at Artificially Low Rates...................................241

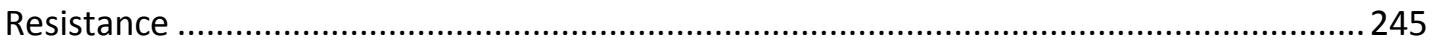

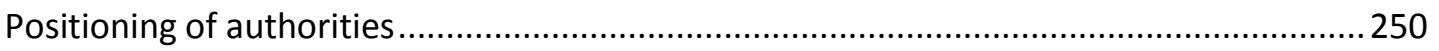

Class Divisions and Conflict amongst the Population ..........................................................253

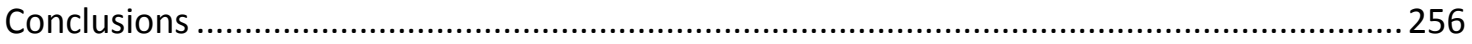

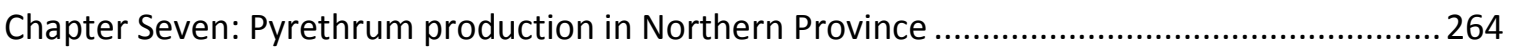

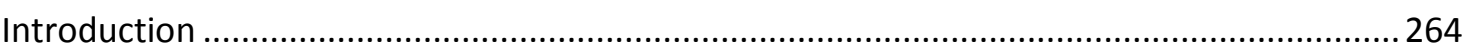

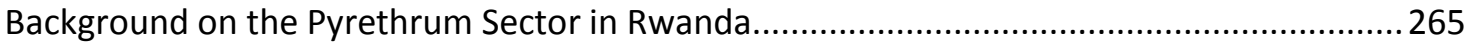

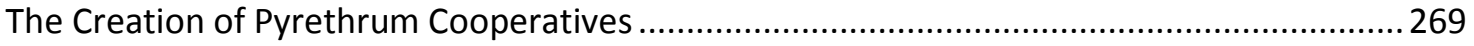

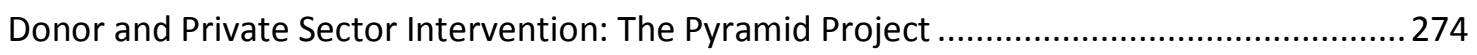

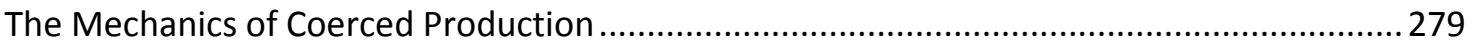

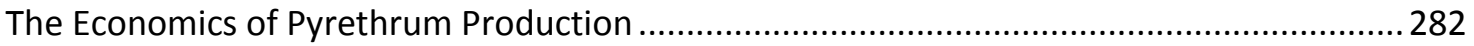

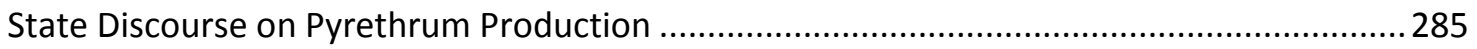

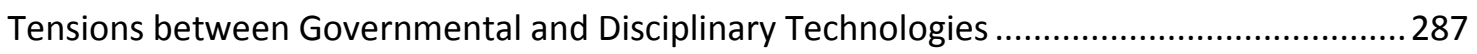

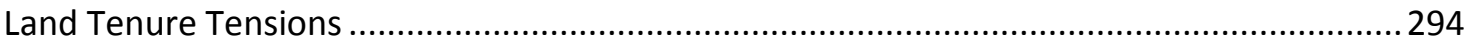

Farmer Perceptions of the Pyrethrum Production and Marketing System ...........................296

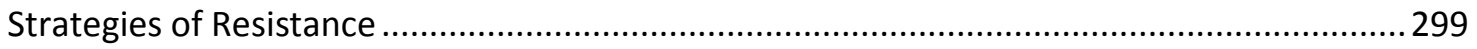

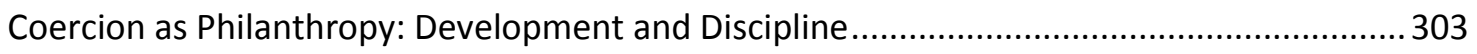

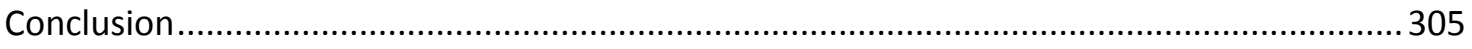

Chapter Eight: Maize Production in Mahama Sector, Kirehe District.......................................... 310

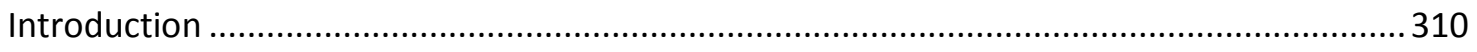

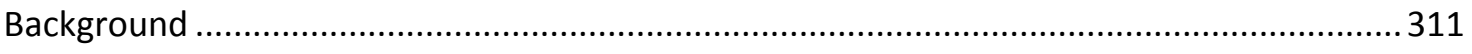

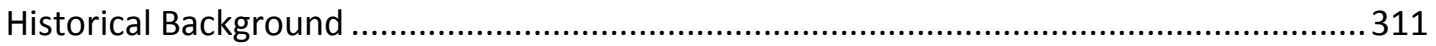

Agro-Ecological Characteristics of Kirehe District ............................................................. 313

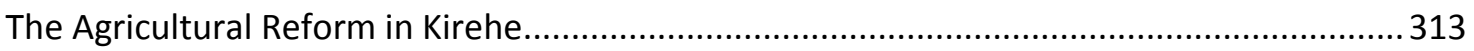




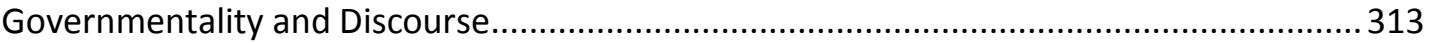

The CIP System for Maize Cultivation in Kirehe District .................................................... 317

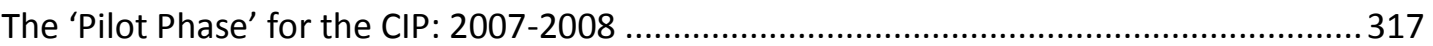

Private Actors and Public-Private Partnerships within the Maize sector .............................322

Illegal and Covert Systems of Private Accumulation within the Maize Sector ......................325

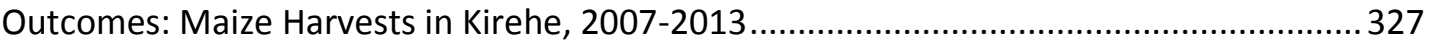

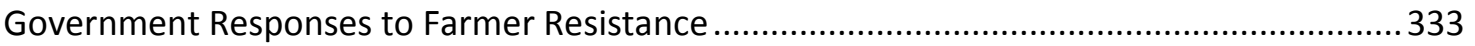

The Rwandan State 'Connectedness Machinery' ................................................................. 337

High Modernism or Developmentalist Macro-Economics? .................................................. 344

Authoritarian High Modernism and Local Government 'Flexibility' ......................................345

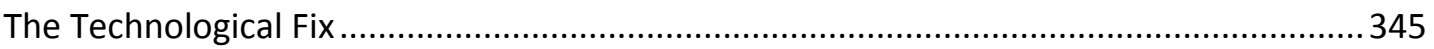

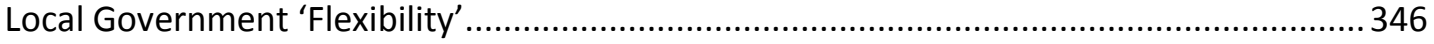

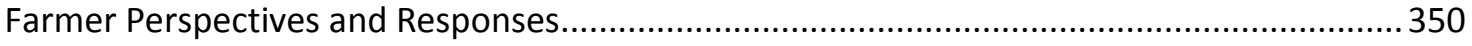

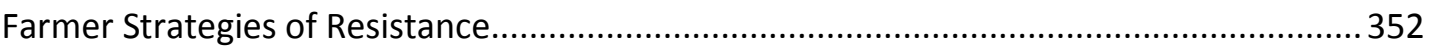

Emigration to neighbouring Countries and Migration within Rwanda ..................................356

Smallholder Farmer Discourses on Agricultural policy implementation ..............................358

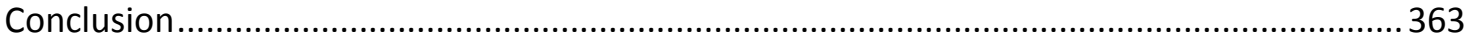

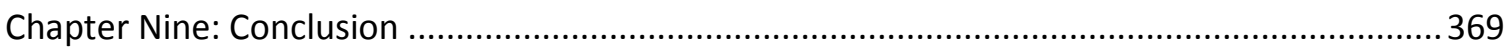

Governmentality, Markets, and Spaces of Governance ….................................................. 381

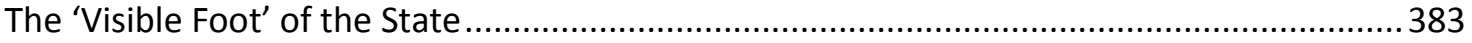

Farmers' Responses and Emerging Alternatives to the 'Model Farmer' Model.......................388

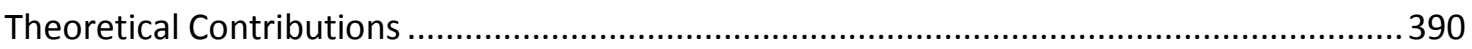

Theoretical and Methodological Implications of the Research, and Recommendations for

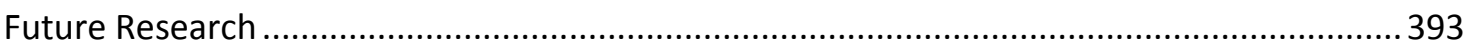

Appendix One: Comparative Value of Pyrethrum and Potato Crops ........................................399

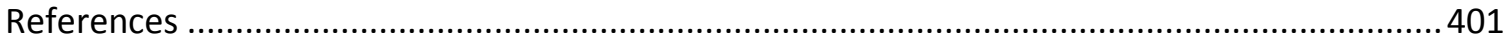




\section{List of Acronyms}

\begin{tabular}{|c|c|}
\hline APRM & African Peer Review Mechanism \\
\hline BRD & Banque Rwandaise de Developpement \\
\hline CAADP & Comprehensive Africa Agriculture Development Programme \\
\hline CIP & Crop Intensification Programme \\
\hline $\mathrm{CSO}$ & Civil Society Organization \\
\hline DFID & Department for International Development \\
\hline DRC & Democratic Republic of Congo \\
\hline ENAS & Entreprise Nkubili Alfred and Sons \\
\hline FDI & Foreign Direct Investment \\
\hline GIS & Geographic Information System \\
\hline GPS & Global Positioning System \\
\hline IRST & Institute of Scientific and Technological Research \\
\hline ISAR & Rwanda Agricultural Research Institute \\
\hline OCIR-café & Rwanda Coffee Authority \\
\hline OCIR-thé & Rwanda Tea Authority \\
\hline
\end{tabular}




\begin{tabular}{|c|c|}
\hline JGA & Joint Governance Assessment \\
\hline LDF & Local Defence Forces \\
\hline MCA & Millennium Challenge Account \\
\hline MDG & Millennium Development Goals \\
\hline MINAGRI & Ministry of Agriculture and Animal Resources \\
\hline MINALOC & Ministry of Local Government \\
\hline MINECOFIN & Ministry of Finance and Economic Planning \\
\hline MINICOM & Ministry of Trade and Industry \\
\hline MININFRA & Ministry Of Infrastructure \\
\hline MINITERE & Ministry of Lands Environment, Forests, Water and Mines \\
\hline NGO & Non-Governmental Organization \\
\hline NIRDA & National Industrial Research and Development Agency \\
\hline NISR & National Institute of Statistics of Rwanda \\
\hline NLC & National Land Commission \\
\hline NLTRP & National Land Tenure Regularisation Programme \\
\hline NURC & National Unity and Reconciliation Commission \\
\hline A & Rwanda Agricultural Development Authority \\
\hline
\end{tabular}


RDB

REMA

RPF

RWF

SOPYRWA

SPAT

SPREAD

TIG

USAID
Rwanda Development Board

Rwanda Environment Management Authority

Rwandan Patriotic Front

Rwandan Francs

Société du Pyrethe au Rwanda

Strategic Plan for Agricultural Transformation

Sustaining Partnerships to enhance Rural Enterprise and

Agribusiness Development

Travail d'Intérêt Général

United States Agency for International Development 


\section{List of Figures}

Map One: Approximate Locations of Fieldsites

Figure One: Organisational Chart of the Rwandan Administrative System

Figure Two: Rwandan Pyrethrum Production by Year

Figure Three: Area under Maize Production and Total Maize Production

Figure Four: Area under Maize Production and Average National Maize Yield

Figure Five: Maize Yields per Hectare, Kirehe District, 2007-2012 


\section{List of Appendices}

Appendix One: Comparative Value of Pyrethrum and Potato Crops

399 


\section{Chapter One: Introduction and Research Questions}

\section{Post-Genocide Rwanda and Authoritarian High Modernism}

James Scott's (1998) masterful work on the ambitious visions of 'modernity' pursued by many regimes throughout recent history describes how states impose their own, simplified logics of standardisation upon complex social, ecological and economic systems. The results are often highly problematic. Scott emphasises that the authoritarian high modernism he describes is not necessarily linked to any single political system, and can be found in capitalist as well as socialist contexts. He contends (1998: 4-5) that authoritarian high modernist regimes have four key characteristics:

1. The administrative ordering of nature and society [according to] transformative state simplifications.

2. A strong...version of the self-confidence about scientific and technological progress...commensurate with the scientific understanding of natural laws.

3. An authoritarian state which is willing and able to use the full weight of its coercive power to bring these high-modernist designs into being.

4. A prostrate civil society that lacks the capacity to resist these plans. 
Furthermore, Scott emphasises that for high modernist planners, 'the past is an impediment; a history that must be transcended; the present is the platform for launching plans for a better future' (Scott, 1998: 95).

Substantial evidence suggests that Scott's description can be applied to the contemporary government of Rwanda. The post-genocide state has embarked on a number of very large-scale, ambitious programmes which involve re-ordering the natural and social landscape, based almost exclusively on a centralized, top-down model of design and implementation which undervalues local knowledge and perceptions. Where citizens, or non-governmental organizations, have attempted to mount an energetic critique of these programmes, the state has found ways to silence them, whether through cooptation or intimidation.

These programmes of social and environmental re-ordering include (in approximately chronological order):

- The 'villagization' of hundreds of thousands of people across the country in the years 1996-2000 (Human Rights Watch, 2001; Newbury, 2011)

- The establishment of new systems of 'civil re-education' (ingando and itorero) and the 're-education' of hundreds of thousands of people since $1999 .^{1}$

\footnotetext{
${ }^{1}$ The ingando camps were first initiated in 1996, but were extended in scope in 1999. It is the intention of the NURC that every Rwandan goes through ingando at some point (Mgbako, 2005). Some 87,000 people have been through itorero in the last two years according to the government, and the intention is to decentralize itorero to the village level (Buhura, 2011).
} 
- The villagization of hundreds of thousands of people across the country since 2007 , with the aim of ensuring that $70 \%$ of the national population lives in planned villages by 2020, from a level of 20\% in 2007 (Havugimana, 2009: 49)

- The introduction of a long list of infractions related to hygiene, tidiness of appearance, and environmental management, punishable by fines and other sanctions (Ingelaere, 2011: 74)

- National-level agricultural reform typified by large-scale marshland reclamation, radical terracing of hundreds of hillsides, and the rapid enrolment of the population into cooperatives (Ansoms, 2009; Huggins, 2009a)

- A national-level systematic land registration programme implemented extremely rapidly between 2008 and 2012 (Sagashya and English, 2010; Huggins, 2009a)

- A master-plan for the comprehensive redevelopment of Kigali city which emphasizes high-value commercial real estate and provides few liveable spaces for the urban poor. As part of a set of 'African Urban Fantasies' (Watson, 2012), it represents a new variation on the high modernism model. ${ }^{2}$

Many of these programmes have involved coercion, which can take different forms. The threats and use of violence against people and property during the 1996-2000 villagization programme have been well-documented (Human Rights Watch, 2001; Newbury, 2011); while the various 'infractions' around hygiene and appearance are punishable by fines, even though they have not been supported by any legislation. As

\footnotetext{
${ }^{2}$ Watson states that such plans are 'based on images of Dubai, Shanghai and Singapore, but are still rooted in the work of 1930s French [modernist] architect Le Corbusier' (2012, Slide 2).
} 
will be discussed in this dissertation, the agricultural reform, which has resulted in massive increases in production of many crops, has been implemented partly through the use of force in some cases (Pritchard, 2013; Newbury, 2011; Ansoms 2009; Huggins, 2009a; Ingelaere, 2007). This is not unique. The Green Revolution in Asia was associated with some degree of coercive control over farmers. Raj Patel has argued that, 'the Philippines, India, Pakistan, Chile, Indonesia; all of them required strong authoritarian states [...] in order for the Green Revolution to work as we know it, it required not only better seeds but guns' (cited in Foster, 2011). Jirstrom (2005: 40) argues that in India and Bangladesh, programmes were designed and implemented in a 'top-down' fashion (Djurfeldt and Jirstrom, 2005: 60). In Indonesia too, the authoritarian Suharto regime (1966-1998) provided a uniform package of inputs, credit and technologies to millions of farmers, whether they wanted them or not (Takeshi et al, 2011). The emphasis on increasing rice production led to the implementation of a simple, standard intervention, reminiscent of that described by Scott in his critique of industrial farming models, which were not based on local demand or tailored to local socio-economic or agro-ecological conditions.

In Rwanda, the ruling party's faith in technical expertise and science as a means of overcoming social and environmental constraints is everywhere evident within the agricultural policy, as well as the broader vision of becoming a 'Singapore in Africa', a world-class centre for financial, high-tech, and other highly-skilled services, by 2020 (Mills, 2010). Government personnel speak confidently about the country soon hosting factories that would function 24 hours per day (Ansoms, 2011: 245). Increased access to 
information communication technologies, in particular, is a key element of the country's development policies. Computer access has been facilitated by hundreds of kilometres of fibre-optic cable, and the installation of a $4 \mathrm{G}$ wireless network across Kigali, in what has been described as 'a typically Rwandan approach - aim big and sort the details out as you go' (BBC, 2009). This emphasis on high-tech aspects of 'development', particularly in large urban centres, is paralleled by a denigration of 'customary' and informal knowledge and practices, especially in rural areas.

Rwanda is, on the face of it, a multi-party democracy with open debate on issues of government policy. However, in reality, the ruling Rwandan Patriotic Front (RPF) dominates political life (Uvin, 2003), and civil society in Rwanda has very little political space or freedom of expression (Longman, 2011). This is well documented, even by observers generally very sympathetic to the Rwandan government (see e.g. US Department of State, 2010a).

The invention of a 'New Rwanda' after the genocide is a prime example of the reinvention or 're-imagining' (Pottier, 2002) of the country and emphasis on a brighter future. After the genocide, the RPF introduced a new national flag; launched a national newspaper called the 'New Times'; renamed and restructured the territorial administrative units of the country; and introduced English as one of the national languages, phasing out the use of French. Ethnic identifiers have been abolished and it is considered a crime to openly discuss ethnicity except in a small number of specific instances and within certain conceptual boundaries imposed and policed by the state. 
The colonial and post-independence, pre-genocide history of the country is referred to in official discourse only in negative terms, reminding us that 'the past is an impediment' (Scott, 1998: 95)

For these reasons, many scholars argue that contemporary Rwanda closely fits Scott's characterization of an authoritarian high modernist state. Scholars have argued that particular government programmes are best seen as examples of 'authoritarian high modernism', especially its villagization policy (Ansoms et al, forthcoming; Newbury, 2011; Jackson, 1999) and have also applied the 'high modernist' label to the political programme of the government as a whole (see e.g. Jones et al, 2013; Dagan, 2011; Strauss and Waldorf, 2011; Hasselskog, 2011; Thomson, 2010). The Rwandan agricultural reform, which has been underway since 2007, very much fits the model of authoritarian high modernism. In particular, its emphasis on a small number of 'priority' commercial crops brings to mind the challenges of Scott's chapter on agricultural modernism, 'Taming Nature' (1998: 262-306). The policy has been designed in a highly centralised, top-down manner and has been imposed using coercive measures including fines and destruction of private property (Pritchard, 2013; Newbury, 2011; Ansoms 2009; Huggins, 2009a; Ingelaere, 2007).

However, there is a counter-narrative, produced and communicated by the Rwandan state as well as many of its 'development partners', which emphasises more liberal aspects of state policy. The agricultural policy's focus is seemingly predicated on 'development' through market mechanisms such as an emphasis on: commercial crops; 
mechanization; massive uptakes in the use of fertilizer, hybrid seeds and other inputs; and commercialization in general. The conceptual framework for this agricultural reform, as explained in the agricultural policy, broadly follows the neo-liberal model:

The main principle will be to keep the Government away from activities related to production, processing and marketing of farm products to the benefit of private sector, its role being concentrated on conception activities, reinforcement of laws, planning, promotion and coordination of development of agricultural sector (MINAGRI, 2004a).

The agricultural policy states that 'farmers must produce for the market', and envisions the 'setting up of mechanisms enabling [sic] to shift from subsistence agriculture to market oriented agriculture' (MINAGRI 2009: 9). Indeed, this appears to be occurring, and the reform has also achieved massive increases in the production of priority crops, in terms of both aggregate and per-hectare production (FAO, 2013, Kathiresan, 2012, Concern Worldwide, 2011). Donors have been heavily involved in liberalization of commodity chains of key agricultural and horticultural export crops, such as coffee, tea, and pyrethrum (OECD/WTO, 2011; Boudreaux, and Ahluwalia, 2009). While undoubtedly state-led, the agricultural reform is a heterogeneous phenomenon, incorporating private sector actors, local and international NGOs, donors, and other actors within the policy-making processes and in multiple institutional structures. Prior to the nationwide implementation of the agricultural reform, the government put in place a land policy and land law which emphasize the importance of markets in land, 
and the efficiencies incentives for commercial investment that are likely to result. The government aims to improve private sector involvement in the agriculture sector (Concern Worldwide, 2011) and has developed initiatives to promote 'demand driven' services (ibid). In this context, observers have noted that 'liberalization and privatization processes are ongoing' (Schrader \& Wennink, 2010: 1) and that Rwanda is one of the most 'business-friendly governments in Africa' (De Lorenzo, 2008; cited in Sommers, 2012: 213). Commercial actors include foreign investors as well as Rwandan cooperatives, which have rapidly multiplied in recent years. The government established an Agriculture Guarantee Fund in 2005 to encourage bank lending to the agricultural sector for private-sector investment (Booth \& Golooba-Mutebi, 2012: 10) as well as public funding for cooperatives. The World Bank believes that there has been 'a strong and sustained commitment by national authorities to private sector development' (World Bank, 2013: 37) and notes that in addition to government bodies, 'Civil society, development partners and institutions such as the Presidential Advisory Council have also provided crucial input in shaping the [business regulation] reform agenda' (World Bank, 2013: 38), while international expertise has also been recruited by the state to contribute to the reform (2013: 41). Some observers go as far as to claim that Rwanda has a 'pro-private sector, free market economy' (Crisafulli \& Redmond, 2012: 3). This market-orientation is coupled with an incessant emphasis on the key role of emerging Rwandan 'entrepreneurs'. President Kagame has stated that he considers entrepreneurship to be 'the backbone of a new Rwanda' (Kagame, 2009). In the agricultural sector, this idea of entrepreneurship takes the form of the ideal 'modern 
farmer' who operates on commercial principles, adopts new technologies, and uses private credit to expand and update his or her commercial farm. My dissertation thus aims to explore this apparent contradiction between state-led high modernist development and a neoliberal policy orientation, which involves non-state actors as major actors in the agricultural reform.

\section{Research Questions}

The 'neoliberal' tendencies mentioned above do not easily match the authoritarian high modernism label, as will be described in Chapter Two. However, Scott's theoretical engagement with 'the market' is incomplete and somewhat ambiguous. He argues that 'large-scale capitalism', like high modernism, is a force for 'homogenization, uniformity, grids and heroic simplification' (1998:8), but this claim has been contested. For example, James Ferguson contends, in contrast, that many transnational companies create enclave economies focusing on specific geographic areas of 'value', neglecting less valuable areas, and thus increase the differentiation of local economies, rather than the homogenization of such spaces (Ferguson, 2005). At the same time, Scott argues that authoritarian high modernism is unlikely to occur within a liberal political economy' (1998: 101). While Rwanda's political economy cannot be described as 'liberal', there are some signs of increasing liberalization. My research questions therefore, are: 
What effects does the increased involvement of commercial non-state actors in the agricultural sector have on the processes of spatial and institutional homogenisation, standardisation, and coercion associated with authoritarian high modernism? Given the historically close association between projects of state-building (broadly defined) and processes of commodification and commercialization, how do discourses and practices of (neo)liberalism in the agricultural sector intersect with state efforts to mould ideas of citizenship, development, and governance, within specific geo-spatial contexts? ${ }^{3}$

\section{Dissertation structure}

The dissertation is structured as follows: Chapter Two provides the overall theoretical framework. Noting the relevance of the authoritarian high modernism model to our Rwandan case study, I argue that Scott's framework must be adapted through reference to critical political economy literature, particularly in order to refer to processes of accumulation by dispossession and proletarianization which are evident in the case studies (Chapters Six-Eight). Theory suggests that processes of accumulation by dispossession are linked to commercialization of the agricultural sector, as they benefit powerful actors dominating processes of commercialization. I also bring in a Foucauldian theoretical framework in order to provide a more nuanced version of power relations.

\footnotetext{
3 'State building' has a number of possible interpretations. It can include efforts by both domestic (national) actors and external (foreign) actors to extend the governance capacity and the legitimacy of the state (Fritz and Menocal, 2007). Here I am referring primarily to efforts by the government of Rwanda to extend, or strengthen, its own capacities and powers.
} 
Chapter Three charts the key elements of Rwanda's political economy, examining the government's discourses and practices of neoliberalism, but noting significant nonneoliberal tendencies. This chapter also demonstrates that the incorporation of commercial and non-profit actors into the apparatus of rural development programming reinforces and extends the power of the state, rather than providing alternatives to state policies of homogenization, standardisation and coercion. It contends that profit at the higher levels of agricultural commodity chains, rather than at the level of the farming household, likely motivated the choice of crop types in the crop intensification programme, suggesting that the agricultural reform reflects a neoliberal model of economic growth which facilitates the accumulation of capital by capitalist elites, rather than lower- and middle-income groups. This chapter also includes an explanation of my methodologies which include extensive farmer-focused fieldwork.

In Chapter Four, I situate Rwanda's reform within a broader context of the 'Green Revolution for Africa', and trace the nature of relations between the government of Rwanda and donor agencies, through a 'global governmentality' framework. Such a framework enables me to recognise how international systems of assessment of aid effectiveness and governance (which are linked to foreign investment decision-making, and hence commercialization of agriculture) require states like Rwanda to produce quantitative, aggregate data on policy implementation. Such systems of data collection are a homogenizing technology in the sense that they obscure socio-economic and spatial differentiation. This chapter also describes how multiple actors involved in the agricultural reform function as part of an apparatus which is heterogeneous but 
coordinated. Further, this chapter examines Rwandan governance technologies and demonstrates that they are simultaneously methods of demonstrating policy 'success' to an international audience (including potential foreign investors), and a means to 'mould ideas of citizenship'.

Chapter Five describes the administrative system in rural Rwanda, and the ways in which the agricultural extension system depends upon it. I demonstrate that the 'modern farmer' notion (comprising ideas of commercialization of agriculture and the neoliberal ideal of the self-governing, entrepreneurial individual) that is reproduced by state-dominated apparatus, is inseparable from the wider RPF project of creating ideal post-genocide 'New Rwandan citizens'. Moreover, the chapter describes the key role of non-governmental organizations in the agricultural extension system, and shows that by aligning themselves with government systems of spatial and institutional homogenisation, standardisation and coercion, such organizations can maximise their profits from the sale of services and inputs to farmers, as well as the purchase of crops from farmers.

Chapter Six is the first of three in-depth case studies, based on fieldwork. This chapter starts by providing an overview of the implementation of the Crop Intensification Programme (CIP) in Musanze District, Northern Province. It notes that cooperatives themselves are far from homogenous in nature, though they are all obliged to abide by government policies on crop cultivation. While some cooperatives are formed through government 'mobilization', others are founded more spontaneously by smallholder 
farmers, or wealthier entrepreneurs. While entrepreneurs may be independent from the state, government policy favouring cooperatives provides them with a discursive and institutional framework for exercising control over the land and labour of large numbers of smallholders. The chapter presents the example of a maize and potatoproducers cooperative which was founded by an entrepreneur. The case study illustrates the ways in which private actors may use the same homogenizing technologies as the state while relying on particular 'local' dynamics to ensure their influence and control over agricultural institutions such as cooperatives. It is also an example of overt individual and collective resistance to a very politically and economically powerful individual. This case study suggests that the standard government blueprints for agricultural production are implemented through recourse to highly context-specific relationships and hence result in particular 'spaces of governance'. Homogenous models of agricultural transformation are implemented in diverse, heterogeneous ways.

Chapter Seven examines whether the authoritarian nature of the pyrethrum sector in Musanze District has been altered by an apparent 'privatization' of the state pyrethrum agency, and the investment of foreign capital and bilateral aid. As with other strategic crops, pyrethrum production is associated in local government discourse with patriotism and sacrifice for national development, allowing me to trace very clear links between discourses and practices of (neo) liberalism in the pyrethrum sector and state efforts to mould ideas of citizenship. The commercial firms and bilateral aid agency involved in the pyrethrum sector have coordinated to increase the level of coercion in the pyrethrum- 
producing zone, whilst simultaneously adopting some policies associated with governmental approaches. I identify the pyrethrum zone as an enclave of extraction, in which local people are subjected to particular governance systems that differ from those in other parts of the country. The standardised approach to production within the pyrethrum zone represents a force for homogeneity when viewed at the level of the entire pyrethrum zone; however, from a broader geographical scale, this is a highly context-specific set of practices which represents a specific 'space of governance' within Rwanda.

The final case study, presented in Chapter Eight, describes the disciplinary and governmental approaches to enforcing maize policies in Mahama Sector of Kirehe District. As in the previous case study, state actors called upon people to grow maize because it was their patriotic duty to do so, and because it was associated with 'development'. Whereas farmers often lose money growing maize (as it is not sufficiently drought-tolerant for the local agro-ecological conditions), commercialization of the maize sector in Mahama Sector, Kirehe District has involved new financial incentives for local authorities, who receive payments when fertilizer is purchased and correctly applied by farmers. This leads to widespread coercion, as many farmers are forced to buy fertilizer. Neoliberal approaches in the maize sector are therefore clearly harnessed to processes of homogenization and coercion. Many farmers feel that their role, as citizen-producers within the contemporary Rwandan rural political economy, is reduced to a labour force. Characterizing the state as interested only in the profit of elites, describing the state and farmers as in a state of 'war', perceiving of themselves as 
being impoverished by the continued insistence on maize, utilizing similar rhetoric of 'slavery' to that found in Musanze District (Chapter Seven), citizens in Mahama sector have engaged in a number of covert strategies which go beyond 'everyday forms of resistance' and amount to radical reconfiguration of livelihood strategies.

Chapter Nine presents my conclusions. I contend that although the government of Rwanda has incorporated neo-liberal policy tools into its administrative structures, this does not necessarily result in 'liberalization'. The agricultural sector is a complex mixture of policies and programmes, implying that that Scott's generalizations regarding markets and liberal political economy require greater nuance to be useful. My research shows that increased involvement of non-state actors has tended to reinforce processes of spatial and institutional homogenisation, standardisation, and coercion. The commercial objectives of non-state actors have become incorporated within state-administered governance technologies which are both homogenizing and coercive in nature, while the introduction of private profit-making mechanisms into state-directed systems characterised by coercion have provided material incentives for state and non-state actors to continue to use coercive measures to increase profits.

The dissertation shows how projects of state-building in Rwanda (such as programmes operating under the banner of unity and reconciliation) have incorporated capitalist development objectives within them, which emphasise economic growth. In addition, production of agricultural commodities which are prioritised by the government is associated in state discourse with 'patriotism', while farmers avoiding government- 
approved crops risk being accused of sedition and hatred of the Rwandan nation itself. Discourses and practices associated with liberalism and neoliberalism in the agricultural sector are part of broader attempts by the Rwandan state to create a new kind of Rwandan citizen, a 'modern farmer' who is entrepreneurial in nature, obedient in following state policies, and fully integrated into commercial commodity-chains. The integration of farmers into priority commodity-chains is facilitated by mechanisms which incorporate the demands of commercial actors within governance systems explicitly designed to produce 'good citizens' and 'good governance'. The discursive and 'material' activities of the government are therefore clearly intended to simultaneously encourage forms of commercialization and entrepreneurship associated with neoliberalism in the agricultural sector and mould farmers' ideas of citizenship, development, and governance. Entrepreneurship, subjection to restrictive government policies, and patriotic and reconciliatory 'good citizenship' are discursively intertwined. This generates various tensions and contradictions.

These relationships are more explicit in some geo-spatial contexts than others. I identify certain areas in which the disciplinary aspects of governance are particularly evident, and where some technologies of governance are tailored to reduce the abilities of farmers to avoid integration into priority agricultural commodity-chains. As such, these areas represent emerging 'spaces of governance' with particular characteristics. Such an analysis demonstrates that the concept of homogeneity can only be understood through references to scale: within the spaces of governance, standardised systems of discipline impose homogeneity. This often has problematic results, as standard blueprints are not 
adapted to local-level agro-ecological variation and complexity. When seen from a national level, these particular spaces of governance demonstrate that the strategies of the state (with the involvement of non-state actors) are not completely uniform across Rwanda, and are hence heterogeneous. 


\section{Chapter Two: Theoretical Framework}

After the austerity measures of the 1980s and 1990s, the 'big state', and state-driven development, is again a significant feature of academic and policy debates about economic development and poverty reduction in the global South. States are engaged in a number of large-scale efforts at, for example, land policy and land law reform in Africa, as well as agricultural development under the rubric of the African Green Revolution.

In Africa, many states have gone from civil conflict in the 1990s to rule by a 'strong' state structure in the 2000s. Although they perform the rituals of democracy - such as multiparty elections - many of these countries are essentially one-party states (with opposition parties muzzled or co-opted) with highly centralized forms of decisionmaking and political control. This centralized control is to some extent relaxed in the economic sphere, which has been characterized by privatization of many state serviceproviders, and in contrast to earlier decades, almost all such states are eager to link their economies with global capital and invite foreign investment. They have embraced, to varying degrees, a broadly neo-liberal economic programme, and are therefore described as 'hybrid regimes' which have both authoritarian and liberal (and sometimes democratic) features (Levitsky \& Way, 2002). ${ }^{4}$ Through their links with multinational

\footnotetext{
${ }^{4}$ Levitsky and Way (2002) note that the term 'hybrid regimes' incorporates many different models of state composition and orientation, so that it obscures as much as it reveals; and also express concerns that much of the literature on such states assumes, without any substantive basis, that they are on a path towards democracy.
} 
corporations and broad acceptance of dominant economic paradigms and programmes (as put forward by the IMF and World Bank, for example), these governments can enjoy considerable legitimacy and influence at the global level. Their legitimacy, in some cases, is also based on an image of technical and administrative efficiency and proficiency. Several contemporary market authoritarian states are regularly described as 'developmental states' (Johnson, 1982), by those who argue that state authoritarianism is exercised largely in the public interest. Examples of such countries in Africa include Eritrea, Ethiopia, Uganda, and Rwanda (Booth and Golooba-Mutebi, 2011, Meyns and Musamba, 2010, Mkandawire, 2001). In Southeast Asia somewhat similar patterns can be seen, with the conflicts of the 1970s-1980s giving way to the emergence of authoritarian capitalist regimes in Cambodia and Vietnam, for example. The transformation of China's economic system over the past 15 years has resulted in the world's most powerful market-friendly authoritarian state.

The increasing prevalence and influence of what we might call the 'market-friendly authoritarianism' model has brought James C. Scott's seminal work SeeingLike a State back into prominence within various academic debates. However, as will be described, the increasingly commercial and international nature of high modernist schemes requires additions and modifications to this model. 


\section{The Authoritarian High Modernism Theoretical Framework: its Strengths and Limitations}

The first component of my theoretical framework is Scott (1998). Scott shows how the 'optics' of a bureaucratic machinery, the means by which it 'sees' (conceptualizes, describes, maps, or otherwise visualizes), are dependent upon processes of abstraction, simplification, and standardisation. Through cases studies of urban planning, villagization, scientific forestry, and monoculture commercial agriculture, Scott explores the ways in which the 'grid of legibility' which is brought to bear upon the world by high modernist state agencies prevent government bureaucracies from 'seeing' complexity and diversity. This failure to see the 'whole' is often combined with an elevated sense of the infallibility of institutionalized forms of 'science', and a willingness to impose blueprint solutions on populations which are seen as less knowledgeable. The result is a bureaucratic process of erasure of difference. Rather than recognizing particular 'places', with complex and unique histories of human-ecological interaction and particular socio-political dynamics, high modernist projects see only blank spaces upon which to impose blueprint designs. The blueprints of high modernism attempt a more complete form of transformation than modernist plans, and require not only a material 'blank space' but also a radical reboot within society through which to enact a social transformation. Where geographical specificity is recognized, the state often tries to diminish it. The most problematic form of this myopia occurs in authoritarian contexts, when the state is willing to use coercion to overcome dissent from civil society and to force the population to play its pre-arranged part in the state's grand schemes. 
Scott emphasises that authoritarian high modernism is not necessarily linked to any single political system (of which more below). As mentioned previously, he contends that authoritarian high modernist regimes have four key characteristics, which concern 1) the administrative ordering of nature and society, 2) extreme confidence about the state's ability to succeed in its aims through technological means, 3) willingness and capacity to impose its plans upon society, and 4) a weak civil society that is unable to resist these plans (Scott, 1998: 4-5)

As illustrated by numerous case studies, these dynamics frequently result in projects which 'fail', according to the standards of the state as well as the local population. The natural environment, and the people involved as 'objects' of development, act as conscious or unconscious agents of resistance, undermining the monolithic projects of the state. The particularities of 'places' reassert themselves against the uniform grids of the planners. It should be noted that the Rwandan agricultural reform is not 'failing' in the same way as many of the case studies in Seeing Like a State. It has resulted in rapid increases in crop yields, particularly for government-approved cereals. Nonetheless, it is having some unintended, and largely unrecognised effects, as will be described throughout this dissertation.

Scott's 'seminal' conceptual framework (Bähre and Lecocq, 2007) has been extremely influential. Nevertheless, there are a number of theoretical lacunae which act as an impediment to the study of large-scale state-driven projects. These are not necessarily failings of the book - given the broad range of case studies covered in the text, Scott 
intentionally limited its theoretical scope in order to make its central arguments more coherent and compelling.

The 'Authoritarian High Modernism' model and the Fallacy of the Monolithic State Institutions and Actors

Scott's large-scale conceptual lens in Seeing Like a State tends to create a picture of a state which is rather self-evident and self-contained in nature, with clear 'borders'. The examples of high modernist projects do not include details of the controversies and reinterpretations of policy inside the state machinery. In emphasising the ways in which the high modernist state attempts to present itself as unified and monolithic, Scott perhaps spends too much time exploring the image, rather than the institutional reality (Geschiere, 2007: 130). This has led to an overestimation of the 'seamless' nature of decision-making and policy implementation by the state.

There is recognition in the book of the differences between the decision-makers in central government and the local government actors who are asked to implement policy. However, these two categories (central and local state actors) appear as a simplistic binary opposition rather than an inherently diverse constellation of interrelated actors. In reality, power relations within the central state apparatus, and 
not just at the village level, determine how programmes are designed and implemented. In the words of one sympathetic critic of the book:

The conception of the state as a unified actor having a single mode of vision is particularly problematic.... [in Latin America], "Obedezco pero no cumplo" (I obey, but I do not comply) expressed the conventional response of state officials in the Americas to commands from imperial Spain, a veiled effort to adjust plans to local conditions and power relations. Colonial officials learned when to apply, ignore, or flexibly interpret laws and design (Coronil, 2001)

The boundaries between state and non-state actors appear to be clear in Seeing Like a State. Even though Scott does mention village authorities who were 'reluctant to impose fines on their neighbours' (presumably because of social entanglements; 1998: 240) the relationships between planners and policy-makers, local administrators, and the broader rural population are not explored in any great detail. Scott treats actors as rather one-dimensional. In reality, especially in contexts where state officials are poorlypaid, individuals have multiple roles within the community, within the economy, and sometimes within the state and the ruling party. Individual state employees are embedded in the local political economy, which often results in conflicts of interest. Such an emphasis is particularly important within a neoliberal policy context, where market principles (such as competition) are incorporated within state systems, or state responsibilities are sub-contracted to non-state actors. 
Processes of liberalization, such as that purportedly underway in Rwanda, are often typified by the multiplication of non-state actors, such as cooperatives and NGOs. In another case of potential over-simplification of actors, Scott's conception of 'civil society' seems to largely follow a western definition, which tends to be biased towards formal 'organizations' such as NGOs (Purdeková, 2011, citing Mbembe 2001, and Uvin 1998). The role of informal groupings and customary institutions are not explored; these are numerous in non-Western contexts and often more resilient to state repression than formal organizations. His case studies also pre-date the 'globalization' era and hence say little about transnational actors such as international NGOs or multinational corporations. More profoundly, his conceptual model for civil society generally seems to suggest an empiricist and pluralist view, which assumes that individual actors have clear intentions that can be inferred from their actions, and that they generally attempt to occupy 'non-state spaces' (Jessop, 2002). The implication is that non-state spaces of a self-evidently 'independent civil society' can exist: such assumptions are questioned by more constructivist positions, for example (ibid). In addition, a recent call for a move away from a theoretical fixation on the sovereign territorial state has been based on the idea of the city, as a space where multiple kinds of authorities simultaneously interact with each other, and with citizens, at different scales and in very different ways, opening up different possibilities for political relationships between various actors (Magnusson, 2011). Based in part (Magnusson, 2011: $113 \mathrm{FN}$ ) upon Foucault's notion of governmentality, which deconstructs the simplistic duality of the 'governors' and the 'governed', Magnusson seeks to use the 
notion of urban governance to avoid a lazy (if usually implicit) assumption that any theoretical alternative to a territorial sovereignty model should be categorised as an idealistic form of 'anarchism' (Magnusson, 2011: 151; Magnusson, 2008).

Unfortunately, Magnusson's focus on the city is somewhat arbitrary, as it ignores numerous examples of self-governance and reconfigurations of sovereignty in rural contexts (King, 2013), and his arguments are too urban-centric to be of great utility to explorations of agricultural areas in the Global South. Magnusson does not provide a very detailed critique of Scott's (1998) theoretical framework, even though his own title is a play on the title of Scott's work. Hence, while Magnusson's contribution has been influential, it is of limited relevance to my chosen case-study.

Nevertheless, as Magnusson points out, we need to move away from a monolithic view of the state and an overly simple model of state-people relations. In order to better understand how policies come to be designed and implemented, we need to consider 'the fragmented, the ambiguous and ambivalent in the nexus of development, community and the state' (Bähre \& Lecocq, 2007). The idea of a state-dominated apparatus or dispositif (Foucault, 1980: 194), provides a more accurate model for understanding the ways in which different ministries, levels of government, ideological camps within the state, and donors (to mention just a few ways of categorizing different interest-groups) cooperate, often in a loose and constantly re-negotiated relationship. We can add to this model the Gramscian idea that civil society institutions also function to some degree as instruments of state power and influence (Adamson, 1987; Macdonald, 1997: 19). 
Different strategies or tactics are used by states to ensure that policies are implemented. Scott (1998) puts emphasis on the use of coercion, and ignores the broader range of disciplinary and governmental tactics (described below) which are employed by many states, particularly those associated with liberalism. In the context of authoritarianism, as it is commonly understood, emphasis is normally placed on strategies of explicit forcible control, such as propaganda, punishment, and direct state intervention of various other kinds. However, indirect intervention, including through partnership with 'non-state' actors may also be important. Scott doesn't consider the idea of different varieties of authoritarian governance, beyond the 'high modernist' category. In contrast, political scientists and others have developed typologies including categories such as 'semi-authoritarianism', 'soft authoritarianism', and the like (Levitsky \& Way, 2002). While I do not attempt to place Rwanda in a particular category, identifying the different forms of coercion or control, and the actors implicated in them, allows me to better understand how Rwanda can be presented internationally as a 'success story' despite its authoritarian tendencies.

The state's use of different strategies, in partnership with different actors, is also an important issue regarding the genealogy of high modernism. Schneider (2007) points out that Scott treats authoritarianism - that is, the willingness to rely on various forms of coercive force - as an exogenous variable, and as something that may contribute to the failure of state schemes, but is not itself a major cause of failure. Scott argues that the faith in central planning and aesthetically-motivated blueprints are the principle causes of failure of high modernist schemes. This assumption may be problematic. 
Schneider (2007) argues that rather than being exogenous, in Tanzania, 'modernisationist self-image and its authoritarianism were constitutive of one another' (Schneider 2007: 33). Convinced of their potential to make historic change in their country, as well as the ignorance of the rural population as an 'obstacle' to that change, state actors saw coercion as justified and necessary. This has two major implications for our understanding of development schemes: first, according to this reading, Scott makes a somewhat arbitrary distinction between 'high modernism' and development programmes based on a more general notion of modernity. By focussing on "high modernism', Scott underemphasises the degree to which the entire idea of modernisation, or development, is based on imperialist foundations and unequal power relations (Duffield, 2007). Secondly, while Scott does consider the notion of the 'primitive' in his work, he does not pay sustained attention to the dialectical relationship between the discursively-constituted 'responsible' ideal modern subject and its antonym, the 'backward' citizen who must be managed through coercive means. This theme will be picked up later in this chapter.

\section{Political Economy Perspectives}

Perhaps the key limitation of Scott`s model of authoritarian high modernism is that it ignores the key roles of profit-making and the market in the designs of the state, and the particular ways in which those designs play out in different contexts. This is particularly problematic given the ways in which neo-liberal ideas have permeated public policy in many countries around the world over the past three decades. This has resulted in the logic of the market (such as the principle of competition, performance- 
based incentives, etc.) becoming embedded in state institutions, various state functions and responsibilities being placed in private hands, and the 'public-private partnership' model becoming increasingly hegemonic (Harvey, 2005; Plehwe et al 2006). Scott barely mentions the possible role of corporations and markets in high modernist projects, except for a brief line in the introduction:

Large-scale capitalism is just as much an agency of homogenization, uniformity, grids, and heroic simplification as the state is, with the difference that, for capitalists, simplification must pay. A market necessarily reduces quality to quantity via the price mechanism and promotes standardisation; in markets, money talks, not people. Today, global capitalism is perhaps the most powerful force for homogenization. (1998:8)

Such a statement evokes other conceptions of 'globalization' as a 'flattening' and 'equalizing' force (Friedmann, 2007). This dissertation will examine the incorporation of large-scale capitalist firms, as well as smaller-scale corporations, maize and pyrethrum commodity-chains in the Rwandan agricultural sector as explicit aims of state policies. Elsewhere in the book, Scott is a little bit more specific on the ways in which capitalism might lead to 'standardisation', in this case, regarding agriculture:

One of the basic sources of increasing uniformity in crops arises from the intense commercial pressures to maximise profits in a competitive mass market. The growth of great supermarket chains, with their standard 
routines of shipping, packaging, and display, has inexorably led to an emphasis on the uniformity of size, shape, colour, and 'eye appeal' (1998: 266)

One major limitation of Scott's discussion of the homogenizing effects of capitalism (see also Scott, 2010) is that he focuses on the standardisation of commodities: he does not sufficiently consider effects on labour, or land and other productive assets. While transnational agribusinesses might require similar agricultural commodities to be produced, the forms of labour relations they put in place (according to local laws and politico-economic circumstances) differ greatly: they procure salaried labour (skilled or unskilled, permanent or casual) to work on plantations (bought or rented by the company); or enter into contracts with outgrowers (individuals or cooperatives) who might access technology, credit, inputs, and land through a great variety of formal or informal mechanisms. Thus the standardised ear of corn, for example, might be produced under myriad systems of production. More generally, certain areas might be targeted for intensive 'investment' while others are not. James Ferguson, for example, has used the example of the mining sector in Africa to argue that despite a dominant view of a free-flowing 'global' capitalism, the dominant reality of global capital penetration in many African countries is 'not homogenization within a national grid [of standardised investments and administrative systems] but, more often, the abandonment of the idea of national grids altogether, along with the intensive exploitation of separately administered enclaves' (Ferguson, 2005: 379). Ferguson argues that capital does not flow smoothly around the world but rather 'hops' (ibid) 
directly to enclaves of extractive opportunity, bypassing areas designated as less commercially viable. Of course, as noted by Harvey (2005), the 'uneven geographical developments' experienced in contemporary times stem not only from the uneven nature of geological or geographical endowments across the world, but also from the extent to which political and administrative institutions allow the infusion of foreign capital and the various forms of power associated with it. Scott does not pay much attention to the very wide range of interactions between states and corporations in the modern era.

More profoundly, perhaps, Coronil detects an epistemological 'opposition between state and market that structures the book' (2001: 214). In this sense, the market is positioned in the book as part of civil society, presented as inherently inimitable to the homogenizing ambitions of the state. Civil society is portrayed as too dense, variegated and rooted in local custom to be a channel for state simplifications. Thus the market becomes subsumed within a broader binary opposition of state-society, remarked upon by Li (2005). As Coronil argues, this false opposition of the concepts of state and market serves to obscure

the mutual historical constitution of "state" and "market," their close interaction, and their ongoing transformation... [M]ajor states... help define the shifting legal, cultural, and political parameters that shape capitalism. While Weberian and Marxist discussions of the state have been premised on a separation between the state and society (or the economy), new 
approaches suggest the inseparability of the political and the social,

particularly now that it is easier to see how the capitalist market has

imposed its logic on society and become a "political" force of its own. (2001:

124).

Whereas classical economics considers the market to be inherent to society - something that merely requires to be left free from excessive regulation-critical political economy does not necessarily accept that markets or commodities exist as existential objects, separate from the broader dynamics of society. Polanyi, for example, describes the ways in which land, labour and money are commodified. This entails the separation of certain activities from the social context in which they are embedded, a process that requires considerable effort and organization of the kind that few institutions other than the state are able to exert. For this reason, Polanyi claims that the laissez-faire economy was the product of deliberate state action' (2001: 147). ${ }^{5}$ Further, he argues that such state intervention is not momentary but rather continuous:

The road to the free market was opened and kept open by an enormous increase in continuous, centrally organized and controlled interventionism. ... Witness the complexity of the provisions in the innumerable enclosure laws; the amount of bureaucratic control involved in the administration of the New Poor Laws which for the first time since Queen Elizabeth's reign

\footnotetext{
${ }^{5}$ By contrast, Polanyi argues, the state has often been forced to put in place measures to protect sections of the population from exposure to markets, in unplanned ways, due to popular resistance. This combination of planned and more spontaneous state interventions forms the 'double movement' of capitalist expansion.
} 
were effectively supervised by central authority; or the increase in governmental administration entailed in the meritorious task of municipal reform. And yet all these strongholds of governmental interference were erected with a view to the organizing of some simple freedom - such as that of land, labor, or municipal administration (Polanyi, 2001: 56).

Critical theorists emphasize the historical role of the state in creating a capitalist class and hence driving the early development of capitalism. This dynamic is of relevance to areas where home-consumption, systems of reciprocity, and other non-capitalist relations exist. The case study most commonly invoked to illustrate these dynamics is the emergence of capitalism in England. The state provided various legislative, regulatory, and coercive means to permit a rising class of wealthy landowners to further accumulate land through the privatization of that which was previously held in common (Perelman, 2000). In the $18^{\text {th }}$ century, for example, the law came to favour the enclosure of the commons, becoming 'an instrument of the theft of the people's land' (Marx, 1967: 724). Through legislative and other processes 'The poor no longer had rights to commons, hunting rights, grazing rights, or farming rights... the rich were in possession of the countryside and factories, while the poor were working as wage labourers in the factories' (Waters, 2007: 60).

This process was associated with considerable suffering and the threat or use of violence. Agreeing with Marx that capitalism 'had its origin in agriculture', Wood argues 
that the role of state-backed force in processes of capitalist accumulation illustrates that capitalism 'Is not a sphere of choice and freedom, but a system of coercion, imposing its imperatives on the provision of life's basic necessities' (Wood, 2009: 55).

Privatisation and accumulation of property achieved three primary ends; first, it transformed property into a commodity, which could be transacted on the market, stimulating economic activity; second, it further enriched a wealthy class, which would use their wealth to engage in commercial activity; and three, created a class of landless labourers who were forced to work for others in order to have a salary. This latter process is known as proletarianization, or depeasantisation (Araghi, 2009). ${ }^{6}$

After this process of 'primitive accumulation' had propelled the emergence of capitalism in England, it was continually reproduced in different places and forms. Marx contends that once the separation of the peasantry and the land has been achieved, capitalism 'not only maintains this separation, but reproduces it on a continually extending scale' (1967: 714). According to many Marxists, capitalism is inherently bound to seek new frontiers for accumulation (Duffield, 2007: 216). This explains the myriad new forms of property being developed today, as well as the geographical spread of capitalism more generally. Harvey describes some processes of primitive accumulation:

...the commodification and privatization of land and the forceful expulsion of peasant populations (as in Mexico and India in recent times); conversion of various forms of property rights (common, collective, state etc.) into

\footnotetext{
${ }^{6}$ Araghi argues however that the two terms are not synonymous and comprise various kinds of processes and outcomes (Araghi, 2009).
} 
exclusive private property rights; suppression of rights to the commons;

commodification of labor power and the suppression of alternative

(indigenous) forms of production and consumption; colonial, neo-colonial

and imperial processes of appropriation of assets (including natural

resources); monetarization of exchange and taxation, particularly of land.

(2005: 32)

Such processes are not only driven by commercial private actors but also by

governments which provide the legal, political, and discursive frameworks that facilitate

them. Harvey argues that, 'the neoliberal state is particularly assiduous in seeking the

privatization of assets as a means to open up fresh fields for capital accumulation'

(2005: 19).

The areas and assets opened up by capital are not only spatial and material, but may also be habits, networks and practices of non-capitalist production, consumption, and exchange, along with the discourses that enable and legitimise them. Accumulation by dispossession is a particularly important process in areas of the world where peasant or petty-commodity producer ${ }^{7}$ households retain control over land and other means of production and produce at least partly for subsistence consumption, barter, or other non-monetary forms of circulation of goods and services. However, commodification is

\footnotetext{
${ }^{7}$ The literature on the definitions and characteristics of the 'peasant' is extensive and marked by divergence of opinion ( $\varnothing$ sterud, 1976). Longstanding definitions such as those proposed by Shanin (1971) and Chayanov (1966) that emphasise autonomy, self-sufficiency, the importance of the demographic cycle within the family, a subordinate position within society and an incorporation within state systems of control, and other characteristics, are considered by some to be outdated, so that in the modern era, 'peasant-like ways of farming often exist as practices without theoretical representation' (Van der Ploeg 2008:19). Bernstein (2009: 29) considers petty commodity producers to be peasants (who therefore 'own or have access to means of production and employ their own labour') who produce for capitalist markets and cannot make a livelihood outside of capitalist circuits.
} 
in evidence not only in such familiar contexts but also in novel areas: for example, states have played a number of key roles in the creation of new markets in 'carbon credits' through schemes such as 'Reducing Emissions from Deforestation and Forest Degradation "plus" conservation' (REDD+) (Lohmann, 2006). ${ }^{8}$

Harvey has argued that neoliberal state projects involving commercialization and commodification have the ultimate result of redistributing valuable assets from various strata of society to the wealthiest tier (2005: 16), often through processes of accumulation by dispossession. This assertion fits with the Marxist view that the capitalist state is largely an instrument of the dominant class; wealthy capitalists.

Scott, by contrast, tends to assume that high modernist programmes, including the imposition of what he calls the 'production and profit' model of modernist agriculture (1998: 262), were not 'cynical grabs for power and wealth', but were rather 'animated by a genuine desire to improve the human condition' (Scott, 1998: 342). These planners were, 'committed to a more egalitarian society, to meeting the basic needs of its citizens (especially the working class) and to making the amenities of a modern society available to all' (1998: 346). As mentioned above, he sees state officials primarily or only in their function as public servants, choosing not to consider their multiple private roles, which may involve contradictory motivations, especially those of individual profit. More profoundly perhaps, scholars have critically deconstructed the notion of the 'will to improve' (Escobar, 1995; Li, 2007a). Although Scott traces the roots of high modernism

\footnotetext{
${ }^{8}$ States have put in place legislation and regulatory regimes at the national level, have taken active roles within multilateral organizations and have often used various forms of less 'official' influence to create carbon markets.
} 
back to the colonial project, the genealogy of 'development' that he presents is not as rigorous or as critical as that presented by scholars such as Cowan and Shenton (2003) Duffield (2007), and Escobar (1995). As pointed out by Schneider (2007), Scott sometimes seems critical of the entire concept of development (1998:340), but more often presents a limited critique, based on the risks of an unrealistic belief in science and planning (Scott 1998:6, 304). When combined with his argument that liberal political economy can act as a bulwark against authoritarian high modernism, this latter argument fails to recognise the common ontological roots of liberal conceptions of development, and authoritarian high modernism.

Where Scott does note that state programmes were 'captured' by state elites, he emphasises not the financial aspects, but rather the motivations to enhance the 'power and status' of officials and state agencies (1998: 264). Indeed, where he mentions commercial competition, he tends to situate it outside of the state, as 'competitive pressure on states' (1998: 263), reinforcing the idea of a binary opposition between states and the market; this binary theoretical structure prevents a class-based analysis of the state and its programmes.

Related to this is a concern that Scott also pays insufficient attention to the political economies of particular 'varieties' or manifestations of high modernism, noting simply that high modernism can 'be found across the political spectrum from left to right' (1998: 5). However, 'liberal political economy' (1998: 101) is seen as incompatible with authoritarian high modernism, as Scott posits that 'the economy was far too complex 
for it to ever be managed in detail by a hierarchical administration' (1998: 102). This statement fails to acknowledge the huge range of debates over the nature of what might be called 'liberal political economy' and, in particular, the many different varieties of politico-economic thought that operate under the banner of 'liberalism'. ${ }^{9}$

Most obviously, Scott's blanket statement regarding 'liberal political economy' seems rather archaic given the emergence over the last twenty years of various regimes, notably the 'Asian Tigers', which have combined liberal economic policies (particularly in terms of allowing forms of Foreign Direct Investment, or FDI) with more authoritarian and centrally-planned policies in the civic and political spheres. Concepts and tools from liberal economics have been configured within diverse geographical, cultural, political and institutional settings. It is also important to consider the transnational nature of much economic activity. Transnational companies with their origins in liberal economic systems have conducted business in authoritarian countries.

Given the importance of forms of redistribution (often from the poor to the rich) and proletarianization during processes of commodification and market expansion, the state has a vested political interest in obscuring its own role in such phenomena. The notion of 'the market', and in particular 'self-regulation' by the market, is often invoked in order to obscure the role of the state in facilitating or causing such events. This argument utilises the idea of the 'invisible hand' of the market (derived from Adam

\footnotetext{
${ }^{9}$ The term 'liberal political economy' is so broad that it could arguably be applied to classical political economy, from Ricardo and Adam Smith through to Keynes to more contemporary theorists of neoliberalism such as Milton Friedman. While none of the mainstream liberal theorists support comprehensive central-planning, they do propose various forms of state intervention and state regulation.
} 
Smith, 1759) to contend, first, that markets largely regulate themselves, and second, notwithstanding temporary or localised negative impacts, the overall impacts of market penetration will be beneficial. The theory essentially claims that through market dynamics, prices and systems of distribution of commodities will benefit consumers but also reflect the value of investments in the making of commodities while allowing profit to be made by the producer. Friedman, for example, claimed that the 'invisible hand' concept represents 'the possibility of cooperation without coercion' (Friedman, 1958) as the system is in the aggregate beneficial to all who are willing to invest their labour and assets in processes of market exchange. However, according to classical economic theory the system benefits producers of commodities only if production is achieved efficiently: hence the invisible hand, according to classical theory, 'plays a necessary role in eliminating inefficient producers' (Araghi, 2009: 112). Citing these arguments, governments may describe episodes of accumulation by dispossession as temporary and necessary, if painful, events through which assets are acquired through market processes to those who can most efficiently utilize them to derive a profit and create economic growth.

However, critical theorists largely reject the notion of the 'invisible hand' (emphasising the role of the state in regulating markets), and emphasise that the state, as mentioned previously, played an immense role in stimulating capitalism and facilitating processes of socio-economic differentiation. Processes of dispossession and proletarianization are often caused by what has been termed the 'visible foot' of state policy (Araghi, 2009: 112), which includes: 
State policies that dismantle social welfare systems; deregulate land markets; remove import controls and food subsidies; impose agro-exporting regimes; and expose millions of agrarian petty producers in the South to competition with heavily subsidized food transnational corporations and highly capitalized agricultural producers in the North. We also see the visible foot in... 'enclosure-induced displacement' (Araghi, 2009: 112).

The transnational nature of these phenomena signals the importance of what can be broadly termed 'globalization' to processes of commercialization of the agricultural sector or, to put it another way, penetration by capital of rural 'spaces' (in the broadest sense of the term) of non- or semi-capitalist relations. Such global dimensions are largely ignored by Scott in Seeing Like a State. There are exceptions to this: he traces the exchange of ideas between countries and time-periods ${ }^{10}$ and acknowledges the role of colonial regimes, and foreign donors in high modernist schemes in Africa (Scott, 1998: 247). However, transnational profit-seeking is not emphasized. Even when he documents the global export of the US agricultural model by the US government between 1945 and 1975, nothing is said of the overall commercial implications or goals of this effort (1998: 270). Of course, other writers have uncovered the ways in which US aid and trade contributed to broader commercial aims (see e.g. Patel, 2007; Escobar 1995: 127; Mitchell 1991). Such analysis requires attention to the broader patterns and

\footnotetext{
${ }^{10}$ For example, he notes that Soviet Russia borrowed high modernist ideas with their origins in the United States and capitalist western Europe (1998: 200).
} 
structures of international economic exchange and global 'governance', which are outside of the remit that Scott set himself in Seeing Like a State.

\section{Forms of Power: Discipline, Sovereignty and Governmentality}

While Scott's treatment of socio-political structures - such as class, or global systems of commerce - is not comprehensively theoretically developed in the book, his use of binary oppositions including 'state-society', 'state space-nonstate space', and 'powerresistance' (Li, 2005: 384) create a dependence on what might be called a structural approach. In addition, while he does mention the high modernist concerns with 'visual aesthetics' (Scott, 1998: 4; 237) of neatness, regularity, and order, he does not venture much further into the symbolic and discursive aspects of high modernism. In short, his approach is largely materialist and structuralist, and does not adequately examine links between discourses and practices of (neo) liberalism, on the one hand, and state efforts to exert its influence through the conscious moulding of identity-types and subjects of 'development', on the other hand. Scott often implies that the primary role of citizens under authoritarian high modernist projects is to provide labour according to systems of production tightly regulated and overseen by the state. However, the ideal subject of neoliberal regimes is a responsible, self-governing and entrepreneurial individual. This tension between an authoritarian desire for obedience, and a neoliberal focus on the entrepreneurial subject, is evident in Rwanda, as will be discussed in Chapters Four and Five, in particular. 
The implicit theory of power evident in Seeing Like a State is similar to the simple dichotomy of domination and submission (Dahl, 1957), where power is defined as the ability of one actor to force another to do something they would not otherwise do. The 'resistance' model, and his conclusion that many schemes fail because of indirect resistance, recognises the agency of local actors but only within the confines of the simple oppositional dynamic described above. By invoking the ability of less powerful actors to enact 'various forms of quiet resistance and evasion' (Scott, 1998: 24), Scott is often accused of locating power exclusively within the state while delegating spaces outside of the state to the status of the autonomous and largely unexamined 'other', seemingly outside power relations (Moore, 2005: 23). A more effective schema would recognise that power relations are present in all social interaction, and that power has no 'outside'. Scott's formulation of power is particularly problematic when we attempt to describe the many types of interaction between state and non-state actors in complex contexts of 'liberalization' and 'commercialization', where categories such as state and non-state, public and private, are blurred. In addition, Scott and other scholars using a model of 'resistance' to demonstrate that those individuals living under conditions of domination are autonomous actors, capable of independent agency, imply that a clear separation exists between the 'outward' behaviour of those being acted upon by powerful forces, and their 'inner' behaviour, or consciousness (Mitchell, 1990). Such a dualistic notion is at odds with various theories of power, and in particular the Foucauldian framework referred to in this dissertation, which consider some forms of power to be able to influence the inner, mental life of an individual (and broader 
collectives of individuals) without their being conscious of that influence. The Foucauldian idea of subjectification, for example, acknowledges the ways in which powerful forces act on the inner life of individuals while nevertheless providing space for certain circulations which, while never free from power, may be conceived of as freedoms. Foucault argues that resistance and power are intertwined in complex ways, so that, 'resistance is never in a position of exteriority in relation to power' (1978:9596).

I rely largely upon the concept of 'resistance' in my analysis of case studies in Chapters Six and Seven, largely because interview data did not provide sufficient evidence to enable me to deploy an alternative approach. However, in Chapter Nine, as will be explained below, I utilise a more Foucauldian approach.

In order to better understand the relations between the state and citizens affected by high modernist projects, we need to refer to a more sophisticated model of power. Lukes (1974) theorized three dimensions of power relations. The first dimension is the simple coercive model defined by Dahl; the second dimension concerns the abilities of actors to influence political or policy agendas in order to limit the bounds of debate; the third form of power relations involves the ability of actors to shape the opinions and ideas of others in order to gain supremacy without open conflict. Through shaping their opinions and thinking processes, powerful actors can make others blind to their subordination. 
The latter two dimensions of power introduce the notion of political, discursive, and institutional structures, raising the question of their permanence or rigidity. The Gramscian concept of hegemony is relevant here. According to Gramsci, the state maintains its power not only through its own organs but through many of the institutions of civil society, which also contribute to the 'cultural formation' of hegemonic ideas. Thus many aspects of civil society can be seen as instruments of 'indirect domination' by the state (Macdonald, 1997: 19). By theorizing the reproduction of dominant ideas not simply through coercion but principally through 'a substantial degree of popular consent' (Hall, 1986: 15), the concept of hegemony has some commonalities with the relational notion of power developed by Michel Foucault, who describes power not as 'inherent' to particular individuals, institutions or structures, but rather something enacted through specific actions (Foucault, 2003: 28). His work, particularly the concept of governmentality (Foucault, 2007), deconstructs notions of 'coercion' and 'consent', exploring 'arts of government' which shape the range of actions available to individuals and the larger populations that they compose. Whereas disciplinary technologies operate at the level of the individual, targeting and controlling individuals as corporeal bodies, governmentality works at the level of a large community or population. Scott is concerned mainly with strategies of (primarily spatial) discipline that control the bodies of the targeted population. Governmentality, in contrast, concerns the indirect administration of the population. According to Foucault, governmental strategies attempt to realize the objectives of the state and linked institutions through processes of subjectification - the creation of particular types of 
subjects. Governmentality relies upon the idea that an existing set of psycho-social desires can be guided and moulded in order to create willing subjects of 'development' that do not need to be directly coerced. Governmentality is therefore the 'conduct of conduct': the putting in place of schemes, ideologies and systems which facilitate the development of certain kinds of conduct. In advanced liberal states, the ideal subject is self-governing and 'responsible', managing him/herself in ways which accord with state ideas of good conduct. Non-state actors, including commercial operators, may contribute to the diffusion of such a model, with ideas of consumerism and citizenship becoming intertwined in complex ways and co-created by various actors. Foucault 'endeavors to show how the modern sovereign state and the modern autonomous individual co-determine each other's emergence' (Lemke, 2007: 2). The governmentality concept allows for the identification of particular ideas of 'development' held by the state and other institutions, and rather than representing a monolithic master-plan, governmental projects can emerge from the practices of various actors. In cases where non-state actors are embedded within governmental frameworks they may represent 'government beyond the state' (Swyngedouw, 2005). ${ }^{11}$

There are several possible interpretations of Foucault's work on governmentality. Many 'neo-Foucauldians' focus exclusively on the modern (neo) liberal state. ${ }^{12}$ Some scholars contend that Foucault's theory of governmentality primarily concerns neo-liberalism

\footnotetext{
${ }^{11}$ This instrumentalization does not preclude the possibility that such institutions can also exercise power, as will be discussed throughout the dissertation.

${ }^{12}$ Many such scholars focus on Foucault's comparative analyses of the German 'Ordoliberal' model and the Chicago School, widely seen as one some the earliest elaborators of neo-liberal thought, to build a particular model associated with advanced liberalism (Foucault, 2004b).
} 
and has elements of compatibility with Marxism, linking themes of commodification with ideas of the production of a modern identity. Gournelos, for example, argues that Foucault allows readers to comprehend processes of 'commodification of identity within a liberal framework, in which freedom, success, rights, and politics become fully integrated into a system of commodity and governmentality' (2009: 290; cited in Flew, 2012: 179). Such 'full integration' into markets arguably requires an elaborate set of practices and technologies linking systems of 'legibility' with diverse and sophisticated market mechanisms; a legal and socio-cultural separation between the modern subject and the means of production, which is associated with commodification; and other prerequisites. The association between governmentality and advanced liberalism has therefore led certain critics to question the validity of applying ideas of governmentality in contexts other than the high-income, liberal, essentially Western states (Death, 2011; citing e.g. Joseph, 2010 and Abrahamsen, 2003). Foucault tended to ignore non-Western states in his work. We must therefore proceed from a brief discussion of the prerequisites for governmentality: what capacities must states possess to deploy governmental strategies?

\section{Governmentality and State Capacity in Africa}

The political, the economic, the social are tied together like the strands of a

$$
\text { rope. }
$$


(Paul Kagame, cited in McGreal, 2013: 3)

The things which the government is to be concerned about are men, but men in their relations, their links, their imbrications with those other things that are wealth, resources, means of subsistence, the territory with its specific qualities, climate, irrigation, fertility, etc.; men in their relation to... customs, habits, ways of doing and thinking, etc. (Foucault, 1991: 93-94).

Different strategies of state governance require different mechanisms and capacities. Technologies associated with sovereign forms of power, which Foucault also terms the approach of 'law' and prohibition, tend to require capacity for enforcement. The law of the sovereign often operates through the power of exemplary punishment, and the idea of the legitimacy of the sovereign (Foucault, 2007: 5, 98). Systems of law therefore need not be efficient and all-encompassing, but do require force of arms. Disciplinary technologies, in contrast, operate on a more routinized basis and function through control of particular spaces, as well as schedules, quotas, and other forms of demands upon labour (time and productivity). The state, capitalist firms, and other institutions working through disciplinary means, must have the capacity to structure particular spaces, and the incentives and sanctions to demand obedience to the rigours of scheduled work. In short, the expansion of disciplinary technologies is associated in Foucault's work with a measure of industrial-scale economic and social control. Though Foucault's examples (factories, hospitals, and prisons) are specific to Western Europe, they should not blind us to the possibilities of other, non-Western forms of discipline. 
Technologies associated with a governmental approach are more diffuse, requiring the capacity to discursively and physically influence the population in a wide range of spaces through multiple platforms. Moreover, they are sufficiently sophisticated to allow for 'circulation' (of ideas, people, and goods) whilst also monitoring and policing that circulation (Foucault, 2007: 16-17). Governmental methods rely on the generation and management of information about individuals, communities, and the population, as well as the ability to map (cartographically and conceptually) and physically alter the milieu (Foucault, 2007: 22). Governmental strategies are often assumed to require greater sophistication within both state machinery and the social realm.

The question, then, is what forms of power may be exercised in contexts other than advanced liberalism? Purdekova (2011, citing Herbst, 2000) notes that discussions of the capacity and territorial 'reach' of the state in Africa tend to be dominated by a perception of state 'weakness': an inability to maintain a centrally-coordinated presence across the entire state territory. This weakness is often linked to the sparsely-populated nature of many parts of the continent (Death, 2011 citing Joseph, 2010 and Larner and Walters, 2002; Rabasa and Peters, 2007) and related paucity of infrastructure - such as roads, or postal and telecommunications systems - that limit the ability of the state to monitor and communicate with the population, and manage circulations of goods and services. Such patterns are of course neither 'natural' nor free from history, and trajectories of population concentration and dispersion were established, or at least accelerated, during the colonial period (Mbembe, 2000). When administrative and physical infrastructure related to production and export of cash crops and extraction of 
mineral and forest resources, was put in place, in many cases, coercive policies on movement and settlement were also implemented.

Many discussions of state capacity are limited by what Howard and Shain (2004: 9) identify as the biases of modernisation theory, and rely only upon the mapping of formal, concrete infrastructure and tangible symbols of power and authority such as schools, administrative offices, and roads. Non-material aspects - what we might call the software of the state,--are also significant. Many regimes relied less on physical infrastructure than systems of power relations rooted in particular socio-political and socio-cultural circumstances. ${ }^{13}$ A simple mapping of state infrastructure fails to appreciate myriad intangible interrelationships. While the state may have the capacity to monitor citizens and impose certain obligations upon them, the kind of 'power' that this represents (the degrees of legitimacy, counter-forces of resistance that may be engendered, etc.) may vary according to time, place and circumstance. Following Foucault, I contend that power is exercised and contested not only through 'actions' but also through discourse, as 'we cannot exercise power except through the production of truth' (Foucault, 1980: 93); and this means state governance is also a product of mutable and contested notions of nation, identity, and related phenomena.

Finally, it is important to consider not only the 'capacity' of the state, but also the legitimacy of the state. While the state may be able to exercise power, it may lack the

\footnotetext{
${ }^{13}$ For example, Hughes notes that in many parts of Southern Africa, where populations were both sparse and highly mobile, pre-colonial kingdoms drew their power not from direct control over land (which might be visible through field boundaries and other physical markers), but rather from 'rights in persons' (Hughes, 2006: 6; cf Kopytoff, 1987).
} 
legitimacy that makes it easier to gain some degree of consent, and facilitates its various programmes. Histories of colonialism, coups d'état, and discrimination against identitygroups may undermine state legitimacy. Naturally, questions of state legitimacy are complex and contingent upon experiences of interactions with the state, regional differences in state policy, and ambiguities between state and private activities mentioned above, amongst other issues (see e.g. Moore, 2005). In many cases, commercial exploitation has historically been a part of the material and discursive project of state-building. The ways in which commercial actors deploy, adapt, and undermine discourses associated with the state are of importance to the present study.

\section{Governmentality and Neoliberalism in Africa}

The combination of these various stereotypical African signifiers - sparse population, limited physical infrastructure, and disputed state legitimacy - have led to a common assumption that strategies or projects of governmentality, as laid out by Foucault and those influenced by him (Rose, 1999; Dean, 1999; Barry et al, 1996) cannot succeed in Africa. The state is not 'strong' or 'present' enough. In many studies, the archetypal African state is described as little more than an elaborate system of patronage, or a 'shadow' or 'shell' utilized for the purposes of a kleptocratic elite (Bayart et al, 1999;

Reno, 1999; Ferguson, 2006: 39). The state possesses neither a unifying vision beyond individual enrichment, nor the capacity to act upon such a vision. Many such analyses are founded upon a critique of the colonial state, and a contention that post-colonial 
regimes have been unable to transform inherently problematic colonial socio-political structures.

In other work, African states are seen as suffering from their economically and politically marginal position within world systems. In such cases, African governments are seen as limited in their governance options, and largely forced to accept direction in matters of the economy and internal governance from external institutions, particularly international financial institutions (Harvey 2005: 17; Mbembe 2001, 74; Ezeonu 2003). James Ferguson, for example, argues that 'neo-liberalism' in Africa is associated with the restructuring of the state, austerity measures in public spending, and other phenomena that diminish the state's abilities to engineer the self-governing subject:

"neoliberalism" in Africa refers to a quite fundamentally different situation than it does in Western Europe and North America. The hasty and uncritical application of ideas of neoliberalism-as-rationality to Africa is thus clearly a mistake, based on a simple confusion (an art of government versus a crude battering open of Third World markets) (Ferguson, 2009: 173)

While Ferguson's point is broadly valid, it is not universally true. Such arguments may be refuted in at least three ways. Firstly, as Death (2011) maintains, there are various understandings of 'governmentality': he differentiates between the use of the concept to refer to a specific form of rule, associated with neoliberalism or 'advanced liberalism', and the use of governmentality as a framework for understanding governance in general 
(i.e. in diverse political contexts). ${ }^{14}$ Several scholars, while tending to focus their attentions on advanced liberal systems of government (Dean, 1999:10; Rose, 1999:4 ) have developed analytical lenses (focusing particularly on forms of visibility, the tactics and techniques of rule, the conceptual frameworks and analytical functions deployed by ruling groups, and various forms of identity-formation) that can arguably be applied to any political system. In this dissertation, rather than making a direct link between the Rwandan state and a particular form of neoliberalism, we are broadly following the second school of thought that contends that the governmentality concept has broad applicability. Several prominent scholars have usefully applied tools derived from the governmentality literature to non-Western cases (e.g. Li, 2007a; Mitchell, 1998; Watts, 2008; Bayart, 2009).

Secondly, Foucault's governmentality work examines states in Europe undergoing a shift from pre-modern to modern arts of government. The concept of governmentality hence encompasses not only processes of subjectification, but also state formation (Brockling et al, 2011: 2). While contemporary Africa is of course far removed from $18^{\text {th }}$ and $19^{\text {th }}$ century Europe, it can nonetheless be noted that many contemporary African states are undergoing processes of significant change. These may be variously described as projects of 'modernisation', post-conflict reconstitution, decentralization programmes, etc. But they may be generally seen as consolidation of state presence. Foucault was interested in 'the long-term processes of co-evolution of modern statehood and modern

\footnotetext{
${ }^{14}$ The latter interpretation of the governmentality concept is associated particularly with Foucault's discussion of the German Ordo-Liberals (Foucault, 2004b). See Lemke, 2001.
} 
subjectivity' (Brockling et al, 2011: 2), and this broad scope is of relevance to contemporary processes in Africa and elsewhere.

Thirdly, it is possible to argue that aspects of the 'neoliberalism-as-rationality' model can be found in Africa, in places such as Rwanda. In order to identify these aspects, it is necessary to avoid the reification of certain concepts such as 'neoliberalism': to reject the idea of a 'pure' or 'essential' form of neoliberal governmentality. In practice neoliberalism is often a messy concoction of policies and tactics which frequently deviates from the abstract principles of neoliberalism identified in much of the theoretical literature. Indeed, Ferguson himself, in the same article cited above, makes this very point: citing Harvey (2005) he argues that neoliberal doctrine is utopian, and could never be fully and completely implemented in the real world; so that, 'neoliberal policy is thus much more complicated than a reading of neoliberal doctrine might suggest' (Ferguson, 2009: 171)

Indeed, some scholars argue that the tensions between neoliberal doctrine (often characterized by a rhetoric of laissez-faire) and the realities of policymaking are inherent in the neoliberal theoretical framework itself, which has a paradoxical 'passion for intervention in the name of non-intervention' (Miller, 2010: 56). Neoliberalism relies upon the concept of the self-governing subject, kept in check by market principles and its own economic rationalism. However, there are risks involved in giving such a pivotal role to the governmental project of subjectification, and measures are put in place to manage these risks: 'The new art of government appears as the management of 
freedom ... Liberalism must produce freedom, but this very act entails the establishment of limitations, controls, forms of coercion, and obligations relying on threats' (Foucault 2008: 63-4).

Many of these measures to 'manage freedom' are, of course, familiar from Foucault's earlier work on disciplinary technologies (Flew, 2012). Foucault was explicit in this regard, that even in advanced liberal societies, governmentality did not replace other forms of governance, but rather formed 'a triangle, sovereignty-discipline-government' (Foucault, 1991 [1978]: 102). In moving towards a liberal mode of government, the state picks up the pen, the bullhorn and the map in order to understand and manage the population: but it never completely puts down the sword and the pistol. Rather than seeing neoliberalism as a grand design, it is therefore possible to see it as a combination of mechanisms and technologies, 'arts of government', which are configured with other forms of control in various contingent ways. The kinds of neoliberal strategies associated with governmentality were developed in order to facilitate the emergence of a self-governing, entrepreneurial subject precisely because of a paradigm of a need for adaptation in the face of risk, change and exposure to markets. In other words, they emerge in accordance with an argument that the central state cannot or should not control economic and other dynamics. However, Foucault insists that even as liberal and governmental forms of governance came to dominate state policy-making, the state continued to deploy mechanisms of discipline and reproduce paradigms of sovereign power. To use the language of Harvey, rather than Foucault, neoliberalism: 
...creates the paradox of intense state interventions and government by elites and 'experts' in a world where the state is supposed not to be interventionist... Faced with social movements that seek collective interventions, therefore, the neoliberal state is itself forced to intervene, sometimes repressively, thus denying the very freedoms it is supposed to uphold (Harvey, 2005: 69).

The repressive forms of undemocratic governance and the intense state interventions Harvey mentions can be understood, from a Foucauldian perspective, as disciplinary mechanisms underpinned by essentially sovereign claims to power.

To return to my earlier concerns that the authoritarian high modernism model may be seen as an exception to the broader liberal project of international development, the implication here is that while outright coercion seen in authoritarian contexts may be rare in (neo)liberal contexts, mechanisms of control and containment of the population are present in both. Furthermore, these forms of control may be linked to similar processes of subjectification - the creation of a primitive 'other' - that is used to justify authoritarian coercion.

\section{Resistance or Subjectification?}

Some readings of the governmentality literature tend to emphasise the insidious and omnipresent nature of state influence. Robins, for example, contends that James Scott (1998) and Timothy Mitchell (1998) 'tend to emphasise the omnipotence of state 
discourses and the docility of subject-citizens, who appear in these writings as passive victims of an all-encompassing modern state apparatus'( (2002: 681) ${ }^{15}$. Watts finds that some readings of Foucault can create a 'panoptic sense of closure and overwhelming aura of domination... [through] the well-oiled machine of disciplinary and biopower' (Watts, 2008: 535). However, Foucault's model of power, as mentioned above, acknowledges capacities for individual agency even under situations of domination. Those who interpret the Rwandan context largely through the conceptual framework of Seeing Like a State emphasise the forms of 'resistance' mentioned in that work (and in Scott, 1985): namely 'various forms of quiet resistance and evasion' (Scott, 1998: 24), 'foot-dragging' (Scott, 1998: 217), and 'resistance, subversion, and political calculation' (Scott, 1998: 130). ${ }^{16}$ For example, academics have studied the 'everyday forms of resistance' in Rwanda (Thomson, 2009: 9), noting that 'overt resistance to government policy in Rwanda is risky,' (Newbury, 2011: 236). This is indeed the reality in contemporary Rwanda. As mentioned above, I rely largely upon the concept of 'resistance' in my discussion of agricultural cooperatives in Chapters Six and Seven. However, in Chapter Eight, I use analysis of farmer discourses to show that farmers have developed a novel form of subjectivity, by adopting some aspects of the state's model of the 'ideal development subject' (Purdekova, 2012a: 192) while simultaneously subverting or rejecting aspects of this model. The governmentality concept allows me

\footnotetext{
${ }^{15}$ Robins' critique of Mitchell is most salient to our discussion, as Mitchell explicitly references Foucault in his work. Scott (1998), while seemingly influenced by some of Foucault's ideas (1998: 23; 101; $378 \mathrm{FN}$ $16 ; 381 \mathrm{FN} \mathrm{50),} \mathrm{does} \mathrm{not} \mathrm{invoke} \mathrm{a} \mathrm{governmental} \mathrm{framework.}$

${ }^{16}$ To be fair, Scott does also mention outright rebellion and other more overt and forceful forms of resistance in Seeing Like a State; however, the overall emphasis is on the indirect forms of resistance due to the importance in the theoretical model of 'prostrate civil society whose capacity for active resistance is limited' (ibid: 97).
} 
to explore the ways in which the actions and discourses of particular citizens, including forms of 'resistance', come to represent a form of the modern subject which is cocreated by state, as well as individual citizens. The actions of citizens are not merely 'reactions' to state policies but also represent conscious choices, within the range of opportunities open to them. The extent to which individual actions might indicate the emergence of particular types of subject may be indicated by the extent to which particular activities are situated (discursively or otherwise) within narratives, patterns of historical repetition and variation, and performances of consent being given or withheld.

Emphasis by academics on state capacity and citizen 'powerlessness' sometimes derives from an over-reliance on analysis of policies, institutional frameworks, and official discourse, rather than empirical field data. It is the actual programmes and actions of the government, as well as the discourses that frame and make these practices possible, that comprise the arts of government (Foucault, 1977: 27; Li, 2007b). These are developed through dialectical relations with citizens. Rather than separating discourse and action, Foucault illuminated the ways in which power and knowledge are intertwined. Moreover, we can only start to understand discourses and actions if we appreciate the circumstances under which they develop: in other words, their specific geographical and historical context. 


\section{Geographical Context and 'Spaces of Governance'}

Ferguson argues that, "The new "arts of government" developed within First World neoliberalism might take on new life in other contexts' (Ferguson, 2009: 173). It is important to be aware of ways in which western ideas of the state permeate international discourse on governance but also how they have been re-interpreted and adapted or appropriated in different contexts. More broadly, it is necessary to 'examine how various languages of stateness have spread and combined in various parts of the world' (Hansen and Stepputat, 2001: 10).

Discourses and programmes of state-building, capitalist expansion, and creation of specific kinds of citizen-subjects also combine in different ways within state boundaries. States should be considered heterogeneous spaces rather than homogenous 'places'. For example, particular administrative jurisdictions may be associated with more-or-less rigorous or effective enforcement of national rules and regulations, and agro-ecological zones present particular opportunities or challenges to policy implementation, as will be demonstrated in Chapters Seven and Eight.

For geographers, the natural and built environment is part of the framework of subjectification and is responsible for some of the diversity within the manifestation of 'subjectivity'. Stephanie Rutherford argues that a sensitivity to geographical factors allow us to see that, 'power is enacted somewhere - not just as a metaphor but as a spatial reality... spatial analysis becomes key... a geographic analysis is well-positioned to avoid some of the pitfalls of a monolithic application of governmentality theory' 
(Rutherford, 2007: 303). Her understanding of 'geographic analysis' is more sophisticated than the simple biophysical and materialist lenses sometimes employed, which treat space as 'natural' (Herbst, 1990: 56) or a static and one-dimensional surface upon which are scattered the assets of the population and the state. Such simplistic readings of space, in the absence of significant contextualization within the field of international, national and local-level power relations, can lead to a 'rendering technical' (LI, 2007A) of what are in fact highly political issues.

In contrast to those emphasizing the 'naturalness' of space, Rutherford (2001) reminds us that a spatial analysis must go beyond the biophysical to consider how 'space is discursively determined in official discourses' (56). This lens enables him to identify the different forms of 'government' which are tied to particular combinations of racial identity, land tenure, and labour relations in Zimbabwe, and which become associated with narratives of 'modernisation' and 'development'. Like Rutherford, Moore agrees that colonial rule in Zimbabwe created 'multiple territories within a single colony' (Moore, 2005: 7), and links the ideas of 'development' within the governmentality of the Zimbabwean state, and the material consequences of this at the local level, to international markets and discourses. However, this discursive creation of different categories of citizen and subject, and different spatial territories, is not necessarily stable and is contested in various ways by local people (Moore, 2005: 58). 


\section{'Global Governmentality’}

As noted above, Foucault focused on western states. In addition, he was generally 'internalist', ignoring the 'international forms of government' (Hansen and Stepputat, 2001: 42). Nevertheless, many scholars have applied concepts from the governmentality literature to the spheres of international relations and international development. The 'global' or international context is an important part of any theoretical framework that seeks to avoid an artificial and theoretically limiting focus on a state, and a multi-scalar approach is an important feature of contemporary critical political economy and political ecology (Robbins, 2012: 20).

Particularly given the fact that almost $50 \%$ of its annual national budget comes from donor funding, it is impossible to discuss 'development' in Rwanda without considering the relations between Rwanda and the rest of the world.

The international development architecture was dominated in the 1980 s and the first half of the 1990s, approximately, by aid 'conditionalities' which were to a large degree imposed upon those countries receiving foreign assistance from institutions such as the World Bank or IMF (Williams, 1989). In the mid-late 1990s however, there was a shift in the international development discourse towards greater 'ownership' by beneficiary countries, which were no longer termed beneficiaries but rather 'development partners', who were more 'involved' in setting aid priorities through their preparation of national Poverty Reduction Strategy Papers (PRSP), for example (Abrahamsen, 2004). However, these 'participatory' mechanisms did not overturn or radically disturb power 
relations, but are a continuation of a relationship in which some actors such as bilateral and multilateral donor agency personnel have control over flows of money, whilst others such as government officials in 'recipient' states, or staff of national civil society organizations, have no direct control over this process. Moreover, participation depends upon an adherence to certain broad political and conceptual boundaries of debate. For example, the UK government requires that partner governments, 'have a commitment to the principles of the agreed international development targets and ... [pursue] policies designed to achieve these', (DFID, 1997, cited in Abrahamsen, 2004: 1461)

The 'agency' asserted during participatory processes is always bounded within power relations, and the forms of participation reproduce the narrative of development 'hence legitimating the norms of the world order' (Ruckert, 2007, cited in Lazarus, 2008). In addition to a 'legitimation' function, participatory processes also make participants more legible to the development architecture and to domestic and foreign investors. As Scott (1998) and Foucault (1991 [1978]: 92-3) point out, statistical data about a particular population allows the state (and other organizations) to characterise and visualize communities in particular ways which allow for large-scale planning. The various regimes, programmes and projects of international development aid, like the modern state, 'employ sophisticated technologies of surveillance, observation, normalization, calculation, evaluation, and differentiation' (Dillon, 1995: 324). 
Like the modern individual subject within the broader context of governmentality, an individual state is in an, 'ambiguous position as an object of knowledge and as a subject that knows' (Foucault, 1989: 312, cited in Dillon 1995, 324). A state must develop its own systems of surveillance, observation, normalization etc. in order to make its development objectives, the characteristics of its population, the nature of the milieu, available to the international regimes of power/knowledge on the basis of (neo) liberal terminologies and units of measurement. It is also granted the freedom, under the partnership model, to use these systems of surveillance and forms of information to develop its own strategies of national development, as long as they are in accord with the logics of (neo) liberal governmentality. Indeed, its ability to retain the 'freedom' to develop its own strategies is dependent upon its continual demonstration of its willingness and ability to do this. Through the use of memoranda of understanding and other instruments of governance, which encompass the logics of liberal 'development', 'recipients [of aid] are enlisted as the active agents of their own reform according to accepted and agreed standards' (Abrahamsen, 2004: 1461).

Such 'voluntary' arrangements relate not only to international financial institutions and other formal donors but, importantly, to transnational corporations and foreign investors. Political leaders in both Indonesia and Nicaragua, for example, have explicitly linked the 'governance audit' performed upon their countries - specifically by the Millennium Challenge Corporation (see below) to their ability to attract investors (Lowenheim, 2008). 
The conduct of states - both within its national boundaries and in the international realm - is assessed and evaluated through various indicators, which must be legible and credible to a variety of actors. The Paris Declaration on Aid Effectiveness insists that, 'Governments and external partners will need to shift... towards developing resultsoriented frameworks during the coming years' (World Bank 2007: xvi, cited in Joseph, 2010b): results must be coded in ways legible to international institutions. The need for legibility that Scott (1998) emphasises does not therefore stem only from the state's own processes of planning and implementation, but also from the need to articulate the nature of 'improvement' within international networks.

As noted previously, the governmentality framework is sometimes accused of suggesting an overly smooth and coherent model of interaction (Watts, 2008: 535). However, such readings are based on overly abstracted, theoretical aspects of the governmentality literature which rely heavily on formal plans and policy statements, rather than empirical information which reveals the 'micro-physics of power' (Foucault, 1977: 27): the actual practices as they occurred in particular times and spaces. Such practices may reveal that the governmental apparatus is best described as a dispositif or assemblage. Foucault defined 'apparatus' as:

a thoroughly heterogeneous ensemble consisting of discourses, institutions, architectural forms, regulatory decisions, laws, administrative measures, scientific statements, philosophical, moral and philanthropic propositions... 
The apparatus itself is the system of relations that can be established between these elements (Foucault, 1980: 194).

Importantly, Foucault emphasized that this relationship can change over time: 'between these elements, whether discursive or non-discursive, there is a sort of interplay of shifts of position and modifications of function which can also vary very widely' (Foucault, 1980: 194). Li discusses how such diverse elements are 'assembled to constitute a technical field fit to be governed and improved' (Li, 2007c: 286). The conversion of these complex political and social dimensions into 'indicators' of development is therefore a process of simplifying and 'rendering technical' something which is comprised of complex relations of power/knowledge (Li, 2007c: 286).

In terms of what has been termed 'global governmentality', international relations between states, multilateral organizations, transnational organizations and other actors are not regulated by any truly global, liberal, unified apparatus (Joseph, 2010a; Dean, 2004; Fraser, 2003). In contrast, 'unevenness' arises from the interactions of many different kinds of state governance models, and there are difficulties in 'combining' different 'multileveled' governance tools associated with them (Joseph, 2010a). International systems play disciplinary roles, often in contested and controversial circumstances. 


\section{Conclusion}

This chapter has outlined the broad theoretical framework which informs this

dissertation. The framework is largely based on the authoritarian high modernism

model, and I accept the first three characteristics of such programmes put forward by

Scott: '1. The administrative ordering of nature and society [according to]

transformative state simplifications, 2. A strong...version of the self-confidence about

scientific and technological progress... 3. An authoritarian state which is willing and able to use the full weight of its coercive power' (Scott, 1998: 4-5). However, as will be described below, I do not accept the fourth characteristic, contending that civil society need not be 'prostrate' for authoritarian schemes to be implemented.

The dissertation departs from Scott's model, bringing in a more nuanced approach to state and non-state institutions and actors, and the often blurred lines between their roles; it also pays greater attention to a range of non-state actors, reflecting the complex, large-scale, and multi-institutional nature of contemporary national agricultural reform. Specifically, rather than focusing only on the state, my theoretical framework centres on the state-dominated dispositif composed of various actors. This approach enables me to discuss the 'increased involvement of non-state actors in the agricultural sector', as part of the research question. Non-state actors are incorporated into the dispositif not only through the use of coercion but through other forms of power and influence (such as cooptation), as well as due to self-interest.

Using the critical political economy literature (in particular the work of Karl Marx, David Harvey, Karl Polanyi, and Farshad Araghi), and in response to critiques of Scott's 
apparent separation of 'state' and 'market' in his work, I described the historical processes through which states have put in place the structures and dynamics that drive capitalism. In particular, I drew attention to processes of commodification and proletarianization, including through processes of accumulation by dispossession. In contrast to discourses of a 'naturally' self-regulating laissez-faire capitalism, I noted that states have intervened massively in society in order to create the possibility of (neo) liberal capitalism. Therefore, while Scott implicitly sees the actions of corporations and states as distinct, my theoretical framework acknowledges the links between state policies and corporate activities. More specifically, while Scott argues that high modernist schemes are intended to 'improve the human condition' (Scott, 1998: 342), my theoretical framework emphasises the ways in which states consider an increase in the commercialization and corporate penetration of rural economies to be an 'improvement', despite any potentially negative effects on segments of the population associated with processes of proletarianization. While Scott sees private enrichment (through processes that I would identify as accumulation by dispossession) as unintended consequences of high modernist programmes, my theoretical framework considers them to be integral to the processes of large-scale agrarian transformation planned by the Rwandan state. I am not arguing that the state primarily intends to enrich some actors at the expense of others as an aim in itself; rather, that the statedominated dispositif implementing agricultural reform facilitates accumulation by dispossession in order to affect the socio-economic differentiation that can result in an agrarian transition which is its ultimate aim. 
I then turned to Scott's treatment of power relations, which is based on a fundamental opposition between a 'dominant' state and a 'resistant' peasantry that acts in response to state coercion. In preference to such a model, I outlined the different forms of power in Michel Foucault's work, and focused especially on governmentality, arguing that diffuse forms of power and processes of subjectification associated with it can be found in some African contexts. In this dissertation, I consider the use of sanctions such as fines, imprisonment, and intimidation to represent 'coercion'. The Foucauldian concepts of 'sovereign power', also called the power of 'law' (Foucault, 2004: 4) and 'discipline' may often, broadly speaking, be considered to be coercive forms of power. Strategies associated with governmentality, on the other hand, do not fall under the category of coercion. This distinction between different forms of power, and identification of governmental strategies in particular, allows me to bring together the themes of 'statebuilding' and 'state efforts to mould citizenship, development, and governance' in the research question. While the concept of 'resistance' to state dominance is referred to throughout the dissertation, the consideration of the governmental form of power permits me to consider how the state-dominated dispositif may influence not only the outward behaviour, but also the reflexive 'positioning' of the individual subject in relation to concepts of agricultural production, land ownership, the rights and responsibilities of citizenship, and the like. Because of the key role of the 'desires of the population' (Foucault, 2007: 73) in governmental approaches, the actions of citizens may go beyond mere 'resistance' and have an impact on state plans and programmes. Such a framework allows me to consider the ways in which 'spaces of governance' are 
not simply imposed by the state, but may be to some extent co-created by citizens and the state-dominated dispositif.

I also noted that an attention to particular geographical and discursive aspects of 'space' may allow us to identify specific kinds of spaces of governance within a single country. In this sense, my theoretical framework allows me to identify ways in which the agricultural reform produces heterogeneity as well as the homogeneity on which Scott places so much emphasis.

Finally, I deployed the concept of global governmentality, in order to be able to take a multi-scalar approach and place the government of Rwanda, as a recipient of foreign aid and an actor in the diplomatic realm, within an international context. This internationalist approach (rather than the more internalist approach often taken by Scott) helps me to describe some of the means through which different actors are incorporated within the state-dominated dispositif.

I continue to draw upon these themes throughout the dissertation.

In the following chapter, I turn to the specific Rwandan case study, using aspects of this critical political economy framework to analyse the Rwandan government approach to rural development and governance more generally. I also discuss the methods I used for this study. 


\section{Chapter Three: An Overview of the Political Economy of Agricultural Reform in}

\section{Rwanda}

\section{Introduction}

This chapter provides an overview of the political economy of Rwanda in order to explore the extent to which it can be considered 'liberal', 'neoliberal', or 'liberalizing'. It presents the 'internal' or 'domestic' drivers of reform in the agricultural sector, to shed light on the goals of the reform, and explain how its legal and regulatory architecture, as well as the broader institutional culture of the government of Rwanda, can be at least partially understood through the theoretical frame of 'authoritarian high modernism'. The chapter shows that disciplinary technologies are available to administrators wishing to oblige farmers to follow nominally 'voluntary' policies (such as regional crop specialization). This means that the agricultural policy represents a 'homogenizing' force, imposing particular crop varieties and farming systems on smallholder farmers, notwithstanding the viability of these crops and systems within local agro-ecological and social contexts. Some of the state-directed mechanisms through which commercial actors are becoming incorporated within agricultural commodity chains - such as the imihigo performance contracts - are also part of this homogenizing dynamic. Following this description of the political economy of Rwanda and the agricultural reform, I describe how I tailored my research methods to this particular context, and the challenges that it poses to the collection and interpretation of secondary and primary data. 


\section{The RPF and Post-Genocide State-Building}

The government of Rwanda has, over the past seven years, embarked upon a process of radically re-structuring the agricultural sector. This restructuring has been designed by the ruling Rwandan Patriotic Front (RPF) political party, which has officially ruled since the end of the political transition period in 2003; and was unofficially also the major decision-making entity in the government of national unity during the post-genocide transition-period as well.

Though influenced by 'left wing ideas' in the 1960s and 1970s (Prunier, 1998), and the so-called 'no-party' (in reality, a single-party) system of late 1980s-late 1990s Uganda, the RPF leadership has been characterised by political pragmatism. The post-genocide government was faced with a mammoth task of reconstructing state institutions after the genocide, in which over 800,000 people were killed and much social and material infrastructure was destroyed (Desforges, 1999; Prunier, 1995; African Rights, 1995). Educated and trained personnel had been murdered; government offices looted; the state treasury ransacked. In the process of reconstruction, the government and donors made a symbolic 'break' with the past. The government version of colonial and postcolonial history emphasises 'bad leadership'; social divisions which were initiated and encouraged by Belgian colonialists; and a history of genocide and genocidal ideology that stretches back decades, with the 1994 genocide only the climactic moment of this longer history (Hilker, 2011). The inherent difficulties of re-writing history have meant 
that efforts to develop educational syllabi and materials have been long-postponed and highly politicised (Freedman et al, 2011: 298).

In creating a 'New Rwanda' (Kagame, 2009), the government rapidly created and enacted economic policies associated with neoliberalism (Cannon, 2005) while avoiding many of the policy debates that go along with more gradual processes of privatization (Harrison, 2010: 107). In many post-conflict and post-atrocity contexts, the extreme difficulties of everyday life for the majority of citizens, and the scale of the challenge of rebuilding state and civil society institutions, are cited to justify an 'exceptional' situation in which the normal processes of policy debate may be avoided. The concept of the end of conflict providing a 'fresh start' through which neoliberal policies may be quickly put in place is relatively common in the popular state-focused discourse of postconflict reconstruction, and also occurred in post-civil war Uganda and Ethiopia, for example (Harrison, 2010: 107). In the case of Rwanda, the influence of the RPF in the transitional government was such that legislation proposed by the party was not seriously contested by Parliamentarians, despite some efforts to increase the independence of Parliament (Sebarenzi, 2009: 118), and that the RPF-dominated Executive enjoyed much more power than in most democratic systems (Sebarenzi, 2009: 118-119). More generally, policy documents or policy-related research avoided the kind of politically, socially and economically nuanced analysis that would locate government strategies within a political economy frame that might allow for a discussion of what 'neoliberalism' or its alternatives might entail. As in other places, the government's 'development partners' were deeply implicated in an 'anti-politics machine' in Rwanda 
(Pottier, 2002: 200, citing Ferguson, 1994). For example, a major World Bank study on the causes and depth of poverty in Rwanda ignored any serious investigation of class structures, increases in income inequality, or other issues related to the uneven distribution of the benefits of national reconstruction (Banque Mondiale, 1998, cited in Pottier, 2002: 200). This omission is all the more striking, given the widely-held view that a 'deep socioeconomic cleavage between the elite and the poor created a precondition for the political manipulation of and mass mobilization around ethnicity' which resulted in the 1994 genocide (Cannon, 2005: 1).

It has been shown that this socio-economic cleavage, generally accepted as an important contributing factor to genocide, was exacerbated by the neoliberal Structural Adjustment Policies linked to IMF and World Bank loans, which were introduced in 1990-1 (Cannon, 2005: 8-9; Vandeginste, 2005: 126). President Habyarimana accepted these policies in order to benefit from foreign currency (Cannon, 2005: 12) during a long-standing economic crisis. The new policies were, in the words of the World Bank, intended to dismantle the 'centralized socialist system' (World Bank Operations Evaluation Department, 2004, cited in Vandeginste, 2005: 126), though the characterisation of Rwandan policies as 'socialist' was misleading. The new policies resulted in higher prices for commercial goods, higher taxes, and increased fees for public services, all of which disproportionately affected the poor (Cannon, 2005: 9).

The post-genocide regime, which had very little access to bilateral funding in the immediate aftermath of the genocide, had little choice but to look to the IMF and World Bank for loans, which were linked to liberalization policies including fiscal reforms to 
increase transparency, a decrease in regulation of the labour market, and the adoption of a more private sector-friendly legal and regulatory framework (Vandeginste, 2005: 127). Trade regulations were reformed to reduce import and export taxes and most of the 53 parastatal corporations were privatized (Cannon: 2005).

The government has tended to adopt a 'user pays' approach to development, with an aim to making state-subsidised projects and programmes financially self-sustaining over time. ${ }^{17}$ The government of Rwanda has welcomed foreign investment in almost all sectors of the economy, including in the agricultural sector, where a large state-run sugar factory was privatised in the late 1990s and the coffee sector, in particular, has undergone liberalization with substantial technical and financial assistance from the United States Agency for International Development (USAID) (Boudreaux, \& Ahluwalia, 2009). The investment law 'aims at facilitating procedures for investors and, crucially, it provides significant incentives for investors, in terms of a number of tax breaks' (Veldman and Lankhorst 2011), and special economic zones have been established with particular benefits for investors. Indeed, Rwanda provides the most generous tax incentives in the East African Community for FDI and domestic investment (IPAR, 2011). The number of bureaucratic procedures involved in the foreign investment process has been reduced, and Rwanda has accordingly moved rapidly up the ranking of the World Bank's Doing Business report. ${ }^{18}$ Market principles, such as competition, have also been

\footnotetext{
${ }^{17}$ While service provision is often subsidised in the early stages of programming, the government generally attempts to progressively reduce or remove subsidies. This is occurring in the fertilizer sector, for example.

${ }^{18}$ Rwanda was 'the number 2 improver globally and top improver in Sub-Saharan Africa since 2005' (World Bank, 2013:9) and was ranked no. 52 globally in 2013, compared to no. 150 in 2008.
} 
institutionalised within the state: there are various rankings and competitions for state agencies. Like other countries around the globe, Rwanda is following a path that might be termed 'market-oriented authoritarianism'.

This politico-economic orientation has its own internal contradictions and tensions, most notably around the rhetoric of administrative decentralization (for the purposes of increased efficiency and responsiveness to demand) which is contradicted by a reality of highly centralized decision-making; and the existence of corporations owned by the RPF (often staffed and partly-owned by the military), which enjoy privileged access to state contracts in various sectors and hence undermine economic competition (Gokgur, 2012; Booth and Golooba-Mutebi, 2011). ${ }^{19}$ One of the most significant roles of the Rwanda Defence Forces in the economic redevelopment of the country evolved following the invasion of the neighbouring Democratic Republic of Congo (DRC) by Rwanda in 1996. In a strategy that one analyst has called 'military commercialism' (Cannon, 2005: 12), the Rwandan military took extensive control of the most valuable commercial networks of Eastern DRC, notably mineral export networks (particularly coltan, gold, and cassiterite), repatriating the profits through RPF-owned companies such as Tri-Star (Booth and Golooba-Mutebi, 2011).

Rwanda has also implemented various social welfare programmes, such as a health insurance scheme which, while based on user contributions, is subsidised; the Vision

\footnotetext{
${ }^{19}$ RPF-owned companies dominate many sectors including 'construction, engineering, real estate development, furniture making and importing, packing materials, agro-processing, tea factories and coffee-washing stations, energy, pyrethrum processing, telecommunications, communications, broadcasting and media, internet services and security' (Gokgur, 2011: 13 citing Booth and GoloobaMutebi, 2012 and 2011a).
} 
2020 Umurenge programme which provides cash support to citizens identified as particularly vulnerable; the 'One Cow per Poor Family Programme' and special support for genocide orphans and other vulnerable categories of the population (Unicef, 2011). These programmes do not completely accord with neoliberal doctrine, which generally maintains welfare programmes at the lowest level that is politically possible.

The complex nature of Rwandan economic governance, and the fact that the government 'has not been fully consistent' (Booth and Golooba-Mutebi, 2011: 22) in its approach to state or ruling party intervention in the economy, has led different observers to categorise it in various ways. Such assessments range from a 'pro-private sector, free market economy' (Crisafulli \& Redmond, 2012: 3) to a 'developmental patrimonial' regime which retains considerable control over the economy in order to channel the proceeds of economic rents (income protected from competition) towards projects in the public interest (Booth and Golooba-Mutebi, 2011). Others argue that while the political economy of Rwanda is indeed 'patrimonial', there is little evidence to suggest that RPF-owned enterprises that benefit from economic rents invest their profits in public goods; suggesting rather that such enterprises serve only Rwanda's politically-connected elite (Gokgur, 2011).

Clearly, the 'neoliberal' label can therefore only be applied to Rwanda if various caveats are attached. This is not unusual; indeed, the 'pure' neoliberal model put forward by theorists is rarely if ever found in the real world, and the realities of implementation tend to result in various re-interpretations and compromises of neoliberal doctrine. Citing Harvey (2005) James Ferguson argues that neoliberal doctrine is utopian, so that 
'Neoliberal policy is thus much more complicated than a reading of neoliberal doctrine might suggest' (Ferguson, 2009: 171).

The RPF has designed development policies that mobilise concepts from mainstream liberal and neo-liberal economic and 'development' discourses, which can nonetheless be adapted to the broader political context, centralized authoritarianism (Strauss and Waldorf, 2011). ${ }^{20}$ (. The government purports to support political consensus-building within a broader framework of multiparty democracy. This image is carefully reproduced, with the help of US and British public relations firms (York, 2012), but elections, whether at local or national levels, are routinely rigged or interfered with by the government (Ingelaere, 2011; US Department of State, 2010b; Longman, 2011) and the government's discourse on political 'consensus' signals a political philosophy of centralised and opaque decision-making. Opposition parties have faced regulations that banned political activity at the local level (Longman, 2011: 38) as well as a variety of other legal and extra-legal forms of control.

Rather than address the post-genocide questions of national reconciliation through processes of open political negotiation, debate or candid self-appraisal, the government has preferred to contain the 'reconciliation' process within fairly narrow conceptual and institutional boundaries (as will be discussed in more detail in Chapter Five) while attempting to achieve very rapid rates of economic development. The RPF is essentially attempting to achieve legitimacy and ensure its political survival not primarily through

\footnotetext{
${ }^{20}$ These mechanisms include imihigo, which will be discussed in Chapter Four.
} 
client-patronage networks ${ }^{21}$ ) or primarily through political-administrative systems of direct accountability to the electorate, but through delivering significant increases in income and improvements in life-chances for the majority of the population. ${ }^{22}$ Rather than participation in decision-making, Rwandan citizens are offered economic development, political 'stability' and effective controls on bureaucratic corruption. Indeed, external actors have argued that the RPF 'can only achieve legitimacy by delivering results' (Sommers, 2012: 213). This model is similar, of course, to the 'developmental state' concept (Johnston, 1982; Mkandawire, 2001). Government ministers have explicitly referred to the Rwandan governance model as following the developmental state (Nsanzabaganwa, 2011: 11) and external observers have also made this connection (Booth, 2012).

However, the rapid pace of changes in the policy realm in Rwanda, as well as the sheer scale and scope of socio-economic transformation, and the numbers of actors, approaches, and programmes involved, mean that it is difficult to neatly categorise the political economy of the country. This makes it a useful case study for the current exploration of how states 'see' during processes of commercialization.

\footnotetext{
${ }^{21}$ This was largely the case in Rwanda from 1962-1994 and is the case in many multi-party states, such as Kenya (Kelsall, 2011).

${ }^{22}$ This general statement requires some caveats, only a few of which may be mentioned here. It should be noted for example that at the level of elite politics, patron-client relations likely exist, particularly in terms of interlinked commercial and political interests, though the largely opaque nature of some high-level political and planning decisions makes these interests difficult to track (Reyntjens, 2013: 73). It should also be noted that while Rwanda is providing important services to the general population - notably improved health and education services - these should not necessarily be construed as completely equitable, or universally 'pro-poor' (Ron-Balsera, 2011). For example, government support to the education sector is directed mainly to the elementary (primary) level and the tertiary (college and university) level, while the high school (secondary) level remains under-funded (Sommers, 2012: 37). This pattern is likely to result in a highly stratified population, with most people achieving only an elementary education while a smaller section of society gains a university degree.
} 


\section{Internal Drivers of Change in the Rwandan Agricultural Sector}

The government of Rwanda arguably paid little attention to the agricultural sector in the first post-genocide decade. The focus was instead on the shelter and settlement, justice, education and health sectors, which were seen as part of an important transition from post-genocide 'emergency' towards development programming. Given the nature of the post-genocide context (characterized by a housing crisis, overcrowding in the jails, and limited access to basic services in the countryside), this prioritization is understandable. Donors also prioritised these sectors (Booth \& Golooba-Mutebi, 2012). From the early 2000s, emphasis was placed on the construction of physical and Information technology infrastructure in Kigali, and to a lesser extent other urban centres. The relative lack of attention to farming until the mid-2000's can also be explained not only by the urgent needs of other sectors, but also by the minimal influence that the poor smallholder majority has on the political situation in Rwanda, despite comprising around $80 \%$ of the population. ${ }^{23}$ As discussed in detail by Ansoms (2009) the inner core of the RPF are highly-educated urbanites, most of who lived in exile before returning to Rwanda after 1994. Many government decision-makers therefore lost any direct links to the countryside through tragic family histories of forced displacement, exile, and genocide. The political system in Rwanda is also delinked from territoriality: elected Members of Parliament are not affiliated with any geographical constituency. Policy-makers

\footnotetext{
${ }^{23}$ As discussed further below, various sources provide different figures for those 'primarily' relying on agriculture, from $72.6 \%$ to around 85\% (Pritchard, 2013; NISR, 2012g).
} 
therefore have few institutional or personal connections to rural development issues, and many tend to have a condescending or even disdainful attitude to poor smallholders (Ansoms, 2009). Rwandan civil society, which includes many rural development and farmers' organizations, has limited capacity to influence policy and as a result of state practices of cooptation and control, have been largely reduced to a role of 'policy implementation' (Gready, 2011; Musahara and Huggins, 2005). Rather than a 'prostrate' civil society, as per Scott's model, the Rwandan version is a co-opted and compliant civil society, which is nevertheless actively involved in the state's schemes, as will be described below.

Rather than responding to particular demands 'from below', then, the Rwandan government 's current investment in agricultural reform comes 'from the top'.

\section{Agricultural Policy Development}

In contrast to the long process of elaboration of the land policy and 2005 land law, the agricultural policy was formulated rapidly after a consultation process that can best be described as perfunctory, and included 'seminars' and meetings with :

Representatives from the agro-industry, traders and exporters of agriculture produces [sic] which has put in place a focal team of six private operators ...officers of MINAGRI and its partners (MINECOFIN, DMU, Labour Intensive (HIMO), CDF, Prefects of provinces, Mayors of districts etc.); the main actors of rural development cluster [donors and NGOs]; partners of MINAGRI; Prefects of provinces and Directors of agriculture, animal resources and 
forestry in provinces; donors; the private sector community. (MINAGRI, $2004 a)^{24}$

It can be seen that farmers' organizations are noticeably missing from this list, and that these 'seminars' were not intended to spur national debate. The finalization of the government's Strategic Plan for Agricultural Transformation (SPAT) also seems to have taken place after such cursory consultations. A workshop was held in every District to discuss the SPAT; each involved only 40 participants. These included 'CDC [Community Development Committees, part of the local authority structure], the district sectors, producers and farmers' organisations, technical services, private economic operators, NGOs and projects' (MINAGRI, 2004b:93). It is doubtful, therefore, whether any smallholder farmers themselves were ever actually present during these 'consultations'. This approach, which is described as 'bottom up' in official documents, seems more designed to collect elite viewpoints than to seriously comprehend the views of the rural majority.

The government has given the agricultural policy a gloss of a 'participatory approach.' According to the Ministry of Agriculture and Animal Resources (MINAGRI), 'the crop intensification policy seeks to change crop cultivation processes based on potential for increased value, ecosystem characteristics, and the preferences of farmers' (Republic of Rwanda/United Nations, 2007 - emphasis added), while the National Agricultural

\footnotetext{
${ }^{24}$ DMU stands for Disaster Management Unit; HIMO stands for Haute Intensité de Main-d'œuvre, and CDF stands for Community Development Fund.
} 
Extension Strategy includes as one of its 'guiding principles' the concept of, ‘Participatory extension' (MINAGRI, 2009a).

However, the government's own documentation of the program demonstrates that the crop intensification program was developed by state agencies, not farmers' associations or any other organization directly representing the interests of farmers. The Progress Report on [sic] Integrated Development Program, dated September 2007, describes the consultations between state entities and parastatal organizations (Anonymous, 2007). ${ }^{25}$ The document goes on to detail the crops to be grown in particular sectors, and minimum targets. For example, a minimum of 20,000 ha of maize is to be grown in Eastern Province. No procedures for consultation with farmers are listed in the report. In contrast, particularly, with the land registration programme's intensive piloting of proposed approaches and systems, there was a striking lack of field testing regarding the agricultural policy. The SPAT's one year 'pilot phase' in 2005, appears to have involved only institutional and regulatory activities, without any field trial elements (MINAGRI, 2004b). ${ }^{26}$ Crops included in the regional crop specialization programme were

\footnotetext{
${ }^{25}$ Those Ministries and agencies are: MINALOC (Ministry of Local Government), MINAGRI (Ministry of Agriculture and Animal Resources), MINICOM (Ministry of Trade and Industry), MINITERE (Ministry of Lands Environment, Forests, Water and Mines), MINECOFIN (Ministry of Finance and Economic Planning), MININFRA (Ministry Of Infrastructure) OCIR-thé, OCIR-café (Rwanda Coffee Authority), RADA (Rwanda Agricultural Development Authority), ISAR (Rwanda Agricultural Research Institute), and REMA (Rwanda Environment Management Authority).

${ }^{26}$ The document states that, 'The first year (2005) is considered as a pilot phase. It is partly meant for perfection of the strategy and its operational tools, mobilize the partners and resources and prepare a Medium-Term Expenditure Framework (MTEF) for the period 2006-2008. It will also be devoted to the formulation of specific policies in some important domains such as extension, communication and gender. It will also be used to restructure MINAGRI, redefine its missions and the roles and responsibilities of all stakeholders in the sector. The year 2005 is a year of initiation of pilot actions, particularly in commodity
} 
chosen following a rather short pilot programme (Ansoms, 2009). According to MINAGRI (2004b), the choice of approved crops was based on the SPAT District consultations mentioned above. The justification for the choice of crops owe much to the existence of processing facilities for certain crops, suggesting the importance of industrial-scale value-addition, as will be described below. Agro-ecological 'favourability' is mentioned, but this does not seem to be an overriding concern. In general, the justification does not seem to be based on particularly detailed analysis of all the relevant factors (e.g., macroand micro-economic, environmental, social, political, and cultural) or any systematic ranking, weighting, risk analysis or other transparent approach (MINAGRI, 2004b). ${ }^{27}$ In particular, given the agro-ecological diversity of the country, it is not clear that the regional crop specialization policy has involved sufficient sector-level analysis of crop viability. The average size of an administrative sector in Rwanda is approximately 64.5 square kilometres. ${ }^{28}$ Given the generally hilly topography (which presents various microclimatic niches, soil conditions and hydrological characteristics) and the fact that 'Rwanda is ecologically diverse for its size' (Fewsnet, 2011: 4), such an area may represent various agro-ecological conditions. Therefore, while the choice of priority crops at national level does not immediately suggest the folly of the high-modernist blueprint, the way that these crop choices are imposed at the local level does appear to chains sector, agribusiness and the establishment of an Agricultural Guarantee and Credit Fund.' (MINAGRI, 2004b)

${ }^{27}$ According to Stone et al (2011: 2), priority crops should 'play an important role in the national economy; have comparative advantage in the context of national, regional and international markets; be assured of appropriate transport, storage, conservation and processing facilities; exhibit appropriate nutritional potential; and have high yield and processing potential'. However, regarding nutritional potential, it is noticeable that maize, a priority crop, is no more nutritionally valuable than sorghum, which is not a priority, as they have roughly the same proportion of protein (FAO, 1995; FAO, 1992).

${ }^{28}$ There are 416 sectors in Rwanda, which has a total land area of $26,798 \mathrm{~km}^{2}$ 
be unresponsive to agro-ecological and social diversity. It is a homogenizing and oversimplifying approach. An example of this (maize production in Mahama Sector, Kirehe District) will be presented in Chapter Eight.

In 2007, an assessment of the agricultural research and extension systems in Rwanda noted a lack of information on the production costs of crops, and advised that without such data, it is impossible to make informed decisions on investments in value chains and other aspects of agricultural production and marketing systems (Tizikara et al, 2007). Despite this absence of data, these original planning assumptions and decisions have not significantly altered since the mid-2000s. This would seem to indicate that the government, which sometimes demonstrates an overriding faith in the capacity of science and technology to overcome natural and social obstacles - one of the characteristics of the high modernist paradigm (Scott, 1998: 4) - does not necessarily base its planning processes primarily on scientific assessments, but on often opaque political and economic criteria.

The impetus for agricultural reform seems to be largely driven by three dynamics: a government desire for agricultural intensification and commercialization as catalysts for macro-economic growth; government concern over land scarcity and fragmentation as economic problems and potential sources of social conflict, within a context of 'mediocre' subsistence agriculture (MINITERE, 2004: 43); and a broader, Africa-wide pattern of land and agricultural reform under the banner of the Green Revolution for 
Africa and the Comprehensive Africa Agriculture Development Programme (CAADP).

These are treated in more detail below.

Firstly, the highly ambitious targets for national development in Rwanda's 'Vision 2020' document (MINECOFIN, 2000) necessitate that the economic impacts of agriculture increase quickly. 'Vision 2020' which is, constantly referred to by policy-makers, has the aim of increasing economic growth by an average of $13 \%$ per year to make Rwanda a middle-income country by 2020 (MINECOFIN, 2000). Agricultural growth and commercialisation of the agricultural sector are identified as key elements of economic expansion; more so, for example, than industrialisation, which has until recently been somewhat de-prioritised. The selection of priority crops under the Crop Intensification Programme (CIP) of the agricultural policy are linked to objectives of value-addition in the agricultural sector at the industrial-scale. CIP priority crops include maize, wheat, rice, Irish potato, beans and cassava. While these all serve some kind of food security function (i.e. they are part of the Rwandan diet and serve local markets) it is noticeable that most (if not all) of these crops are intended to be processed, and sold not only domestically, but also regionally and globally. For example, the government justifies its choice of crops for the former Provinces of Kigali-Ngali, Kibuye and Gikongoro by referencing the existence of processing facilities (MINAGRI, 2004b). This is true even of cassava, which historically has been seen as a drought-resistant food crop which can be grown in relatively nutrient-poor soils. According to the government, cassava can be processed in various ways and has 'enormous potential for industrial applications' (RAB, 2013). The government has constructed an $\$ 8.4$ million cassava factory in Southern 
Province, to serve regional and global markets. The factory was financed by the Rwanda Development Bank, the investment arm of the government (Harding, 2011). Supporting local processing firms in this way makes sense from a perspective of industrialization. Linking agricultural reform to agro-processing plants is an effective way to generate greater value from agriculture, as well as potentially creating jobs in the agro-processing sector (and various related packaging, distribution and other 'downstream' activities).

It becomes apparent then that the government is primarily interested in value-addition, particularly through large-scale processing plants, and crops with export potential. This is also evident from the relative lack of government interest in crops such as beer bananas and sorghum which are in fact highly commercialised within Rwanda ${ }^{29}$ but are not seen as important for processing and regional trade. Government documents have acknowledged that, 'there are scenarios where the profitability of other (non priority) crops appears to be significantly higher over [sic] the priority crops proposed under land use consolidation' (Kathiresan, 2011). This suggests that the key criterion for the government is not necessarily profit for farmers, but the potential for value-addition and profit further up the commodity chain.

The government's interest in commercialising agricultural production is aimed primarily at the national-level formal sector, rather than the local and informal sector (Holden, 2012). The goal is to generate taxable income, particularly commercial exports which are projected to increase from $\$ 200$ million in 2011 to $\$ 1.5$ billion in 2020 (Holden,

\footnotetext{
${ }^{29}$ For example, 39\% and 32\%, respectively, of all beer bananas and sorghum is sold, rather than consumed by the smallholder producers (NISR 2012c).
} 
2012: 139). This approach is certainly not 'market-led' in the sense of the neo-liberal economic development model. This is intervention along the developmental state model, heavily subsidised by the government and dependent upon central-planning and state coercion. Central planning, particularly in the form of the regional crop specialization programme, appears to be acting counter to the 'market-oriented' discourse around the reform. The World Bank, for example, has called for a 'marketbased food crop distribution system' to be put in place due to 'stark regional differences in food availability and food security, connected to seasonality' (World Bank, 2011: 5). The World Bank does not analyze the causes of these differences between provinces, but they suggest that current policies have not resulted in populations in some provinces accessing sufficient amounts of key staples. This theory is supported by an economic study on market prices. The study compared one dataset on bean prices from 1999 to 2003 with another dataset from 2007 to 2012, after the introduction of the agricultural reform. The study found that average prices did not change, as would be expected in a liberal market economy during a process of improved access to market information:

Their stationarity [price] behavior is not consistent with an open market behavior where prices are expected to be non-stationary without any tie to their historical mean. This raises the question of whether the introduction of the liberalization policies... have helped in opening up the staple food markets in Rwanda. (Bizimana et al, 2013) 
Centrally-planned crop specialization is not entirely consistent with government of Rwanda discourse, particularly in terms of its engagement with mechanisms of global governmentality, which have their roots in a largely liberal conception of political economy. In addition, this emphasis on large-scale processing and export markets tends to support the biggest and most powerful actors in the commodity chain, who will come to further dominate the sector. There are countervailing tendencies: for example, government support to cooperatives through the Rwanda Development Bank and other mechanisms provides credit that can be used to create small processing plants for locallevel value-addition. However, it appears that because of the size of the investments that the government has made in large-scale facilities, the CIP and other government agricultural programmes are aimed at feeding the demands of those factories to ensure that they can rapidly become profitable. The integration of large-scale commercial actors such as maize processors, though it often involves willing-buyer, willing-seller negotiations, is associated with homogeneity in commodity-choice due to the regional crop specialization policy. Government-supported millers accept maize varieties approved by the government.

The government wants to reduce the number of people farming the land, completely commercialize agriculture, and effectively consign smallholder farming to history. As will be described below, while government discourse emphases the role of 'the market' in driving this change, various forms of 'administrative ordering of nature and society' 
(Scott, 1998: 4) have been designed and implemented to drive this change. The 'transformation' envisaged by the Rwandan state is not only a technical one (towards more intensive forms of cultivation) or a financial one (towards more fully commercialized models of production and processing) but is deeply embedded in a broader political and ideological project of creating a 'New Rwanda', populated by the ideal 'New Rwandan' citizen. The concept of modernisation, in Rwanda, is intertwined with particular ideas of 'post-ethnic', 'post regional' identity, as well as the visual aesthetics of modernity which are more central to Scott's work (Scott, 1998: 4; 237).

The second main impetus for the agricultural reform, according to the government, is that land scarcity also necessitates urgent intervention. The government is particularly concerned about the negative effects of land fragmentation (MINITERE, 2004). Average population density is now more than 400 people per square $\mathrm{km}$ by some estimates (MINAGRI, 2012a), the highest in Africa; most households farm just over a half hectare of land which is not particularly fertile; per hectare yields are low, even by regional standards; and the population growth rate remains very high. For many years now, observers have been arguing that, 'Rwandan agriculture is at an abyss' (Robins, 1990). The government seems to agree: senior administrative personnel have described land scarcity as Rwanda's 'time bomb' (Sommers, 2006). ${ }^{30}$ Increasing the productivity of land is presented as a way to minimise these risks. The forms of intensification supported by the government include the increased use of external inputs, technologies such as

\footnotetext{
${ }^{30}$ The Government of Rwanda has created a discourse in which the country has emerged from conflict and crisis into a present and future characterised by stability, unity and economic growth.
} 
greenhouses, irrigation systems, motorized ploughing machinery, and other imported equipment. The government assumes that the knowledge and material inputs for intensification will originate in Rwanda's specialized agricultural research institutions and the global marketplace. The possibility that there may be indigenous, smallholder sources of adaptation or intensification is not considered. The image of smallholder farming that appears in Rwandan state discourse is almost entirely negative: the average farming household is associated, in official documents, speeches and progovernment media articles, with: environmental degradation; a 'conservative' outlook (Musahara, 2006), resistance to change; low productivity (MINECOFIN, 2000) and ignorance in matters of nutrition, for example (Musoni, 2011a). The National Land Policy perhaps summarises this perception most succinctly when it states that the peasants are practicing a mediocre agriculture that has no future' (MINITERE, 2004: 43).

Often, customary modes of production are associated with 'subsistence' and 'irrational' beliefs. For example, the pro-government New Times has decried 'farmer's ignorance and traditional attitude' (Rwembeho, 2010b), while MINAGRI claims that larger, consolidated fields are 'more rational' than customary landholding and cultivation patterns (MINAGRI, 2013). The National Land Policy describes customary marshland farming as 'simple self-subsistence agriculture based on working the land without caring for its conservation or the improvement of its production capacity' (MINITERE, 2004: 44). 
This emphasis on 'self-subsistence' is misleading. While potatoes, cassava and other foodcrops are consumed by households, a significant amount of household produce is sold. An average of $16 \%$ of the harvest was sold, before the reform (aggregate figure for all major crops); this has now increased to $20.9 \%$ and is higher for crops such as beer bananas (39\%) and sorghum (32\%) (NISR, 2012d: 17); these figures do not account for food which may be bartered. In Kirehe, administrators blame farmers' unwillingness to purchase artificial fertilizer on an 'irrational' belief that fertilizer damages the soil; rather than acknowledging smallholders' clearly articulated concerns over climatic risk and the costs and benefits involved in using commercial fertilizer for a crop such as maize. ${ }^{31}$

This particularly negative view of customary forms of agricultural production reflect a rigid distinction in Rwandan policy-making circles between 'expert' or scientific knowledge, which is privileged; and smallholder or oral knowledge, which is not taken seriously. Government concern over land scarcity and land fragmentation leads to a prescription of market transactions in land, as well as the eventual disappearance of the 'customary' smallholder farmer, as will be described below.

\section{The Goals of the Agricultural Reform}

One of the main goals of the reform is to increase agricultural production, particularly of selected crops, on a total aggregate basis as well as a per-hectare basis (Kathiresan, 2011). The government has achieved this goal, as noted above (FAO, 2013, Kathiresan,

\footnotetext{
${ }^{31}$ These concerns will be described in more detail in Chapter Eight.
} 
2012, Concern Worldwide, 2011), and has also improved great improvements in food security. This dissertation is not primarily concerned with the national-level aggregate increases in crop production, but rather the ways in which the policy has been implemented at the more local scale (sector- and cellule-scales). Despite using Scott (1998) as a key element of my conceptual framework, my argument is not that the agricultural reform is a 'failed scheme', but rather that the design and implementation of the policy has been misrepresented in policy discourse and in some academic contexts as well. In addition to looking at the details of policy implementation in three cases, I also look at the ways in which the policy seeks to achieve political objectives beyond increased agricultural production.

One of these political objectives is to achieve an agrarian transition from an agricultural to a service-based economy. The Vision 2020 document aims to reduce the numbers of people relying on agriculture, from $90 \%$ of the total population in 2000 , to $50 \%$ in 2020 (MINECOFIN, 2000). This aligns with government plans for mechanization, land use consolidation, and economies of scale which reduce the labour-intensity of production. According to some sources, the proportion primarily engaged in agriculture has already declined to $72.6 \%$ (NISR, 2012g), though others assume a current figure of $80-85 \%{ }^{32}$ This goal, within Rwanda's policy context, suggests a desire to re-engineer the socio-

\footnotetext{
${ }^{32}$ The NISR figures are complicated by the fact that most Rwandans have at least two sources of income; and by difficulties in interpretation of the data. For example, while an increase in paid on-farm employment might represent an increasing commercialisation of agriculture associated with economic growth in this sector, it might also represent an increase in the number of landless or land-poor people depending on poorly-paid casual labour as they have too few assets to produce sufficient food for their subsistence and for financial needs. The percentage of Rwandese households cultivating at least one parcel of land is just over 90\% (NISR, 2012d).
} 
economic structure of the country, in ways reminiscent of the authoritarian high modernism model.

Socio-economic differentiation is an explicit part of this transformation: some smallholders will become 'professional farmers', while others who fail to adapt to the new agro-economic structures will drop out of the agricultural sector altogether. The Environmental Management Agency, for example, argues that, 'Enormous efforts must be made in order to ensure that agriculture changes its nature and that Rwandan professional farmers change their vision, mode of work and mode of life' (Rema, 2009). This paradigm of 'modernisation', which is conceptually intertwined with a commercialization discourse, is broadly similar to the late colonial models of agricultural transformation in countries such as South Africa and Zimbabwe in the 1940s and 1950s (Moore, 2005; Worby, 2000 and 1998). Ideas of 'professional' or 'modern farming' are often bound up with economic, as well as technical, assessments of activities and performance. For example, access to credit is often mentioned as a benefit of 'professionalization', and modern farmers are primarily associated with commercial activities and high incomes (Tindiwensi, 2008; Anonymous, 2011). According to this discourse, the 'guiding rule' of the reform has been an emphasis on 'what makes more profits to the farmer' (Nsanzabaganwa, 2012:166), though, as noted above, profits higher up the commodity chain may be a more significant criterion for the government. The 'modern farmer' category includes multiple components, such as competent management of the financial, bio-physical, and technological aspects of farm life, and crucially, membership in broader market processes and state-sanctioned institutions 
such as cooperatives. It is therefore linked to the main tenets of (neo) liberal modernisation theory as well as the visions and programmes of the Rwandan state. It is also defined by the performance of 'proper forms of decorum and morality' (Rutherford, 2008: 80, citing Ferguson, 1999: 96ff). The moral framing is linked in subtle ways to the close association that the RPF has discursively created between 'the government' and 'the nation': to be against government policies is to be un-Rwandan. For example, citizens are exhorted to invest energy and money in growing crops such as maize and pyrethrum because they are valuable export crops that help to 'build the nation'. In the post-genocide context, it is a short step from being 'against' government programmes to having an 'opposition mentality', which is again a very slippery slope towards an accusation of genocide ideology. ${ }^{33}$

Mechanization, with the explicit goal of reducing human labour requirements, is also being aggressively promoted. Therefore, the main strategy of the government appears to be to increase the rate at which petty commodity producers (who produce both for the market as well as for household consumption) are either a) enabled to access credit, accumulate sufficient land, market resources, farm equipment and techno-institutional knowledge to further integrate into markets and become agrarian (proto-) capitalists; or b) exit the agricultural sector. Those exiting the agricultural sector could do so as part of a conscious strategy, or in contrast be pulled or pushed into spirals of debt and forced

\footnotetext{
${ }^{33}$ For example, in a peri-urban area of Rwanda, local administrators intimidated farmers to sell land to politically-connected individuals at below market rates; when a Rwandan opposed this practice, he was first accused of having an 'opposition mentality'; later he was unofficially accused of having a genocide ideology. Interviews with residents of Masaka Sector, Kabuga District, Kigali Ngali, October 252006 and December 212006.
} 
sales of land, resulting in their proletarianization and exit from farming through circumstance, not through their own volition.

It is far from clear what alternative livelihood options are available to an emerging landless class. According to most sources, relatively few new sources of employment have been created in recent years (USAID, 2011), though the government's own statistics suggest that waged off-farm employment has increased by $7.7 \%$ since 2005 (NISR, 2012d: 5). The question is whether job creation can keep up with the rate of increase in the numbers of the landless and land-poor. The government has focused on an information technology and service-based 'knowledge economy' model which seems likely to benefit a relatively small proportion of the population. Many informal livelihoods in urban areas are banned in order to protect formal businesses and those informal activities in rural areas which were deemed to be environmentally unfriendly have also been outlawed, such as traditional forms of brick-making (Sommers, 2012; Ansoms, 2009). The impending reality of a very large rural 'surplus population', exacerbated by the focus on capital-intensity in the agricultural and other sectors, rather than labour-intensity, has been acknowledged in some government documents (MINITERE, 2004: 35) but realistic plans for addressing this challenge have not been put forward (USAID, 2012). Based on current trends, these individuals would be largely unskilled and would fit the Marxist definition of the proletariat, as they would lack any land assets or other means of production and would be completely dependent on wagelabour. 
In government documents, such processes of proletarianization are discursively framed, implicitly or explicitly, as functions of market behaviour (e.g. economically 'rational' land transactions) within a context of land scarcity (MINITERE, 2004: 16). In reality, it is not only the market, but the state that mediates access to land, and farmers may gain or lose access to land depending on their orientation towards particular state discourses and policies. Those who oppose state policies, either through words or deeds, may be denied access to various goods and services. Access to land, goods and services is mediated through various processes of normalization and calculus conducted by state actors, as will be shown in the following sections and chapters. The land law and related legal and regulatory apparatus provide examples of this, while the crop intensification programme is the most comprehensive agricultural reform mechanism directly impacting farmers through face-to-face contact between farmers and state and nonstate agronomists, local administrators, and other members of the agricultural reform apparatus.

\section{The Crop Intensification Programme}

The Crop Intensification Programme (CIP) is often analysed in technical terms, within the institutional and conceptual boundaries of the 'agricultural sector' (e.g. Kathiresan, 2011; IFDC/CATALIST, 2010). . However, in reality, implementation of the CIP is a complex undertaking involving the entire state machinery. Four distinct elements can be identified. 
The first is land use consolidation, which takes place both in valley-bottoms (marshes) which are owned and managed by the state, and farms managed by smallholders on the 'hills'. Under this model, farmers cultivating fields adjacent to each other choose a single crop, and use a single cultivation regime (incorporating choices of inputs, and schedules for planning, weeding, harvesting, etc.), in order to benefit from the goods and services available under the CIP. Land use consolidation is, in theory, voluntary, but it is often imposed on farmers by agronomists, local administrators, and other powerful actors (ARD, 2008). The area of land to be consolidated is largely imposed by central government, and these targets have been perceived by local administrators in some areas (such as Kirehe district) as 'disconnected from the reality on the ground' i.e. unrealistically high (Nsanzabaganwa, 2011: 48). The exact criteria used to select particular parcels of land for consolidation are not entirely clear - particularly given the lack of enthusiasm for it amongst farmers - but likely combine agro-ecological, logistical, and local socio-political factors.

The second element is the 'delivery' of key agricultural inputs to the farming population, notably government-approved maize seeds and subsidised fertilisers. Fertilizers are subsidized at a rate of $50 \%$ by the government. These fertilizers are intended to be used only for the production of crops approved by the CIP, a policy that is strictly enforced, as will be described in Chapter Eight.

The third key element is agricultural extension. This has 'advisory', 'monitoring' and 'enforcement' functions, that will be elucidated further below. Agronomists, in 
conjunction with local authorities (umudugudu leaders), ensure that fertilizer is only used on government-approved crops and oversee land use consolidation, which incorporates a shift from intercropping of diverse crops to monocropping. In many cases, agricultural extension focuses on government-approved crops to the exclusion of others.

The fourth element is post-harvest storage and sale of crops. This is largely managed through cooperatives, which act as conduits for the collection of the harvest, and are also typically responsible for the transport and sale of the crops. However, local authorities have also been very involved in facilitating contacts with buyers and negotiating prices. In many cases, cooperative leaders were essentially appointed by local authorities (who ensured that their favoured candidates won elections) and smallholders are often obliged to market all their CIP crops through the cooperatives.

Each of these elements is highly dependent upon the others. For example, to supply the correct amount of fertilizer and seeds, it is necessary to know the amount of land devoted to a particular crop that season. As the season progresses, monitoring of the condition of the crop is important to estimate total harvest, which can help in early identification of market opportunities. It is in part this need for constant exchange of information and close coordination of various delivery and monitoring systems which explains the government's insistence upon a model of land use consolidation and monocropping. Using Scott's (1998) framework, it becomes apparent that the customary model of Rwandan farming (intercropping, in different combinations 
depending on local conditions, and cultivation of several small plots, each with a different agro-ecological niche) is very difficult for the state to monitor, analyse, and quantify. These are 'complex farming systems' (MINAGRI, 2004a:10) which are not readily 'legible' to state systems of quantification and calculation.

The land use consolidation model makes surveillance and calculation much easier. In particular, Global Positioning System (GPS) technologies can be easily used, eliminating human error: in Kirehe district, for example, inaccurate estimates of consolidated land led to inadequate amounts of inputs being delivered in 2009; the error was corrected through a GPS survey (IFDC/CATALIST, 2010: 29).

In addition, when farmers are grouped together within cooperatives to farm consolidated land, the logistical task of distribution of inputs becomes simpler. This is perhaps why MINAGRI claims that productivity gains have been achieved through the 'sheer efficiency' of the CIP (MINAGRI, 2013). However, this process of simplifying agricultural systems has frequently proven counter-productive, as the human, climatic and agro-ecological context has in some areas proven to be too complex and variable for the survival of such a simple and unadaptive model.

Scholarly research supports the popular view that intercropping, under certain circumstances, offers greater benefits that monocropping (Blarel et al. 1992, 252; cited in Pottier, 2006; Spio, 1996). Traditional household farming systems have been described as 'inventive and efficient' (Verwimp, 2002 citing Bart, 1993). A single household in the south of Rwanda will typically grow as many as 14 different crops in 50 
different rotations with the view of maintaining fertility of the soil. (Huggins \& Musahara, 2004). Growing a variety of crops simultaneously allows households to space out labor requirements and access to food for household consumption and cash through sales, during the year.Intercropping can represent a highly effective soil and water erosion measure, whereas a shift to row- and monocropping can lead to increased rates of soil erosion when compared to the inter-cropped fields commonly seen today (Chemonics, 2002). Intercropping can reduce the incidence of certain diseases and pests (Davis, 1989). The particular drawbacks and benefits of intercropping are highly location- and crop-specific. For example, beans and maize can successfully be intercropped (Davis, 1989) and intercropping coffee with beans or bananas is widely seen as more beneficial than monocropping coffee (Fairhead1990; Pottier 1999, 37-8; Van Asten et al 2011). Under certain conditions, intercropping can reduce crop vulnerability to the impacts of climate change (IITA, 2012), which is particularly important in drought-prone Kirehe.

The desire for legibility explains, to a great degree, the government's insistence upon monocropping. The authoritarian high modernism model is also relevant in terms of its reference to a fetishization of particular expressions of 'modernity': an aesthetic predilection for neat, straight lines associated with urban planning, rather than the more complex forms of the rural farmland.

However, economic effects of monoculture are also significant at the household-level: by enforcing a switch from crop diversity to specialization and monoculture, the government is also causing households to market more of their produce; after all, a 
household cannot subsist on a single crop. The monoculture model is also an intrinsic part of the government's strategy of agricultural commercialization and accelerated commodification of household production. The state has also provided both 'soft' and 'hard' infrastructure to facilitate the marketing of farm produce, from the construction of large market-places, to the launching of a digital commodity-price monitoring service (see Chapter Four), to the support offered to agricultural cooperatives, which are often the main instruments of commercialization. It is for these reasons that the 'staggering' rate of commercialization of food production over the last 20-30 years is best understood as 'an engineered facet of Rwandan society today' (Pottier, 2012: 11; emphasis added).

\section{Exemplary Hills - Agasozi Ndatwa}

The government has also attempted to encourage the adoption of its preferred crops and agricultural technologies through the system of 'exemplary hills', or agasozi ndatwa in Kinyarwanda. This system, initiated in 2008 by the Ministry of Agriculture and the Ministry of Local Government, involves the selection of one entire village (umudugudu) (Bizoza, 2011: 29) which is instructed to create a 'model farm' of at least 100 ha to serve as a 'example' for the agricultural reform (MINAGRI, 2008: 38). The specifications for every agasozi ndatwa are described in a template developed by the Ministry of Agriculture. ${ }^{34}$ Normally, each sector has one agasozi ndatwa. The choice of location is imposed by the authorities.

\footnotetext{
${ }^{34}$ These include 'soil erosion infrastructure; modern farming techniques, especially the use of inputs; irrigation where necessary; crop rotation; land use consolidation; benefits of farmer cooperatives; fruit
} 
Households within the agasozi ndatwa are expected to follow government policies on issues such as soil and water conservation, agricultural intensification, animal husbandry, water management, the creation of kitchen gardens and land consolidation, which are enforced even more strictly than elsewhere. Incentives are provided for the umudugudu leaders and 'model farmers' who stick closely to government guidelines (Bizoza 2011:29). Along with the incentives, administrators feel under 'pressure' to succeed (Purdeková, 2011) and coercion is also used, at least in some cases. Interviews with farmers living in agasozi ndatwa in Musanze revealed that they were often dissatisfied with elements of the agricultural regime, but were unable to refuse. The exemplary hills, which are framed in government discourse as inspiring reform through the power of 'example', are areas of intense surveillance and disciplinary control, which is euphemistically termed 'community mobilisation' in government discourse (MINAGRI, 2008: 3). They are frequent sites of visits by donors, raising the possibility that they are linked to an aesthetic of modernity designed to appeal to foreign donors and investors as well as Rwandans (examples of field trips are cited in Ngabonziza, 2011, Siri, 2010). When viewed superficially, without attention to coercive mechanisms of 'mobilisation' that may be involved, the sites are neat, orderly centres of intensified agricultural production. Likewise, across much of the country, the CIP in general has resulted in improved yields for government-approved crops, as discussed below.

\section{The Aggregate Material Outcomes of the CIP}


The massive input of fertiliser, germplasm and other inputs into the Rwandan agricultural system through the CIP and related programmes have resulted in increased yields for many crop types. For example, total cereal production increased from approximately $320,000 \mathrm{MT}$ in $2004 / 5$ to more than $600,000 \mathrm{MT}$ in $2009 / 10$ (GIEWS/FAO, 2010). According to government data, cassava production has almost tripled and total Irish potato, soybean and beans yields have approximately doubled (MINAGRI, 2012b) ${ }^{35}$. Per hectare yields for other commodities have increased in the aggregate as well. The total land area cultivated has increased by $13 \%$ in recent years (MINAGRI, 2012b). These gains have translated into a national level reduction in the incidences of malnutrition (Kalibata, 2010) and an improvement in food security more generally. These are important gains, and many actors have celebrated them. However, less attention has been paid to the differentiated impacts of the agricultural policy at the micro-level; and the ways in which the profits from increased production have been redistributed.

\section{The Land Law Reform}

The land Law reform, which in many ways underpins government designs for agricultural transformation, was largely based on the ideas that 'land tenure security' could encourage individuals and corporations to increase investment in land, and provide them with the ability to access bank loans, stimulating economic development. The aim of the reform was to convert customary rights to land into formal rights, through a process of 'land tenure regularisation' (involving land surveys, dispute

\footnotetext{
${ }^{35}$ However, government figures may be inflated (van der Laan, 2011:4).
} 
resolution, and provision of documentation for rights to land). Customary systems of land ownership are based on individual ownership (usually by a man) and are characterized by lively rental and sale markets, which may be informal or formal (in which case the sale is recognized in writing by a local administrator and a sales tax is paid to the local authorities). The land tenure regularization programme (LTPR) allowed for women to register claims to land, and for family members to be registered as having 'an interest' in particular parcels of land (which gives them a legal right to veto transactions of the land). It also, as will be described further below, used a terminology of 'land ownership' by citizens, but resulted in the provision of leasehold documents, rather than title deeds, as the state is the ultimate owner of land in Rwanda (MINITERE, 2005). Nevertheless, these leases were intended to be fully transferable through commercial transactions as well as through inheritance.

The economic arguments for land registration recognize that it would stimulate land transactions. Through land markets, according to liberal property rights theory, which characterizes land owners as rational economic actors, land tends to come into the ownership of those who have sufficient capital and skills to generate maximal economic profit from it. The land reform has been generally seen as successful, resulting in an increase in investment in, and maintenance of, soil conservation measures (Ali et al, 2011and more frequent registration of women's land rights (Ali et al, 2011, Daley et al, 2010). The2005 law has been cited internationally as an indicator of Rwanda's economic potential and has been particularly influential in terms of Rwanda's perceived readiness for foreign direct investment (US Department of State, 2013; LandAC, n.d) It 
has implicitly been interpreted within an understanding of 'land tenure security' common to Western countries, particularly those following the Roman Law tradition. This understanding of rights to land can be termed the 'absolute right to property': the rights to use, benefit from, and dispose of the land (e.g. by sale or inheritance) as they see fit. ${ }^{36}$ The broad discursive alignment of the land reform with liberal 'best practices' (e.g. De Soto, 2000), as well as the active advocacy for this approach by government officials within international fora on land tenure (e.g. Sagashya and English, 2010; Rurangwa, 2002), suggest that the reform and the data associated with it should be understood within the perspective of Rwanda's engagement with global indicators of governance. Public 'awareness-raising' around the law was couched entirely in terms of liberal, de Soto-inspired language. Government personnel routinely talked about land ownership and title deeds, rather than lease documents, in public meetings. Indeed, the 2005 land law (MINITERE, 2005) mentions 'landowners' rather than leaseholders (see e.g. Articles 42, 43, 54).

Detailed attention to the evolution of the land law, and particularly the draft version of the land law which was promulgated in June 2013, suggests that the government of Rwanda debated the extent to which the land law should be used as a disciplinary tool, linked explicitly to the agricultural policy. This will be discussed below. While the land law and a programme of land registration have quite effectively delineated land parcels

\footnotetext{
${ }^{36}$ Property rights systems which broadly allow an 'absolute right to property' (for example through freehold title) do allow for some regulation and limitation of those rights by the state in the public interest. However, these limitations generally only become relevant in situations where particular landuses are deemed to represent a risk to the surrounding community, or where the state claims rights to sub-soil resources such as high-value minerals.
} 
and clarified the rights of individuals to land, the particular form that these rights take differs radically from that of absolute ownership, the liberal ideal. Under the 2005 land law, land is owned by the state and is accessed by land users through leases, which are in the first instance acquired by 'regularization' of customary ownership. ${ }^{37}$ In rural areas leases have a duration of 99 years, while in urban areas they are shorter. Leases are transferable and inheritable. Parcels larger than two hectares in rural areas must be paid for through an annual leasing fee. Such a long-term leasing system is generally understood by land tenure specialists to represent a secure form of tenure that encourages investment. As leases are transferable, they will likely be transacted in much the same way as a freehold title would be transacted.

However, the idea of leasing land from the state has not been well-received by many smallholder farmers, who under customary systems, considered themselves to be absolute owners of the land..$^{38}$ Indeed, there was widespread confusion amongst the population over the nature of land access permitted under the land law. As acknowledged by land registration officials, many citizens have asked local officials for clarification over whether they are really renting the land from the state. ${ }^{39}$ The

\footnotetext{
${ }^{37}$ Once a claim to land has been registered and a lease has been provided by the state, a third party may purchase the lease, or rent the land from the land-user, under conditions of sub-letting.

${ }^{38}$ Customary systems under which land was owned by the monarchy (the igikingi system) or powerful local lineage-heads (the ubukonde system), with land users only enjoying access rights, are generally considered to have been extinguished, and were abolished by previous post-colonial land laws. Under ubukonde, for example, land was accessed by 'clients' of landowners in exchange for goods such as banana beer. The landowner enjoyed substantial powers to withdraw access to land from the clients (Musahara and Huggins, 2005: 278 and 293). Such systems were replaced with a ubiquitous customary system emphasizing individual ownership and allowing outright sale of land. Land was customarily acquired through inheritance or purchase, and more rarely as a gift.

${ }^{39}$ Interview with parasurveyor involved in national land registration process, Ruhengeri town, $30^{\text {th }}$ April 2011.
} 
leasehold system is particularly amenable to the use of disciplinary measures, as will be described below.

The government of Rwanda has planned since 1996 to use the land law to provide a framework for agricultural commercialization. In the early 2000s, it was clear that officials in the Ministry of lands had designed the 2005 land law in order to create a set of legal constraints, responsibilities and rights to facilitate land consolidation, deemed key for agricultural commercialisation. Principle amongst these was the ban on fragmentation of land under one hectare (Art. 20) as well as a clause permitting the Minister of agriculture to 'approve' consolidation of plots of land. The Land Policy talks of 'a new method of plot distribution by consolidation of parcelled and scattered land, by establishing normal and adjoining plots of land' (MINITERE, 2004: 42). Interviewed in the mid-2000s, government officials defined land consolidation as consolidation of plots through transfers of legal ownership and the avoidance of land fragmentation through inheritance (Musahara and Huggins, 2005). The issue of inheritance of land was to be addressed through one of the successors essentially 'buying out' his/her siblings and taking on ownership of the entire family plot his/herself (MINITERE, 2004: 29). ${ }^{40}$ The issue of land consolidation was therefore to be tackled largely through the gradual accumulation of land amongst a decreasing number of individual owners (land concentration).

\footnotetext{
${ }^{40}$ The land policy states that, 'the regulation of buying back land among inheritors will be established so as to render the consolidation of plots effective' (MINITERE, 2004: 29).
} 
The 2005 land law represents therefore, an attempt to achieve some of the state aims through market processes. By regulating land markets in this way, the 2005 land law attempts to operate through legal means at the level of the population, in the Foucauldian sense of the term (Foucault, 2007). Those affected by the provisions have to govern themselves regarding land ownership and use. Such a strategy, though based on state-imposed prohibitions, is therefore broadly in line with a liberal governmentality approach, particularly when embedded within discourses of land as collateral for credit and other benefits of land 'ownership'.

However, the 2005 land law allowed for the Minister for agriculture to 'approve' the consolidation of small plots of land, opening the door to compulsory consolidation. It also included some ambiguous clauses allowing the Minister for Land to 'requisition' land that has not been 'productively' and 'sustainably' used (Art. 62). Such requisitioned land would be used as the state (represented by local authorities) deems fit, at first for a period of several years, then permanently if the land user 're-offends'. These instruments represent disciplinary technologies, in that they operate at the level of the individual parcel and the individual landowner, and they involve the direct involvement and discretion of the Minister for Land and local authorities. They are essentially administrative, interventionist strategies rather than legal regulatory strategies such as those discussed above. Administrators have frequently threatened land-users with confiscation if they do not follow the agricultural policy, based on these clauses of the 2005 land law (Pritchard, 2013; Huggins, 2009a). 
In 2012, a new draft Land bill was debated by the cabinet, which would have facilitated temporary or permanent confiscation of land by the state, and made more explicit the responsibilities of land-users to follow government land use regulations. For example, the draft introduced a new concept of 'assignment', defined as 'a temporary transfer by the State of the right to use land to a third party when the lessee or owner has failed to fulfil land use directives and obligations' (Art. 2, clause 18). The draft law also provided that where there is no suitable third party available, the local authorities (at District level) can use the land for agricultural or other commercial purposes (art. 46). Where the 2005 land law required that the state provides 6 months notice of intention to confiscate land, the new draft required only 15 days notice. ${ }^{41} \mathrm{~A}$ rather open clause provided that the state may impose extra obligations on land users, over and above those specified in the land law: 'contracts granting rights with the State on land shall specify special conditions to be fulfilled for the conservation and exploitation of the land in accordance with the intended use of the land.'(Art 34). The new draft was also more explicit about the need for land users to conform to 'the land use directives of the area' (art. 50).

It appears, when interpreted with reference to the practices of local authorities in some parts of Rwanda, that the draft land bill would have institutionalized, expedited, and provided a legal basis for the use of disciplinary technologies. These could have been

\footnotetext{
${ }^{41}$ There was debate over the draft Bill in Parliament, with civil society organizations making written presentations regarding the draft. According to pro-government media reports, key issues of concern for civil society included compensation for individuals whose land has been appropriated for state-driven villagization, and ceilings for foreign control over land. Concerns about the restrictions on land use rights were not mentioned (Karuhanga 2013a and 2013b), which perhaps indicates the sensitive nature of such debates.
} 
used to enforce the fulfilment of conditions on land use leveled by government through land use masterplans, unspecified 'contracts', and other means.

The draft land bill, when interpreted within the broader Rwandan legal and sociopolitical context, would have facilitated the 'administrative ordering of nature and society' as per Scott's model (1998: 4), though it claimed to be based upon market principles. However, the 2013 land law does not include some of the most problematic aspects of the draft bill. There are no longer any clear linkages to 'land use directives', and the only justification for requisition of land by the state is a failure to use the land for 3 consecutive years (Article 52) ${ }^{42}$. Indeed, the law makes clear that land may be considered to be properly used as long as at least half of its area is under cultivation or is used for pasture, and it is protected from soil erosion (Art. 41). It seems clear then, that provisions for requisition of land in the 2013 land law are intended to prevent land speculation, or are meant more broadly to ensure that productive land is being used. Parliamentarians seem to have moved away from the earlier version of the text which would have enabled the law to be used as an instrument to enforce adherence to agricultural policies. The 2013 land law, following debate and revision, is now more broadly supportive of a governmental mode than a disciplinary approach based on the power of the state to confiscate land.

In the years 2006-8, during which time the national land registration programme was being designed and piloted, there seems to have been a shift towards the use of

\footnotetext{
42 The definition of land assignment (Art. 2) mentions failure to follow land use directives as a reason for land being assigned to others; but this is not supported by any mechanisms within the body of the law.
} 
agricultural policy, rather the land law, to drive change in the agricultural sector. This is signalled not only by events at the farm level in some areas, but also by a request to foreign donors by the Minister of Agriculture for options for a draft regulation on land consolidation (ARD, 2008). Donor-funded consultants, concerned about the possibility of compulsory consolidation, prepared a briefing note emphasising a voluntary, incentivebased approach. At a workshop in 2007, the Minister of Agriculture stated that the government would not make consolidation obligatory (ARD, 2008). However, despite these assurances, land use consolidation has effectively become obligatory, at least in areas in which the CIP is being promoted. The government Decree on land consolidation pays lip-service to consultation with farmers, but a clause stating that the government will 'determine possibilities [sic] of farmers and private investors to voluntary [sic] support in the programme [sic]' (MINAGRI, 2010c) strongly suggests that while the state would prefer to gain the consent, it will go ahead and force consolidation if necessary. Compulsory consolidation of crop use is now the norm across much of the country (ARD, 2008), and represents a move away from a governmental approach towards disciplinary mechanisms harnessed to homogenous, standardised production models in the agricultural policy apparatus.

\section{The Emergence of New Spaces of Governance in Rwanda}

Recent scholarship on Rwanda has hinted at the links between agricultural reform and a new form of regionalism. With reference specifically to the implementation of the land 
registration process and agricultural reform in Rwanda, Pritchard (2013) has argued that these processes are causing the emergence of different 'polities':

The aggressive implementation of registration and consolidation has divided rural communities into a series of distinct polities according to what stage specific recipients are at in the overall transformation process. On the one hand, where rural reforms have not yet been implemented, farmers eagerly await state intervention in land use and management systems. On the other hand, in areas that have experienced state led registration and crop consolidation, decreasing food and tenure security have increased fears of large-scale confiscations, as well as frustration with both the goals and methods of land and agricultural reforms (Pritchard, 2013)

This 'frustration' has also been documented by pro-government media, which has reported that the population is 'not happy' with the agricultural policy (Ntambara, 2007) and described how 'angry residents...criticised the local authorities especially the cell leaders for enforcing the new move against the will of the locals' (Mukombozi, 2009a). For Pritchard, the local socio-political environment is changing according to farmers' perceptions of the potential and actual impacts of the land and agricultural reforms, both positive and negative. This is an important idea, and is justifiable due to the central roles that access to land and modalities of rural livelihoods play within the Rwandan socio-political sphere. 
We will broaden the understanding of how such 'polities' emerge through an analysis of the legal and policy architecture (such as the agricultural policy) administrative tools and regulations, such as the performance contract (imihigo), that demand that citizens perform particular kinds of location-specific activities (see especially Chapter Four); and an exploration of the moral and political framing of state-led 'development', and specifically the 'good citizen' and 'modern farmer' tropes (see Chapter Five).

These will show that, by claiming ultimate ownership of all land in the country, and assigning the population the role of 'land user' through a leasehold system, the state has discursively separated 'people' from 'land'. The emphasis on land use consolidation and land concentration in government land policy, with its emphasis on accelerated market transactions in land, further seeks to dissuade individuals from identifying with specific 'ancestral' parcels of land.

This policy should be understood within the context of land scarcity in Rwanda mentioned above, which results in intense competition for land amongst farmers (Musahara and Huggins, 2005; MINITERE, 2004). Pauline Peters notes that competition and conflicts over land in Africa have since the 1990s tended to take the form of a: 'process of narrowing in the definition of belonging ... [as] group boundaries are more exclusively defined' (2004: 302, cited in Rutherford, 2008: 78).

The government's ban on 'divisionism' has further restricted any potential attempts to 'narrow the definition of belonging' to particular parcels of land through the deployment of discourses around identity. 
The government has prioritized certain land uses and certain kinds of agricultural crops and practices over others, and has linking these to the continued 'right' to use land (e.g. by claiming powers to requisition land that is not used 'properly'). It is therefore directly engaged in struggles to control access to land and use of land. By restricting recourse to ethnic identity-tropes, and by systematically undermining the legitimacy of customary forms of farming, the state has attempted to ensure that in order to stake claims to land, individuals and groups must follow government discourse and policies around land use in order to 'define group boundaries' (to use Peters' language once again). In the Rwandan context, one can expect such groups to be cooperatives and other corporate entities, rather than ethnic groups. The state attempts to ensure that citizens must attempt to perform the role of the 'modern farmer', as a particular subset of the 'good citizen' or the 'ideal development subject' (Purdekova, 2012a: 192), in order to seek access to land as well as goods and services. In fact, by establishing a legal and administrative regime which punishes those unwilling or unable to follow state policies, the government effectively forces local people to adopt the 'modern farmer' identity in order to continue to access land, agricultural inputs, credit, and basic administrative services.

The criteria a smallholder must meet in order to be seen as a 'modern farmer' may differ depending on where he or she lives. The repertoire of policy implementation measures used by administrators is contingent upon historic-political factors specific to the local area, as well as the spatial and agro-ecological characteristics of each zone. The principle of spaces of governance is evident from the different ways in which the 
umuganda communal work institution is implemented in different areas. On umuganda days, the entire adult population is required to provide unpaid labour on public works projects, such as maintenance of secondary roads. Importantly, these are often held weekly or biweekly in rural areas (or even more frequently if major imihigo deadlines are looming), whereas they are only held once per month (with participation less rigorously monitored) in cities such as Kigali (Kartas and Jütersonke, 2012:23). The responsibilities of citizenship are therefore different in rural areas and urban zones. The result of differential governance systems in rural areas, as will be shown in Chapters SixEight, are significant variations in the impacts of the agricultural reform, and the emergence of particular spaces of governance in Rwanda which represent specific forms of 'homogenization' within a broader national situation of diversity. These specific spaces of governance are often associated with the interventions of commercial actors, within the framework of state policies and implicit or explicit institutional support and facilitation. It is therefore important to consider the importance of commercial actors in the contemporary agricultural sector in Rwanda.

\section{Domestic and Foreign Corporate Investment in the Agricultural Sector}

Domestic investment in agriculture has not yet met the Rwandan government's expectations, despite myriad investor-friendly policy reforms including the establishment in 2005 of an Agriculture Guarantee Fund to encourage bank lending to the sector (Booth and Golooba, 2012:10) and a cold-storage facility at the international airport to facilitate horticultural exports (Booth and Golooba-Mutebi, 2012:11). 
There are however signs that domestic and foreign investment is increasing. According to the Rwanda Development Board (RDB), agriculture was for the first time in 2011 the most significant sector in terms of planned investment (domestic and foreign). Some US\$116.3m of investment in agriculture was registered at the RDB in 2011, of a total of US\$ 598 million for all sectors of the economy combined. Of this US\$598, approximately US\$371 million was foreign direct investment (Oluoch-Ojiwah, 2012). ${ }^{43}$

Much investment has been directed towards commercial development of marshland areas, which are owned by the state (Ansoms, 2012). Outside the marshes, the government seems to be more cautious about very large-scale land acquisition. One large-scale lease was approved in 2009 for jatropha production (Kagire 2009b; Huggins 2011) but appears to contradict the energy policy. ${ }^{44}$

This case is unusual. More typically, the state is in the process of 'actively negotiating public-private joint ventures in which the state subsidises the initial learning costs and demonstration effects' (Booth and Golooba-Mutebi, 2012:12), for example by providing land for demonstration farms. The government seems to be encouraging only relatively small-scale commercial land acquisition at present: it is currently offering a 200ha plot in Eastern Province for the development of a high-tech flower farm ${ }^{45}$ and has 'given'

\footnotetext{
${ }^{43}$ However, actual investments may turn out to be less than this: for 2005-10, only one-third of what foreign investors pledged with Rwandan Development Board (BRD) was actually invested (Gökgür, 2011). ${ }^{44}$ The policy states that because biofuel production tends to require subsidies, and due to general land scarcity, 'careful research [is] to be conducted into the potential of largescale biofuel production' before large-scale production commences (Ministry of Infrastructure, 2009).

${ }^{45}$ Advertised on the website of the Rwanda Development Board; accessed $18^{\text {th }}$ July 2012 at http://www.rdb.rw/rdb/agriculture.html
} 
600 ha of land to a maize and soya farm ${ }^{46}$ At the moment, the standard model in Rwanda is for investors - whether domestic or foreign - to enter into production contracts with local cooperatives, while accessing medium-sized plots for demonstration farms for corporate production. ${ }^{47}$

Increased use of contract farming models is signalled by the 2010 Land Consolidation Decree, which in its definitions of 'facilitated contract farming', is clear about the intention of the government to intervene in negotiations. Within the particular political context of Rwanda, we can interpret this intervention to represent, in most cases, 'state-imposed contract farming'. The Decree states that while, 'the terms of the farming contract shall be negotiated between farmers and the buyer', the Ministry of Agriculture, 'may facilitate in the negotiations to ensure that both parties come to an agreement' (Republic of Rwanda, 2010). The Decree also lays out, in some detail, the various daily activities conducted by farming cooperatives or contract farmers in which the government will intervene, which include:

- understanding and participating in market-based agriculture;

- crop selection;

- determination of prices;

- provision of inputs;

- loans;

\footnotetext{
${ }^{46}$ This is managed by Bralirwa, the private brewing firm, and maize processing firm Minimex: Bramin.
}

${ }^{47}$ Plots are 'medium sized' relative to the average Rwandan land parcel. 
- agricultural sensitization services; and

- facilitation of the sale of the crops to buyers. (Republic of Rwanda, 2010)

The case studies that follow (Chapters Six-Eight) provide insight into the ways in which government 'facilitation' of contract farming, while based on standardised, nationwide models of agricultural intensification (such as those under the CIP) may have different impacts depending on the combination of disciplinary, governmental and other technologies used.

Institutional changes have been made to facilitate public-private partnerships, which are a key part of global neoliberal doctrine. The Institute of Scientific and Technological Research (IRST), a parastatal research institution, is in the midst of restructuring, becoming the National Industrial Research and Development Agency (NIRDA) in order to shed its social-science aspects and link its technical research more directly with processes of commercialisation. NIRDA has formed a joint public-private company called Rwanda Biodiesel Company Ltd (Karinganire, 2012b). Already, the IRST has entered into agreements with 122 cooperatives (with more than 12,000 members in total) for the production of oil for biodiesel. By May 2012 these cooperatives had planted almost a million oil-producing trees, according to IRST (Karinganire, 2012a). ${ }^{48}$ ISRT has also entered into an agreement with Horizon Inc (Anonymous, 2012b), a company owned by the ruling RPF party (Gokgur, 2012). The restructuring of a state institution to focus on

\footnotetext{
${ }^{48}$ It is unclear from media sources whether these are all jatropha trees. Oil for biodiesel can also be harvested from soybean and moringa, amongst other crops.
} 
public-private partnership (PPP) projects is an example of the increasingly intertwined nature of state, donor, and private activities. Rather than a 'liberalization' process, such coalescence can represent the configuration of private and donor activities with state mechanisms of coercion. For example, IRST was reported to have 'mobilised' families to grow jatropha in Ngororero district, where it has a research station. The Mayor of the District reportedly ordered that, 'every family should grow at least 100 trees on his plots, mixed with other crops' (Karangwa, 2010). This declaration accords with the disciplinary, quantitative, target-oriented approach that the performance contracts (imihigo) represent, as will be described in Chapter Five. Given the emphasis in government policy on the role of cooperatives, understood in the liberal literature as voluntary organizations, it is important to examine how processes of discipline and coercion can be imposed upon such 'voluntary' institutions where members are, in theory, able to simply withdraw their labour at will.

\section{Civil Society Roles: 'Mobilisation' and Cooptation}

Non-governmental organizations play an important role in the implementation of the agricultural policy. NGOs and community-based organizations (CBOs) also played a significant role in rural development in the pre-genocide era. From the late 1970 s onwards, the number of NGOs, cooperatives, and CBOs increased rapidly (Musahara, 2012; Uvin 1998). By 1992 there were 8,752 associations and cooperatives nationwide (Sentama, 2009: 83), most of them working in the agricultural sector (Adamczyck, 2012: 
67). ${ }^{49}$ Some authors claim that by the mid-1980s, 'almost every Rwandan household especially in rural areas belonged to a cooperative' (Musahara, 2012: 10). This was in large part due to the support of the state for the sector: for example, a government office in charge of cooperatives and community development was established in 1975. The state considered cooperatives to be useful mechanisms for implementation of policy (Adamczyck, 2012: 64), and insisted that citizens join them. The cooperative sector was closely linked to the ruling party. Cooperatives and other civil society organizations failed to effectively oppose the genocide (Musahara, 2012; Uvin, 1998) and such structures may have actually facilitated the mobilisation of violence, because they were 'were part of the fabric of the government system that led the population into genocide' (Musahara, 2012: 10).

There are currently almost 5,000 cooperatives in Rwanda, comprising nearly 2.5 million members (Nkuranga and Wilcox, 2013), or more than the quarter of the population. Now, as before, the government's preferred model for civil society is a 'corporatist' one (Longman, 2011: 31) in which non-state actors act as compliant 'partners' for the government, engaged in implementing policies and programmes rather than monitoring or criticising them. In particular, the government insists that cooperatives, for example, contribute to the goals of Vision 2020 (MINALOC, 2000), and conceives of them as a tool for social integration and reconciliation (Sentama, 2009: 88 citing MINALOC and MINECOFIN, 2002:2).

\footnotetext{
${ }^{49}$ Associations, which did not have legal personality, were the dominant model of rural citizen (self-) organization until the mid-2000's, when the government of Rwanda started to insist that associations register as cooperatives, thereby acquiring legal personality.
} 
This is also the case for non-governmental organizations. The state explicitly refuses to accept a civil society which criticises state policies (Gready, 2011). Local civil society organizations have been thoroughly infiltrated by individuals who act as RPF informers (Reyntjens, 2010) whilst others have been the target of intimidation or legal action, particularly under 'genocide ideology' legislation which is sufficiently vague to allow for convictions for a wide range of words or deeds, including political statements or criticisms of the government which do not comprise incitation or justifications for genocide (Waldorf, 2011). International NGOs are widely believed to be staffed with significant numbers of RPF informers, and face increasing restrictions through the legal frameworks for registration of foreign NGOs. They practice extensive self-censorship. Donors have in recent years opted to support 'umbrella' organizations and networks (rather than directly supporting smaller organizations). While some of these, such as LandNet Rwanda, have had some success at the level of policy advocacy, observers contend that such structures have been coopted by the government, with the effect that donor support for such networks seems to 'reinforce the authoritarian structures of Rwandan civil society rather than foster pluralism and participative structures' (Adamczyck, 2012: 71). Organizations working with Rwandan non-governmental organizations confirmed that major farmers" organizations had not been consulted during the elaboration of the agricultural policy, and in particular the CIP, but were simply informed of the policy after it had been finalized. ${ }^{50}$

\footnotetext{
${ }^{50}$ Interview with director of an international non-governmental organization, Kigali, February 28, 2008
} 
Restrictions on civil society extend beyond human rights or political spheres and into the realm of rural development. Prior to the agricultural reform, an NGO called the Forum of Rural Organisations (FOR) was accused of genocide ideology by a Rwandan

Parliamentary Commission, partly because it had introduced granaries and micro-credit offices in rural areas (Frontline, 2005). These efforts, according to the Commission, were intended 'to show the population that the state has done nothing for them and that FOR shows people how to form associations to resolve their problems. It is planned that these associations will have a structure organised like that of the state...' (Commission Parlementaire ad hoc, 2004, cited in Frontline, 2005). FOR was eventually forced to close down. Other agricultural organizations, SDA-IRIBA and IMBARAGA, were also accused of 'genocide ideology' in the Parliamentary Report, which considered 'dissent from government plans for consolidating land holdings' to constitute genocide ideology (HRW, 2004). ${ }^{51}$ It is therefore understandable that, in the words of an international NGO, 'Non-governmental organisations align programmes directly with GoR [Government of Rwanda] priorities in agriculture' (Concern Worldwide, 2011). The most important civil society in the land tenure sector, LandNet Rwanda, has also experienced government restrictions including temporary 'bans' on public activities, despite being generally supportive of government policies (Gready, 2011; Musahara and Huggins, 2005).

\footnotetext{
${ }^{51}$ The parliamentary commission was established following the late 2003 killing of several survivors of the 1994 genocide, to enquire into the existence of 'genocide ideology' in the population (HRW, 2004). The activities of the commission were viewed by many observers as part of a broader government strategy of discrediting, intimidating or punishing potential sources of political opposition or resistance to state policy (Waldorf, 2011).
} 
Civil society actors involved in the agricultural sector have enjoyed increased profile and larger operating budgets as a result of their engagement with the agricultural policy. Their goals and activities are closely aligned with government programmes, and funding increasingly comes from the government. In the case of the Imbaraga farmers' organization, two-thirds of the budgets of its Provincial offices come from the government and international donors (Wongtschowski et al, 2013); with the majority of major donors now channelling their funding to the government through direct budgetary support (Hayman, 2007), the largesse of the state is particularly important. In addition, the business model of Imbaraga (for example) includes the sale of services (such as agricultural training), sale of inputs (such as seeds and fertilizers) and the purchase of crops from farmers. Alignment of their activities with the agricultural intensification model imposed by the government, highly structured and based on coercion, can provide such organizations with a captive market for such activities, as farmers may not be able to refuse (as described in Chapters Six-Eight). International donors, too, work not only in 'collaboration' (IFDC, 2011) with the government of Rwanda, but actually as a part of its policy-design apparatus, taking the lead in drafting policies on fertilizer procurement and sale, for example (Wongtschowski et al, 2013) ${ }^{52}$. Some Rwandan civil society actors have adopted the government's conceptual framework for the 'ordering of nature and society' (Scott, 1998:4), within a context in which they can be sanctioned from deviating from this framework, or rewarded

\footnotetext{
52 The 'stimulation of effective demand for fertilizer among producers' which is an aim of this policy (Wongtschowski et al, 2013) has been translated, as will be described throughout chapters six-eight, into a practice of forcing farmers to buy fertilizer and punishing those who then use it for non-government approved crops.
} 
(through influence, funding, and socio-political status) for adhering to it. While farmers' organizations tend not to use the condescending language that government administrators sometimes use to describe farmers (Ansoms, 2009), they nevertheless relegate farmers to a position of powerlessness and perceived 'ignorance' through the model of top-down knowledge 'transmission' that they subscribe to. While employees of non-governmental organizations might privately critique aspects of the agricultural reform, they should be understood to be part of the apparatus (dispositif) of statedirected policy reform.

This discussion of the nature of the state-dominated agricultural reform apparatus in Rwanda, which shows that 'civil society' should not be understood as an institutional category that is completely autonomous or free from state cooptation, and highlights the extent of coercion in the agricultural sector, suggests some of the difficulties in collecting and interpreting secondary and primary data. In the section that follows, I describe my methodological approaches, emphasizing how they allowed me to conduct fieldwork within a constrained environment, and interpret various discourses with sensitivity to complex contextual factors.

\section{Methodological Approaches}

This recognition that international organizations and Rwandan 'civil society' actors are conceptually and operationally part of the government-directed dispositif of agricultural reform reminds us that, in order to avoid a focus on an overly-abstracted 'monolithic 
state', the research must examine the ways in which the government of Rwanda functions within multiple institutional, financial, and informational circuits at different scales. The adoption of a global governmentality approach, as will be described in Chapter Four, allows me to examine how the Rwandan state does not make its policy choices on a completely autonomous basis, but rather within a particular aid-dependent context in which aid recipient states must clearly locate themselves as part of a particular 'good governance' discursive, with political and economic implications. Part of my methodology is to examine the different forms of 'auditing' and self-scrutiny that aid-recipient states must subject themselves to, while recognizing that the selfidentification of states like Rwanda as 'effective' managers of aid allows them to exercise some control over the situation.

The model of the agricultural sector dispositif also has implications for potential sources of 'independent' information regarding the reform. In Chapter Two, I drew attention to the process of 'rendering technical' (Li, 2007A) issues that are inherently political, and pointed out that agricultural policy implementation is often analysed within the relatively narrow institutional and conceptual boundaries of the 'agricultural sector' (e.g. Kathiresan, 2011; IFDC/CATALIST, 2010). This combination of vested interest (that comes from involvement in, or extreme proximity to, government decision-making processes) and 'rendering technical' means that many of the available secondary sources on implementation of the agricultural reform in Rwanda cannot be considered to be independent of government influence, or 'critical' in a theoretical sense. This is an important consideration, because many of those authors (such as Michel Foucault, 
Arturo Escobar, Timothy Mitchell, David Harvey and Rita Abrahamsen) who have influenced the conceptual framework of this dissertation are associated primarily with discourse analysis, and hence a focus on written texts (particularly policies, laws, and other 'official' accounts) rather than field interviews. While this approach has resulted in seminal theoretical contributions, 'by relying mainly on textual sources [such academics] often present an image of development discourse that unwittingly echoes the claims to efficiency made by development agencies', as well as other self-interested actors (Anders, 2010). Such blueprints and well-intentioned documents are not only a highly redacted version of events, but are also, when used as a protocol for implementation of policy in the 'field', open to reinterpretation by local authorities and other key actors (Pottier, 2002). However, many reports on agricultural reform in Rwanda are based primarily on secondary documents or interviews with high- or mid-level 'key informants' (within the government bureaucracy or the development aid system) and do not take account of the narratives of local administrators (who, at sector and cell level, are primarily responsible for 'implementation' of policy) or the farmers who are most directly involved in the reform (e.g. Booth and Golooba-Mutebi, 2012; IFDC, 2010). It is therefore necessary to understand how the programmes and implementation strategies described in the official narratives regarding agricultural reform in Rwanda influence, and are influenced by, smallholder farmers. This can be done through critical attention to the accounts of such farmers.

Given the sheer scale and institutional complexity of the agricultural reform, it was necessary to find a way to focus the research, geographically and conceptually. 
Cooperatives are key to the government model of reform, and are often the 'targets' of improvement (Escobar, 1995) by the state, International NGOs, and other non-state actors. All of the cooperatives had substantial engagement with commercial actors, each of a different nature. This permitted me to consider the dynamics of 'commercialisation'. Focusing on individual cooperatives was a way to look at the nexus of interaction between state and no-state actors, and to focus the research geographically. As well, literature suggests that membership in cooperatives is based on a combination of factors, sometimes including some degree of state coercion as well as more 'voluntary' impulses. From a Foucauldian point of view, the idea of consent is complex. Jean-Francois Bayart concludes that a governmentality approach, in particular, allows for an exploration of the 'subtle tension between servitude and consent' (2007: 287; cited in Death, 2011: 30). This is a way to revisit Scott's concern with coercion, while providing conceptual space for a more nuanced view of power relations.

Rather than assuming that cooperatives followed international definitions (CCA, 2007; ICA, 1995) or seeing them as inherently 'empowering', I approached them from a broadly Foucauldian perspective, conceiving of them as phenomena emerging from particular, geographically, socio-economically, cultural and politically distinct circumstances. As such, they would reflect the complex relations of power/knowledge characterising Rwandan society, and in particular, state-citizen interactions. There are well-documented differences between 'public transcripts' in Rwanda - public utterances by members of the Rwandan 'public', state officials, NGO personnel, and other 
Rwandans, which often tend to echo official RPF rhetoric - and 'private transcripts' aired only with confidantes (Thomson,2011; Begley, 2012; Zorbas, 2009; Burnet, 2008b). Academic literature has critically deconstructed the public transcripts, which are typically seen as representing an imposed, and hence artificial, 'consensus' which is 'performed' in public. Rwandans are particularly likely to echo government discourse when they believe they are under scrutiny by government or pro-government actors. Hence, interviews were almost always conducted in private, with one respondent per interview. Under these circumstances, the discourse of most respondents diverged significantly from official versions regarding the implementation and impacts of the agricultural policy. However, I do not treat these private transcripts as necessarily 'authentic': 'private transcripts' gleaned from informants are as much the product of complex socio-political and psycho-social processes as public transcripts, and should also be treated as 'constructs'. More so, perhaps, than in other places, people in Rwanda communicate 'strategically' (de Vulpian, 2004: 82; cited in Rettig, 2011: 199). Informal discourses, like more formal or scientific ones, are the product of mutually constitutive claims to power and claims to knowledge, and Rwandan citizens are careful in the ways in which they make such claims.

There were signs of differences between the perspectives of male and female informants on women's associations (with some men arguing that they have divisive effects at the household level) suggesting that gender is a differentiating factor in the production of informal discourses; however, men and women tended to provide broadly similar analysis of the state's agricultural policies. Efforts were made to talk to equal 
numbers of men and women, though the final gender balance in the data was not equal. This is in part because the research aimed to gain the perspectives of cooperative members (particularly in Musanze District), and because many cooperatives (particularly pyrethrum cooperatives in Musanze District) are dominated by men. In addition, many of the key informants at the local level occupying positions of power (such as cooperative leaders, imidugudu leaders, and SOPYRWA delegates) were male. Of the total 328 interviews, 198 involved men (just over $60 \%$ of the total), 121 involved women (approximately $37 \%$ of the total), and 9 involved both men and women (about $3 \%$ of the total). It was necessary to administer more than 300 interviews because fieldwork was conducted in several different cellules in each fieldwork sector, and I wanted to adequately triangulate the data at each location. Many of the interviews were therefore based on a similar question checklist and are include fairly similar responses. I cite a sample of the interviews to illustrate my findings; these references to interviews are not exhaustive.

The research did not involve collection of any data related to socio-ethnic identity: i.e. the categories of Tutsi, Hutu, and Twa. There are three simple reasons for this, all of which are linked to the government of Rwanda's treatment of these categories. As mentioned above, it is essentially illegal to discuss these categories outside of certain situations controlled by the government (such as in judicial procedures for genocide crimes). The first implication of this policy for the fieldwork is that the Ministry of Education would be highly unlikely to be accept any mention of ethnicity in the interview question checklists, and might have rejected my research permit application. 
The second implication is that mentioning ethnicity in the interviews would have potentially made me, my research assistants, and/or the respondents liable to legal action by the Rwandan authorities. The third implication is that it would not, given the political, historical, and personal resonance of ethnic signifiers, be ethical to ask respondents about their ethnic identity. I therefore have no systematic data on the ethnic composition of the sample. It is generally estimated that Hutu represent at least $85 \%$ of the total population (Goovaerts, 1996), while Batwa represent less than $1 \%$ (Huggins, 2009b), so it is likely that the majority of the respondents were Hutu. While ethnic identity retains some importance in Rwanda (as I suggest in my interpretation in Chapter Nine of the recurrent narrative in many interview responses of 'servitude' or 'slavery',) it is in my view generally less significant than other indicators related to individual's willingness and capacity to identify with the 'ideal development subject' (Purdekova, 2012a: 192). Other authors have also found that ethnic identity is less important than other forms of social differentiation (see for example, Newbury 1988; Uvin 1998; Burnet 2012; de Lame 2005). While I draw attention to the ways in which the government uses accusations of divisionism and genocide ideology, and contrasting narratives of patriotism, to impose its model of the ideal citizen, it should be noted that such accusations have been levelled not only at Hutu or Twa but also at Tutsi (Waldorf, 2011). Therefore, while ethnicity is relevant to my overall analysis, it is not crucial, and the lack of data on ethnicity in the sample does not affect my argument.

Locating private transcripts within broader patterns and structures of oral discourses and place-specific networks is challenging, as such discourses and behaviours are largely 
undocumented and not readily 'legible' to non-locals. Some patterns are intended to remain covert such as the ceceka, an implicit code amongst some Hutu to 'say nothing' during the gacaca genocide trials (Rettig, 2011: 202; Burnet, 2008b:179). Naturally, tracking such intangible institutions pose considerable problems for researchers. In addition, many private transcripts represent counter-narratives to those of the Rwandan state, and conducting research into their structure would involve risks for local respondents as well as the researchers involved.

While it is impossible to fully contextualize private transcripts, it is important to consider the ways in which I and my research assistants might be perceived, and how this might affect interview responses. It was important to be seen as neither 'for' nor 'against' government policy; and to avoid a perception that we were conducting research in order to launch a development project or bring other forms of material benefits to the communities. Therefore, a statement regarding the independent, academic nature of the research was made before interviews commenced. Checklists of semi-structured questions were composed in order to avoid leading respondents in particular directions (pro- or against policy) and respondents were always asked to provide concrete examples to support their qualitative statements, to avoid unsubstantiated rhetoric.

The complex socio-political context in Rwanda and wide variation between public and private transcripts meant that it was not possible to rely upon secondary or purely official sources to build a useful and reasonably detailed model of the ways in which a particular cooperative functioned. Instead, sustained fieldwork, involving interviews 
with dozens of farmers per cooperative, was necessary in order to uncover not only the fundamental mechanics of the cooperative`s operations, but the ways in which they were embedded in state policy and discursive structures as well as the geographicallyspecific socio-political context. This meant that a comparative survey of a small number of cases, based as far as possible on triangulated data, and represented through `thick description` (Geertz, 1993) was preferred to the alternative: a wider sample based on un-triangulated, thin, and hence suspect, data.

During fieldwork, myself and research associates (see below) were based in urban centres (Ruhengeri in Musanze District, and Nyakarambi in Kirehe District) which were relatively close to the field sites. We traveled to the field sites using public buses or minibuses and/or motorbike taxis. Upon arrival we used local bicycle or motorbike taxis, or simply walked. Our research activities were less noticeable than if we had arrived in a private vehicle, and made it easier to ensure the anonymity of respondents. Also, respondents were unlikely to assume we were coming to launch a development project, or were operating on behalf of the government.

The vast majority of interviews were conducted with only one interviewee, in order to ensure the anonymity of respondents. Focus-group discussions were restricted to topics which were not directly related to policy, and hence not very politically-sensitive, such as the 'customary' gender dimensions of agricultural production for particular crops. Interviews were conducted in areas that ensured as much privacy as possible. Interviews 
were conducted using a check-list of questions but the format was semi-structured. This meant that respondents were able to have some control over the conversation. Repeat interviews were rarely conducted, as this may have signalled to any observers that those informants were becoming 'key respondents', and may have impacted them negatively.

Separate checklists were developed for semi-structured interviews with different kinds of informants (smallholder farmers, agronomists, local authorities, abunzi mediators, cooperative leaders, etc.), though there were similarities between the checklists. Questions were related to the changes in local land-use, ownership of land, amounts of labour invested in particular crops by different actors, particular farming practices (such as intercropping, spacing of individual plants, weeding, etc.), access to agricultural inputs such as seeds and fertilizer, financial investments in land and agriculture, storage technologies, marketing practices, income, and other relevant issues. This level of detail was necessary in order to map the 'micro-physics of power' as well as the impacts of agricultural reform. The questions focused on the actors and decision-making processes involved in these phenomena - particularly the relations between state and non-state actors - as much as the material outcomes. Men and women were asked similar questions, except for single-gender focus group discussions on gender dimensions of agricultural production. The list of questions for these focus group discussions was carefully crafted to avoid any potentially sensitive topics; and mono-sex groups were preferred partially to avoid any risk that responses might trigger gender-tensions amongst households or communities. Of a total of 328 interviews, 43 of these were conducted with small groups, while the rest were conducted with individuals. Of these 
small groups, 31 were mono-sex. Sampling methods are described below. A total of 149 interviews were conducted in Musanze District, while 166 were conducted in Kirehe. An additional three interviews were conducted in Kigali with key informants, eight were conducted in the US (mainly in Washington D.C.) including two by phone with respondents based in the US, and two were conducted in Ottawa, Canada.

Field research was conducted in conjunction with a small Rwandan non-governmental organization. This approach is required by the Rwandan government's research permission guidelines. The organization was selected based on the 'fit' between its institutional mandate and the themes under study, as well as its considerable experience in conducting fieldwork in rural areas. Personnel from the organization participated in the fieldwork, particularly in terms of interpretation (KinyarwandaFrench), but the specific research questions, research tools (question lists for semistructured interviews), lists of types of respondents to be targeted, and other elements were my sole responsibility. This was important in order to insulate the institution as much as possible from any negative impacts from the research findings, such as criticism by the government of Rwanda. Nevertheless, adverse impacts were felt, as a member of the organization was interrogated by Rwandan authorities on several occasions in March 2013 regarding the research, and had their laptop temporarily confiscated. The trigger for these events appears to have been the publication of some results of the research (Huggins, 2013). Following these events, the researcher was advised by Carleton University's Research Ethics Board that fieldwork should be terminated. At that point, 327 interviews had already been conducted, meaning that sufficient data was 
available to respond to the research questions. In addition, while this made it impossible to do as many interviews with government officials as originally planned, I consulted a wide range of official and unofficial sources regarding the claims and perspectives of state officials regarding the agricultural policy, and I emailed a list of questions to key policy-makers and managers of government institutions in early May 2013. The availability of independent and pro-government media resources online, as well as the large 'digital footprint' of the government of Rwanda, meant that I was able to access many useful examples of government discourse and other secondary sources.

While it appears that the government has ceased such approaches, which are a cause for great concern, the name of the organization and researchers involved will be withheld to avoid creating further problems. An independent research assistant was also employed for part of the research period and, following training, conducted some interviews without direct supervision (using research tools I had developed). This allowed for two research teams to operate simultaneously and greatly speeded up the research process.

\section{Selection of Field Sites}

Given the relatively diverse agro-ecological and socio-political geography of Rwanda, I decided to use a comparative approach. Field research was conducted in two Districts; Musanze, in the North-West; and Kirehe, in the South-East. My rationale is that, firstly, Musanze and Kirehe Districts were pilot areas for the agricultural policy, and hosted 
pilot cellules for the national land registration programme. These areas might provide evidence of the policies' impacts to a greater degree than non-pilot districts. Within the two districts, a particular fieldwork area was chosen, according to somewhat different criteria. In Kirehe, I chose to conduct fieldwork in Mahama sector, in which one of the pilot cellules of the National Land Tenure Regularisation Programme (NLTRP) is found (Mwoga Cellule). I had visited this cellule in 2006 while working for Human Rights Watch (HRW), in order to monitor the implementation of the land reform, and again in 2008 on a short research consultancy for Human Rights Watch. Based on these observations, I concluded that the attention paid to Mwoga cellule by state authorities from Kigali and members of international organizations, bilateral donors, and other foreign institutions, had promoted local authorities to move ahead rapidly with the implementation of the agricultural policy. Large fields of monoculture maize production were visible, and demonstrated that land consolidation had been conducted. Research in the four cellules of Mahama sector (Mwoga, Kamombo, Saruhembe and Munini) would therefore provide an insight into the impacts of several years of efforts by local administrators to promote change in the agricultural realm. Some unpublished interview material from my research with HRW has been used in this dissertation. ${ }^{53}$

\footnotetext{
${ }^{53}$ The HRW research was conducted using rigorous procedures to guarantee the anonymity of respondents. This material has been included in order to provide a comprehensive chronological account of the implementation of the agricultural reform from its beginnings until early 2013. It represents a relatively small proportion of the primary data presented in the dissertation.
} 
In Musanze, I opted not to conduct research in the NLTRP pilot cellule (Kabushinge,

Rwaza sector). ${ }^{54}$ Using Rwaza sector as a research area would have resulted in the study

relying upon data from two areas which could both be considered economically

marginal and geographically remote. This would not be representative of the diverse

nature of Rwanda's farming communities.

Instead, a linear zone of areas adjacent to the Ruhengeri-Bisate road were chosen for

fieldwork. These areas include parts of the sectors of Cyuve, Nyange, and Kinigi. The

proximity of this zone to the tourist area of the Volcano National Park, as well as

Ruhengeri town, and the existence of a good quality tarmac road, has led to many

commercial operations being launched in the area, both large-and small-scale. These

include dozens of kiosks, shops and restaurants that line the road, and the small town of

Kinigi, which hosts a bustling market, many permanent shops and restaurants, and the

headquarters of several agricultural cooperatives. There are at least 29 cooperatives

registered in Kinigi sector, for example. ${ }^{55}$

The two districts have very different ecological, topographic and demographic

characteristics. Population density is significantly higher in Musanze District than in

\footnotetext{
${ }^{54}$ The NLTRP area is located in a rural sector, is extremely hilly (resulting in less viable farm plots on very steep slopes) and is a distance $(12 \mathrm{~km})$ from Ruhengeri town. While precise information about cell-and sector-level poverty is not available, as the Musanze District Profile does not include sector-level data (NISR, 2011), the sector is home to few commercial operations and is not on the tourist route. For example, according to the Rwandan Cooperative Agency, there are only eight cooperatives in the entire sector, and this total includes all cooperatives, not just agricultural cooperatives (Rwanda Cooperatives Agency, 2013). It is therefore reasonable to assume that this sector is more economically marginal than areas to the North of Ruhengeri town, which are nearer to the Volcano National Park and the various tourist facilities associated with it.

${ }^{55}$ This total includes all cooperatives, not just agricultural cooperatives. Database accessed on May $6^{\text {th }}$, 2013, at http://www.rca.gov.rw/wemis/registration/all.php?start=20
} 
Kirehe. Agricultural plots are smaller in Musanze, which has generally fertile soils and four different agro-ecological zones, providing good conditions for a wide range of crops (NISR, 2010). The Ruhengeri-Bisate road, which rises from Ruhengeri town toward the foothills of the Sabyinyo and Karisimbi volcanoes, encompasses a variety of agroecological conditions. By contrast, the topography of Mahama sector in Kirehe is characterised by low, rolling hills and wide, shallow marshlands. It is categorised as part of the Eastern Savannah zone, or alternatively the Eastern semi-arid agropastoral zone (MINAGRI, 2012a; FEWSNET, 2011). Musanze has been densely populated since the colonial period; Kirehe was reserved as pasture during the colonial period, and became inhabited through in-migration over the past forty years. Musanze has areas of 'traditional' settlement patterns, with individual houses spatially dispersed across the landscape, in addition to planned villages (imidugudu); the majority of houses in Kirehe, in contrast, are located in planned villages created since the mid 1990s.

Map One below shows the approximate areas where fieldwork was conducted. More detailed visual information has not been provided in order to protect the anonymity of cooperatives and informants. 


\section{Map One: Approximate locations of fieldsites}

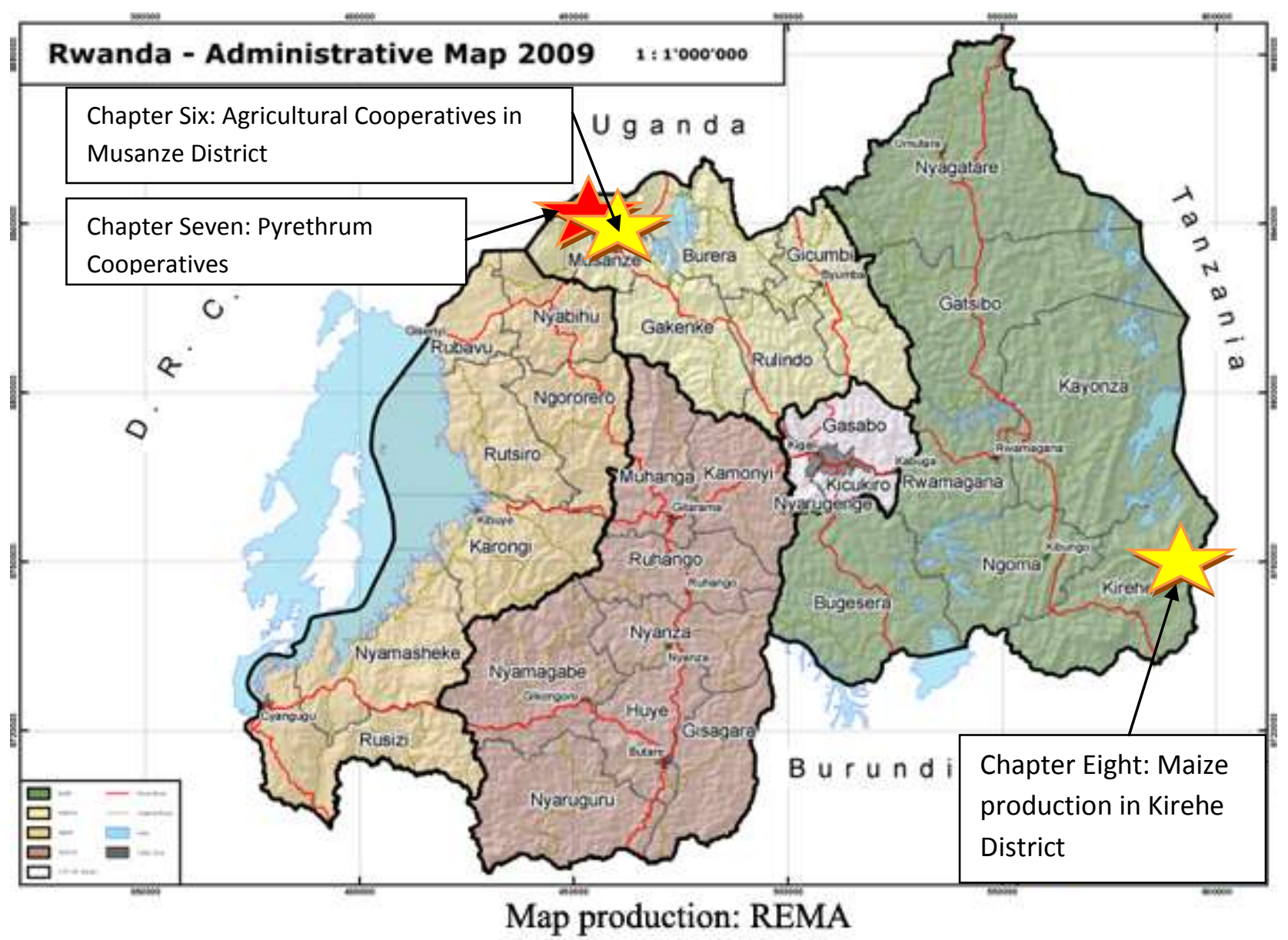

\section{Sampling Methods}

Respondents were identified in different ways, depending on their socio-political and institutional positioning. Individuals working directly or indirectly for state institutions were identified and interviewed without any process of randomisation. I have tried to ensure that they remain anonymous whenever possible, through the selective use of biographical, geographical and institutional information.

Particular agricultural cooperatives were selected through a semi-randomised process. In Musanze, I accessed a list of all agricultural cooperatives in the District. Farmers' 
organizations and government agronomists then provided more detailed information regarding the cooperatives. I did not reveal to farmers' organizations or government personnel which cooperatives I had selected. I used two variables to select cooperatives for research: first, crop types; and secondly, the involvement of different actors in the foundation and management of the cooperatives. In terms of the first variable, I selected cooperatives involved in the cultivation of different crops; all of which were on the list of government approved crops under the crop intensification programme (CIP). This was intended to reduce any inherent biases that might emerge from the study of a single crop. I selected a cooperative involved in potato marketing; pyrethrum production cooperatives; and a producer cooperative growing maize (as well as potatoes). While I wanted to look at the cultivation of different crops within Musanze, I wanted to be able to compare the production and marketing systems for the same crop - maize - in both Musanze and Kirehe. Regarding the second variable, I identified a cooperative that had been founded by local farmers (who had previously been members of potato marketing associations) without significant external intervention; ascertained that cooperatives in the pyrethrum sector had been 'restructured' with significant intervention from external actors (a 'party-statal ${ }^{56}$ profit-making firm and major bilateral donor); and selected another agricultural cooperative that had been founded through the forceful intervention of a professional businessman.

In Mahama sector, Kirehe District, maize is by far the most important crop within the government's agricultural reform framework, partly because the area's agro-ecological

\footnotetext{
${ }^{56}$ The term 'party-statal' in this context was coined by Gokgur, 2012.
} 
profile does not support the wide range of crops that can be found in a single sector in Musanze District. The majority of the fields under land consolidation are dedicated to maize (District of Kirehe, 2011b). While banana and beans are also significant, these crops were already produced in great numbers before the agricultural reform. Maize has historically been a less significant crop, so a shift towards maize production represents a major change in farm profiles.

Once it became apparent that local agronomists focused almost completely on maize production, it became necessary to temporarily forgo the first criteria mentioned above (studying different crops) in order to conduct a more thorough inquiry into how maize production varied, whether geographically or temporally. Research therefore involved interviews with cooperative leadership and smallholder farmers engaged in maize production in the sector, all of whom are required by authorities to sell their maize to the 'sector' cooperative, as it is often called. The intention was to conduct research into other crops at a later date, but this was not possible due to the decision to indefinitely suspend fieldwork in March 2013.

Local farmers were selected in a semi-random fashion. Villages (imidugudu) in the sector were selected at random from a list assembled from interviews with administrators and farmers (and cross-checked using online resources, such as the District of Kirehe official website). Upon arriving to conduct interviews, I separated a village into four parts (east, west, north, and south) and, taking a transect walk through each part, visited every fifth 
or eighth house (if empty, I moved on to the adjacent house) ${ }^{57}$ The position of a house doesn't necessarily correspond to the location of fields, as imidugudu were often constructed far from fields. A similar approach was taken for focus group interviews, with people in two neighbouring houses being asked whether they wanted to participate. As mentioned above, focus group discussions were intended to generate data on less politically-sensitive aspects of the reform, as anonymity was not possible with such an approach.

Given that the theoretical framework pays attention to spatial geographies, a sampling approach which allowed for a highly granular spatial analysis might have provided useful data. Such an approach could have utilised global positioning systems (GPS) or participatory mapping methods, for example. However, it was apparent from a literature review as well as my pre-PhD experience in Rwanda that in some places, the agricultural reform was characterised by state coercion, and was not necessarily supported by smallholder farmers. This would mean that some of the research questions would be politically sensitive. I therefore postulated that systematically targeting respondents based on micro-level spatial indicators (such as the precise location of agricultural fields, or the precise location of house) or on biographical profiles (age, gender, socio-economic profile) could have negative consequences. These could include self-censorship and a risk that authorities would be able to trace the identity of the respondents, for example through identifying patterns in the sample. A

\footnotetext{
${ }^{57}$ I alternated between the fifth and eighth house in order to avoid making the sampling methodology obvious to anyone who might try to replicate it, for example for purposes of identifying the respondents.
} 
more random approach was therefore taken, which limited access to micro-level spatial analysis.

The risk that authorities might monitor the research was particularly acute in Musanze District, which borders the D.R. Congo. Parts of Eastern Congo have been affected by an active rebellion (as well as many instances of more generalized conflict) since $2008 .^{58}$ Rwanda has been accused of supporting the rebel movement (HRW, 2012), a charge it denies. Some of the evidence for these accusations was collected in the District of Musanze (HRW, 2012). As a result of the tensions over the insurgency, the government of Rwanda 'started deploying more soldiers and spies to this region' (Begley, 2012: 72) and surveillance by government informants has caused some academic researchers to curtail their activities (ibid: 80). In addition, several academic and other researchers have been interrogated by RPF officials regarding their research or have had their notes stolen. $^{59}$

While such politically sensitive conflict issues are not found in Kirehe, the implementation of the agricultural reform there included coercion (Huggins, 2009a), making research potentially sensitive.

\footnotetext{
${ }^{58}$ The rebellion, by the National Congress for the Defence of the People (CNDP), officially ended with a agreement with the Congolese government in 2009 but restarted in 2012 when a part of the CNDP relaunched its war against the Congolese state under the name ' $M 23$ '.

${ }^{59}$ Interviews with academic and journalistic researchers, Kigali, 2005-2007; also Thomson, 2009.
} 
For this reason, I took primary responsibility for the design of the research, the choice of informants, and all data analysis, without involving field assistants or informants in any of these potentially sensitive activities. ${ }^{60}$

\section{Conclusion}

In order to start to contribute to my research question, this chapter charted the key elements of Rwanda's political economy, examining the government's discourses and practices of neoliberalism, as well as other characteristics. I noted that the political economy of Rwandan rural development defies easy categorization. On the one hand, Rwanda's administrative systems incorporate adaptations of neoliberal technologies, and the Rwandan leadership reproduces a discourse of 'entrepreneurship' associated with neoliberalism. To some extent, this discourse echoes the dominant thinking on 'good governance' (Taylor, 2004; Besancon, 2003; Abrahamsen, 2000) which largely frames donor assistance to countries such as Rwanda. The Rwandan state arguably has a vested interest in promoting an interpretation of its policies as broadly neoliberal, in order to encourage continued donor support. On the other hand, the political sphere is characterized by highly centralized decision-making processes, while RPF-owned 'party-

\footnotetext{
${ }^{60}$ It is preferable to involve respondents in the design of the research, to seek to understand local perspectives on such research and use local terminologies as much as possible, and to provide respondents with research findings to allow them to critique, add, or otherwise contribute to them. However, such an approach demands sustained and repeated contact with a group of participants, and this was not possible due to the need to assure the anonymity of respondents. In addition, implicating local people in the design of the research would also expose them to greater risk of government scrutiny and harassment.
} 
statal' corporations enjoy a pre-eminent and privileged position within various economic sectors, both phenomena which are associated with authoritarian and neopatrimonial governance models. The chapter situated the agricultural reform within a particular post-genocide political context, in which the government uses various forms of control (from cooptation to intimidation) to limit the extent to which CSOs can challenge state policy. In particular, I described how the concept of 'genocide ideology' has been used by the government as a means to control those suggesting alternatives to the RPF narrative: this will be linked in the following chapter to the creation of a particular kind of 'ideal development subject' (Purdekova, 2012a) who cultivates stateapproved crops as a patriotic duty. While the incorporation of commercial and nonprofit actors into the apparatus of rural development programming (such as foreign and domestic corporations and local NGOs and cooperatives) might suggest 'liberalization' and alternative sources of power and influence to the state, my analysis suggested that such actors are incorporated on the basis that they follow government policies. In that sense, they reinforce and extend the power of the state, rather than provide alternatives to it.

In my analysis of the Rwandan government's motivations for designing the agricultural reform and my presentation of the broad policy and legal architecture, I emphasized some of the tensions and contradictions between the official narrative of entrepreneurship and liberalization, and the reality of centralized decision-making. Looking at the criteria for selection of priority crops, for example, I showed that the imposition of these crops militates against the idea of individual economic autonomy 
that the 'entrepreneurship' model represents; and demonstrated that it is profit at the higher levels of agricultural commodity chains, rather than at the level of the farming household, that likely motivated the choice of crop types. This reveals a tension between a discourse of smallholder-focused agricultural reform, and a reality in which the preferences of the individual farmer do not appear to be at the centre of government decision-making. A such, it suggests a neoliberal model of economic growth which facilitates the accumulation of capital by capitalist elites, rather than the lower- and middle-income groups in society (Harvey, 2005: 16).

In order to show that the government is neither monolithic nor static in its policy orientation, I chronicled the development and promulgation of the 2005 and 2013 Land Laws. The draft land bill tabled in Parliament in 2012 would have represented the extension of state power over land (including powers of confiscation), and a restriction in the property rights of landusers, in the name of improved 'land tenure security'. In Foucauldian terms, such a land law would have represented a disciplinary technology. After deliberations, however, the Rwandan Parliament and Cabinet removed the clauses which would have facilitated the confiscation of land by the state in the case of nonadherence to agricultural policies. It can therefore be described as a system that attempts to influence land use primarily through land markets, and hence, in a context of broader governmental technologies, through the 'desires of the population' (Foucault, 2007: 73). 
Turning to methodological issues, I noted that the difficulties of interpreting and characterising the complex political economy of Rwanda preclude any academic methodology that relies only on secondary sources, particularly because of an assertive government campaign to frame state policies as (broadly) neoliberal and to downplay or discredit accusations of authoritarianism (Kagame, 2012; Anonymous, 2010; Butamire, 2011). Official policy documents or publications originating from the government of Rwanda are part of the government's information-management strategy designed to ensure that all such documents reflect officially-approved RPF ideas. There are few, if any, civil society organizations which are not closely aligned with the state; and the capacity of the government to monitor and suppress dissenting voices means that there are few independent research programmes which would allow triangulation of the information presented by the government. While academic literature on agricultural reform in Rwanda exists (Pritchard, 2013; Newbury, 2011; Ansoms, 2009; Huggins, 2009a), it does not yet represent a comprehensive or authoritative record of policy implementation in different agro-ecological and institutional contexts, such as might allow for an assessment of dynamics of homogenization and differentiation at different scales. Hence, my methodological section described the fieldwork focus on smallholder farmers, particularly those who are members of cooperatives, in order to generate original primary data on the way that the labour and assets of smallholder farmers are being incorporated into systems of agricultural transformation.

The chapter that follows will situate Rwanda's agricultural reform within a broader set of discourses and flows of development aid, in order to investigate the degree to which 
the government is autonomous in its decision-making on agricultural reform, or is rather directed by aid donors and other powerful international actors. It also utilises the concept of global or international governmentality to problematize the indicators by which the impact of the agricultural reform is measured, and to critically examine the narratives of 'success' associated with it. Having established the broad parameters of government action in Rwanda, in the next chapter I take a closer look at some specific tools of rural governance which are deployed by the Rwandan state in order to effect rapid change in the agricultural sector (as well as other sectors). This will allow me to start to trace some tangible connections between the state's use of governance technologies (such as imihigo) and its facilitation of commercial investment in the farming sector. 


\section{Chapter Four: Rwanda's Modernist Agricultural Reform in an International Context}

\section{Introduction}

This chapter situates the Rwandan reform within the broader context of the 'Green Revolution for Africa', and asserts that the Green Revolution model, rather than being directed globally or regionally by particular hegemonic actors, is the result of interaction between a wide range of institutions. This interaction provides scope for the Rwandan government to develop its own approaches to agricultural reform, while operating within the conceptual frame of the Green Revolution and other international concepts and institutions (such as the Comprehensive Africa Agriculture Development Programme, and the Millennium Development Goals).The chapter also describes donorgovernment articulations and contends that the involvement of donors, NGOs and other actors in various aspects of the reform, as well as the Rwandan government's desire to be seen as an 'African success story', may act as a deterrent against the most direct forms of coercion. However, some donors do provide support for disciplinary technologies which, in combination with various legal and administrative instruments, have coercive effects.

This chapter examines the roles of different actors in the design of the reform in order to suggest that the agricultural reform does not represent a straightforward implantation of global neoliberal models within a Rwandan context - a particular form 
of 'homogenization' -but something appropriated and tailored by the government to a particular context.

Broadly speaking, the government of Rwanda's vision for agricultural development is strikingly similar to that of the World Bank, as encapsulated in the 2003 World Development Report, for example. The main elements of the World Bank approach include, according to a critical review by Akram-Lodhi (2008: 1149),

Better soil, water and environmental management ... accelerated adoption of new agricultural technologies... in part through increased investments in research and extension services, [which] can also contribute to improved competitiveness. Improved access to financial systems, including microfinance schemes... Even 'marketsmart' subsidies... deepening and broadening the export orientation of agricultural production... a renewed focus on the promotion of non-traditional agricultural exports will enhance integration into agricultural globalization.

In the discourse of the government, and in Rwandan and international media coverage of the agricultural reform, the Rwandan policy is framed as part of the 'African Green Revolution'. It is therefore important to explore that ways in which the Rwandan agricultural reform is conceptually or institutionally linked to mainstream liberal global models, and examine the roles of different international actors in the agricultural reform. The reform is highly dependent upon foreign aid: as of early 2011, more than 
$55 \%$ of the total funding for the government's Agriculture Sector Investment Plan20092012, was provided by foreign institutions (USAID, 2011). ${ }^{61}$

Proponents of the Green Revolution concept, particularly those associated with the biological sciences, tend to emphasise the role of scientific innovation, as if the Green Revolution can be reduced to 'a package of technological innovations, attributable to a handful of scientists and unrelated to any geopolitical agenda' (Ross, 2003: 438). Critiques of the African Green Revolution or the Green Revolution concept more generally often centre on the role of biotechnology, especially genetically modified organisms (GMOs), and/or the role of chemical inputs, such as fertilizer, pesticides and herbicides. Such critiques are based on a number of arguments, including the negative environmental impacts of such technologies, the potential human health impacts, the financial risks that such technologies might present, particularly for the poor, and the long-term effects on agro-ecological diversity and ultimately, food security (Shiva, 1991; Ross, 2003: 454). Indeed, it is important to critically assess the short, medium and longterm effects of the application of such technologies in different agro-environmental and socio-economic contexts.

However, the predominance of such arguments in the critical literature has tended to favour a minimalist definition of the Green Revolution idea. While the implementation of agricultural technologies is often presented purely in 'technical' terms, it can be seen

\footnotetext{
${ }^{61}$ The Agriculture Sector Investment Plan 2009-2012 was costed at $\$ 815,400,000$. Some $\$ 436,000,000$ had been committed by early 2011: of this, $\$ 194,200,000$ was provided by the Rwandan government, while $\$ 221,200,000$ was provided by donors, and $\$ 20,600,000$ by the private sector. There was a shortfall of $\$ 379,400,000$ at that point (USAID, 2011).
} 
that actual implementations have historically been intertwined with political objectives, and have been driven by the state. Djurfeldt et al emphasise the key role of the state in the implementation of the Asian Green Revolution, which they define as, 'a state-driven, market-mediated and small farmer-based strategy to increase the national selfsufficiency in food grains' (2005b: 3). The technological inputs to the agricultural system, they argue, would not have had such a significant cumulative impact without the institutional and policy frameworks that enabled rapid, large-scale transformation of agricultural production and marketing systems. The Green Revolution in Asia, resulted in significant improvements in food security in many countries, as well as a rise in average incomes (Larson et al, 2010, Africa Research Institute, 2009; Djurfeldt et al, 2005a)

It is often stated that Africa 'has never had' a Green Revolution, or that the Green Revolution was attempted in Africa, but simply failed (Dano, 2007: 1). In reality, there have been many attempts, with varying results. According to Holmen (2005a: 68): 'the question, therefore, rather than 'why have Green Revolutions been absent in Africa?' should be, 'why have they not been sustained?'.

Many previous African efforts at encouraging intensified agricultural production incorporated elements of the Green Revolution model (Holmen, 2005b: 88). However, few of them included the comprehensive combination of technical and institutional factors now being recommended by mainstream agricultural development specialists (Mosley, 2002), or have involved sustained financial and political commitment by African states. Djurfeldt et al argue convincingly that only a sustained and significant financial 
and political commitment by African states will result in agricultural transformation. The critiques of authoritarian high modernism in Scott's (1998) theoretical model do not represent a blanket criticism of state intervention, and my personal position is that the state must play a key role in coordinating and funding agricultural intensification if food security and rural incomes are to be improved through investment in the rural sector. This dissertation then, is not a critique of state intervention in the agricultural sector per se, or necessarily a critique of developmentalism more generally; it is, rather, a critique of the particular homogenizing and coercive effects of the systems through which the agricultural policy is being implemented in Rwanda.

\section{The African Green Revolution}

Contemporary, consistent calls for an African Green Revolution date from the late 1990s, and stem in part from the work of Gordon Conway, both as an author of a book calling for an environmentally-friendly Green Revolution in Africa (Conway, 1997) and as President of the Rockefeller Foundation (Dano, 2007: 6). Conway's message was rapidly taken up by dozens of other organizations, and became, in the $21^{\text {st }}$ century, linked to a broader sense of optimism about African economic growth and African governance (see e.g. The Economist, 2011).

Some critics consider the main impetus for the African Green Revolution to come from multinational companies, many of which, such as MONSANTO and SYNGENTA, dominate the trade in a variety of inputs including improved seeds, pesticides, and inorganic 
fertilisers. According to these critics, such corporations play an important role, largely behind the scenes, while 'allowing' multilateral research organizations, African regional and non-governmental institutions, and African political figures to 'appear' to take the lead:

Corporations have notably downplayed their role in the push for a new green revolution by appearing to remain on the sidelines... these corporations have allowed public research institutions to be at the forefront in Africa, along with their philanthropic backers. Corporations have also managed to subtly plant their most sophisticated operators in philanthropy as well as in the international research centres in an effective way so as to directly influence decision-making and research priorities. (Dano, 2007: 56).

There is much to agree with in this statement. ${ }^{62}$ Based on the view that the African Green Revolution concept is largely driven by multinational corporations, countries such as Rwanda have been described as 'capitulating' to corporate interests (Milz, 2011). In the case of Rwanda, this analysis is based on the fact that multinationals supply many of the inputs purchased by government and farmers; for example massive amounts of fertilizers used in Rwanda are being supplied by the Norwegian company Yara

\footnotetext{
${ }^{62}$ Examples of individuals who have moved from private to public or philanthropic roles include Robert Horsch, former Vice President at Monsanto, currently working at the Gates Foundation (Richardson, 2013) and Dr. Gerard Barry, previously of Monsanto, who moved in 2003 to the International Rice Research Institute (IRRI) (Dano, 2007).
} 
International ASA. In 2012 Yara awarded the Rwandan Minister for Agriculture an international award recognizing the achievements of the Rwandan agricultural reform. ${ }^{63}$

However, the agency of multinational corporations is often over-emphasized in the critical literature, while that of African governments and entrepreneurs is underestimated. Too little attention has been paid to, 'how these international processes interact with domestic political economy, what role the state plays in agricultural investment and its role in influencing changing agrarian relations' (Lavers, 2012)

The 'African Green Revolution' is often conceptualized as a single unified programme or vision, with a specific agenda. For example, some critics have decried the Green Revolution as 'a 'Trojan horse' paving the way for entry by multinationals' (Dano, 2007: 1). This idea of a 'colonisation' of African policy-making processes through 'a false notion of all-powerful Western development institutions' (Mosse, 2005:6) is overly simplistic. Attention to the historical development of the Green Revolution concept, and its application in Africa, as well as the uses of the term by various actors, reveals that it can be more accurately perceived as a collection of separate phenomena, involving a very wide range of institutions. It could therefore be described as, 'a systematic convergence of interests of various actors guided by a similar worldview' (Dano, 2007: 55).

Moreover, rather than imagining a static, stable or predetermined programme, it is important to acknowledge that 'knowledge and policy are constructed together'

\footnotetext{
${ }^{63}$ A previous winner of the Yara award was the Ethiopian government, which has also used coercion to achieve agricultural goals, including getting farmers to purchase large amounts of Yara fertilizer.
} 
(Scoones, 2005: 110) in a constant context-specific process of (re)-interpretation involving the amplification of some elements, whilst others are de-emphasized. However, this is not to say that it is without structure or hierarchy. There are clearly some institutions, individuals and ideas that are more influential or powerful than others. African efforts to design agricultural policies must by necessity do this within a broader discourse dominated by western capitalist values, vocabulary, and actors. Policies emerge from, and reflect, knowledge systems enmeshed in unequal power relations (Foucault, 1980; Escobar, 1994). That being said, the government of Rwanda has managed to retain a high degree of control over its policy-making processes (Zorbas, 2011; Hayman, 2009). The government, rather than foreign corporations or bilateral donors, has played a dominant role in the broad design of the policy. The government has put its own stamp on the generic model of the 'African Green Revolution', especially in terms of regional crop specialisation (which is generally discouraged under liberal and neo-liberal policies) and land consolidation. This is possible in part because of government control over the financing of the reform.

For example, the state has told some donors to cease supporting the agricultural sector in favour of other donors which were asked to channel greater resources to this sector. While some donor funding is directed towards specific projects (such as USAID's support for the SPREAD project in the coffee and pyrethrum sectors, see below) the majority of donor funding goes directly to the government budget where it can be used without much direction from donors. Around 45 percent of the identified agricultural budget from 2009-12 was funded by foreign donors, according to the Ministry of Agriculture 
(MINAGRI, 2010b). In line with the commitments it made as part of the CAADP, the government has increased the annual budgetary allocation to agriculture, from 4.2 percent of the national budget in 2008 , to more than seven percent in $2010 / 11$ (Concern, 2010). ${ }^{64}$

\section{Rwanda's Engagement in International Governmental Networks}

Due to the significant financial, technical, diplomatic, and other forms of support from donors and NGOs, it is important to consider how the agricultural reform is embedded within the international aid architecture. As mentioned in Chapter Two, international aid to Africa in the 1980s and the first half of the 1990s, approximately, tended to be dominated by a model of aid conditionalities, which resulted in high unemployment rates, cuts in salaries and welfare services, increased user fees for basic services, and a sense of 'deep social desperation' in many African countries by the mid-1990s (Leal, 2007). As these problems became apparent, Leal argues, major institutions such as the World Bank embraced the concept of recipient country 'participation' and 'ownership', arguing that such problems were not inherent to the overall model, but could be overcome through the use of more participatory approaches.

\footnotetext{
${ }^{64}$ Estimates vary, possibly because not all of the allocated funding has been spent, and the Government has therefore been described as somewhat inconsistent in its actions (Booth and Golooba-Mutebi, 2012). Concern International estimated the 2010-11 figure at nearly ten percent (Concern, 2010).
} 
The World Bank and other mainstream organizations adopted techniques associated with participatory approaches, but disconnected these approaches from the sociopolitical emancipation theories (Freire, 1973; Chambers, 1983) that gave rise to them.

The shift in the international development discourse towards greater 'ownership' by beneficiary countries, which were no longer termed beneficiaries but rather 'development partners' (Abrahamsen, 2004), was encapsulated in the 2005 Paris Declaration on Aid Effectiveness, which emphasises the responsibilities of donors to better coordinate their activities, improved 'ownership' of development processes by the receiving government, and alignment of donor priorities with those of the receiving government (OECD, 2008). Many Southern leaders, including President Kagame, have echoed the language of the Paris Declaration in their own statements on foreign aid (Zorbas, 2011).

\section{The Agricultural Reform in Rwanda and International Governmentality}

The extensive use of qualitative targets within Rwanda's plans and policies reflect the broader patterns of 'rendering calculable' cited in the discussion of governmentality in Chapter Two. This is not surprising, as the broadest objectives - such as a reduction in the numbers of people relying on agriculture for their livelihood - derive from highlevel, strategic policy documents (such as Vision 20/20) designed to directly plug into the networks of international development aid 'calculus'. For example, the government has embedded the agricultural reform within discourse around the Millennium Development Goals (MDGs), such as the targets set out in MDG 1, to eradicate hunger 
and malnutrition by 2015 (see e.g. MINAGRI, 2010a). Rwanda was the first country to submit key agricultural policy documents, the Strategic Plan for the Transformation of Agriculture in Rwanda, Phase II (PSTA-II) and its associated Agriculture Sector Investment Plan (ASIP), to peer review by a team led by the African Union (USAID, 2011).

While there is insufficient space here to comprehensively examine Rwanda's relationships with donors, it is important to note that some 'governance' issues (such as Rwandan support for armed groups in the D.R. Congo) have provoked some donors to suspend aid funding on several occasions (such as the Dutch and Swedish governments in 2008; the US, UK, Germany, the European Union and others in $2012-2013 .{ }^{65}$ Such differing responses by donors indicate divergence, rather than smooth coordination, within international governance mechanisms. Following suspension of aid by several donors in 2012, Kagame stated:

There is no country in this world that receives aid and accounts for it better than Rwanda. There is none. So, I am not sure if these people who give us aid want us to develop. They give us aid and expect us to remain beggars. They give you aid so that you forever glorify them and depend on them. They keep using it as a tool of control and management. (Kagame, 2012b)

\footnotetext{
${ }^{65}$ In the most recent example, following reports in 2012 from several human rights groups and the United Nations Panel of Experts for the D.R.C., most major bilateral donors to Rwanda accepted the accusations that Rwanda was providing direct military and financial support to the M23 rebel group in Eastern D.R.C. Several different tranches of aid were suspended or blocked completely as a result (Smith, 2013 and 2012; Economist, 2012).
} 
The last phrase, 'control and management', is startlingly reminiscent of the literature on governmentality. Through 'voluntarily' submitting itself to various disciplinary technologies of 'good governance', Rwanda validates them, hence 'glorifying' them. The Rwandan government appears expert at performing the role of the 'responsible state' within the international networks of aid, but recognises that this role involves both empowerment and subjection. Donors have been unable to completely impose the liberal political and economic model associated with 'good governance' on Rwanda. Part of the reasons for the Rwandan state's success in resisting such pressures is the government's assertiveness in pro-actively setting the agenda for debate across multiple platforms, rather than only responding to criticisms or external policy blueprints. In particular, the government and its supporters in pro-government media houses and other institutions have sought to put forward a particular image of Rwanda using digital technologies such as websites. One recent example is the creation, with the financial backing of the government of Rwanda and the African Development Bank, of an online encyclopedia dedicated to Rwanda, called Rwandapedia (which is superficially styled after the user-generated encyclopedia, 'wikipedia'). ${ }^{66}$ Of more relevance to my topic, there are examples of the agricultural sector being promoted online.

\section{Digital Technologies in the Agricultural Sector}

The government has made agricultural statistical information available as part of its broader policies and practices of 'e-government', which are some of the most advanced

${ }^{66}$ Accessed online on October 30, 2013 at http://rwandapedia.rw/ 
on the African continent (Mwangi, 2006). Digital information diffusion allows rapid and ongoing configuration with global systems of calculation around the various indices of 'good governance'. One example, the eSoko project, provides almost real-time price information for 78 agricultural commodities at 50 major marketplaces around Rwanda. Users access the service by sending a text from their cellphone, for a small fee; or subscribing to an internet-based service accessed by computer. ESoko was introduced in 2009 as part of a broader World Bank-funded eGovernment programme, though the Ministry of Agriculture now maintains and manages the system, paying for any costs which are not recovered through user fees.

Beneficiaries of data from eSoko include the National Bank of Rwanda (BNR), National Institute of Statistics of Rwanda (NISR), Regional Agriculture Trade Network (RATIN), and the East Africa Grain Council (EAGC), all of which are mandated to collect market information.

The eSoko model fits with notions of commercialisation and entrepreneurship, as it provides market information that could help farmers make decision regarding which crops to grow, buy, and sell. It is framed as 'empowering farmers' (MINAGRI, 2013). As a service working indirectly at the level of the population, it is recognisably a 'governmental' technology.

The project has been widely publicised around the world and was a winner in the Technology in Government in Africa (TIGA) Awards, 2011 held in Addis Ababa, Ethiopia. However, available evidence does not necessarily suggest that eSoko has had a massive 
impact in terms of usage by smallholder farmers. In 2011, eSoko sent/received 27,293 text messages (an average of 74/day); this approximately doubled to 54,000 in 2012 (Ministry of Youth and ICT, 2012). This doesn't seem a particularly high number for a nationwide service aimed at the average smallholder farmer. Moreover, there does not seem to be any publically available disaggregated information on usage. It is feasible that many of these users are urban-based merchants, local authorities, and government planners, rather than the target group of farmers (Niyongabo, 2011).

An economic study assessed impacts of the eSoko service on market prices. In theory, improved access to market information should, over time, result in greater market efficiencies and a movement towards price equilibrium across the country. The study found that average prices did not change, which, 'raises the question of whether the introduction of the liberalization policies since the 1990s and more recently the E-Soko market information platform have helped in opening up the staple food markets in Rwanda' (Bizimana et al, 2013).

This supports my interpretation of the agricultural reform, as characterised largely by the imposition of centrally-planned targets, through the performance contract system, and coercive measures which actually restrict, rather than enhance, the options open to farmers. Markets have not changed as rapidly as would be expected from a liberal reform based purely on increasing farmer options and access to markets. Nevertheless, eSoko has performed other roles within the context of global systems of governmentality. The project has strengthened the dominant narrative - shared by most bilateral missions, development agencies and the Rwandan government - of the 
importance of 'entrepreneurship'. Within the context of Rwanda's role within international networks with flows of aid and private investment, the project is a success, notwithstanding the unproven question of whether it actually assists smallholder farmers.

\section{Assessing 'Success'}

The eSoko example raises the question of how 'success' of agricultural reform might be measured. The data presented by the government of Rwanda, and reproduced by donors, some international NGOs, and other actors, tends to be aggregate, nationallevel data. This is partly because such data is highly legible to international systems of governmental calculus. Examples include the 'area of land under production' for particular crops, which encourage systems of land use consolidation (see Chapter Eight on maize production in Kirehe) and district-level food security indicators (that do not include detailed information on specific vulnerable groups). However, Rwanda has not actively collected or published data on some indicators recommended by the international organizations promoting and coordinating the Green Revolution for Africa. For example, while Rwanda has various policies in place to assist specific groups identified as 'vulnerable' (such as the Batwa 'historically marginalized' community and genocide orphans), implementation and monitoring of the agricultural reform has paid insufficient attention to indicators recommended by some organizations in order to monitor impacts at the micro-level. Rwandan monitoring and evaluation systems have paid insufficient attention to indicators such as 'Improvement in the household asset 
and/or income levels of targeted vulnerable populations' (CAADP, 2009: 35), or to the impacts of agricultural transformation in especially marginal agro-ecological zones. Therefore, while CAADP emphasises that, 'the point is not only to know what Pillar III [of the CAADP process, focusing on food security] is achieving, but also whether these impacts are doing any good' (CAADP, 2009: 35), Rwanda has only focussed on the broadest and simplest definition of 'good', such as average per capita calorie intake. Secondary and tertiary impacts of the agricultural reform remain unexplored by governmental agencies, prompting some donors to devote resources to monitoring and evaluation, despite the reticence of Rwandan policy-makers (USAID Land Project, 2013). The government is extremely sensitive about 'divergent' narratives. Researchers who conduct provincial- or national-level surveys without submitting to the supervision of the National Institute of Statistics of Rwanda (NISR) can be jailed for up to six months $(\text { NISR, 2012f) })^{67}$.

Scott's account of the dangers of simplification, standardisation and abstraction is useful in reminding us that such general data obscures geographic, demographic, and temporal variations. The 'thin' quantitative approach to assessment of progress within the farming sector means that the 'local', seasonal, and socio-culturally-specific challenges posed by agricultural policies remain unexplored. Simple notions of 'participation' mean that the numbers of people involved in particular activities, rather than the basis on which they are involved, act as proxy indicators for the 'involvement' of farmers. Such

\footnotetext{
${ }^{67}$ There is a three-month punishment for conducting the survey without permission, which is doubled if the survey results are published without the consent of the NISR (NISR, 2012f)
} 
an approach, which values 'products' rather than 'process', encourages the government to intervene directly in the agricultural sector in order to ensure that quantitative targets are met. The government of Rwanda is able to further obscure the nature of farmer involvement in state programmes of agricultural transformation (such as the degree to which it is based on consent) by framing disciplinary technologies (such as imihigo) within a discursive field of Rwandan socio-cultural 'exceptionalism', supposedly impervious to outsider analysis, as will be described below.

This need to achieve a seamless programme of action derived from central state objectives and international discourses of 'Green Revolution' is, nevertheless, to be achieved through the inclusion of non-state actors, such as agricultural cooperatives and farmer's unions, which are theorised in the (neo) liberal conceptual framework as active, self-governing entities enjoying 'ownership' of the policies, programmes, and targets. There is a fundamental tension between the necessarily monolithic nature of central plans and the diverse range of decentralized 'actors' expected to contribute to both the design and implementation of those plans. In many cases, this tension starts when state entities actually organize the creation of local 'civil society' organizations designed to fulfil the needs of the agricultural policy (see chapters six, seven and eight for examples) and staffed with hand-picked individuals. 


\section{The Imihigo Performance Contract System}

One of the key mechanisms of coherence and connection within the agricultural sector, as within other sectors, is the imihigo performance contract system, which ensures that specific development targets are shared through a hierarchical structure of obligations from the level of the District, through the sectors, the cellules, umudugudu, cooperatives and other local organizations, the household, and ultimately the Rwandan individual. Independent studies have found that government officials 'used a top-down approach' (Bugingo and Interayamahanga, 2010: 45) in selecting targets as well as the contributions (in cash or in labour) pledged by the affected organizations and individuals. This was confirmed by interviews. ${ }^{68}$ The household-level imihigo are based on a 'template containing priorities' distributed to householders by umudugudu leaders (Bugingo \& Interayamahanga, 2010: 44). The template for umudugudu level officials includes sections on security, ideology, development (which includes agricultural activities), social affairs, and justice (Sommers, 2012: 245-9). Particular agricultural activities to be conducted by the population include 'terrace cultivation; modern animal husbandry [and] farming; soil protection; antierosion techniques, fertilizers; vegetable gardens, fruit trees; saving (crops, money); promoting the innovation culture and creative activities'(Sommers, 2012: 247; Nsabimana, 2010: 47). Several respondents, including local authorities, mentioned that contributions to the Agaciro Development Fund would be included in the imihigo targets. ${ }^{69}$ The Agaciro Development Fund, which

\footnotetext{
${ }^{68}$ Interview A of $12^{\text {th }}$ May with member of farmers' organization, Ruhengeri town.

${ }^{69}$ Interview E of February 142013 with umudugudu leader, location withheld to protect anonymity; Interview G of $16^{\text {th }}$ Feb 2013, Kinigi Sector, Musanze District.
} 
goes directly into central state coffers, is another system that, while formally 'voluntary', is discursively associated with values of patriotism, and hence becomes difficult to avoid. Companies, local government organs and other organizations compete with each other to make the largest donation (Kanuma, 2012). In some areas, local authorities have forced citizens to make contributions (Karinganire, 2012c). Building such a 'voluntary' contribution into the imihigo template essentially makes it mandatory.

Due to this top-down, template approach, imihigo is primarily a force for homogenization, promoting a standard package of obligations across the country. However, when combined with regional crop specialization policies and the particular demands of commercial actors, the imihigo becomes les homogenizing and more individually-crafted. District level performance contracts include agricultural targets. During 2007 for example, all districts set targets related to agricultural production, mostly in terms of production of specific crops, whilst one district in Eastern Province set targets for fertilizer use (MINECOFIN, 2007: 6). The Kirehe District Performance Contract, for example, specifies that the District should achieve maize production of 50,000 tonnes, as well as 2,340 tonnes of 'Kamala' bananas, 16,800 tonnes of pineapples, 5,950 tonnes of coffee, and 4,200 tonnes of rice. The contract also states that each household will have planted at least five fruit trees (District of Kirehe, 2008). The performance contract for Ngoma District includes targets of seven million new coffee trees, cultivation of 500 hectares of rice, 450 hectares of pineapples and the 'revival' of 2000 hectares of banana plantations (Asiimwe, 2008). State personnel claimed that targets are based on farmer's estimates of how much they will be able to 
produce. ${ }^{70}$ However, other sources indicate that performance contracts are written with little, if any, input from community members (Purdeková, 2011). A member of the umudugudu authorities in Nyagatare District stated that the contract targets came from the District level, though some negotiation was possible between the District and the more micro-levels. He did not mention local community input. ${ }^{71}$ The particular targets in each district, sector, cell, umudugudu and household contract, in conjunction with the agro-ecological conditions, socio-political situation, and the orientation of the administrative machinery within which it is embedded, will contribute to particular conditions of governance. Imihigo contracts, therefore, while homogenizing at some levels, also contribute to the emergence of particular 'spaces of governance' within Rwanda.

The idea of competition is important in the imihigo system: administrative units are ranked according to their achievement of imihigo targets, successful leaders are rewarded, and those with low rates of success are expected to resign. In December 2007, the Governor of Eastern Province, told all district leaders in his Province 'to double their performance or resign their positions' (Mwesigye, 2007). A member of a Rwandan NGO described a conversation with the executive secretary of a cellule in Northern Province, who told him that he was expected to achieve imihigo targets, even if it involved committing 'injustices' against the people. The executive Secretary reportedly said: 'If we don't, we will lose our jobs... I won't lose my job because of the

\footnotetext{
${ }^{70}$ Interview with Musanze District state personnel, Ruhengeri town, February 252008

${ }^{71}$ Interview with umudugudu leader, Nyagatare District, February 202008
} 
injustices against the population; instead, I'll be rewarded for having done what I was asked to $\mathrm{do}^{\prime} .^{72}$

It is not surprising then that during implementation of the imihigo, 'leaders may disregard their citizens' fundamental rights in order to meet their pledges at any cost' (Bugingo and Interayamahanga, 2010: 49). It is likely coercion, for example, that allowed Nyamagabe District, Southern Province, to achieve 95.4\% membership in the health insurance scheme by 2009 , and to aim for $100 \%$ coverage the following year (Ntambara, 2009). This tension between promised 'freedoms' and autocratically-imposed targets which become conceptualised as citizens' 'duties' or 'responsibilities' (Babu, 2009) may be managed, on paper, through 'customisation' of the national-level objectives at the local level (Babu, 2009) but remains problematic both in theory and practice.

The government portrays the imihigo, like several other institutions developed by the contemporary Rwandan state (e.g. gacaca, and ingando), as rooted in Rwandan historical and cultural norms (Desrosiers and Thomson, 2011: 446; IDRP, 2010: 39). This discursive tactic represents a process of divorcing complex phenomena from the fields of power in which they are imbricated. The pre-colonial past has been 're-invented' in official discourse as a time of an unlikely degree of harmony and peace, where ethnicity, to all intents and purposes, did not exist (Thomson, 2011: 336-7).

The customary form of imihigo is described as 'a public pledge made in front of local leaders to perform a brave act or other collective interest achievement' (Bugingo and

\footnotetext{
${ }^{72}$ Interview with member of Rwandan NGO, Kibungo town, February 172008
} 
Interayamahanga, 2010) dating from the pre-colonial period, and hence 'in the ancient tradition of Rwanda' (Vianney, 2010: 11). It has also been associated with the precolonial military (Woodrow Wilson School of Public and International Affairs, 2010). As such, it is discursively linked to values such as determination, loyalty, and patriotism. It follows that failure to achieve imihigo targets, within this conceptual model, should be a source of shame and dishonour. By situating state initiatives within a specifically Rwandan 'traditional' context, the government of Rwanda has implicitly insulated these from 'external' analysis based on a more 'universal' etymology: an argument explicitly made by state officials who argued that only Rwandans could really 'know' their country (Zorbas, 2011). Indeed, aid industry documents uncritically recite government positions on these 'indigenous institutions' (UNIFEM, 2010), and in one scholarly example, such Rwandan institutions are uncritically essentialized as embodying 'community spirit' through 'home-grown' models of 'communal activities' (Matovu, 2011).

Notwithstanding cultural specifics, we can recognise characteristics of contemporary governmentality approaches within it, as it represents the embedding of market-based principles (such as competition), state austerity through citizen contributions, and governance-beyond-the-state, which provides legitimacy through the idea of 'ownership' of policies by local, non-state actors. The imihigo system is described in progovernment discourse as a mechanism to achieve the Millennium Development Goals, Vision 2020 objectives, and other international and national 'good governance' standards, and has been widely cited as a useful tool for enhancing government 
'accountability' (Ngendahimana, 2012;Woodrow Wilson School Of Public And International Affairs, 2010).

Imihigo are now being signed at household level. By the beginning of 2012, half of the households in the District of Kirehe had signed imihigo (District of Kirehe, 2011b). A key question, of course, is what actions the state will take regarding households which achieve their imihigo goals, and those that 'fail'. At the moment I can only speculate about the outcomes for farmers. Those who stand out (either through success or failure) can presumably expect consequences. The likelihood is that the imihigo at the household level will become what Foucault calls a normalizing technology, a system that sets 'a minimal threshold, as an average to be respected or as an optimum towards which one must move' (Foucault, 1977, 183). It is a mechanism for recognising those falling outside of the normal range of behaviour. As a technology of surveillance and discipline, it represents the crystallization of the 'connectedness' paradigm in Rwanda (see below and Chapter Eight). Citizens will be judged not only according to their ability and willingness to contribute to official state targets, but will also likely be judged as 'good' or 'bad' citizens based on 'unofficial' targets regarding the Agaciro Development Fund for example. It is not yet clear whether failure to meet imihigo targets will be linked to citizens' continued right to lease land from the government.

The Rwandan state has begun to harness the imihigo structure for corporate interests. The government information service has announced for example that investors, in conjunction with the Scientific and Technological Research Institute (IRST), are 
interested in buying jatropha from Kirehe District (Eastern Province), on the basis that it is added to the District Imihigo and hence produced across the 'whole District' (Kanyumba, 2011). ${ }^{73}$ There will likely be an imposed convergence between imihigo targets at different administrative levels (district, sector, cellule and household) and corporate production goals, in order to increase state and corporate control over agricultural commodity chains from the household field, through to the moment of export. The involvement of commercial actors in rural Rwanda may therefore be associated not with a liberalization, but rather a deepening of patterns of coercion across a particular administrative zone.

The imihigo therefore combines elements of the government's moral and ideological framing of 'development' as a patriotic duty of each citizen; international ideas of target-led development; corporate targets to encourage commercial contract farming; while operating as a disciplinary technology.

\section{The Government of Rwanda and International Governmentality}

Despite the success of the government's attempts to gain more control over governmental technologies, some of processes of assessment of Rwanda's conduct have resulted in significant friction and disagreement between Rwanda and donor countries. A very brief examination of the way that Rwanda positions itself within international development assistance networks will demonstrate the ways in which the Rwandan

\footnotetext{
${ }^{73}$ Unofficial translation of Kinyarwanda original.
} 
state creates the idea of Rwandan citizenship as a particular, specific notion which cannot be understood through reference to international notions of 'good governance'. This is of relevance to the issue of coercion in Rwanda, and how it is viewed or regulated by external actors. It is also linked to homogeneity: different configurations of rights and obligations associated with citizenship may be established in different parts of the country. These insights will allow me to locate the co-creation of specific kinds of Rwandan 'subject' within a broader context, hence avoiding treating Rwanda in a vacuum, which risks validating a problematic narrative of Rwandan uniqueness and 'exceptionalism'.

Rwanda was the second country to voluntarily undergo the African Peer Review Mechanism (APRM) process. The APRM, managed by the New Partnership for Africa's Development (NEPAD), is a process of evaluation based on a set of questions related to democracy and political governance, economic governance and management, corporate governance, and socio-economic development. The APRM represents a 'willing subjection to supranational discipline and authority' (Jordaan, 2006: 334) and a disciplinary mechanism within the broader governmental framework of international development aid (Abrahamsen: 2004, 1461). The APRM evaluation was positive regarding Rwanda's economic policies, but critical regarding lack of political freedoms and the government policies on the Batwa ethnic minority. ${ }^{74}$ In its official comments on the APRM, the government of Rwanda pushed back hard (NEPAD, 2006: 51) maintaining

\footnotetext{
${ }^{74}$ In terms of political space, the team found that fundamental aspects of democracy and political freedoms 'were not clearly visible' and that opposition political parties were 'not able to operate freely' (NEPAD, 2006: 37). In terms of Batwa rights, the APRM team stated that government policies represented 'a desire to obliterate distinctive identities' (NEPAD, 2006: 51).
} 
that problems stemmed from 'the review team not understanding Rwanda's unique situation' (Beswick, 2011: 502). The government of Rwanda was arguing that the APRM good governance criteria are not appropriate to its specific historical-political situation; a fundamental challenge to the entire global governance project. The APRM review disrupted Rwanda's well-managed narrative of political 'unity', but its overall impact on the policies and programmes of the government of Rwanda has been relatively minor (Killander, 2008:73).

The attitude of the Rwandan government to a good governance assessment designed by its most significant donor and political ally, the US government, also reveals the complex nature of government: donor relations. The Millennium Challenge Account (MCA) is a US government foreign aid programme which ranks potential aid recipient countries according to 17 governance indicators. Following assessment, Rwanda was categorised as 'on the threshold of eligibility for Millennium Challenge Account compact assistance' (MCC, 2008), worth hundreds of millions of dollars. The MCA is an incentive system for reductions in levels of state coercion, amongst other things. However, Kagame reportedly said that he 'did not care' if Rwanda never reached compact status (Hayman, 2012 :125). Rwanda's scores on indicators related to 'political rights', 'civil liberties', and 'freedom of information' declined during the period of the threshold programme (MCC, 2013). It appears that the programme, which concluded in 2012 , has been quietly put aside, as Rwanda has little hope of achieving 'Compact country status' which would 
provide with access to hundreds of millions of dollars of U.S. aid. ${ }^{75}$ However, the Rwandan government's failure to achieve certain 'good governance' goals seems not to have affected its broader standing with the US government. This raises the question of how such governance indicators are linked to broader foreign policy agendas amongst donor countries. The articulation between assessments and indicators of 'good governance' and policy-making is rarely made transparent or systematic.

\section{Donor-government Coordination Mechanisms within Rwanda}

Networks of international governmentality do not function only through states feeding information to global mechanisms but also through mechanisms of donor calculus embedded within the recipient state.

In Rwanda, as elsewhere, donors have gained increasing access to policy-making processes and can monitor how aid is used (Hayman, 2009: 161). Staff from international development agencies (notably Belgian Technical Cooperation and the UK's Department for International Development, DFID) are often seconded to Rwandan Ministries and play important roles in writing policy documents. Those international institutions close to the government refer to this as 'embedded support' (Office of Tony Blair, 2011). Such mechanisms are so ubiquitous under the development partnership model that Harrison (2001) has suggested that it is more useful to conceive of donors 'as part of the [recipient] state itself' (cited in Abrahamsen, 2004:1463). One reading of this

\footnotetext{
${ }^{75}$ Interview with individual involved in the MCC threshold programme, Washington D.C., April 162012
} 
pattern is that Rwanda is a 'governance state' (Harrison, 2004). In such states, national governance institutions become so closely intertwined with international mechanisms that the state has partially surrendered sovereignty over a vast domestic policy domain. According to this reading, Rwandan policies and institutions represent the products of a shared interest between institutions and individuals who are embedded in an increasingly cohesive transnational discourse and network of neoliberal aid (Gould, 2005). Such an interpretation would put greater emphasis on the hegemonic nature of normative frameworks of governance amongst a transnational elite, which straddles bilateral, multilateral, and domestic (Rwandan) institutions, than upon discourses within Rwanda amongst administrators, policy-makers, and other aspects of the politicoadministrative architecture.

Donors providing direct budget support participate with the government in a series of Joint Sector Reviews (JSRs), during which sectoral progress is monitored and policy and budgetary priorities are discussed (USAID, 2011). The outcomes of these discussions are used to create a Common Performance Assessment Framework (CPAF), a decisionmaking tool for donors (with the participation of the government of Rwanda) regarding the disbursement of funds. Donors providing direct budget support also participate in twice-annual Joint Budget Support Reviews (JBSRs), during which donors discuss with government officials the budget priorities and the progress of implementation of particular sectoral programs. A working group dedicated to the agriculture sector meets monthly to share information, and monitor and discuss sectoral progress (USAID, 2011). 
However, even when international actors are deeply involved in policy- and law-making processes, the Rwandan government has tended to retain control over the broad parameters, and has refused to follow international 'best practices' where these do not fit its objectives. For example, following the promulgation of the 2005 Land Law, pieces of associated legislation as well as various regulations were drafted and published, with substantial technical input of international consultants funded by DFID and USAID (see Sagashya and English, 2010; ARD, 2008, particularly the annexes). It would be wrong, however, to assume that these laws and policies simply reflect donor perspectives. For example, the Expropriation Law (Republic of Rwanda, 2007) was criticized by donorfunded consultants for creating a situation where the state could initiate compulsory expropriation processes against citizens - using state personnel and other resources on behalf of private investors. ${ }^{76}$ Despite donor critiques that such an approach did not reflect international norms, the government has maintained this approach.

There have been signs of friction within the donor-government of Rwanda 'coordination' process. Friction can be viewed not merely from a perspective of dominance and submission (Dahl, 1957) but from a more critical understanding of the nature of governance 'tools'. Simultaneously texts and practices, governance tools such as memoranda of understanding and development targets are inherently and inescapably intertextual - referencing other 'texts', whether written or verbal, documented or mythological - and are hence open to multiple interpretations. In a

\footnotetext{
${ }^{76}$ Because the Expropriation Law includes a vaguely-worded concept of 'economic development' in the definition of the 'public interest', the state could initiate compulsory expropriation processes against citizens - using state personnel and other resources - on behalf of private investors.
} 
study of the global dissemination of 'new public management' (NPM) technologies, scholars argue that:

At the local level, interpretations of the globally hegemonic NPM discourse follow contextually defined logics, latching it onto local discourses and harnessing it for local projects that need not be grounded in the political and ideological inclinations widely believed inherent in NPM (Salskov-Iversen et al, 2000: 184).

Interpretation of policy by administrators has a significant impact on how policy is implemented (Pottier, 2002) but may be poorly understood by external actors. One agricultural specialist working for an NGO suggested that, 'there is the formal policy, and the informal policy. The formal policy is discussed here in Kigali, things are written down, and it looks nice. But then there is the informal policy. You know, here in Rwanda we have a long tradition of oral culture. The informal policy is not written, it is spoken'. ${ }^{77}$

The imihigo performance contract, discussed previously, is a clear example of an NPM technology which has been adapted to the political conditions in Rwanda. Whereas I have characterised it as a disciplinary mechanism, many donors, NGOs and some scholars consider the imihigo to represent an important tool for transparent, decentralized governance, and accept the government's cultural framing of the technology (see, e.g., Woodrow Wilson School of Public and International Affairs, 2010). They do not recognize its disciplinary elements. Unfortunately, many donors have a

\footnotetext{
${ }^{77}$ Interview with member of national NGO, Kigali, February 272008.
} 
limited understanding of Rwandan socio-politics. While donors providing direct budgetary support have privileged access to government information, statistics, etc. through their 'embedded support', they may have fewer opportunities to understand the particular context in which administrators interpret and enforce policies. Under the project-based model of development, donors typically visit 'fieldsites' regularly and receive updates on project implementation from various actors. However, under the direct budgetary support model, donors do not have any particular projects or 'fieldsites' to visit and rely more heavily on the state for information. Staff at one of the biggest donors in Rwanda, the UK's DFID, left their offices to visit rural areas on average only one day per year (Ingelaere, 2009). In addition, development agency staff have commented that there is 'not much' available in terms of independent assessment of the impacts of the agricultural policy. ${ }^{78}$ Indeed, there have been several documented cases where scientific research has been interfered with by the government of Rwanda or where the government has intervened to undermine the credibility of such research (Ingelaere, 2009: 17). It is therefore an open question to what extent donor attitudes are based on sufficient understanding of the socio-cultural and political context. Within the agricultural sector, donors have raised uncomfortable questions regarding coercion in the implementation of the agricultural policy, requiring the government of Rwanda to admit 'problems' and even to conduct a survey into farmer perceptions of the extent of coercion (Republic of Rwanda/United Nations, 2007). The survey presented aggregate responses from across the country to suggest that coercion, while

\footnotetext{
${ }^{78}$ Email communication with personnel from international development agency, July 8, 2011
} 
not infrequent, was not the norm. However, lack of micro-level data prevented an analysis of whether there may be geographical or other 'pockets' of coercion. The government of Rwanda denied that coercion was systemic and blamed it on 'miscommunication' and the well-meaning errors of individual administrators. The involvement of donors and civil society organizations may cause the government to pull back from using 'the full weight of its coercive powers' (Scott, 1998: 5). Nevertheless, as will be shown in Chapters Six-Eight coercion continues, and indeed, donors may wittingly or unwittingly support systems of discipline which are coercive in nature.

At a broader level, the Joint Governance Assessment (JGA) exercise conducted in 2008 was characterized by a high degree of disagreement between government of Rwanda and donors, and considerable friction between different donors regarding the best way to engage with the government of (Williams et al, 2009; see also Hayman, 2011: 123). ${ }^{79}$ The JGA resulted in a list of 45 governance indicators which could be used in ongoing monitoring. However, these have not been integrated into the strategies of donors such as DFID, which uses its own Memorandum of Understanding with the government of Rwanda (HRW, 2011).

The governmental frameworks within which Rwanda is enmeshed are not characterised by seamless coordination or consensus between donors. Policies towards Rwanda are motivated by the national interests of the donor government. Rwanda, for example, is seen as key to regional security interests of major donor countries, and the role of the

\footnotetext{
${ }^{79}$ Telephone interview with former staff-member of donor mission, USA (precise location withheld to ensure anonymity), January 272012
} 
foreign policy institutions is generally to 'bring Rwanda forward as a beacon in the region $^{\prime 80}$ in order to further these national security interests. Moreover, both aid agencies and bilateral foreign policy agencies have a vested interest in demonstrating that 'investments' in aid have resulted in positive impacts. No one wants to hear that money has been wasted. ${ }^{81}$ At its most extreme, such an interest can influence the entire 'framing' of a particular policy sector. Rwanda has been held up as a positive example of African 'development' in a context in which donors are actively searching for 'success stories'. One influential policy analyst (former founding Director of the International Food Policy Research Institute, and Chief Economist of USAID) argued in 2002 that:

Africa desperately needs some success stories... Of course, most of African agriculture that grew rapidly in the 1960's was largely led by the export commodities -- so there is some history of large-scale success. But now there are few ongoing success stories... Rwanda is the logical candidate for a contemporary success story. Such a success would boost morale in both African countries and in the donor community (Mellor, 2002: 18)

It appears that donors agreed with him. Rwanda -and the information generated by the various national monitoring systems- is therefore 'groomed' for success. The government of Rwanda itself is very clear that it wants to be an 'exemplary' country, a success story for other African states to follow (Sommer, 2012: 212, citing Kinzer 2008). By presenting its policies as successful, the Rwandan state attracts external funding and

\footnotetext{
${ }^{80}$ Interview with bilateral aid agency employee, Arlington Virginia, USA, May 242013.

${ }^{81}$ Interview of $13^{\text {th }}$ February 2013 with civil servant, Ottawa.
} 
political support, and may also build its credibility amongst the Rwandan population. This positioning within global development policy debates may act as a brake on outright coercion; at the same time, by claiming Rwandan exceptionalism (as discussed above) the Rwandan state seeks to justify some forms of coercion as appropriate to the Rwandan context. This desire for acceptance as a 'success' also drives the central state to choose highly ambitious development targets.

Within such a policy framework, there are few rewards for those uncovering data which runs counter to this hegemonic narrative. Indeed, donor staff may see their careers negatively affected if they question the RPF line, so they routinely 'pretend... everything's OK.' (Sommers, 2012: 21). Indeed, donors routinely practice selfcensorship, fearing sanctions from the government (Sommers, 2012: 20-21). Indeed, the range of state technologies make it easy for non-governmental, multilateral, and other non-state organizations to 'mobilize' the population for their own purposes. There are historical precedents for this: aid agencies working in Rwanda in the late 1980s and early 1990s did relatively little to denounce the coercive activities of the state, in part because they indirectly benefitted from this coercion (Uvin, 1998). This is perhaps part of the reason why most donors and many multilateral and non-governmental organizations tend to echo government of Rwanda discourses regarding the marketoriented nature of the reform, rather than acknowledging the elements of centralplanning and coercion which deviate from the liberal model. 


\section{Conclusion}

The governmentality literature suggests that the international development architecture regulates the conduct of states and their governments, which generate data in forms legible to governance systems. While aid recipient states 'choose' how to engage with networks of governmentality, they do so within a disciplinary context that restricts funding to those states that fail to participate actively and 'correctly' within governmental processes. The government of Rwanda participates actively and assertively in international systems of governmental assessment, but is vocally critical of the disciplinary aspects of such systems. The Rwandan state therefore takes on a role of ideal development subject, but in a reflexive way, recognizing that governmental systems are systems of 'control' (Kagame, 2012b) as well as consensual 'participation'. The Rwandan state has been criticised within the disciplinary technologies of the international development architecture for its coercive policies; however the long-term impact of such criticism is highly questionable.

The kinds of quantitative indicators used within such international systems of governance 'calculus' provide the government of Rwanda with an incentive to 'achieve results' through direct intervention and coercion. While Rwandan data collection is in many ways impressive (see various district-specific reports by the National Institute of Statistics of Rwanda, as well as the thematic report on agriculture) indicators are not geographically- and demographically-specific enough to allow for detailed evaluation of impacts at the local level. The 'thin' nature of data (with an emphasis on quantitative 
indicators) provides little insight into state-citizen relations or other complex dynamics that might result from this far-reaching reform. In many ways then, aggregated indicators are a 'homogenizing' technology, in the sense that they erase or obscure local differentiation. If, as suggested in this chapter, such aggregated data is presented by the government of Rwanda to external actors partially or primarily in order to attract foreign investment, this would suggest that the answer to the first part of my research question ('What effects does the increased involvement of commercial non-state actors in the agricultural sector have on the processes of spatial and institutional homogenisation, [and] standardisation') is that increased involvement is encouraging the government to provide more homogenized data, separated from the local context. Of course, this data does not necessarily reflect a reality of homogenous and uniform implementation of policy. The reality of policy implementation will be investigated in Chapters Six-Eight.

The spread of governmental technologies within the international aid architecture has resulted in the government of Rwanda gaining more control over the use of donor funds, through direct budgetary support (compared to previous project-based funding models). Such governmental technologies are associated with donor systems becoming linked to government planning processes, and with donor staff becoming 'embedded' within the Rwandan state. Rwandan civil society actors are also very important to the implementation of the agricultural policy, although they have little power within processes of planning. This suggests, in contrast to the more monolithic model of Seeing Like a State, that the Rwandan agricultural policy design and implementation apparatus 
functions as a dispositif incorporating various institutions working in a coordinated way within a similar conceptual framework. Disciplinary elements within this dispositif, that might give donors significant control over the ways in which policy is designed and put into practice, do not necessarily have a strong influence on the government of Rwanda, which remains very much in the policy 'driving seat'. This is because the government has adapted global 'good governance' concepts in ways that suit its own purposes, and because it chooses not to be influenced by some of the incentives offered for 'good conduct'. In addition, donors appear to be operating with limited information. The government's discursive framing of its own disciplinary apparatus as 'indigenous' and 'locally appropriate' makes it more difficult for external actors to clearly identify its coercive dimensions. As will be described in Chapter Five on governmentality, the coercive elements that require the population to follow the (nominally voluntary) regional crop specialization policy are part of a broader set of discourses and practices which are not immediately identifiable as part of a disciplinary machinery.

Through analyzing mechanisms such as the imihigo performance contract, I have started to develop a narrative describing how such technologies that encourage increased investment in the agricultural sector are also simultaneously methods of demonstrating policy 'success' to an international audience, and a means to 'mould ideas of citizenship'. However, tools such as imihigo, with their recourse to Rwandan cultural tropes, are arguably more successful in performing a role within the international governmentality context than actually changing the mind-sets and perceptions of Rwandan smallholder farmers. As will be described in Chapters Six-Eight, most farmers 
seem to be aware of, and opposed to, the coercive nature of such governance mechanisms. 


\section{Chapter Five: Systems of Governmentality and Discipline in Rwanda}

Changing people here is like bending steel. The people were bent into one shape over 40 years and they have to be bent back. If we do it too fast we will just break them. We have to exert pressure gradually.

Deo Nkusi, RPF regional military governor, cited in McGreal, 2013:3

We have to work on the minds of our people. We have to take them to a level where people respect work and work hard, which has not been the case in the past. You have to push and push. I hear whispers of criticism, complaints that people are being pushed too hard. I have no sympathy with that. People have to be pushed hard, until it hurts.

Paul Kagame, cited in Kinzer, 2008: 6

\section{Introduction}

This chapter describes the administrative system in rural Rwanda, and the agricultural extension system that is linked to it; particularly in terms of their combined capacity to put in place governmental technologies associated with the emergence of the 'modern farmer'. This explication will demonstrate that the 'modern farmer' ideal that is reproduced by the government and a wide variety of media, NGO, and other 
institutions, is inseparable from the wider RPF project of creating ideal 'new Rwandan citizens' who support, and are indeed enmeshed in, state policies, and programmes. The state's discursive framing of engaging in state-driven 'development' as part of every citizen's patriotic duty means that those declining to participate in state schemes risk being labelled as 'opposition' and, implicitly, against national unity and reconciliation. Through a detailed examination of the scale and 'reach' of the agricultural extension machinery, the chapter will show that different actors are involved in the agricultural reform as part of a broad dispositif with disciplinary elements as well as pedagogical ones. This supports the argument that civil society in Rwanda is not 'prostrate' so much as implicated in policy implementation. The disciplinary function of agricultural extension work is not a new phenomenon in Rwanda, but has pre-genocide precedents.

This analysis of state investment in agricultural extension capacity will also place the 'significance' of the 'modern farmer' into context, suggesting which aspects of the modern farmer trope are most important to the government.

\section{The Tools of Government in Rwanda}

\section{Historical conditions}

As mentioned in Chapter Two, analysis of the arts of government are linked to debates around state capacities. Some of these debates have been embedded in essentially western conceptions of social relations; in discussing the case of Rwanda, it is important 
to consider the local context and avoid untested assumptions derived from other examples.

Rwanda, in contrast to the stereotypical image of Africa mentioned above, has one of the highest rural population densities in the world. The area now known as Rwanda was relatively densely populated even in pre-colonial times, and the fertile soil and favourable climate found in most parts of the country allowed for permanent settlement (Vansina, 2004). ${ }^{82}$ This situation, along with the eventual use of a single language (Kinyarwanda) by all of the inhabitants, facilitated the rise of a central state, in the form of a powerful monarchy, in pre-colonial times; but there were also several 'micro-polities' found in different areas. ${ }^{83}$ Indeed, both the study areas (present-day Musanze and Kirehe Districts) are located in regions which had independent political structures during this period. In the eighteenth and nineteenth centuries, the monarchy expanded its influence and control (generally through military conquest) so that most of the smaller polities became absorbed into the central Kingdom (Newbury, 1988; Pottier, 2002: 198;). Those areas that still lay outside of central control when the Germans arrived, such as the North-West, were brought under the power of the King (Mwami) with German military support in the early years of the $20^{\text {th }}$ century. Different Kings (Mwami) adjusted the powers and responsibilities of chiefs and subchiefs in order to enhance control by the central aristocracy (Jefremovas, 1997). Each hill (the most common descriptor of the micro-level spatial environment in Rwanda)

\footnotetext{
82 Though members of the minority Batwa ethnic community were more peripatetic, practising hunting and gathering (Huggins, 2009b).

83 The extent to which the state conditioned the use of Kinrwanda, or existing use of Kinyarwanda facilitated state-building, is debatable.
} 
would typically be under the control of two or three sub-chiefs, each with different responsibilities (for example, for military recruitment; managing land tenure issues; or for organizing cattle grazing) (Pottier, 2002; Mamdani, 2001). However, the forms of land tenure over which they presided, control over labour, abilities to mobilise local men for warfare, and other characteristics of rule fluctuated over time. The Germans, and later the Belgians, used a system of indirect administration, exercising their power largely through the existing institutions. However they did intervene in these institutions to shape local governance.

These customary institutions were abolished following the so-called 'social revolution' of 1959, which led to the flight into exile of many chiefs. The newly-independent republic of Rwanda established a new administrative system which was in many ways similar to the earlier systems (Ingelaere, 2011): it was hierarchical, and extended down to the micro-level, enabling the state to closely survey and monitor the movements and characteristics of the population. The administrative system in Rwanda has been generally held to be one of the most effective in Africa, in terms of state goals of control over information (both collection and dissemination), for example. Some scholars have argued that it was the seemingly omnipresent nature of the state, and its ability to survey and communicate with the population, that partially explains the speed at which the genocide was carried out, as well as the fact that massacres occurred almost across the entire state-controlled territory (Straus, 2006; Uvin, 1998). 
Importantly, the Tutsi diaspora (composed of those who had fled Rwanda during or after 1959) also developed institutions for self-management and the reproduction of key ideas around identity when they were in exile (Lischer, 2011: 268). During the civil

war (1990-1994), the RPF ran 'political schools' to educate new recruits (Lischer, 2011: 268 citing Reed, 1996), which are generally seen as the predecessors of the contemporary ingando (Purdekova, 2011b). The RPF brought a sophisticated politicomilitary machinery to Rwanda when it assumed control over the country in 1994 following the genocide. Importantly, elements of Marxist and Maoist theory led the RPF to emphasize the importance of comprehensive social engineering in order to bring about radical social and political change (Prunier, 1998). This RPF vision was implanted directly into the state administrative and policy machinery after the genocide, while RPF elements were also enacted in parallel to existing systems: for example local RPF informers and RPF political officers reported directly to the party machinery. In many ways, the post-genocide politico-administrative system is, in its utopianism and in the effectiveness of its bureaucratic machinery, similar to the high modernist regimes described by Scott (1998).

\section{The Contemporary Administrative System}

Much of the local-level planning and decision-making activities of the contemporary administrative system in Rwanda take place at the sector level, though these processes generally involve the interpretation and implementation of directives from higher levels 
(Purdekova, 2011a). The actual business of communication with, and monitoring of, citizens usually takes place at either the level of the cell or the umudugudu, the most 'micro' level of state presence. For example, local leaders keep registers of visitors to the umudugudu. Communication with the populace is often known in Rwanda as 'sensitization' (e.g. awareness-raising, usually a one-way flow of information from the state to the citizenry) and 'mobilization' (encouraging or ordering citizens to carry out specific tasks).

The state presence at the cell and sector levels consists of both government-appointed officials (such as executive secretaries) and locally-elected officials (such as coordinators). Only appointed officials receive a salary, which makes them able to work full-time, and in practice, appointees have considerably more power than elected officials (Thomson, 2013; Ansoms, 2009: 307; Ingelaere, 2007). Thus the central government has direct control over governance at the local level. In addition, it is often reported that elections for local-level administrative positions are interfered with by the ruling party (Longman, 2011; Ingelaere, 2011). In addition to the formal positions (see Figure One below), there are also cell- and umudugudu-level committees on different sectoral issues (such as hygiene, gender-based violence, and education) with volunteer 'representatives' of different sectors of society (such as youth, women, etc.; Kartas and Jütersonke, 2012; Purdekova, 2011a). These committee structures ensure that many adult members of the local population are involved in the administrative machinery in some way. 
In addition, the police and military often have a significant presence at the local level.

While official duties are restricted to issues of 'security', in practice the security forces

have a much broader reach. Purdekova (2009) provides an example of police

interference in gacaca trials; while conducting research for Human Rights Watch in

2006, I also witnessed military interference in gacaca trials. ${ }^{84}$ Military personnel have

also threatened or beaten farmers for not following agricultural policy zealously enough

(Huggins, 2009a), and have been involved in clearing land for consolidation and

'training' residents in agricultural techniques, partly through the army's agribusiness,

Agro Processing Industries Ltd (API), and partly through ad hoc activities (Olanyo, 2011).

Purdekova (2009) also mentions the RPF's own well-developed apparatus which has

branches at every cell, sector and district, which are described by Ingelaere (2011: 68) as

'parallel channels of command and control'. In practice, the RPF activities are not

'parallel' in the sense that they duplicate or undermine the official administrative

system: rather, they reinforce elements of the official system as necessary, ensuring

coherence and loyalty to RPF tenets. The fact that many local-level RPF leaders are also

holders of important government posts ensures that the overlap between RPF and state

influence is complementary.

The interaction of a panoply of institutions involved in 'governing' Rwanda can be well-

understood using a governmentality model. On the one hand, the powerful appointed

\footnotetext{
${ }^{84}$ Observation of a gacaca in Rulindo District, November 2006, and interviews by the author with members of the gacaca judges from a jurisdiction in Rulindo District. Interviews conducted in Kigali, November 28 2006. Military personnel - some in uniform, others in plainclothes - passed notes to the judges during the trial and were very vocal members of the General Assembly (commenting on the testimonies provided); they also allegedly intimidated gacaca judges outside of the trial context.
} 
administrative personnel, military officers, police officers, RPF cadres, intelligence personnel (see below) and other individuals each act according to a separate mandate and set of instructions from above. This means that there may at times be dissonance between their short-term goals and activities. On the other hand, their actions are all embedded within a coordinated RPF 'vision' which is constantly maintained within, and disseminated from, the centre of power. The coherence of their actions within the very well-articulated RPF vision, in addition to the information-sharing and coordination which clearly takes place, means that their actions form a dispositif or apparatus which, while changing over time, remains stable.

Figure One: Organisational Chart of the Rwandan Administrative System

Level

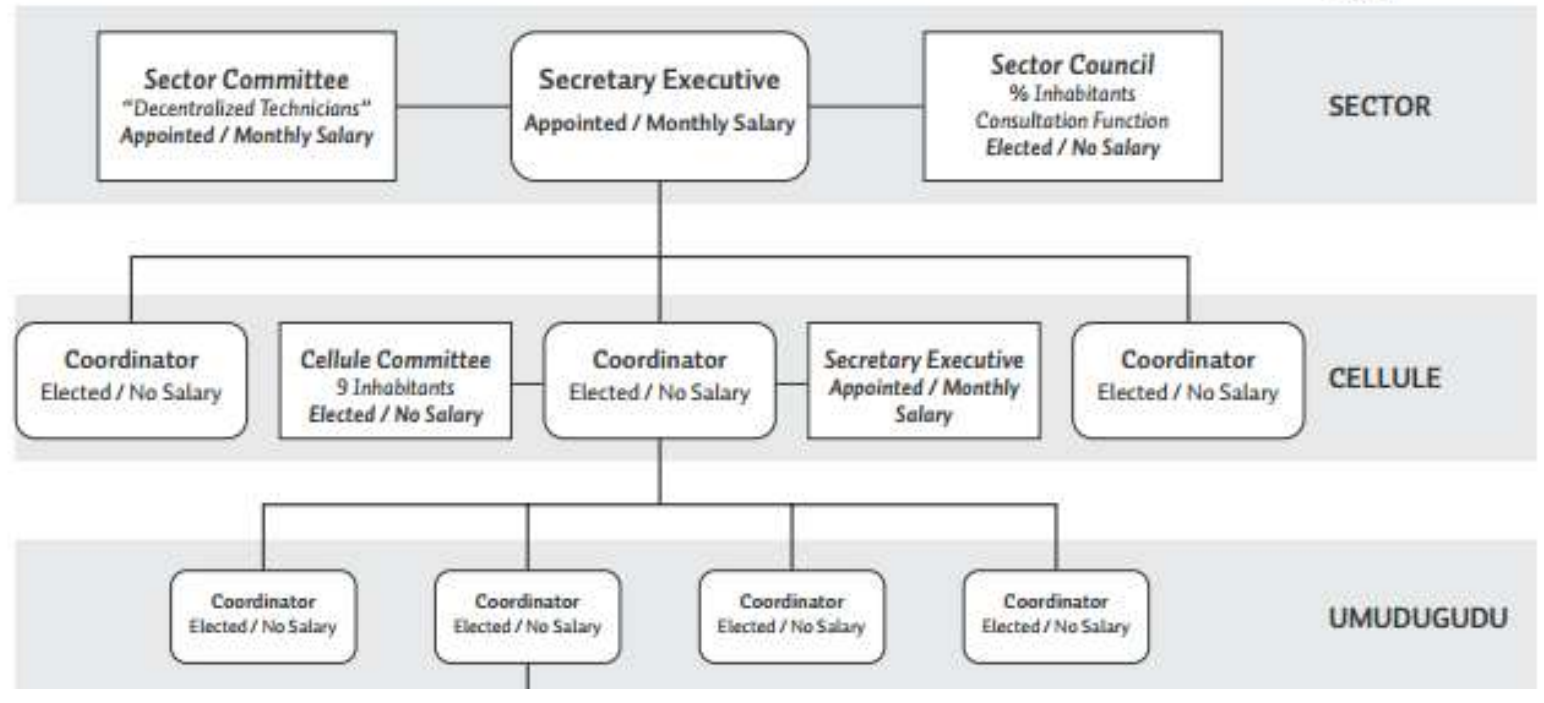




\section{Source: Ingelaere, $2007^{85}$}

Local officials control a range of mechanisms for 'sensitization' and 'mobilisation'. Some of these are formally institutionalised and scheduled, such as the umuganda communal work activities (which are mandatory and often held weekly or biweekly in rural areas). The actual physical work (such as construction or maintenance of roads or drainage infrastructure) is 'secondary', according to some observers, to the 'sensitization' activities that follow, where authorities, 'explain government policies, inform about laws and appropriate behaviour, and gather information' (Kartas and Jütersonke, 2012:23). Other mechanisms can be used on a more ad hoc basis.

As noted by Purdekova (2009), state presence is not restricted to the official activities of state administrators. Purdekova includes three forms of state presence:

(i) the 'administrative apparatus'; (ii) the 'information apparatus' that lies at its disposal; (iii) the spectrum of 'grass-roots' activities which it not only organises but through which it governs (Purdekova, 2011a: 475)

The 'information apparatus' described by Purdekova includes government informers, who are recruited by many different government organizations (Begley, 2012). The covert nature of the network of informers adds to the state's ability to exert its control over space. After all, the purpose of covert surveillance is not only to monitor dissension, but also to act as a disincentive against dissenting discourses. The mere

\footnotetext{
${ }^{85}$ The original image in the 2007 paper includes the nyumbakumi (ten household) level. This level was abolished in 2006, though there are reports of nyumbakumi being active informally after this date (Purdekova, 2011a).
} 
threat or risk of being overheard or observed by a state informant acts as a disincentive, and this threat-effect is achieved not by complete saturation of public and private space, but by the effect of 'probability' (Purdekova, 2012b). The knowledge that informants exist, combined with uncertainty regarding their identity and number, causes Rwandans to calculate the risks involved in making certain statements or performing certain actions (such as failing to attend obligatory state events), even in the absence of a visible, official state presence. The use of probability to diffuse the impacts of surveillance is reminiscent of a governmental technology, shaping behaviour at the level of the population. This insight allows us to understand some of the ways in which the Rwandan state is able to exert an influence over the spatial imaginary of the citizenry, and forces us to look beyond the mere 'vertical hierarchy' shown in Figure One above. In conjunction with the state's efforts to achieve information-sharing and cooperation between different aspects of what a senior government figure has called a 'connectedness machinery' (Nsanzabaganwa, 2012: 142), this can be seen as a version of the panopticon (Foucault, 1977: 216), an 'all-seeing' technology of discipline.

The 'grass roots' activities are many, and include, in addition to umuganda (described above), ubudehe which is a process through which, following participatory poverty ranking activities, each administrative cell receives about US $\$ 1000$ for development activities (Niringiye and Ayebale, 2012; Purdekova, 2011a). Some unpaid community labour is also devoted to itorero activities. Itorero is a civic education program emphasizing Rwandan cultural values, the need for unity and reconciliation (National University of Rwanda, 2013) and pledges of labour to various development projects. 
These are explicitly designed to enable 'a change of the mindsets' of the population (NURC, 2012a:5).

Similar to itorero, ingando camps are held to provide civic education for specific sectors of society (such as former prisoners, high school graduates, etc.) often with donor funding (Purdekova, 2011b; NURC, 2012a). RPF officials are open about their intention to change the 'ideologies' of participants through ingando (Mgbako, 2005: 211). While they have to date targeted specific sections of the population (such as demobilised soldiers, released prisoners, students, and many other groups - Purdekova, 2011b) the government wants all adults to participate in ingando at least once during their lifetime (Sommers, 2012: 39)

The imihigo system has increasingly been adapted so that it becomes has lateral or horizontal aspects as well as vertical ones (Purdekova, 2011a). For example, households are asked to sign imihigo, as well as clubs, societies, and even private corporations. Increasingly, non-state 'space' is being brought under the purview of the stateadministered imihigo system.

Other activities include speeches and government-organized celebrations of national holidays, which provide an opportunity for public dissemination of government discourses: didactic community entertainment and celebrations, known as ubusabane, are an established part of the strategy of the NURC as well as other institutions (VillaVicencio et al, 2005). Local administrators collect monetary contributions from local people for various ongoing, day-to-day state-run activities such as night security patrols 
(Kartas and Jütersonke, 2012) or ad hoc projects (such as construction or renovation of a cellule office). Termed umusanzu in Kinyarwanda, most of these contributions are optional in theory, but obligatory in practice: people who do not make contributions risk being labelled as 'opposition' - a dangerous situation in Rwanda - or seeing their access to basic administrative services, such as renewal of identity documents, compromised.

These various activities do not only represent opportunities for the Rwandan state to monitor various aspects of community life and disseminate official discourse, but also result in many citizens becoming directly engaged in ongoing state-managed activities. Citizens who become part of organizing committees or development projects dedicate many hours of unpaid time to state efforts. This limits the time available to other activities, and is arguably a useful way for the Rwandan state to prevent citizens from organizing in covert opposition to state activities. More profoundly perhaps, the involvement of large numbers of people in organizing and carrying out state-run tasks results in them being immersed in an environment saturated by state-sanctioned ideas. Rather than a model of a small number of people disseminating RPF thinking to a larger 'audience', the system instead draws large numbers of citizens into the role of organizing and reproducing the RPF discourse, so that the distinction between 'audience' and 'organizer' is to some extent blurred. This means that many Rwandans have what might be called an ongoing immersive or experiential engagement with state activities, rather than a more sporadic and passive one. In spatial terms, these 'voluntary' committees represent a means for the state - at little or no cost - to enlarge 'state spaces' and to draw private citizens into those spaces. This strategy is reminiscent 
of the governmental mode, which relies on the 'diffusion' of state power throughout society. Such institutions allow state-sanctioned ideas to circulate within the rural milieu.

However, the ways in which the state facilitates monitors and controls such institutions potentially limit their effectiveness as governmental technologies. Foucault pointed out that as governmental strategies allow for 'freedoms' and circulations of various kinds, institutions of 'police' and 'security' (in their Foucauldian senses) are put in place to manage the risks associated with such circulations. Technologies of security operate through statistical and other understandings of the population: 'its opinions, ways of doing things, forms of behaviour, customs, fears, prejudices, and requirements; it is what one gets hold of through education, campaigns, and convictions' (Foucault, 2007: 75). Based on these various forms of knowledge (which emerged from the development of entire schools and methods of study during the early modern period in Europe), state authorities can 'police' the various economic, political, social and other freedoms and circulations, through acting 'on a range of factors and elements that seem far removed from the population itself and its immediate behaviour' (Foucault, 2007: 72). Such factors and elements might include, for example, tariffs on imports, or tax breaks for corporations. This is very different, following Foucault, from 'getting subjects to obey the sovereign's will' (Foucault, 2007: 72).

In Rwanda, the instruments of diffusion of ideas of 'good citizenship', such as the clubs and associations mentioned above, are so closely facilitated and controlled by the state 
as to lose their governmental function. In one striking example, villagers concerned about the terracing and monocropping policy were advised by a state agronomist to start a cooperative. The cooperative leaders, who were appointed by the agronomist, simply ensured that government policies were followed and banned the farmers from planting sorghum, with the result that the newly-terraced land remained unused (Berglund, 2012). Here, an institution with the potential for collective, innovative action, took on a disciplinary role. The discursive and legal support of the Rwandan state for various forms of empowerment of women has also resulted in women's societies and associations being seen by some Rwandan men as instruments designed by the state to divide the typical Rwandan household. ${ }^{86}$ The strong 'stamp' of state presence upon such institutions, tends to ensure that they are perceived as structures of 'containment' rather than institutions facilitating the circulation of ideas.

As shown by Ingelaere (2007), the Rwandan state has developed a system of regulations which are broadly imposed from the centre, but are elaborated and enforced at the local level. Those who fail to abide by the regulations are punished, typically with a fine, which may be followed by detention if the 'illegal' behaviour is not rectified. These regulations include, for example, requirements that all houses have gutters and rainwater barrels, 'modern' cooking stoves, a compost bin, clothesline, an enclosed toilet, a table for cooking utensils, and an indoor drinking water receptacle; and prohibitions against selling homemade products (butter, cheese) without authorisation,

\footnotetext{
${ }^{86}$ Group discussion C of $15^{\text {th }}$ Feb 2013, Kinigi Sector, Musanze District; Interview A of $17^{\text {th }}$ Feb 2013, Kinigi Sector, Musanze District
} 
wearing dirty clothes, drinking with a straw (which is traditionally shared amongst friends and family and thus seen as unhygienic ), and walking barefoot in public (Ingelaere, 2007 and 2011). Ingelaere notes that these regulations largely result in rural Rwandans 'looking' less poor; but actually becoming poorer due to the various investments necessary to abide by the rules, as well as the significant fines, which represent a month's wages for many people (Ingelaere, 2011: 73). Many of these state interventions are linked to an aesthetic of modernity, which may not necessarily correspond to local notions of improvement.

For example, while citizens are expected to wear shoes in public, many rural people prefer to walk barefoot, carrying their shoes to be worn in public, monitored spaces such as markets or government offices. ${ }^{87}$ We would add that these regulations represent an expansion of the state's domain deep into the private sphere of the household compound. This is a new phenomenon in the Rwandan context, where the 'rugo' (household compound) has been seen as a place of household identity and autonomy (De Lame, 2005: 129) and where certain activities - particularly those associated with eating - have historically been considered private (Gravel, 1965). This state regulation of 'private' spaces and activities represents a 'totalizing' effort by the state to change behaviour: the visual uniformity and aesthetic of modernity imposed by the state regulations (e.g. every house has tiles or metal roofing; all houses have guttering and rain-barrels, a compost bin, etc.) provides a visual analogue of the 'unity'

\footnotetext{
${ }^{87}$ Personal observations, various rural areas of Rwanda, 2007-8.
} 
associated with the ideal Rwandan population; and there are few remaining spaces outside of state claims to authority and control.

In addition to Purdekova's list of activities organized by the state, we can add activities which are planned and organized by non-state entities. These are relevant to an understanding of state presence because they are vetted and approved by government officials at different levels; indeed, local officials are generally invited to participate. ${ }^{88}$ In order to make it successfully through the vetting process, activities have to broadly match the RPF's vision of 'development' and 'citizenship' and often make reference to ongoing government campaigns. Some non-state activities may consciously or unconsciously provide potentials for counter-narratives or alternative readings of development; however, to avoid suppression, such activities are embedded with state discourses and overlapping with the state apparatus, though not a stable part of it.

We can see then that the state machinery operates not just hierarchically but also 'laterally', drawing large numbers of citizens into committees, societies, anti-genocide ideology 'clubs' and other institutions. Following Purdekova (2011a) and Burnet (2008a), we can describe the networks of state activity and influence, and the demands placed upon Rwandan citizens (particularly in rural areas) as 'dense'. While recognising that government control is not absolute, and that forms of dissent can and do exist in Rwanda, Purdekova argues that the state is increasingly permeating all aspects of society, and saturating discursive space (2011a). In many studies of the administrative

\footnotetext{
${ }^{88}$ An example is the 'Farmers' Day' for pyrethrum farmers organized by commercial actors and donors, described in Chapter Seven.
} 
system (Ingelaere, 2011) emphasis has been placed on the means that it provides for political control at various levels, through the generation of data for use within multiscale government monitoring and decision-making systems. Of course, the unpaid labour of the population, channeled through umuganda and similar mechanisms, assists the government to meet its development objectives which can be plugged into international systems of governmentality (using indicators of number of roads rehabilitated, schools constructed, and similar tangible achievements).

Moving beyond an analysis that privileges 'control', Purdekova, Burnet and Desrosiers \& Thomson (2011) recognise the intertwined nature of 'development' and 'good citizenship'. This depends upon diffusion of certain ideas through discursive space, as mentioned above. A former government Minister recommends that:

More structured and systematic work has to be done by different institutions in central and local government to organize change management with a local content. There is need to create a critical mass of change managers in all walks of life of Rwandans (Nsanzabaganwa, 2012: 180; italics added)

This situation of a highly diffuse model of state presence and influence is, as mentioned previously, reminiscent of governmental approaches. Many of the technologies discussed previously involve the transformation of attitudes amongst the Rwandan population, which has long been a part of broader RPF discourse. President Kagame has also emphasized the idea that 'development' is embedded in 'politics': 
If the politics were wrong, the agriculture would not be right... Because agriculture involves Rwandans. These are Rwandans who are doing agriculture, feeding themselves, doing everything. So it's politics behind it, driving it. (Kagame, 2012c)

The themes of material development, political 'unity' and reconciliation are often discursively linked through themes of 'liberation' and references to the RPF's conflict (1990-1993) against the Habyarimana government and the regime that carried out the genocide in 1994. During the annual Heroes Day celebration, for example, when dead RPF military figures and other national heroes are remembered, Rwandans are frequently exhorted to show the same heroism in ongoing 'struggles' against poverty. Citizens are asked to work at the 'frontline' of development (Desrosiers and Thomson, 2011: 45). During celebrations in 2009, and referring specifically to the goal of achieving national financial self-sufficiency and doing without foreign aid, President Kagame: '...strategically bonded this economic liberation struggle with our past struggles for people's basic rights to justice, education, healthcare, as well as all the freedoms for which our heroes stood up' (Munyaneza, 2009).

During preparations in 2012, local authorities in Kamonyi told residents that: 'Heroes worth remembering include; fallen heroes like [former RPF Commander-in-Chief] Fred Gisa Rwigema and living heroes who have continued to develop the country' (Gahiji, 2013). This conceptual merging of the RPF military campaign and the ongoing government-led programme of national development creates a discursive field of power 
relations in which 'good' citizens are patriotic; and that those who don't follow government policies are unpatriotic. It implies that resistance to government ideas of 'development' also represent a refusal to 'reconcile' and embrace 'unity'. It is then a short and slippery conceptual slope towards resistance to the government being seen as 'divisionist' (Sommers, 2012: 21): as essentially genocidal. In order to understand the sub-texts of morality and nationalism which underpin 'development' activities it is necessary to briefly examine the literature on 'reconciliation' in Rwanda.

These will show that the RPF therefore seems to be highly politically invested in the potentials of governmentality. At the same time, and as discussed throughout this dissertation, the contemporary Rwandan socio-political system is structured by mechanisms of surveillance, control, and coercion, reminiscent of disciplinary technologies rather than processes of subjectification. There is an inherent tension in the RPF political programme, which is founded upon the idea that a new, self-governing citizenry can emerge through process of critical reflection; but also demands complete, uncritical adherence to government policies and programmes.

\section{'Eradicating Genocide Ideology' and 'Promoting National Unity and Reconciliation' in Rwanda}

It is important to state at the outset of this discussion that there are several dimensions to the government's actions in 'promoting national unity and reconciliation' and ending 
'genocide ideology', many institutions involved, and many different theoretical lenses through which it may be understood. ${ }^{89}$ From a Foucauldian perspective, Turner (2011) has noted that the campaign against genocide ideology has aspects representing both bio-political and sovereign modes of government: elements of government policy affirm that mentalities may be changed through re-education, yet other elements involve punishment for those accused of having this 'ideology', often based on flimsy evidence.

Purdekova (2012) contends that activities conducted in the name of unity and reconciliation are most accurately seen as part of a broader effort to pursue 'development' and 'progress'. Working very explicitly under the assumptions that 'poverty generates conflict', and that unity and reconciliation can result from economic development, government civic education and other activities framed as promoting unity and reconciliation include 'education' on agricultural 'modernisation', the importance of savings and investment, and other economic themes (Purdekova, 2012).

Development and progress are associated with self-reliance, defined as a move away from support from foreign donors or NGOs, as well as greater individual responsibility (Zorbas, 2009) as per the neo-liberal ideal of the self-governing individual. The theme of self-reliance occurred more often in Presidential speeches (between 1994 and 2005) than any other facet of 'reconciliation', according to Zorbas (2009: 99). ${ }^{90}$ Importantly,

\footnotetext{
${ }^{89}$ The following discussion of the campaign to eradicate genocide ideology does not consider the broader party-political or social effects of the campaign, and indeed does not consider the ways in which those formally or informally accused of genocide ideology were treated within the socio-political milieu or the justice system (see for example Cowell, 2012; Waldorf, 2011; Amnesty International, 2010). I restrict the discussion to the elements of (re)education within the campaign, in order to draw inferences for the study of governmentality in Rwanda.

${ }^{90}$ In total, Zorbas analyzed 44 Presidential speeches which contained some references to reconciliation.
} 
the construction of a new kind of citizen is explicitly linked in some state discourse with a form of entrepreneurship, 'loving work' (NURC, 2007: 7) and 'working hard' (Kagame, 2011; cited in Nsanzabaganwa, 2012: 8) ${ }^{91}$ and the encouragement of capitalist growth. Government slogans broadcast on radio and television such as 'Kwihesha agaciro' (translated as 'fight for your dignity'), and 'Kwanga gusindagizwa' ('refuse dependency') (Nsanzabaganwa, 2012: 148) discursively link dignity and development so that those seen as reluctant to 'develop' are seen as a national embarrassment: Kagame has repeatedly described hunger as 'shameful' (Riungu, 2011). The implication that the poor can escape their problems through 'hard work' echoes the neoliberal governmentality model, with its emphasis on self-help.

Self-reliance is also associated with critical awareness, which accords with the emphasis on the need for innovation to achieve an entrepreneurial model of development (Kagame, 2009). Kagame has stated that, 'we [Rwandans] need to be the agents of our own development' (Kagame, 2011; cited in Nsanzabaganwa, 2012: 8). ${ }^{92}$

RPF officials contend that in order to create a new citizenry, the government must help Rwandans to 'develop the capacity for independent critical thought' (Zorbas, 2009: 137; NURC, 2007: 8), and to 'fulfill his or her auto-realisation' (Nsanzabaganwa, 2011: 10). In order to do this, many RPF officials argue that Rwandans should be encouraged to express their thoughts - including critical ones - openly (Zorbas, 2009). This is in order

\footnotetext{
${ }^{91}$ The speech is not properly cited in Nsanzabaganwa, 2012. Only the date is provided: 16/3/2011.

${ }^{92}$ As mentioned above, the speech is not fully cited: only the date is provided: $16 / 3 / 2011$.
} 
to avoid the 'blind obedience' that had allowed Rwandans to be manipulated to commit genocide (Musoni, 2007: 12).

It is this idea of the responsible, self-governing individual that creates a logical paradox for the government project of 'reconciliation'. For by definition, the self-governing individual makes up his or her mind within a sphere of (relative) mental autonomy, through a process of critical reflection.

However, diversity of opinion is conceived of by various state bodies as part of the Rwandan 'problem', not the solution. An organizer of ingando maintains that participants 'must have one way of looking at things, especially government policy' (cited in Purdekova, 2011b: 14). The national policy on Unity and Reconciliation, for example, includes the following in the list of 'obstacles' to reconciliation: 'Mixing feelings with analysis of the country's problems due to division, genocide ideology, individual interests... Various interpretations of history [sic] of Rwanda' (NURC, 2007: 5).

Furthermore, the National Unity and Reconciliation Commission (NURC) actively fosters support for state policies amongst the population. The NURC strategy includes mobilizing Rwandans to 'respond positively to Government programmes' and 'implement State programmes' (NURC, 2007:10, 16). It seems that the critical reflection that the new Rwandan citizen is to embody should not be applied to state activities, and that the 'self-reliance' and 'self-development' (NURC, 2007: 16) expected of individuals and communities should not take away from their responsibilities to simply follow state policies. This position is a 'circular' logic 
identified by Foucault as a position of the sovereign: 'the good is obedience to the law; so the good proposed by sovereignty is that people obey it' (Foucault, 2007: 98).

This paradox - the attempt by the state to create a critically-aware, self-governing citizenship through imposing government programmes on the population, and insisting that these programmes should not be criticized - has its corollary within the agricultural sector. Calls for modernisation, professionalization and commercialisation are based on an implicit or explicit model of the farmer-asinnovator, adapting to market conditions and technological changes. However, agricultural policies of crop specialization, obligatory purchase of fertilizer, and mandatory sale of produce to 'approved' buyers tend to restrict, rather than increase, the range of options open to Rwandan farmers and hence stifle adaptation.

\section{Creating an Ideal Farmer: Governmentality in the Agricultural Sector} ...there is also an improvement of [the farmers'] mentality... with the district authorities, we found strategies for trying to change the mentalities of the farmers without brutalizing them. ${ }^{93}$

\footnotetext{
${ }^{93}$ Interview B of 29 April 2011_with two agronomists for major farmer's organization, Ruhengeri town.
} 
Having looked at the local-level state apparatus, we now turn specifically to the agricultural sector to identify some of the tools and mechanisms that the state has at its disposal to create 'modern farmers'. As mentioned previously, aspects of the 'modern farmer' trope are reminiscent of pre-genocide state discourses on agriculture. The Habyarimana regime developed an official discourse that honoured manual labour, and agriculture in particular (Desrosiers and Thomson, 2011; Verwimp, 2003, 2006). However this discourse of hardworking, nationalistic peasants was intended to create particular kinds of subjects: those who would work hard, unquestioningly, to produce export crops - notably coffee and tea (Verwimp, 2006), and to a lesser extent pyrethrum - for the benefit of the state, and also to grow sufficient foodcrops to sustain the population, without expecting significant state assistance. The government communicated that although the peasants possessed the capacity to build the nation, 'they needed to be 'energised' and 'guided" by the state (Desrosiers and Thomson, 2011). After 1959 the local administration was, to different degrees at different historical moments, an instrument for extraction of rural surplus and coercive political 'mobilisation'. In particular, the continued use of unpaid umuganda labour during the Second Republic, the deployment of colonial laws prohibiting a switch away from cashcrops such as coffee, and the use of the paysannat farm production model in certain areas, all point to continuities in the form of the rural subject. It is mechanisms such as these that enabled the Rwandan state to turn much of the countryside into what resembled a 'labour camp' (Uvin, 1998: 135). 
Urban populations, while subject to monthly umuganda, were largely exempt from many of the forms of state extraction of value from peasant labour. Official administrative controls were placed on the movement of citizens around the country, particularly movement from the countryside into the towns. Official state rhetoric glorified the rural life, emphasizing the contributions of farmers to national development goals, and warned of the 'corrupting' influences of urban centres (Verwimp, 2006). However, farmers were expected to fulfill a narrow subject-category. The agricultural extension framework was, and still is, central to state projects of intensification and/or reform. Historically, state extension services have remained institutionally similar to the top-down, highly coercive colonial model, which made chiefs responsible for ensuring that quotas for coffee production were met. Chiefs used the unpaid ubureetwa labour of the local Hutu population to meet those quotas, as well as to work on the chief's own private farms (Newbury, 1988: 142). After independence, the extension service continued to prioritise cash crop production over subsistence production. International aid agencies noted that their extension methods, focused on 'training and visits', were paternalistic, and that extension officers were accountable not to the smallholder farmers, but rather to their superiors in the institutional hierarchy.

Agricultural extension workers had little interest in learning from local forms of agricultural knowledge, treating 'scientific' knowledge as inherently superior. Modernity was associated not only with objective indicators such as yields, but also aesthetic factors such as the 'neatness' of plots (with intercropping seen as messy in 
comparison with monoculture) and value judgments attached to crop choices (Pottier and Nkundabashaka, 1992: 161). In addition, power relations were highly gendered, with little attention paid to the activities and knowledge of women. In summary, 'interaction [between agronomists and farmers] boils down to a one-way, dogmatic delivery of textbook instructions' (Pottier and Nkundabashaka, 1992: 151).

During the first two decades of the post-colonial period (1962 to 1980) farmers failing to achieve 'targets' assigned to them by agronomists could expect to be punished (MINAGRI, 2009; Uvin, 1998: 133). The government planned to confiscate land if it was not adequately used (Pottier and Nkundabashaka, 1992), though this policy was not implemented. From the mid-1980s on, the Habyarimana regime implemented an agricultural intensification policy and also promoted greater regional specialization in agricultural production. 'Packages' of inputs and techniques that were centrally developed and disseminated to farmers were never open for debate or redesign through farmer consultation. Agricultural extension officers were seen by the local people as 'policemen' (Newbury, 1992: 207). Importantly, even programmes that built upon local knowledge were subject to re-interpretation and appropriation by powerful local interests, especially local administrators, who used them 'for the purpose of control' (Pottier, 1999: 183). When incentive programmes were put in place, such as the 'model farmer' system or competitions for the most productive farmer, these were often dominated by the wealthy (Uvin, 1998: 133). 
Nevertheless, for a variety of reasons, international donors and many NGOs continued to enthusiastically support the Rwandan government. The World Bank implicitly supported the coercive mobilization of community labour, for example, stating that 'the objective should be to capitalize on the energies and resources of local people' (Newbury, 1992: 205). This support continued even as the repressive nature of rural 'development' became linked to corruption in the mid-late 1980s, and overt oppression of the Tutsi minority increased in the lead-up to the 1994 genocide.

Following the genocide, the existing extension system was reinstated, but was primarily involved in the distribution of emergency relief items (Tizikara et al, 2007); it was dismantled in 1998, apparently in order to reduce costs associated with a system perceived as inefficient (ibid). During this period, the government was investing time and resources in questions related to national security, the justice system, and other sectors. The agricultural sector was arguably a lower priority for the government, allocated few public funds (Booth and Galooba-Mutebi, 2012).

In the early 2000s, studies were conducted in order to plan for restructuring agricultural research capacity and extension services. They found a fundamental disconnect between national research institutions and extension services, with little regard paid for farmer demands (Tizikara et al, 2007).

In the mid-2000s, the extension system was taken out of the control of the Ministry in charge of Agriculture, and placed under the Ministry for Local Administration (MINALOC). MINALOC is generally considered to be one of the most powerful Ministries, 
with significant financial resources as its disposal as well as control over the allimportant local authority structure. It has much less technical capacity, however, regarding the agricultural sector, and the disconnect between the agricultural research sector (still largely affiliated with MINAGRI, though institutionalised in several different organizations) and the extension sector (run by MINALOC) has been remarked upon in several assessments of the agricultural sector (e.g. Swanson et al, 2011; Tizikara et al, 2007). MINALOC is in charge of the disciplinary machinery described above.

The current extension system is much smaller, in terms of numbers of personnel, than the pre-1998 model (Tizikara et al, 2007). There are approximately 969 agricultural extension staff at District and Sector levels (AEASW, 2012), working in 30 districts and 416 sectors. Given that the average population of a sector is more than 26,000 people, it is difficult for extension staff to maintain a face-to-face relationship with farmers. ${ }^{94}$ Indeed, some extension staff are unable to work full-time on the farming sector, being given responsibilities outside of the farming sector, such as monitoring the construction of housing (Swanson et al, 2011). It is not surprising then, that a survey in three Districts found that only 37 percent of respondents received agricultural advice from the state (Concern Worldwide, 2010).

This reflects state spending patterns. The vast majority of the CIP budget was spent on material inputs - seeds and fertilizer -while only 3.37 percent was used to pay for extension service providers (IFDC, 2010). In areas under the CIP, extension workers are recruited and managed by the service providers (corporations or cooperatives) that

\footnotetext{
${ }^{94}$ The official population figure of Rwanda for 2011 was 10,718,379 (NISR, 2013).
} 
have the local CIP implementation contract. According to the CIP policy, there is one proximity extension agent to every 500 ha in land use consolidated areas (IFDC, 2010). These extension agents work only on the priority crops under the CIP. An independent assessment of the CIP found that extension workers lacked training materials and required re-training (IFDC/Catalist, 2010).

In addition to the government extension system, there are pilot government programmes, NGO projects, and volunteer-based systems. These include, for example, the MINAGRI managed and Belgian-financed National Agriculture Extension Support Project (PASNVA) ; programmes run by religious development and relief organizations such as Caritas and Catholic Relief Services; systems put in place by international NGOs such as Concern; structures introduced by Rwandan farmers' organizations such as INGABO and IMBARAGA, and private extension services which are sometimes contracted by the larger and more wealthy cooperatives or farming companies. In some cases, agro-processing firms may provide extension services to outgrowers or cooperatives (under contract farming arrangements) (Booth and Golooba-Mutebi, 2012). All such programmes emphasize the ways in which they closely follow and support the country's agricultural policy (e.g. PASNVA, 2012; Concern Worldwide, 2011). Many also include training for local government officials in the implementation of the policy (e.g. PASNVA, 2011).

Their goals and activities are so closely aligned with government programmes that during interviews, some civil society actors conflated government programmes their 
own 'non-governmental' activities. Interviews with local representatives of a major farmers' organization demonstrated that, like the government, NGOs take a direct role in the establishment of farmers' cooperatives. One respondent said that, 'We advise them [farmers] to work in groups of 20-25 people - we group them according to the number of hectares [of their fields], then they can become cooperatives.... When they have been convinced to form the groups, then we start to transmit or transfer our techniques. ${ }^{95}$ The activities of the NGO are based entirely on government priorities, in particular the targets of the Crop Intensification Programme, as laid out in local imihigo contracts: 'we have targets that have been provided by the Ministry of Agriculture, while some targets are given by the District [authorities]... each sector-level trainer works to achieve these objectives. ${ }^{96}$ Like the authorities, some local civil society representatives are very clear about their intention to change not only the behaviour, but also but the socio-political identity of farmers: 'with the district authorities, we found strategies for trying to change the mentalities of the farmers without brutalizing them. $^{\text {97 }}$

In addition to those agricultural extension workers who are contracted and paid, there are also a number of farmers who have been trained under various aspects of the programmes outlined above as volunteer 'mobilisers', or 'model farmers'. Such farmers are encouraged to train their neighbours. Such efforts, while common, are not systematic and are not formally overseen or regulated by state agencies.

\footnotetext{
${ }^{95}$ Interview B of 29 April_with two agronomists for major farmers' organization, Ruhengeri town. ${ }^{96}$ Ibid.

${ }^{97}$ Ibid.
} 
At the District level, the agricultural officer is typically a university graduate; at sector level, he or she will usually have a diploma (Hakizimana, 2007). However, colleges and universities providing training in agricultural extension currently provide training only in 'technical', biochemical, aspects of the role. Training in the principles of pedagogy (instruction, demand-led priority identification, participatory methods, etc.) or management is not provided (Swanson et al, 2011).

In summary, the government's agricultural extension system is very thinly-stretched, under-funded, and under-trained. The extension model is explicitly pluralistic, relying heavily on the activities of NGOs and private contractors. Further, government plans to gradually disengage from direct extension service delivery (MINAGRI, 2009). These facts seem odd, given the state's constant emphasis on the central need to educate farmers in order to change their mindset. Extension workers would seem to be well-placed to play this governmental role, given their involvement in the mechanics of agricultural intensification. Why then would the state invest so little in agricultural extension?

\section{The Agricultural Extension System and Governmentality}

The realization that the extension system is so skeletal also leads us to question the relevance of the most common reading of the 'Seeing Like a State' narrative to explain contemporary Rwanda: the idea that the state tends to exert its power directly on citizens and landscapes through the implementation of a blueprint approach via a vertical hierarchy of state officials. Of course, state officials are indeed key players, and 
the fact that the extension services were placed under the powerful Ministry of Local government attests to the importance of state control over farming. However, this vertical extension hierarchy stops at the sector level. This is partially explained by the fact that state intervention in the agricultural sector is not only technical and pedagogical in nature but is also disciplinary and coercive. Cell- and umudugudu-level administrators, despite a lack of agricultural training, can therefore play an important role in monitoring the conduct of local people and enforcing the various obligations associated with the agricultural reform, as was reported by many informants including administrators themselves. ${ }^{98}$

However, an equally important aspect is that those working in the agricultural extension sector at the cell- level, the primary zone of direct contact with farmers, are not state employees but private contractors working for NGOs or firms, or volunteers. Here we notice another difference from, or at least a modification of, one of the key elements of the 'Seeing Like a State' model: 'a prostrate civil society' (Scott, 1998: 4-5) which is 'incapacitated' (ibid: 89). In Rwanda, the key role played by international and local NGOs, and indeed the extent to which civil society organizations have actively celebrated the reform (see e.g. Concern Worldwide, 2011) suggests that the reality is more complex than Scott's theory suggests. Rwandan civil society organizations have indeed been severely curtailed in terms of their ability to publically critique the reform; but they are not 'incapacitated' in terms of their ability to conduct activities in the field.

\footnotetext{
${ }^{98}$ See e.g. interview D of February 142013 in Mahama Sector; location withheld to protect anonymity
} 
If anything, the agricultural reform has provided opportunities for NGOs to expand their activities and to grow in social status.

This information provides four insights into the agricultural reform and Rwandan government claims that it can create 'modern farmers'. First, given the 'dense' and intertwined nature of the state machinery, it would be misleading to present the agricultural sector as a completely separate sphere from the broader administrative sphere described above. Various mechanisms and programmes - such as ingando, umuganda, and itorero - include promotion of the 'Green Revolution' paradigm and the government's vision for commercialisation of the agricultural sector. Highlighting what she calls the 'interpenetration of themes', Purdekova (2012: 199) discusses how the Executive Secretary of NURC lectured not only on reconciliation, but on the importance of the 'economic revolution and the green revolution'. Researchers and the government emphasize how growing coffee can promote reconciliation (Boudreaux and Ahluwalia, 2009) and local authorities routinely lecture citizens on agricultural production and intensification (RIU, 2009). There are therefore systematic thematic interlinkages and forms of institutional cooperation between different elements of the Rwandan state. This is an attempt at governmental 'diffusion' of ideas.

Secondly, commercialisation of the agricultural sector is being promoted not only through training, but also through the broader state policies of monetization of the rural socio-economic sphere. While this was not a main focus of the research, interviews provided data on the array of payments that farmers make, under various degrees of 
state pressure (ranging from explicit obligations to pay for state services, to informal pressure to make 'voluntary' contributions to the RPF, for example). These act as an extra 'push' factor, forcing commercialisation. Taxation, fines, and user fees of various kinds all contribute to a financial burden for local people. For the vast majority of the rural population, the main means of generating cash to meet these various demands is to sell more of their harvest or household assets (such as small livestock). While many rural households have somewhat diversified livelihood strategies (incorporating petty businesses, for example) agriculture still remains the main source of income and food security for most people, and selling foodcrops is the simplest way to generate cash in a hurry. $^{99}$

Thirdly, and related to the point above, is a sense that the RPF's decision-making elite is not particularly interested in the details involved in training Rwandan farmers to be technically proficient in land husbandry and agricultural intensification. Their interest is, instead, in creating a group of farm-managers more conversant with accessing a bank loan, or managing a casual labour force, than the micro-practices of cultivation. In one concrete example of where the priorities lie, a cooperative in Musanze that was established by a powerful local RPF leader (discussed in more detail in Chapter Six) relied upon hired agricultural workers, rather than insisting on each householder becoming trained and cultivating themselves. This pattern likely stems from a combination of factors, including the dismissal of agriculture as a low-status activity (a

\footnotetext{
${ }^{99}$ Approximately 66 percent of household production, on average, is consumed in the household (Concern Worldwide, 2010).
} 
bias long-held in Rwanda) and the RPF emphasis on a particular, technology-driven, view of 'modernity'. ${ }^{100}$ As in several of Scott's case studies, the state is more interested in a visual aesthetic, or an idea of modernity, than the exact scientific and technical processes that are involved in a transformation of production systems. An additional factor driving this approach, and one that may be more decisive, is that local authorities are under pressure to meet imihigo targets (e.g. those requiring a certain number of hectares to be put under commercial crop plantation). Rather than investing in the technical expertise of individual farmers, the authorities have often found ways to bring in external mechanisms to increase production. In Kirehe, for example, sector authorities mobilised prisoners to cultivate fields, under the community service known as travail d'intérêt général, or TIG (see Chapter Eight).

A third way of understanding this emphasis on the 'managerial' aspects of farming is that one of the main objectives of the government is not (only) to increase agricultural production, but to change the nature of the relationships between land, labour, and agricultural production. To use Polanyi's language, the extension system (and broader administrative machinery) is helping to separate agricultural activities from the social context in which they are embedded, resulting in a monitization or commercialization of the smallholder farming system.

\footnotetext{
${ }^{100}$ The celebration of the 'modern farmer' is, in part, based on a conceptual separation between so-called 'modern farming' and customary agricultural practices.
} 
Fourthly, the skeletal nature of the agricultural extension services, combined with the ambitious targets in the local imihigo contracts, means that agricultural technicians are likely to focus heavily on the cultivation of CIP priority crops and the inputs associated with them (particularly artificial fertilizers). Such a focus on particular crops detracts from the broader discourse of 'entrepreneurship' and innovation, and is likely to make farmers feel that their role within the reform is to merely implement state-directed policy, rather than to be the architects of their own livelihood transformations. This is certainly the case in Kirehe, as will be shown in Chapter Eight.

\section{Conclusion}

This chapter has described the similarities between the Rwandan local government bureaucracy and the authoritarian high modernism model (Scott, 1998). However, through reference to Foucauldian notions, I have argued that the state machinery does not rely only on the kinds of coercive functions emphasized by Scott, but also on the diffusion of government ideas of 'good citizenship' through myriad associations, clubs, committees and other institutions at the local level, which represent an attempt to saturate discursive space (Purdekova, 2012a) and block alternative ideas. There is an inherent tension between the two dynamics, because coercion relies heavily on systems of containment, while the governmental concept of creating an 'ideal development subject' requires the circulation of ideas and people. A further tension was identified within this model of the ideal development subject, or its sub-type in the agricultural sector, the 'modern farmer'. In reference to the research question, processes of state- 
building intended to create a New Rwandan ideal development subject are intimately bound up with capitalist notions of development which emphasise commodification and commercialisation. The model of an 'active', development-oriented citizen is based, in part, on the capacity for the individual citizen to critically analyse the various systems that he or she sees around him or her, in order to identify solutions and initiate capitalist 'development projects'. This idea of critical thinking is, however, at odds with another key component of the government's concept of the ideal citizen: complete compliance with government programmes. A parallel relationship is the emphasis on innovation and entrepreneurship in the 'modern farmer' trope, which contrasts with the government's demands that all farmers abide by the crop specialization policy, purchase particular kinds and amounts of seeds and fertilizer, and sell produce to particular firms or cooperatives. While the government attempts to intertwine 'discourses and practices of (neo)liberalism in the agricultural sector' with 'state efforts to mould ideas of citizenship, development, and governance', as mentioned in the research question, there are contradictions in this approach which, as we will see in Chapters Six-Eight, are evident to many smallholder farmers.

Following my examination of the extension system, I noted that the actual numbers of government-recruited and paid agricultural extension officers 'on the ground' is relatively low. This means that the government relies heavily on extension staff who are trained, managed and paid by commercial and not-for-profit organizations, and reinforces the importance of the Foucauldian idea of the dispositif. Rather than simply incapacitating civil society organizations, the government has provided opportunities 
for NGOs to expand their activities and to grow in financial turnover and social status, while restricting the possibility that such non-state actors might facilitate or allow agricultural practices which do not align with government policy by ensuring that all government staff are engaged in monitoring and enforcement. As mentioned in Chapter Three, the business model of some civil society organizations includes the sale of services and inputs to farmers, as well as the purchase of crops from farmers. It can be seen then that the increased involvement of non-state commercial actors in the agricultural sector' mentioned in the research question can include membership-based farmers' organizations, as they have commercial functions. By aligning themselves with government systems of spatial and institutional homogenisation, standardisation and coercion, such organizations can maximise their profits. As such, their incorporation into the agricultural reform dispositif, with a restricted ability to advocate for changes to the policy (as described in Chapter Three), reinforces homogenisation, standardisation and coercion. 


\section{Chapter Six: Agricultural Cooperatives in Musanze District}

\section{Introduction}

This chapter starts by providing an overview of the implementation of the Crop Intensification Programme (CIP) in Musanze District, Northern Province. It notes that cooperatives themselves are far from homogenous in nature, though they are limited by the need to abide by government policies on crop cultivation, including regional crop specialization. While some cooperatives are formed through government 'mobilization', others are founded by smallholder farmers, or entrepreneurs who do not themselves engage in farming. While entrepreneurs may be 'independent' from the state, the state policy favouring cooperatives provides them with a discursive and institutional framework for exercising control over the land and labour of large numbers of smallholders. The chapter presents the example of a maize and potato-producers cooperative which was founded by an entrepreneur. Contrary to the apparent dichotomy between 'market' and 'state' dynamics in Scott's (1998) framework, the entrepreneur, operating on market principles, followed a similar homogenization model to state-imposed farms under the Crop Intensification Programme, and deployed coercive strategies. The cooperative became an instrument for primitive accumulation, through purchase of land at below-market rates, for example. This primitive accumulation was possible in part because of the failure of the authorities to respond to members' concerns over management of the cooperative, but also because of the particular capacities of the entrepreneur, who was able to intimidate many local people. 
Nevertheless, some citizens engaged in various forms of 'resistance' to the policy entrepreneur.

The case study illustrates the ways in which private actors may, independent from state prompting and oversight, use the same homogenizing technologies while relying on particular 'local' dynamics to ensure their influence and control over agricultural institutions such as cooperatives. As such, it demonstrates the particularly contextspecific power relations which determine the degree to which the agricultural intensification policy is implemented at the local level.

\section{Background on Musanze District}

Musanze District, Northern Province, is a well-watered area with fertile soils, due to the chain of volcanoes that represents the Northern Rwanda-Democratic Republic of Congo (DRC) border. Its generally favourable agro-ecological profile, as well as its ability to reap the benefits of the tourist industry and (less directly) some of the profits from the crossborder trade with DRC, make it a useful field study site to contrast with the much drier and generally poorer Kirehe District. While population displacement occurred during the post-genocide insurgency and counter-insurgency period (1998-2000) most households were able to return to their houses and continue to cultivate the same fields that have been in families for generations. Fieldwork results suggest that the relative socio-economic stability in the area and longer family histories within particular places has provided some powerful families with tools to actively resist certain aspects of the 
agricultural reform (as we will see in the case study below). This is in contrast to Kirehe, where more widespread and recent patterns of migration and settlement mean that families have few kinship-based support networks, shorter histories in the areas where they now live, and where 'resistance' is much less overt in nature.

\section{Implementation of the National Agricultural Policy in Musanze District}

Musanze is generally a highly productive agricultural area, with four different agroecological zones providing good conditions for a wide range of crops (National Institute of Statistics of Rwanda [NSIS], 2010; Wennink, B. and W. Heemskerk 2006). Since the introduction of the Crop Intensification Programme (CIP), the officially sanctioned crops in the area include potatoes, wheat, and maize. Other crops are still grown, but farmers are under pressure from state agronomists and local authorities to devote the majority of their land to these commercial crops.

In May 2011, there were 100 legally-registered cooperatives in Musanze District, of which 28 were agricultural cooperatives ${ }^{101}$; by December 2012 this figure had increased to 163 , of which the majority (47) were agricultural cooperatives (RLDSF, 2013). These include producer and marketing cooperatives. A major farmers' organization has an office in Ruhengeri town, and a strong presence throughout the district. It has played a significant role in the implementation of the policy, especially in terms of promoting the establishment of cooperatives and providing extension services for CIP crops. However,

${ }^{101}$ Interview A of May 2 2011with B. D., District employee. 
these dynamics did not prevent the use of coercion in the agricultural sector, as will be described.

The attempts to implement the agricultural policy in 2008 got off to a difficult start, and coercion by state officials was in evidence in the District, as it was elsewhere. A few examples are provided here, in order to illustrate the 'top-down' and coercive nature of the policy implementation process.

In most parts of the District, the key crop for the early 2008 season was potatoes.

Farmers were told to purchase a specific variety, 'kinigi' potatoes, which are the highest quality and hence the most expensive. ${ }^{102}$ Some farmers complained that they could not afford them. According to local NGOs there were insufficient amounts of seed potatoes available in the Province to allow all farmers to plant them, a problem confirmed by a state Agronomist (Mukombozi, 2008). ${ }^{103}$ Nevertheless, authorities continued to insist that farmers plant potatoes, stating that they would be fined if they had not planted by the third week of February 2008. ${ }^{104}$ Government agronomists have denied that fines were imposed, but did concede that those 'who really opposed the policy' would be fined. ${ }^{105}$ Security personnel at the sector level told residents of many sectors that if they did not plant the required crops at the same time as other members of cooperatives, other people would be brought to cultivate their land. ${ }^{106}$ In the season $\mathrm{B}^{107}$ in early

\footnotetext{
102 Kinigi seed potatoes cost up to $350 \mathrm{FRW} / \mathrm{kg}$ (US \$0.59), while cheaper varieties are available at about $150 \mathrm{FRW} / \mathrm{kg}$ (US\$ 0.25).

103 Interview with government Agronomist, February 252008

${ }^{104}$ Interview with members of local NGO, Musanze District, February 252008.

105 Interview with government Agronomist, February 252008

${ }^{106}$ Interview with members of local NGO, Musanze District, February 252008
} 
2009 , local officials threatened to uproot all crops other than maize, which was the government-approved crop for that season (Twizeyimana, 2010). The governmentapproved maize seeds were late in arriving in the District, and many farmers planted other crops instead. In some areas, these crops were uprooted and replaced with maize on the orders of the authorities once maize seed had arrived. ${ }^{108}$

Those living in areas designated as 'model hills' (agasazi ndatwa) were under particular administrative scrutiny and pressure to conform to the crop specialization policy. One farmer in Musanze, who is also a local-level administrator, revealed that:

They chose my field as a demonstration field because it's by the road and it can be easily seen by people. The choice was made by the authorities, who had a meeting, and chose it. They came to us telling us it was Agasozi Ndatwa after we had already planted beans there, as usual. ${ }^{109}$

He had to uproot the beans to accommodate the CIP priority crop. The local authorities have uprooted the crops of other farmers in agasozi ndatwa as well. ${ }^{110}$

\footnotetext{
${ }^{107}$ Some parts of Rwanda have three planting seasons (A, B and C), while other parts have two seasons (A and $B)$. Season $B$ is the most important season, as it is timed to benefit from the long rainy period (typically mid-February to mid-May). Season B is therefore the potentially most profitable season. Season A benefits from the short rainy season (start of September through to mid-November), while season $C$ (crops planted in June) benefits only from the soil moisture that remains after the long rains, and does not typically receive rain while it is in the fields (FEWSNET, 2013c: 1).

${ }^{108}$ Interview B of April 302011 with government employee, Ruhengeri town.

${ }^{109}$ Interview C of May 1 2011, Ruhengeri town.

${ }^{110}$ Interview B of May 11 2011, Musanze District.
} 
Like many other areas of the country, parts of Musanze District have undergone a programme of radical terracing. Terracing is primarily intended to reduce soil erosion; however, it also serves as a symbol of the power of the state to re-figure the rural landscape, and photographs of terraced hillsides have featured heavily in government of Rwanda documents on the agricultural reform. The geometric layout of the terraces, in contrast to the more variable patchwork of farm parcels seen on unterraced hillsides, also fits with the visual aesthetic of modernity (Scott, 1998: 4; 237) put forward by the government.

Donor-supported public works programmes have been involved in terracing, to provide income for poorer citizens. Prison labour has also been used (specifically that of prisoners doing community service known in French as Travail d'Intérêt Général, or TIG). This indicates the tendency of government to use state resources to make rapid progress towards targets, in contrast with a fully commercialized model, or an objective of employment-creation.

Terracing is usually planned by the authorities without extensive consultation with farmers, with the result that standing crops are destroyed (Pritchard, 2010). One informant said that:

The planning comes from the District: they choose which hill to terrace. They say, 'if you like, you can delay the planting' [to avoid crops being uprooted]. When they arrive on the hill, they uproot any crop that is there. If they find a house that is not very well-constructed, then they demolish 
it... They give each house a deadline for demolition, to warn people before its demolished. If there are vulnerable people, another house is constructed for them through umuganda. ${ }^{111}$

While some informants emphasize the long-term anti-erosive benefits that the terraces will bring, others express the 'anger' mentioned by Pritchard (2010).

In many ways, these experiences reflect an inflexible, top-down implementation of the agricultural policy, blind to its own weaknesses, with administrators simply following policy without adapting to local conditions. As such, it is reminiscent of the authoritarian high modernism model. However, it is important to note the diverse ways in which the agricultural policy has been implemented by different actors. As described below, elements of this contradict the model of a rigid, state-imposed program.

\section{The Diverse Nature of Cooperatives in Musanze District}

There has been considerable pressure on farmers since approximately mid- 2006 to join cooperatives. In addition to cooperatives initiated by farmers and private businesspeople, local authorities have also started cooperatives in order to help meet the targets in their Imihigo performance contracts. ${ }^{112}$

\footnotetext{
${ }^{111}$ Interview J of April 30 2011, Ruhengeri town.

${ }^{112}$ Interview A of 12 May with member of local farmer's organization, Ruhengeri town. This is also the case in the pyrethrum sector: see Chapter Eight.
} 
There are certainly many examples of generally 'successful' agricultural cooperatives, which are large enough to benefit from economies of scale and bargaining power vis-avis agricultural commodity buyers. It is important to acknowledge the opportunities these provide for many local farmers, such as better access to markets, and more favourable prices, than they could have if they were negotiating outside of the cooperative structure. Details of these 'success stories' are not included here due to lack of space.

However, there are various financial and other kinds of costs involved. Most obviously, farmers have to have faith in cooperative management regarding crop prices (though the e-soko system may help with this issue), financial management, etc. The process of formalization and expansion of farmers' organizations often seems to involve increases in membership contributions, which are presumably at least partly justified in order to meet state-imposed financial requirements. It is likely that most cooperatives exclude the poorest farmers. For example, some maize cooperatives in Nyagatare, Eastern District, are dominated by larger-land owners (Rockefeller Foundation, 2013), and research into cooperatives leasing state-owned marshlands indicates that poorer cooperative members are finding it increasingly difficult to gain access to marshland plots (Ansoms, 2012). Women, in particular, may find it difficult to afford the minimum monetary contribution for cooperative membership (GeoSAS, 2012). 
There are also cases where the membership of cooperatives has been vetted by local administrators.

\section{Case Study: A 'Policy Entrepreneur', Conflict, and Primitive Accumulation in an Agricultural Cooperative}

The following case study closely examines the role of a particular individual in establishing an agricultural producer cooperative. With reference to Ansoms' (2011) discussion of the role of 'agricultural entrepreneurs', we prefer the term 'policy implementation entrepreneurs' or 'policy entrepreneurs' for short. The latter term is preferred because it draws attention to the fact that these businesspeople draw heavily on the state for legitimacy and indeed for more tangible support. In some cases such entrepreneurs are at the vanguard of policy implementation: while various collective action dilemmas and financial obstacles may slow down the emergence of farmerinitiated cooperatives, these entrepreneurs tend to monopolise decision-making, and are hence able to make rapid transformations in local agricultural production and marketing systems.

While some of the public policy research on 'policy entrepreneurs' assumes a largely altruistic motive, fieldwork in Rwanda as well as secondary sources suggests that the desire to broadly promote and implement a particular policy is secondary to motives of 
profit. ${ }^{113}$ These cooperative projects are business opportunities for the leadership. Indeed, the policy entrepreneurs cited in this chapter have arguably implemented government policy in name only: the 'cooperatives' that they have founded only superficially resemble cooperatives as defined in the international literature, (which emphasizes voluntary, participatory and transparent governance) ${ }^{114}$ This is not unusual in Rwanda (Peter, 2012).

\section{State Discourse and Private Initiative: Founding the Cooperative}

Soon after the agricultural policy was finalized in 2006, a powerful individual, Mr.

Nsansuwera, ${ }^{115}$ based in an urban centre in Musanze, started to visit his ancestral rural

home in order to convince his distant relatives and their neighbours to form an

agricultural cooperative. Although he was rarely physically present during the day-to-

\footnotetext{
${ }^{113}$ Scholars who have coined the term policy entrepreneur in the literature on public policy define policy entrepreneurs as: '[individuals], who work from outside the formal governmental system to introduce, translate, and implement innovative ideas into public sector practice' (Roberts and King, 1991). In the international development field, Young and Mendizabal (2009) have discussed the ways in which researchers can act as policy entrepreneurs to promote uptake of research findings. However, my use of this term is rather different: one difference is that I am interested in actors that pioneer the implementation of new policies outside of the public sector or research community (with the caveat, of course, that they are part of a broader apparatus as discussed above). Moreover, whereas the term in the public policy and international development literature refers to entrepreneurial traits (such as innovation, risk-taking), my use of the term literally refers to commercial, entrepreneurial activity, with a profit motive.

${ }^{114}$ A cooperative is defined by the International Cooperative Alliance (ICA, 1995) as: 'an autonomous association of persons united voluntarily to meet their common economic, social, and cultural needs and aspirations through a jointly-owned and democratically-controlled enterprise.' A Canadian Co-operative Association (CCA) document coyly mentions that Rwandan cooperatives are characterized by, 'leadership and management that is vested with people with modest entrepreneurial skills, attitudes and integrity, [and] membership that lacks a sense of ownership' (CCA, 2007).

${ }^{115}$ Not his real name.
} 
day work of the cooperative, it is widely seen as 'his' cooperative. ${ }^{116}$ This says much about the nature of his power over the cooperative and those within it.

Nsansuwera is wealthy and has multiple influential roles in Rwandan society, including a relatively important position in the RPF bureaucracy within the District, and a position in the local administration. He also has considerable landholdings in the area (though he did not put his own land under the control of the cooperative). These various sources of power and prestige were important in providing him with credibility amongst some of the targeted population, but his RPF membership, along with his controversial role during the insurgency period (1998-2000), turned some people against him from the start, as will be discussed below. ${ }^{117}$

Mr. Nsansuwera's first formal approaches to the population were facilitated by the state: he was permitted to talk during official public meetings. Given that he also has a role in the local administration, the lines between an essentially private initiative and a government programme were blurred. Several informants remembered that he framed the plan for a cooperative as part of a wider state policy: "he said that it was the government who had sent him'. Other elements of state facilitation are mentioned further below. In his speeches, he focused on the material benefits that would accrue to the members if they joined - they would be able to pay school fees, buy new clothes, and their children would have a good life. He promised that he would look for external

\footnotetext{
${ }^{116}$ The name of the cooperative has been withheld to ensure the anonymity of the informants.

${ }^{117} \mathrm{He}$ is widely suspected of working as an informant for the RPF during the insurgency. Informants are seen as responsible for the forced disappearances of those implicated as working for the insurgents. Further details are withheld to ensure the anonymity of the case study.
} 
funding for the cooperative. Eventually, he said, the residents would move off the land and out of their dispersed settlement pattern, into new houses by the road, while the land would all be consolidated. This vision fits neatly with official government policies on villagization and land consolidation.

But there was more to his argument than claims of economic opportunities. One informant described him as 'preaching a sermon', implying that there was a moral framing to his arguments. ${ }^{118}$ Another respondent mentioned that Nsansuwera promised that each cooperative member would have a new house in the village (umudugudu) 'in order to be civilized' ${ }^{119}$ The modernisation paradigm, with its aura of moral superiority over the 'customary', is clearly at work here. This narrative of commercial, consolidated mono-culture agriculture having a 'civilizing' affect can be linked to the 'mode of belonging' put forward by the Rwandan government: the model of the good, productive, and efficient citizen.

Nsansuwera argued that each resident in a particular rectangular shaped block of individual fields (which were at that time under the usual mixed farming system featuring bananas, beans, and numerous other crops intercropped and rotated), should clear and consolidate their fields and cultivation practices. There were more than 180 separate fields in this block, though a single family could own more than one of the plots. The exact dimensions of the block are unclear and changed over the life of the

\footnotetext{
118 Interview I of May 22011 with farmer, Musanze District.

119 Interview J of May 22011 with farmer, Musanze District.
} 
cooperative. ${ }^{120}$ Of the approximately 80 families living in this area, a significant proportion were distant relations of Nsansuwera, which provided an entry-point for him. In total, 127 people joined the cooperative in $2006 .{ }^{121}$

Nevertheless, some people were either against the idea. A minority of people were explicitly against monoculture based on export-oriented crops, preferring to continue to cultivate bananas, avocadoes, and a variety of other crops. However, a more significant issue was that of trust. Other people who liked the concept distrusted Nsansuwera personally, and some had personal disputes with him, which will be explained in more detail below. Others distrusted him because of the vague way in which he talked about the regulations of the cooperative, without going into details. Several respondents emphasised that no contracts or documents were ever presented to them, and that the agreement was 'just words'.

A key element of the plan was that everybody living and owning fields within the particular area chosen for the cooperative should become part of it. A member of the cooperative executive stated bluntly that, 'we took a block, and whoever was in that block automatically became a member of the association'. When some people were reticent about joining, the pressure was increased, with Nsansuwera telling them in meetings that it was government policy that everyone join a cooperative and cultivate together. According to a former cooperative member, 'they were told, "whether you

\footnotetext{
${ }^{120}$ The source for this information is an online Blog, based on interviews with members of the cooperative executive. The name and URL of the blog are withheld in order to maintain the anonymity of the respondents.

${ }^{121}$ Online Blog (see above).
} 
want to or not, you have to join the cooperative"'. Several informants said that the cooperative was 'started by force', although it nevertheless clear that the majority did not voice opposition to it. Of course, it is debatable whether their acquiescence should be read as full consent, as the project was framed as 'government policy'.

Of the small number that refused outright to join, the most educated (who were perhaps seen as 'opinion-leaders' who could influence others) were summoned by the local authorities to explain themselves. Such an official summons cannot be ignored without the risk of punishment, such as a fine. Some of these summons to the local administrative offices involved intimidation: for example, a respondent was told directly by the authorities that 'if you do not join, you are going against a government programme', and was warned that, "'if you don't like it, you can sell your land"'. ${ }^{122}$ This respondent considered fleeing the country in case they decided to punish him, although in the end he decided to sell his field instead.

\section{The Mechanics of Consolidation}

Nsansuwera accessed credit in the name of the cooperative, in order to hire the workers to uproot the banana, avocado, and other trees and crops in the area targeted for the cooperative, whether their owners had given permission or not. Several people who had refused to join the cooperative tried to physically block the labourers from cutting down their property. The labourers waited till the landowners had left before resuming the operation, with Nsansuwera himself overseeing the work.

\footnotetext{
${ }^{122}$ Interview A of April 302011 with farmer, Musanze District.
} 
Most people received compensation for the lost trees, while others did not. Many people who had previously approved of the plan to form a cooperative had second thoughts on seeing the forceful way in which people's crops had been destroyed, and started to covertly make plans to sell their land.

The cooperative followed a centralized, commercial management model. An agronomist was hired on a full-time basis to direct the farming practices, and an accountant, based in a nearby urban centre, was also paid. According to a member of the cooperative executive, they received financing from the Banque Rwandaise de Developpement (BRD: see discussion below). All the members of the cooperative - and, because of the pressure upon local residents, that meant all the landowners in the selected 'block' had to plant the same crop at the same time, adhere to the same weeding regime, and harvest simultaneously. Agricultural labour was no longer organized by individual families but was instead paid by the cooperative. This means that a system that was previously a mixture of unpaid family labour (and shared inter-household labour) and paid wage-labour became fully monetized. ${ }^{123}$ Members of the cooperative were prioritised for the paid work, if they wanted it, but people from neighbouring farms were also employed. No pressure was reported for cooperative members to work on the fields. Rates for working on the cooperative fields matched market rates (between

\footnotetext{
${ }^{123}$ Most rural households depend on unpaid family labour for day-to-day tasks but recruit others to contribute to specific labour intensive-tasks. In the past, this has been a reciprocal arrangement mediated by gifts of banana or sorghum beer, but it is now typically based on payments of cash.
} 
700 and 1000 RWF for a full day's work). ${ }^{124}$ It is interesting that the agronomist, who after all was the most physically 'present' member of the cooperative's technical or managerial personnel, does not figure prominently in the accounts of the cooperative members. The finer details of agricultural production on the cooperative appear to be uncontroversial. The experiences of technical extension on cooperative land were seen as positive by some cooperative members, who mentioned that would be able to use these new skills in the future. The task of creating 'modern farmers' seems to be secondary to that of simply increasing agricultural production.

During the first two seasons of the cooperative's production, the fields were planted with potatoes, while for the third season, maize was planted. These are the main stateapproved crops for the sector under the regional crop specialization policy. Improved seeds, which were purchased from the parastatal agricultural research institute (ISAR), were planted in rows, with no intercropping permitted. Chemical fertilizers were used, purchased with cooperative funds. When crops were approaching maturity in the fields, guards were recruited and paid to stop anyone - including cooperative members - from taking them.

The first potato harvest was good. Cooperative members were given $15 \mathrm{kgs}$ of potatoes per household for domestic consumption, and were paid about 500 RWF per are of land

\footnotetext{
${ }^{124}$ This is between $\$ 1.16$ and $\$ 1.66$. It is possible that the range in figures provided during interviews represent different payments for different tasks: i.e. heavier tasks may be better paid than those which are seen as less physically arduous.
} 
that they owned. ${ }^{125}$ The distribution of profits from this initial harvest was apparently seen as fair. According to the cooperative executive however, the potato harvest was not as good as had been hoped, and maize was seen as more favourable.

\section{Institutional Aspects}

Despite the successful first harvest, it quickly came apparent that the management of the cooperative was neither transparent nor effective. Cooperative members were informed that the cooperative had a significant debt to repay due to: the labour costs of clearing the fields before planting, cultivation, and harvest; the administrative costs of the cooperative; and the costs of inputs such as improved seeds. However, they were never given detailed information. Moreover, no general meetings were held to make decisions and review the activities of the cooperative. Those who on paper held important positions in the cooperative were in fact powerless. One told me:

I couldn't say a word. The association, or more properly Nsansuwera invited us to meetings and presented us as the staff of the association, but this was just words - we weren't involved in any activities. I never saw the money, I don't know how much was collected, or given out. They gave the money to Nsansuwera - if he was absent, they took the money to his wife.

Several members of the cooperative committee resigned in protest, and were replaced without the proper procedures being followed. The new members of the committee

\footnotetext{
${ }^{125}$ A hectare is 100 ares. Accounts differed slightly regarding the amount of money distributed - perhaps because the theory or practice varied from season to season.
} 
found their work made difficult by the disagreements and disputes with the cooperative members which became more common as time went on. A national farmers' organization initially provided technical training, but stopped when staff realised that the management was so problematic. It is significant however that this 'farmers' organization', which was created to represent the interests of farmers, did nothing further to intervene or call for reform of the institution. This is another example of the ways in which such civil society organizations have become part of the broader agricultural reform apparatus.

\section{Primitive Accumulation: Purchase of Land at Artificially Low Rates}

Those residents who refused to join the cooperative, and instead sold their land to the cooperative, often received a price below market rates. They took this, said informants, because 'they didn't want a dispute with Nsansuwera'. There were at least three people who sold their land to the cooperative soon after it was founded. Another person sold their land to another individual, discretely, to avoid drawing attention to himself from the cooperative management. One of the people who sold land said that, 'I sold my field in 2006 , to avoid problems [with the cooperative management]. The cooperative bought my land. I was paid 400,000 RWF for 30 ares [0.3 hectares]. Normally the market price would be 600,000 , but I had to sell it' ${ }^{126}$ Another informant insisted, 'One couldn't resist

\footnotetext{
${ }^{126} 400,000$ RWF is about US $\$ 667$, while 600,000 is about US $\$ 1,000$.
} 
against this man who has committed murder. So they sold their fields because otherwise he could make them disappear'. ${ }^{127}$

Note that the power associated with Nsansuwera does not directly depend upon the state but is rather a factor of the particular local history of violence and his specific role in it, as well as the sum of his various sources of authority and supposed legitimacy. Another informant clearly highlighted the power and class issues in evidence: 'The association was bought by the rich. It is hard to fight against someone who is rich... because people are scared [of Nsansuwera] they don't try to reclaim their fields'.

The purchase of land at artificially low rates, in a context of coercion, represents a form of primitive accumulation or accumulation by dispossession (Harvey, 2005: 159). Former members of the executive stated that Nsansuwera wanted the cooperative to purchase as much land in the block as possible. The sales of land were part of the design and profit-model of the overall project. However, the cooperative's financial problems meant that only a handful of parcels could be bought.

The agricultural production of the cooperative members was also, it seems, accumulated by Nsansuwera, who underpaid the members and withheld basic financial information from them. While the first harvest was good, and cooperative members felt that they had been fairly paid for it, their revenue from the subsequent harvests was much lower, for unexplained reasons. The system of weighing, storing, selling the

\footnotetext{
${ }^{127}$ The mention of murder is apparently a reference to Nsansuwera's alleged role as an RPF informant.
} 
harvest and then distributing the proceeds was not explained to the members. One informant reported that during one particular potato season, 'when they harvested the potatoes, they didn't even weigh them - they just said that this was going to be a loss, they weren't going to get a good price. I never received anything from the harvest. I had to work in other people's fields in order to get something to eat.'

Informants said that some cooperative members could not pay school expenses for their children as a result, and the children had to drop out of school. On respondent lamented, 'when each has his own farm, he can eat from it, [or] he can sell the harvest. But in an association, you can die of hunger waiting for the money' ${ }^{128}$ Farmers also reported that they didn't receive any revenue from the $3^{\text {rd }}$ crop harvested, which was maize. Once it had been taken to the drying station, 'we didn't hear anything about the maize'.

After the first harvest, the cooperative executive introduced membership fees. Former members of the cooperative executive said that this fee was 5,000 RWF per year, but cooperative members said that it was calculated according to the size of land owned by each member, with 1000 RWF paid per are. ${ }^{129}$ Members are unsure as to how this money was used. Again, it is likely that this was simply stolen as part of the broader pattern of accumulation by Nsansuwera and, possibly, those in his inner circle.

As mentioned above, guards were paid to ensure that no-one could pick crops in the field. This angered some cooperative members, who were used to picking some corn

\footnotetext{
${ }^{128}$ Interview with local farmer, Musanze Sector, Musanze District, February 132008

${ }^{129} 5,000$ RWF is about US $\$ 8.30$. An are is a hundredth of a hectare.
} 
cobs prior to the harvest, in order to feed their children. One man who allegedly took some maize cobs from his own field was arrested, and temporarily detained, although he was never fined. People who took maize from other people's fields were detained in the local administrative lock-up and were fined 20,000 RWF. ${ }^{130}$ The fact that these cooperative members were paying the salaries of the guards who were arresting them angered many cooperative members. Informants asked, rhetorically, what kind of association would refuse its own members access to the crops in the fields to feed their children.

This disciplinary technology is private, rather than directly linked to the state, and further illustrates the point that the cooperative is part of the state-led apparatus, but does not completely rely on the state.

One of the most visible elements in the accounts provided by the former cooperative members is the association between wealth and power. For at least some informants, Nsansuwera's power was an asset, at least at the beginning: 'We were very happy because we saw this man as powerful, we thought that he was going to help us arrive at something, that our lives were going to improve... ${ }^{131}$

Interestingly, none of the informants conflated Nsansuwera with 'the state', despite his important role within the RPF. The cooperative was seen as an extension of Nsansuwera's power, not the power of the state.

\footnotetext{
13020,000 RWF is about US \$33.

${ }^{131}$ Interview J of May 2 2011 with elderly man, Musanze District.
} 


\section{Resistance}

One of the most interesting aspects of the history of this particular cooperative is the wide range of tactics employed by those local residents that refused, or tried to refuse, to join it. Though, as we shall see, the response to the problems in the cooperative became more 'collective' after about two years, many respondents emphasized that each member of the cooperative tends to keep his feelings and plans to him- or herself. The theme of responding to problems in an individual manner was also raised severally. One respondent explained that, 'everyone tries to work in his own way', while another said that, 'each has his own way of doing things'. This sense of 'figuring things out' individually likely reflects the difficulty of accurately evaluating the risks and opportunities in contemporary Rwanda's complex social and political landscape. It also suggests relatively low levels of trust between the members of the cooperative. As mentioned elsewhere, levels of trust are likely to be far lower in institutions which people have been forced to join, than in those that they have voluntarily formed with friends (Bizoza, 2011: 31).

One family living in the area of the cooperative includes a large number of educated 'youth' (defined as individuals who are unmarried or are married but have yet to produce children) who have are seen as economically powerful. This family had a dispute with Nsansuwera which predates the establishment of the cooperative and which is related to the violent intra-Hutu politics of the post-genocide insurgency 
period. ${ }^{132}$ Members of this family were the most vociferous in resisting the formation of the cooperative, although they nevertheless saw their land cleared against their will and cultivated by members of the cooperative, under the cooperative's consolidated farming regime. This plot measures about half a hectare and therefore represented a significant proportion of the total land area controlled by the cooperative. They used a variety of tactics to try to block the cooperative. At first, they attempted to turn other residents against the idea on the basis that Nsansuwera was not to be trusted. The importance of verbal discourse, and metaphors of discourse as 'battle', occurred in several interviews with respondents. Nsansuwera, despite his various sources of 'power', was unable to shut down public criticism.

One cooperative member who had complained to other residents that the cooperative lacked any of the necessary administrative paperwork, 'such as a chequebook' was directly addressed by Nsansuwera during a public meeting. One informant considered that 'he called a meeting specifically to attack the man'. Nevertheless, this person defended their position. They framed their critiques according to the standards set by other cooperatives in the area, arguing that, 'the cooperative doesn't function like the others'. In other words, they accepted the cooperative idea; using it to attack this particular cooperative. This willingness to 'talk back' in public to a more powerful individual suggests that the image of powerlessness, and the trope of 'silence' or 'secrecy' which recurred through many of the interview transcripts, and which accords

\footnotetext{
${ }^{132}$ Details of this relationship are deliberately withheld in order to protect the anonymity of the informants.
} 
with the 'weapons of the weak' model of resistance (Scott, 1985), should not be viewed in absolute terms.

When their attempts to convince the other residents failed, the large and powerful family present in the area used financial means to try to reverse the pattern of land accumulation by the cooperative. When they found out that other residents who opposed the cooperative were planning to sell their land, the family offered to buy it at a higher price, in order to stop the sale to the cooperative. ${ }^{133}$ They were not successful, reportedly because people were scared of what Nsansuwera might do in retaliation.

The third tactic employed was to take Nsansuwera to court. The family argued that their land had been essentially stolen from them, but the tribunal repeatedly postponed the case, causing the family to eventually abandon the litigation. Members of the family felt that the magistrate had probably been bribed to postpone the hearing indefinitely. Asked why some of those who opposed the cooperative had gone to the courts, whilst others had not, most respondents referred to the high costs involved in hiring lawyers. Therefore, their ability to use legal means to contest the cooperative's actions was explained through reference to their economic power. However, we should also note that a legal challenge to such a powerful local member of the RPF represents a 'political' act in the Rwandan context (in other words, a direct challenge to state-sanctioned power, pursued through state-administered systems) and again shows that the idea of a

\footnotetext{
${ }^{133}$ I was not able to gather data on the prices offered.
} 
'powerless' population using only the 'weapons of the weak' to avoid state repression is overly simplistic.

Nevertheless, this was initially the only 'direct' resistance to Nsansuwera. Less powerful individuals, and notably those who were not seen as 'educated' or 'wealthy', appealed to the local authorities to step in. Many of those who saw themselves as 'farmers' went to the sector offices to complain about the forcible nature of the land consolidation and the unaccountable management, but were told that land consolidation was government policy. Some took the issue to the level of the District authorities, which eventually had results (described further below). By contrast, many of those who were locally categorised as 'intellectuals' (i.e. possessing at least a high school level education) preferred to keep a low profile vis-a-vis the administration, fearing that they would be identified as ringleaders of resistance against government policies. Some of these 'intellectuals' already had disputes with local administrators and did not want to further aggravate those existing problems. The politics of the cooperative were embedded in the broader politics of the area.

After the third harvest, in 2008 , for which many cooperative members went unpaid, the dynamic within the cooperative changed. One former member of the cooperative executive started to take back control of the agricultural regime on their parcel. This created a precedent for others, who one by one 'reclaimed' their fields. This was the most important act of resistance that tipped the balance of power within the cooperative and started its decline. One woman described how, when challenged by 
members of the cooperative, she responded rhetorically, 'go take me to the courts', implying that they had no legal basis for their claims over the land. Reference was made in this account to the size of the landholdings that she owned ('hectares and hectares'), some of which were outside of the cooperative zone. Being an owner of relatively large parcels meant that she could afford to risk having crops uprooted or cultivation blocked in part of her fields, compared to someone whose entire landholdings were found within the boundaries of the cooperative. It is worth noting that these assertive actions of a woman, and her links to land, contradict some of the narratives regarding women's customarily 'subordinate' roles in Rwandan society (see e.g. MINAGRI, 2010e: 4, 60).

All of the tactics described thus far have been practiced at the level of the individual. It was only in early 2008 that cooperative members came together in an act of resistance. This, according to informants, was a largely unplanned manoeuvre. Nsansuwera, who was rarely present at the cooperative after the first weeks during which it was being established, visited a nearby administrative office in his car. Seeing his vehicle, an unspecified number of cooperative members surrounded his car at the administrative office and refused to let him leave, 'saying that they were dying of hunger'. Little specific information was available on what some termed the 'demonstration', probably because informants were wary of potentially incriminating themselves or others: such collective events of revolt are extremely rare in Rwanda and would be viewed very negatively by the authorities. ${ }^{134}$ Respondents simply said that 'the population' was

\footnotetext{
${ }^{134}$ Purdeková (2011) discusses the state's rapid and highly organized clampdown on demonstrations held in refugee camps by Congolese Tutsi refugees; these spontaneous or citizen-organized events are
} 
involved, both men and women. Shortly after the demonstration, according to respondents, cooperative members received payments. The exact reasons why the demonstration caused Nsansuwera to ensure that the members were paid are unknown. However, it is likely that such a public display of anger and desperation would have startled and embarrassed the authorities, who may have directed Nsansuwera to ensure that it did not happen again. Public cries of 'we are hungry', the possibility of violence wrought by angry groups of farmers, and implications of financial mismanagement, do not fit with the image of the New Rwanda.

\section{Positioning of authorities}

The positioning of the authorities relative to the cooperative and the various disputes it engendered changed over time. The initial role of the authorities was facilitative. The support of the local authorities for Nsansuwera, both in words and deeds, made it particularly risky, in the eyes of the farmers, to oppose the establishment of the cooperative. One informant associated with the local authorities said that, 'I went to visit the cooperative with other members of the authorities. He [Nsansuwera] wanted to move people off the land so it could be consolidated, and move people next to the road. It was a good idea, and we supported it.. ${ }^{135}$

One of the former members of the cooperative committee stated that 'the local authorities helped us very much' with the process of establishing the cooperative. 'We 
couldn't have done it without them', the respondent added. The District Mayor visited the cooperative to encourage people to join. In addition, the cooperative received a loan from the Banque Rwandaise de Developpement (BRD). The BRD's main shareholder is the government of Rwanda, and its mission statement is to be 'the Government of Rwanda's investment arm that finances the nation's development objectives' (BRD, 2013).

There were direct links too between the local authorities and the cooperative, with one of members of the executive holding a position in the cellule administrative committee. Moreover, the state lent its disciplinary power to the cooperative leadership: when members of the cooperative were fined for picking corncobs from the cooperative fields, these fines were issued by the local authorities, not by the cooperative committee.

When financial problems and disputes emerged within the cooperative, several cooperative members went to the local authorities, starting at the cell level. Some were rebuffed, on the basis that they had yet to pay their fees for the (supposedly voluntary) health insurance scheme (mutuelle de santé) and as such did not have the right to administrative services. Others were listened to, but saw no result from their complaints. Others continued to the administrative level of the sector, which is in many ways the most significant actor in Rwandan policy implementation.

In response to these complaints, the administration stalled for time, probably unsure of how to deal with a dispute involving such a powerful figure as Nsansuwera, a key part of 
the local development 'apparatus'. The Executive Secretary promised to come and talk to the residents on the site of the cooperative, but never followed through on this commitment. 'We realized that he was lying', said a respondent.

Some people then sought an audience with the Mayor, who had first tried to persuade people to stay in the cooperative. According to local residents, he 'told us that the association was a good thing, and that it was done in the name of improving the welfare of the population. The Mayor told us we were very lucky to have someone like [Nsansuwera] to help the area develop. ${ }^{, 136}$ The District Agronomist, a state employee, also visited the site to try to get people working in the fields again. Eventually however, the Mayor evidently decided that telling people to remain in the cooperative was not resolving any of the problems. According to respondents, the Mayor declared in a public meeting that no one was forced to remain in the cooperative:

The Mayor said, "if you really feel that you're not getting anything, then noone is obliged to stay". There were 120 members at the time. 70 left immediately. Another 50 stayed for another 2 months before leaving as well. They took back their fields and the cooperative was dissolved.

It is significant that, despite the willingness of some people to resist Nsanzuwera, most only felt able to leave the cooperative once the Mayor had publically declared that they were free to do so. This suggests that they had found it too socio-politically risky to leave before that point.

${ }^{136}$ Interview with local farmer, Musanze Sector, Musanze District, February 132008. 
According to farmers' organizations, cooperatives which experience episodes of embezzlement or financial mismanagement are required to hold a meeting of the general assembly. At such meetings, a decision is made regarding if and how the money can be reclaimed, and whether the people responsible should be criminally charged or otherwise sanctioned. ${ }^{137}$ No such meeting has been held in the case of this cooperative, and none of the lost money has been repaid to cooperative members. Mr Nsansuwera has not been criminally charged. Indeed, he has been praised in the pro-government media, suggesting that this story of financial failure and exploitation is deemed less important than his commercial successes. ${ }^{138}$

\section{Class Divisions and Conflict amongst the Population}

The population in the area is relatively heterogeneous compared to many rural settings.

Those with fields and houses within the area of the cooperative were not united in their opposition to Nsansuwera, but were rather split down various axes. Key issues which affected their positioning on the viability of the cooperative included their kin relationship to Nsansuwera, historical dealings with him, and, importantly, the extent to which they reside locally, or live in nearby urban or commercial centres. In the view of some residents of the area who still physically lived there, Nsansuwera 'was working

\footnotetext{
137 Interview A of May 122011 with member of farmer's organization, Ruhengeri town.

${ }^{138}$ Citation withheld to ensure anonymity of case study.
} 
together with people living in ... town'. ${ }^{139}$ Another respondent reckoned that once the mismanagement of the cooperative became apparent,

Three quarters of the population was against [Nsansuwera], while one quarter was for him. Those who were living in [commercial centres] but still had fields in the area, were pro-[Nsansuwera]. But those who still live in [the rural zone] were against him.

It is possible that those who lived in urban areas where more fully integrated into the off-farm economy and had a more diverse range of income sources than those living 'on the fields', and were better able to take risks. The other possibility, linked to this, is that more discursive aspects of class identity were at play, with urban households identifying more with the entrepreneurial image of Nsansuwera than the idea of smallholder resistance. This perspective resonates with Nsansuwera's argument that the cooperative would 'civilize' the local people: those people living in town might categorise themselves as already 'civilized' and be unwilling to position themselves in resistance to a 'civilizing' project associated with modernity. The cooperative executive eventually became dominated by 'urban' figures who did not, in some cases, own any land in the project area. ${ }^{140}$

The two interpretations (economic rationality and class identification) are not mutually exclusive. However, respondents did not make systematic references to urban/rural or class categories, hence I cannot do more than speculate on this point.

\footnotetext{
${ }^{139}$ Name of the town withheld.

${ }^{140}$ Interview K of May 32011 with former cooperative executive member, Ruhengeri town.
} 
The majority of respondents stated that disputes still exist between former members: 'after realizing that the cooperative was not working, they fell into arguing. One would say to another, 'it was you who talked me into joining the cooperative'... they regretted all their work for the cooperative, which had borne no fruit'.

Several fields remained uncultivated after the dissolution of the cooperative. These had been bought by the cooperative, and residents were apparently in dispute over the rights to use them. This is a remarkable situation given the extent of land scarcity in the area and the profits that can potentially be made from agriculture. One respondent argued that the fields are abandoned because of 'fear' that Nsansuwera would sanction those who use cooperative property. Local people have sought guidance from the authorities on who has the right to cultivate the fields.

The 'success' of the farmers in ending Nsanzuwera's control over the area cannot, therefore, be seen as a form of 'freedom' from power relations. Local people are still enmeshed in complex power relations; the ongoing disputes and controversies between the smallholders are an indication of this; relations between the administration and farmers are also likely to be affected by the events around the cooperative. The 'resistance' of smallholders resulted in a reconfiguration of power relations, not a freedom from domination that is implied by Scott's (1998) more binary understanding of power (Li, 2005: 384).

The main remaining source of conflict is the feeling of many members of the cooperative that they are owed money by Nsansuwera. The level of anger over the issue 
is still significant, and the possibility of violence is real, according to several informants. One stated, 'he can't set foot in his home area after $6 \mathrm{pm}$, or someone will slit his throat', while another said that his fields are tended by his relatives, as he cannot risk spending time in the area. Speaking metaphorically, the informant said that 'he can't place his feet there, or they will burn them'.

Given the hostility to Nsansuwera, it is striking that many people remain open to the idea of a new cooperative. One informant mentioned that they had learnt useful agricultural methods and techniques. Importantly however, local people remain attached to the idea of a 'leader' who can drive the process of establishing and managing a new cooperative. Such a figure, respondents said, should have the money necessary, as well as the ability to support them institutionally.

\section{Conclusions}

While several links exist between this individual and the state, Nsansuwera is far from the mere obedient instrument of state policy that tends to dominate the 'authoritarian high modernism' model (Scott, 1998). This model does not adequately consider the possibility that individual actors - whether state administrators or private individuals -

will actually use their own initiative to adapt and facilitate the implementation of state policy.

As discussed earlier, Scott's focus on the state's goal of increasing 'legibility' and standardisation ignores the key roles of profit-making and the market in both the 
designs of the state and in the particular ways in which those designs play out in different contexts. Seeing Like a State, as discussed in Chapter Two, focuses on the 'improvement' of society as the major goal of high modernism: the design of a 'more perfect social order'. The roles of processes of capital accumulation in making this happen are not considered.

As mentioned in the theoretical framework, those who interpret the Rwandan context largely through the conceptual lens of Seeing Like a State emphasise the forms of 'resistance' mentioned in that work (and in Scott, 1985): namely 'various forms of quiet resistance and evasion' (Scott, 1998: 24). These kinds of indirect, non-confrontational strategies are in evidence in the pyrethrum sector in Musanze and the maize sector in Kirehe District (Chapters Seven and Eight). However, this case study represents a perhaps surprising example of overt resistance to a very politically and economically powerful individual, as well as collective resistance. While this may not be a typical case, it does show that under certain circumstances, particular individuals and communities engage in these more direct actions. Arguably, a Foucauldian model of power, that avoids the temptation to fall back on overly-simplistic binary models of 'domination and submission' or 'the powerful and the powerless' (a temptation that Scott arguably sometimes succumbs to), can account for these variations, when fully contextualized. The shifts in power that allow for resistance are linked to the 'shifts of position' within the apparatus of reform, as mentioned by Foucault (1980: 194).

The examples of resistance to the cooperative contradict much of the 'received wisdom' about relations between the Rwandan rural population and more powerful actors, 
especially those linked to the state machinery. The idea of a 'passive' peasantry in Rwanda - which remains docile unless mobilized by the state -is pervasive in the informal discourse amongst NGO personnel and government workers, but it is more myth than reality. There are other documented historical examples of resistance to the state or to 'development' activities at a larger scale. As the price of coffee plunged during the 1980s, peasant farmers uprooted hundreds of thousands of coffee trees. ${ }^{141}$ Peasants are also known to have burned government woodlots in protest against local elites and uprooted trees in Gishwati forest (Longman, 1995, cited in Waldorf, 2006).

In this particular place and at this particular time, the force of the state in containing and undermining local efforts to resist state policy was not total, and was not overtly violent in nature: individuals experienced different aspects of state power depending on their own social status. The balance of power in this area is perhaps not as binary as may often be imagined. As Brass (2007:245) reminds us, we must avoid 'counterposing an undifferentiated agrarian bureaucracy to a similarly homogeneous peasantry'. It is important to interrogate the assumption that local administrators are always at an advantage when dealing with rural populations, even in authoritarian contexts, and to examine the roles played by wealthier smallholders, or those farmers who are connected to larger social and political institutions.

The cooperative, which was essentially an instrument of a policy entrepreneur, changed life for the local residents in multiple ways: not only did they lose the right to choose

\footnotetext{
${ }^{141}$ Coffee prices were set by the government, but the price of other commodities increased, so that the exchange value of coffee was drastically reduced (Verwimp, 2002) and Newbury, 1995).
} 
when, what and how they cultivated, but they lost control over the arrangements through which agricultural labour was mobilized. Their farming systems became fully commercialized. From a Foucauldian perspective, the imposition of a new labour regime, fully commercialized (though with cooperative members having first right of refusal for farm-work), as well as the various financial requirements demanded of the members, represent systems of discipline. What kinds of discipline were imposed, and to what ends?

As mentioned above, the intention of the agricultural regime in the cooperative was not to impose disciplinary control on the bodies of the cooperative members, nor to fulfill the governmental goals of creating a broad entrepreneurial class. Landholders were not obliged to cultivate, as paid labour was brought in whenever necessary. Despite the important role played by a full-time agronomist, the accounts of the cooperative members suggest that the technical training supplied by this agronomist was not primarily intended to create 'professional farmers' in the sense of skilled individuals who themselves can replicate and expand the practices of monoculture. Nor were there attempts to train farmers in financial management, negotiation, or other skills that might provide them with the status of 'ideal development subject' (Purdekova, 2012a: 192), as this would have presumably enabled them to become more resistant to the cooperative leadership. Instead, it was simply intended to result in the maximisation of the harvest, and the maximisation of profits. A journalist, basing his account on interviews with members of the cooperative executive, stated that the cooperative members became Nsansuwera's 'workers' implying that he is simply their employer. 
Rather than technical aspects of extension and control over the bodies of the cooperative members, more significant from a perspective of Foucauldian analysis are the financial regimes that were put in place. In conjunction with the importance of a process of accumulation by dispossession, the emphasis is on profit, and the monetization of a rural production system. The commodification of labour and the harvest - in other words, various market relations - provided Nsansuwera with the means to put in place forms of primitive accumulation. Moreover, his power does not derive solely from the legitimisation of state policy but also from his personal kinship networks and other geographically-specific forms of power. He is also wealthy. This case resonates strongly with the idea of state power, in conjunction with processes of commodification, being used by the wealthy and powerful to increase their private profit at the expense of the less powerful (Harvey, 2005). There is, in other words, an element of class struggle involved. In the words of An Ansoms:

Elite networks [in Rwanda] now make use of the opportunities provided by the new discourse on agriculture as a motor for development to secure their control over space (Ansoms, 2011: 10)

Ansoms' work in Southern Province found that cooperatives working on marshlands also imposed considerable financial demands on farmers, under very opaque rules: most farmers were unaware of how the money was used. The ways in which the 'agricultural entrepreneurs' that she identifies came to exploit the local population lead her to conclude that, 
Elite capture of the opportunities provided by the reforms resulted in the reproduction and reinforcement of structural forms of poverty and existing patronage networks (Ansoms, 2011:13).

As discussed elsewhere in this dissertation, this process of 'elite capture' does not emerge in a vacuum: it is at least partly linked to the relations between different aspects of the agricultural reform apparatus. In particular, it is a result of the district- and sectorlevel imihigo contracts and the resulting temptation upon local administrators to do everything necessary to 'facilitate' the establishment of agricultural cooperatives. Administrators will go as far as to organize the creation of cooperatives themselves, and stack the leadership committees with current or former administrative personnel (see Chapters Seven and Eight on maize production and the pyrethrum sector). Moreover, the financial obligations of cooperatives and the expenses involved in the 'homogenizing' processes (clearing fields, sourcing fertilizers and seeds, coordinating harvests and transport of produce) privilege elite actors, who are literate and sufficiently credible in the eyes of financial institutions to be able to access credit. The question arises as to how Mr Nsansuwera is best characterized, given his multiple roles in economic, social, and political life. As noted in Chapter Two, Scott does not provide the best framework for this exploration, as he relies on an overly neat separation between 'state' and 'civil society' actors. Is Nsansuwera most accurately characterised as a wealthy farmer, in which case this failed cooperative mirror experiences in other countries, where, 'junior [state] officials have been unable to 
prevent better-off peasants in agrarian co-operatives from appropriating co-owned resources (land, technical inputs) and employing poor peasants as hired workers' (Brass, 2007). Or is Nsansuwera best characterised as an instrument of the state, in the sense that he is, first, a member of the ruling political cadre, and second, an implementer of the ideal model of agricultural development developed by the government?

Certainly, local people blame Nsansuwera, and not the Rwandan government, for the collapse of the cooperative. While respondents mentioned that he was able to leverage significant state support, he is seen as separate from the state, and described as an entrepreneur. As mentioned previously, Foucault's concept of an apparatus (dispositif) allows us to theorize this kind of partial and fluid engagement with the state. The idea of this agricultural project forming part of a broader apparatus is supported by other research in Rwanda (Ansoms, 2011). An Ansoms describes the strategies of two entrepreneurs who came to control cooperatives located on state-owned marshlands in Southern Rwanda. Interestingly, although they both used very different institutional and financial systems to control production and profit from the marshes, their relationships to the state and its various organs were fairly similar. She notes that both of them used various connections, ranging from membership of the armed forces, influence amongst the District-level authorities, and connections with local NGOs, to access resources to mobilize local support for cooperative production.

Nevertheless, such individuals are not central to the state programme: for example, like Nsanzuwera, one of the entrepreneurs fell out of favour with the local authorities and 
lost control of the cooperative. ${ }^{142}$ The dispositif is not a smoothly functioning machine, but is instead enmeshed in personal, ideological, and historical relationships which mediate the ways in which non-state commercial actors are incorporated into a broadly state-driven agricultural reform. The incorporation of non-state actors into the dispositif of agricultural reform may involve standardised models of agricultural intensification and commodification, but this case study suggests that those standard blueprints are implemented through recourse to highly context-specific relationships (based partly on kinship and class, in this case) and hence result in particular 'spaces of governance'. Homogenous models of agricultural transformation are implemented in diverse, heterogeneous ways.

${ }^{142}$ Ansoms collected various contradictory accounts of the reasons for this change in his fortunes (2011: 11 FN 14). 


\section{Chapter Seven: Pyrethrum production in Northern Province}

Government is still the overseer of the population (SOPYRWA personnel) ${ }^{143}$

\section{Introduction}

Pyrethrum is a variety of chrysanthemum flower which can be dried and processed to produce an insecticide, pyrethrin. The insecticide is used in common household products such as Raid ${ }^{\oplus}$ and Baygon ${ }^{\circledR}$. The political economy of pyrethrum in Rwanda differs from other crops in significant ways, particularly because of the land tenure situation in pyrethrum-producing zones as will be described below; however, recent events in this sector provide broader lessons which can assist us to understand the way in which the agricultural sector is developing. This chapter examines whether the 'authoritarian' nature of pyrethrum production has been altered by an apparent 'privatization' of the state pyrethrum agency, and the investment of international capital and bilateral aid in the sector. In particular, the following case study illustrates the ways in which a variety of powerful actors have become involved in the production and marketing of this crop under the banners of philanthropy and international development, inherently accepting the underlying injustices of the sector. As with other strategic crops, pyrethrum production is associated, in local government discourse, with patriotism and sacrifice for national development. However, as the 'private' company

\footnotetext{
${ }^{143}$ Interview A of May 12 2011with senior SOPYRWA staff, SOPYRWA factory, Ruhengeri town.
} 
controlling the pyrethrum sector is owned by the RPF, both the discourse of patriotism and the state machinery used to regulate the pyrethrum sector have been colonized by the ruling political party.

The long-standing conditionalities attached by the state to the land claims of farmers in the pyrethrum zone mirror the conditionalities which are increasingly being attached to all private land-leases across Rwanda. Indeed, there are striking similarities between the discourses and actions of farmers within the pyrethrum zone and those being told to plant maize in Kirehe district (see Chapter Eight).

The case study also illustrates the ways in which particular spaces of agricultural production and populations inhabiting those spaces can become the objects of governmental strategies, in addition to regimes of discipline. The pyrethrum zone represents an area of intense intervention (by government, the ruling party, donors, and private firms) which targets the bodies of the population, both directly (through spatialized controls on agricultural practices) and indirectly (through 'education' on health, birth control, and other factors). However, regimes of discipline have been reinforced at the same time as governmental strategies have been implemented.

\section{Background on the Pyrethrum Sector in Rwanda}

Pyrethrum can only be grown at high altitudes on volcanic soil, and is therefore only produced by very few countries (including Kenya, Tanzania, and Ecuador). It is a very labour intensive crop: seedlings are hand split and hand sown, weeding must be done 
very regularly, and the flowers are hand-picked over a period of up to six months. It was introduced to Rwanda by Belgian commercial farmers in the 1930s. In 1963, the government of Rwanda excised part of the Volcanoes National Park, in the far North of the country (bordering the DRC), in order to put land under pyrethrum production. The clear demarcation of the pyrethrum zone - bordered by the inviolable and oft-patrolled boundaries of the national park to the North, and physical markers such as a main road and the imidugudu villages of returned refugees to the south - makes it a particularly clear example of a geographically-specific zone of regional crop production.

The Kayibanda-led postcolonial government offered free leases to plots of 2 hectares to households, on condition that they grow pyrethrum on $40 \%$ of that land area. ${ }^{144}$ Households could grow other crops on the remaining $60 \%$. If they did not put the required area of land under cultivation, the land could be temporarily confiscated. Those who continued to violate the conditions of the lease would be evicted. According to staff of the Rwandan pyrethrum company Société du Pyrethe au Rwanda (SOPYRWA), the leases did not permit sub-division, sub-leasing, sale or inheritance of the land parcels. However, the restrictions on inheritance have not been strictly enforced. Most of the parcels of land are currently occupied and farmed by the children or

\footnotetext{
${ }^{144}$ Under the paysanat system, households were granted blocks of land on the condition that they dedicated much of this land to the production of cash crops prioritised by the colonial regime, such as coffee.
} 
grandchildren of the original leaseholders. According to SOPYRWA, there are about 7,000 households currently producing pyrethrum over four Districts. ${ }^{145}$

During the 1960s, the government exported dried unprocessed flowers to countries such as Kenya that had processing capacity, but in 1970 a processing factory was built in Ruhengeri town, which is now the administrative centre of Musanze District. In 1978, a parastal Office of Pyrethrum in Rwanda, OPYRWA, was established to manage the factory and the pyrethrum industry more broadly.

After the genocide, smallholder farmers in the pyrethrum zone ceased growing pyrethrum, replacing it with foodcrops. OPYRWA slowly became operational again, but it was poorly managed. The government has been very involved since the late 1990s in attempts to revive and expand the production of pyrethrum, due to its strategic importance as an export crop. In 2000 , the government privatized the parastatal, which became SOPYRWA.

During the 2000-2008 period, the factory and commodity chain were poorly managed once more. According to SOPYRWA, the amount of flowers harvested declined from 1300 tonnes per year in 2004, to just 300 in 2008 (see Figure Two), and total export of the processed product fell from 30 tonnes in 2006 to just 4.6 tonnes in 2008 (Office of the Prime Minister, 2011). It is likely that diminished monitoring activities by the

\footnotetext{
${ }^{145}$ While the population in the zone has increased, the total land area under the control of SOPYRWA has decreased due to excisions for the purposes of resettling returned refugees in the early 2000s.
} 
SOPYRWA 'delegates' who police the pyrethrum growing zone is one of the main reasons for this. ${ }^{146}$

Figure Two: Rwandan Pyrethrum Production by Year

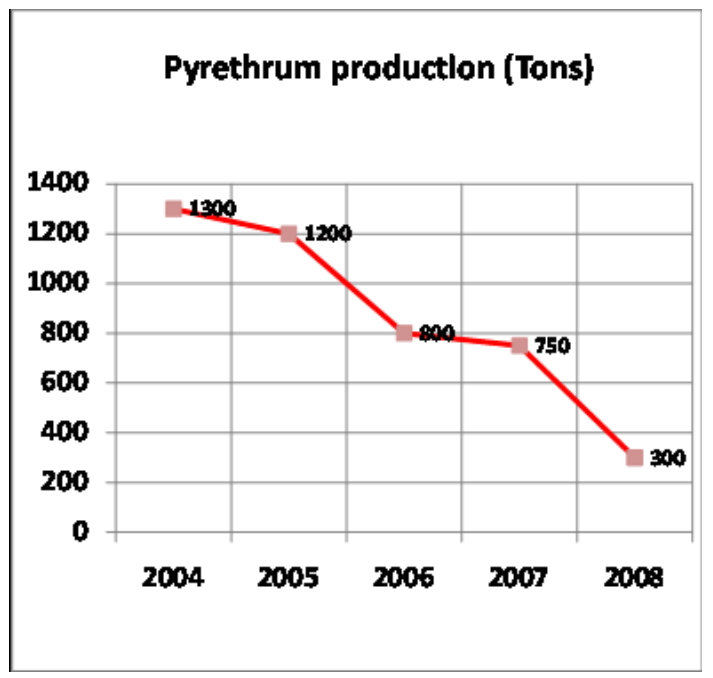

Source: Pyramid Project (n.d.), citing SOPYRWA data

In 2008, SOPYRWA was acquired by Horizon Inc. This company is described by one specialist as a 'party-statal', completely associated with the ruling RPF (Gokgur, 2012), and is staffed mainly by former military personnel (Anonymous, 2011b). In 2011, for example, the Chief Executive Officer was a lieutenant-colonel in the Rwandan Defence Forces (Anonymous, 2011b). It was originally founded by the Rwandan Armed Forces and is often described as 'belonging to the Ministry of Defence' (OECD/WTO, 2011) but the reality is a little more complex than this. Since Horizon took control of SOPYRWA, a discourse associated with 'professionalization' and liberalisation of the sector has been

${ }^{146}$ Interview A of May 122011 with senior SOPYRWA staff, SOPYRWA factory, Ruhengeri town. 
put forward by Horizon, the pro-government media, and donor organizations working in the pyrethrum sector. However, the fundamental structural aspects of production remain unchanged, and the sector cannot be described as liberalized but continues to be a monopoly controlled by SOPYRWA, which owns the only pyrethrum processing plant in the country.

\section{The Creation of Pyrethrum Cooperatives}

In 2009, SOPYRWA directed pyrethrum farmers to organize themselves into producer cooperatives. ${ }^{147}$ This process was initiated by SOPYRWA, rather than by farmers. SOPYRWA staff describe the extent of their intervention into the cooperative sector:

We organized them into small, manageable cooperatives... Initially we found two 'so called' cooperatives, which were actually individuals with money buying from farmers at different prices. We said, 'this can't work, we need a more direct link to the farmers.' So we dissolved these two... We built 24 small cooperatives, [each incorporating] people from the same village. ${ }^{148}$

SOPYRWA has also been very clear about its role in 'setting up' cooperatives in the Gishwati area, where pyrethrum fields are currently being established (Gasore, 2013). The cooperatives in pyrethrum zones, like many of those surveyed during fieldwork in Rwanda in 2011, appear to fall short of the definitions of cooperatives generally used in

\footnotetext{
${ }^{147}$ Interview A of May 122011 with senior SOPYRWA staff, SOPYRWA factory, Ruhengeri town. 148 Ibid.
} 
the liberal literature on cooperatives and international development, particularly in terms of the levels of voluntarism and the extent to which they are democratically governed (International Co-operative Alliance, 2012). ${ }^{149}$ One farmer explained how the authorities mobilized inhabitants of his cellule to join cooperatives:

They came to sensitize the population, saying that he who has a parcel of land must absolutely become a member of the cooperative. If they didn't become a member of a cooperative, his field would be confiscated. It was the [sector] agronomist and the Director of SOPYRWA who did the sensitization. $^{150}$

Few farmers take any interest in the internal decision-making systems of the cooperatives, seeing them as artificial creations of SOPYRWA. Because the cooperatives are seen as under the control of SOPYRWA, many local people they feel that there is no point in taking part in the day-to-day decision making of these institutions. This lack of engagement by the population in the day to day management of the cooperative likely contributes to the ability of some cooperative leaders to enact various questionable policies and practices.

\footnotetext{
${ }^{149}$ Some of the fundamental principles for cooperatives, according to the ICA, include voluntary and open membership; democratic member control; member economic participation; autonomy and independence; education, training and information; co-operation among co-operatives; and concern for community (International Co-operative Alliance, 2012).

${ }^{150}$ Interview I of May 3, 2011 with pyrethrum farmer, Kinigi Sector, Musanze District..
} 
A government agronomist, in discussing how the cooperatives work, emphasized the functional and logistical benefits of cooperatives to SOPYRWA, rather than benefits to local farmers, saying: 'cooperatives operate like collection sites for pyrethrum. ${ }^{151}$

Local people see the cooperatives as instruments of SOPYRWA, which do little to advocate for farmers. ${ }^{152}$ In particular, people see the management of the cooperatives as vulnerable to being changed or intimidated by SOPYRWA. One local farmer emphasised that, 'the Presidents of the Cooperatives cannot speak out against SOPYRWA' ${ }^{153}$

Some of the cooperatives force people to purchase fertilizer for pyrethrum cultivation. Fertilizer is taken on credit and paid back at the time of the harvest. ${ }^{154}$ Many farmers object to having to buy fertilizer. One farmer saw this as the main raison d'être of the cooperatives: 'There is no intervention or advocacy [in favour of farmers] from the pyrethrum cooperatives. They just sell fertilizer. The cooperatives force the members to buy fertiliser on credit'. ${ }^{155}$

The presidents of the pyrethrum cooperatives are elected, but some respondents stated that this process was highly controlled by SOPYRWA. One local mediator (member of

\footnotetext{
${ }^{151}$ Interview C of 29 April 2011 with sector-level Agronomist, Musanze District.

152 Interview A of May 42011 with pyrethrum farmer, Kinigi Sector; interview I of May 42011 with R. B, Musanze District

${ }^{153}$ Interview A of October 52011 with land cell committee member, Kinigi Sector.

154 Interview I of May 4, 2011 with pyrethrum farmer, Kinigi Sector

155 Ibid.
} 
the $a b u n z i)^{156}$ said that: 'The pyrethrum cooperatives are really people who work for SOPYRWA, there aren't any elected members' ${ }^{157}$

According to people who have worked closely with the cooperatives, the Presidents sometimes recruit their family members to roles within the cooperative (such as the role of animateur, which involves communicating information and mobilizing members to attend meetings) which attract a per diem for some activities. In order to maximise the benefits, some cooperatives have been known to hold dozens of meetings each month, each of which generates a per diem for those involved. ${ }^{158}$

SOPYRWA currently refuses to accept pyrethrum from individual farmers or dealers and will purchase only from the cooperatives, at a blanket price of $1035 \mathrm{RWF} / \mathrm{kg}$. Of this, 35 RWF is retained by the cooperatives, so that farmers receive $1000 \mathrm{RWF} / \mathrm{kg}$. This price is substantially better than the price paid before the 2008 buy-out by Horizon Inc (the price was then around $800 \mathrm{RWF} / \mathrm{kg}$, according to farmers). This price increase has been made possible, according to donors, by the increased profits available to SOPYRWA following improvements to the refining technology at its factory (OECD/WTO, 2011).

However, since 2008, Horizon has shifted the responsibility for drying the flowers to the individual farmers. The Pyramid Project (see below) has constructed basic drying facilities for several cooperatives, which can be used without payment by the farmers. Nevertheless, the drying process represents a significant investment of time, and drying

\footnotetext{
${ }^{156}$ The abunzi are members of 12-person mediation committees operational at the cellule level, and are empowered by Rwandan law to mediate in disputes worth less than 3 million RWF. The term abunzi literally means 'those who reconcile' (Mutisi, 2012).

${ }^{157}$ Interview B of October 52011 with local mediator, Kinigi Sector.

${ }^{158}$ Phone interview with development expert for an NGO working in the pyrethrum area, August 302012.
} 
the flowers can be a technically difficult task. If SOPYRWA's laboratory tests determine that the humidity of the dried flowers is above what they deem to be an acceptable standard, the farmer receives less than $1000 \mathrm{RWF} / \mathrm{kg}$.

All of the testing is done behind closed doors in SOPYRWA's laboratory, without any transparency. This leads to accusations by farmers that the data on the harvest that comes back from the lab - regarding humidity levels and sometimes even the weight of the product - differs from that recorded or estimated at the collection points. ${ }^{159}$ There is no procedure of appeal or arbitration when such problems arise. According to informants, cooperatives have not played any kind of an advocacy or mediation role in cases where the quality of the dried flowers is in dispute. Secondly, the harvested material is collected in bulk by SOPYRWA, which means that the harvest of several households is aggregated before testing. This provides a collective action dilemma for the farmers: a household that has invested heavily in the crop in order to have a harvest of high-quality flowers must risk the crop being mixed in with that of neighbours who have been more lax, and receiving a price that reflects the average quality, and not that of their own specific crop. ${ }^{160}$ This is a particular form of 'homogenization'.

These issues of price, quality control, and lack of independent arbitration reflect a broader structural issue: the complete monopoly of the pyrethrum sector currently enjoyed by SOPYRWA. However, it is important to acknowledge that the coercive nature of the structures of pyrethrum production arise from a combination of

\footnotetext{
${ }^{159}$ The sacks of flowers are weighed at the collection point prior to being transported to the SOPYRWA laboratories at the main plant in Ruhengeri town.

${ }^{160}$ Phone interview with development expert for an NGO working in the pyrethrum area, August 302012.
} 
SOPYRWA's monopoly in purchasing and the inability of farmers to shift agricultural production from pyrethrum to other crops (without losing access to their land). This arrangement allows SOPYRWA, with the support of the state, to deploy disciplinary technologies which farmers have few, if any, formal or legal tactics to resist. The informal tactics available to them, as will be discussed below, are only marginally effective and do not have any effect on the conditions of structural exploitation.

This realization assists a comparison with other elements of the Rwandan agricultural sector under the ongoing reform: the pyrethrum sector is not entirely unique, but has structural similarities to some of the new configurations of land tenure, agricultural policy, and corporate investment in other farming sectors. We will return to this point in the conclusion of this chapter.

\section{Donor and Private Sector Intervention: The Pyramid Project}

Pyrethrum has been identified by the government of Rwanda as a 'potential high growth sector', largely due to growing global demand (see e.g. MINICOM, 2011) and has accordingly attracted donor funding for various activities intended to improve the technical capacity of SOPYRWA and to increase the amount of pyrethrum harvested. These interventions have directly contributed to the disciplinary power of SOPYRWA, and have not attempted to alter the structural conditions of production and marketing. Despite this, SOPYRWA and its partners have mobilized a narrative of an improved 'enabling environment' (Anonymous, 2011b) and the project has served to legitimize 
SOPYRWA's operations, glossing exploitative farmer-SOPYRWA relationships with an image of 'development', 'improvement', and 'philanthropy'. As will be described below, these interventions also demonstrate the ways in which donors and NGOs have formed an integral part of the Rwandan state's efforts to create a totalizing field of interventions in the name of 'development', a field in which there is both an 'interpenetration of themes' (Purdekova, 2012: 199) and dense institutional connections.

In 2009, the 'Pyramid Project' was launched, with the involvement of several institutions including SOPYRWA, the United States Agency for International Development (USAID), the multinational pharmaceutical corporation S.C. Johnston (based in Racine, Wisconsin, USA), and the Norman Borlaug Institute for International Agriculture (also based in the USA). This project is an extension of the existing Sustaining Partnerships to enhance Rural Enterprise and Agribusiness Development (SPREAD) project which has worked in the coffee sector in Rwanda. USAID invested \$6 million over 5 years for the SPREAD project between 2006 and 2011 (which includes components such as coffee and chilli pepper production). At least $\$ 160,550$ was invested by SC Johnston (USAID, 2010b). ${ }^{161}$ The project aims to 'help increase incomes and the quality of life for thousands of Rwanda pyrethrum farmers, while boosting the sustainable supply of pyrethrum in East Africa' (Schattenberg, 2009). However, internal documents emphasize the economic motivation of the actors concerned, citing the objective to: 'Achieve growth, profitability

\footnotetext{
${ }^{161}$ SC Johnston staff responded to my request for funding figures with a statement that, 'we do not release that kind of information.' Email correspondence, July 242012.
} 
and sustainability [of SOPYRWA's operations] as a source for high-quality pyrethrum oil for S.C. Johnson' (Pyramid Project, n.d).

An assessment of the pyrethrum sector conducted during the project design phase identified many of the inequitable and problematic structural aspects of pyrethrum production, finding that:

Farmers felt they were being forced to grow an unprofitable crop that took time and effort away from producing a profitable one [potatoes]... producers had little interest and no incentive to produce even a lower quality product, let alone to invest the time and effort required to produce higher volumes of a higher quality product... farmers never made any money producing pyrethrum. (Pyramid Project, n.d. Italics added).

Despite this blunt assessment, the project, as described below, did little to address the economic structures of production and marketing, focussing instead on supporting SOPYRWA's disciplinary mechanisms, technical improvements to seed quality and cultivation regimes, and providing mostly non-material support to farmer 'well-being' through various forms of education and training.

The project aims to encourage farmers to use better production techniques, and to intervene in the value chain, particularly in the areas of drying, transportation and storage. New seedstock has been developed. While higher in levels of pyrethrin (the chemical which provides the flowers with their pesticide qualities, and hence their commercial value), this new variety requires the application of fertilizer, whereas the 
plants previously used by farmers do not. ${ }^{162}$ SOPYRWA has supported credit schemes, and has urged farmers to 'embrace financial discipline to improve their welfare' (Majyambere, 2011). While these interventions may be seen as beneficial to the farmers involved, they may also be interpreted as part of a broader project to further monetarise the rural economy and draw farmers into commercial livelihood models.

Pyrethrum farmers were trained in land preparation and various new cultivation techniques, which according to Pyramid Project documents, could result in per hectare yields tripling (Pyramid Project, 2011); but involve substantial increases in the amount of labour invested by farmers. For example, project documents describe a new regimen whereby the number of plants cultivated per hectare is increased by $60 \%$, and duration of the harvest period is doubled (Pyramid Project, 2011).

It is unclear to what extent the Pyramid Project interventions - technical improvements and restructuring of cooperative structures - represent a version of the high modernist faith in technology and the administrative re-ordering of society. In this case, the obstacles such interventions sought to overcome were not agro-ecological but rather socio-political in nature. Such interventions were implemented instead of, for example, the legal and economic restructuring along a 'liberalization' model, which would alter the control over the means of production.

\footnotetext{
${ }^{162}$ Phone interview with development expert for an NGO working in the pyrethrum area, August 302012. The post-harvest stubble of pyrethrum plants can be dug back into the soil as a mulch, and acts as an organic fertilizer.
} 
The project, through various partners, also provides farmers with information on health issues and promotes family planning. Radio programmes are an important part of this, and a specialized organization, Lifeline Radio, delivered specially designed content as well as specialized radio-recorders to the farmers. In order to provide some incentives for increased production, annual 'Farmers' Days' were established, at which prizes (such as agricultural implements, rubber boots, and other practical items) are given to the farmers and cooperatives that produced the most pyrethrum in a given year. These Farmers' Days are attended by USAID staff, local authorities, and high-level SOPYRWA staff, all of whom give speeches and generally encourage further farmer efforts in the production of the valuable flowers.

The project assisted SOPYRWA in re-organizing cooperatives (Mukombozi, 2009b). It is claimed - without any substantive explanation - that this reorganization will 'empower farmers' (Kayisinga, n.d). The project also aims to increase the tonnage of flowers produced through the development of a 'geographic information system-based production decision support system for SOPYRWA so they can better plan and control pyrethrum plant production and quality' (Schattenberg, 2009), which will be discussed below.

SOPYRWA claims on its website that,

Most of [sic] laborers were initially poor rural people who would otherwise be starving or relying on meager incomes from their subsistence farms. Apparently, farmers employed on pyrethrum farms and farm owners are 
wealthier than those who are exclusively growing traditional crops... (SOPYRWA, 2013)

However, this is untrue, as will be shown below.

\section{The Mechanics of Coerced Production}

The pyrethrum sector works through the enforcement of the original lease agreements, which date from the 1960s, and the daily policing of the fields of the population by employees of SOPYRWA locally known as 'delegates'. Monitoring of the pyrethrum zone by SOPYRWA is intense, as there are several delegates for each cell: in one cell where I conducted research, for example, there is one delegate for every 86 households. This allows the delegates to make regular visits to the pyrethrum fields, and is much more intensive for example than the agricultural extension system described in Chapter Five. The policing of the pyrethrum zone by the delegates is therefore a form of discipline, acting at the level of individual households. The effectiveness of disciplinary technologies such as those used by the delegates has been improved since Horizon Inc took control of SOPYRWA. This was evidenced not only through the description of training for delegates in Pyramid project documents, but also from the comments of interviewees. For example, some female farmers contended that: 'Especially since about 
2 years ago, since the cooperatives were founded, there has been more pressure to cultivate pyrethrum'. ${ }^{163}$

One man said regarding his land parcel that: 'The delegates come here every day. I know that by 9am tomorrow, the delegates will be here to check on my plot' ${ }^{164}$

The delegates ensure that the land areas stipulated in the original lease agreements are planted with pyrethrum, and that farmers are cultivating in the ways approved by SOPYRWA. If the delegates find that farmers are not following the directives of SOPYRWA, they report them to higher-level SOPYRWA staff who may direct that the fields in question are requisitioned and cultivated by others; or that the farmers in question are fined. The money from fines paid by farmers is not retained by the local authorities, but is claimed by SOPYRWA itself. ${ }^{165}$ Fines do not appear to be very unusual: one farmer recalled that a close neighbour had been fined 7,000 RWF for delaying in planting pyrethrum during the previous two weeks. ${ }^{166} \mathrm{He}$ also said that the man had been physically beaten by the delegates, though this seems to be a more unusual occurrence.

In the past, fields could be confiscated for several years, but this was reportedly reduced to one year, after local people appealed to the local authorities in $2008 .{ }^{167}$ Nevertheless, a delegate boasted during an interview that, 'we can even spend 3 years cultivating their

\footnotetext{
163 Interview E. of May 6 2011, Kinigi Sector.

164 Interview A of May 2 2011with pyrethrum farmer, Kinigi Sector.

165 Interview C of May 62011 with SOPYRWA delegate, Kinigi Sector.

166 Interview B of May 2 2011with farmer, Kinigi Sector.

${ }^{167}$ Interview C of May 6 2011with SOPYRWA delegate, Kinigi Sector.
} 
land. ${ }^{168}$ When fields are requisitioned, the agricultural labour is either supplied by SOPYRWA (in which case it retains the entire harvest) or is paid for by the household in cash (in which case the household is allowed to retain the harvest). ${ }^{169}$ Temporary confiscation of land does not seem to be very unusual - several of those farmers interviewed knew of neighbours in their umudugudu who had seen their land confiscated at some point in the last few years. ${ }^{170}$ In some cases, land might be permanently confiscated - one farmer claimed to have gained her land in 1978 from a man who refused to grow pyrethrum. ${ }^{171} \mathrm{~A}$ member of a cellule land committee also stated that in the past, local authorities had distributed land in the pyrethrum zone to members of the (largely landless) Batwa ethnic minority, but SOPYRWA had 'chased this population from the land ${ }^{172}$, presumably due to a failure to grow pyrethrum. Other respondents signalled that this issue was the source of a dispute between SOPYRWA and the local authorities. ${ }^{173}$ This shows that while the dispositif incorporating SOPYRWA and local authorities is effective, it is not completely frictionless.

Delegates were quite open about the coercive nature of their work: 'We intimidate them to work -we threaten to take their land from them - to make them work. ${ }^{174}$ Several farmers mentioned that when they had been threatened with fines or confiscation by SOPYRWA, the cooperatives were unable to help them. Some indicated

\footnotetext{
168 Interview B of May 32011 with SOPYRWA delegate, Kinigi Sector.

169 Interview C of May 62011 with SOPYRWA delegate, Kinigi Sector.

${ }^{170}$ E.g. Interview I of May 4 2011, Kinigi Sector; interview A of October 52011 with land cell committee member, Kinigi Sector.

${ }^{171}$ Interview C of May 22011 with farmer, Kinigi Sector.

172 Interview A of October 52011 with land cell committee member, Kinigi Sector.

173 Interview A of October 62011 with Cell land officer, Kinigi Sector; and interviews E and F of October 6 2011 with cell land committee members, Kinigi Sector.

${ }^{174}$ Interview B of May 32011 with SOPYRWA delegate, Kinigi Sector.
} 
that the cooperatives might advocate on behalf of the farmer, but were essentially powerless. ${ }^{175}$ The delegates are intensely disliked by many local farmers, and according to interviews, occasionally suffer the wrath of the population (e.g., they sometimes have their foodcrops uprooted by unknown persons, or may be physically attacked).

\section{The Economics of Pyrethrum Production}

Disciplinary technologies are necessary because of the economics of production and marketing, which are unfavourable to producers.

Anyone wanting to sell a pyrethrum harvest has to join a cooperative, which involves payment of an annual membership fee. This is usually $5000 \mathrm{RWF}$, about US $\$ 8.50$, which represents more than 8 days of agricultural wage-labour. Farmers commented that prior to the re-organization of cooperatives in 2009 , the associations demanded only 2,000 RWF in membership fees. ${ }^{176}$ The institutional changes overseen by SOPYRWA have therefore resulted in higher costs for the farmers.

While cooperative leaders (as well as individual farmers) publically ask for increases in the farm-gate price (see e.g. Mukombozi, 2011), there is apparently little that they can do to apply pressure on SOPYRWA to increase prices. The structural conditions under which they operate (a monopoly over pyrethrum processing by SOPYRWA; confiscation of land in the cases of non-cultivation of pyrethrum) mean that the usual means through

\footnotetext{
175 Interviews F and G of May 42011 with pyrethrum farmers, Kinigi Sector.

176 Interview B of May 42011 with pyrethrum cooperative member, Kinigi Sector.
} 
which organized labour can increase its bargaining power are not available (e.g.

negotiation with multiple potential buyers; the threat of a strike). USAID documentation disingenuously suggests that the Pyramid Project has improved the 'market links of Rwandan farmers' (USAID, 2010: 14); however the reality is that there is only one market for pyrethrum, controlled entirely by SOPYRWA, and the deepening of 'market links' farming households becoming further enmeshed within SOPYRWA's disciplinary systems.

The economics of pyrethrum cultivation are extremely unfavourable to producers. It has a long gestation period, meaning that it spends at least nine months in the field from planting to the end of the harvest; under the new cultivation regimes introduced by the Pyramid Project, this will increase to a full year. ${ }^{177}$ This compares unfavourably with other crops, such as potatoes, which can be planted and harvested at least twice a year. It is also a highly labour intensive crop. ${ }^{178}$ In interviews, pyrethrum farmers indicated that on a per-hectare basis, pyrethrum provided only $10 \%-38 \%$ of the value of potato production, which is generally the most economically viable crop in the area. These figures are supported by the literature on pyrethrum and potato production in Rwanda (see Appendix One for calculations and sources) which shows that pyrethrum provides only between $5 \%$ and $28 \%$ of the value of potatoes. One study found that while farmers

\footnotetext{
${ }^{177}$ Once seedlings have been transplanted in March or early April, the plants spend about three to four months in the ground before the flowers can be harvested. Harvesting typically continues for up to six months but the Pyramid Project attempts to extend this harvest period to a duration of eight months (Pyramid Project, 2011).

${ }^{178}$ In addition to the long harvesting period, pyrethrum fields must be weeded more intensively than other crops, because the distance between the plants and lack of leaf cover (when compared with other crops such as potatoes).
} 
earn 1,000 Rwf per dry kilogram of flowers, the average production cost is about 2,000 RWF per one kilogram (Tibrichu and Buykusenge, 2009).

The lack of economic benefit from pyrethrum is reflected in the fact that no formal or informal land rental market exists for land under pyrethrum cultivation, even though active rental markets exist in the pyrethrum zone for the cultivation of potatoes and other crops. ${ }^{179}$

Pyramid Project documents claim to have improved farmer incomes: 'These improvements have translated into increases in farmer incomes, from a total of 250,000 USD in 2008, to 1,186,800 USD in 2011' (Pyramid Project, 2011).

However, these 'increases in farmer incomes' represents only the aggregate amount of money paid by SOPYRWA to farmers, rather than profit. ${ }^{180}$ Once again, aggregate figures obscure micro-level patterns. The increases in pyrethrum production result in part from increases in the amount of land put under pyrethrum production, and these figures therefore represent a disinvestment from more profitable crops, such as potatoes. No attempt is made in the project documents to estimate the opportunity costs of this spatial expansion of pyrethrum production. Increased income also results from increases in investments of labour and artificial fertilizer; these inputs are not costed. It is not surprising that a 2011 US government audit of the project found that: 'Although

\footnotetext{
${ }^{179}$ Multiple interviews with local 'conciliators' (abunzi) and members of cell land committees, Musanze District, October 2011. Rental contracts stipulate what crops will be grown by the person leasing the land. ${ }^{180}$ The figures are not disaggregated or explained in the Pyramid report. In response to a request for more information on this figure, Pyramid project staff explained that figures increased because 'production increased and more farmers resumed planting pyrethrum' (email communication with Pyramid project staff, 29 May 2013).
} 
the project had enhanced drying facilities, conducted business training, and exceeded its annual target for production of pyrethrum, few farmers interviewed stated that their incomes had improved because of those activities' (Office of the Inspector General, 2011, italics added).

Rather than improving smallholder incomes, Horizon's main aim is likely to be to make a profit. SOPYRWA has achieved a 380\% increase in export revenues from US\$1,125,000 in 2009 to $\$ 4,315,000$ in 2011.

\section{State Discourse on Pyrethrum Production}

SOPYRWA often uses the pro-government media to put forward a narrative of mutual benefit through pyrethrum production, in which both farmers and the nation benefit financially (Anonymous, 2011b). However, official government documents emphasize the benefits at the national level, rather than local level (MINICOM, 2011).

The government of Rwanda sometimes implicitly acknowledges that the crop is primarily of value not to the smallholders, but to SOPYRWA. During an annual ceremony organized by SOPYRWA to celebrate pyrethrum production, the Governor of Northern Province made a speech in Kinyarwanda, during which he recognised that 'There are some [people] who don't value the cultivation of pyrethrum, saying that it's for the government, but I tell you that one must have the passion of the state and look to the future of the country....' 
Here it is possible to recognise the particular moral framing of 'development' that has been achieved by the RPF, which has the effect of rendering adhesion to government programmes 'patriotic' and criticism as 'unpatriotic'. The Governor went on to ask all institutions involved in pyrethrum production to increase their efforts so that pyrethrum increases its share of national export earnings from $20 \%$ to $40 \%$ by $2015 .^{181}$

Corporate pyrethrum production is linked to state plans. Pyrethrum cultivation was included, in the appropriate agro-ecological zones, as part of the regional crop specialization programme (Tibrichu and Buykusenge, 2009). The state administrative machinery, in addition to the disciplinary technologies of SOPYRWA, is part of the dense institutional and spatial field of control within the pyrethrum zones. For example, the Musanze District Imihigo for 2010-11 planned an increase in the total area under pyrethrum cultivation from 1,512 ha (July 2010 total) to $1542 \mathrm{Ha}$ (District of Musanze, 2011). In fact, this target was surpassed: an additional 52 ha came under pyrethrum cultivation in 2011.

The quantitative targets set by the government, SOPYRWA, and their partners in the Pyramid Project are all related to either production targets (e.g. aggregate annual yields, yields per hectare) or income for SOPYRWA (i.e. SOPYRWA's profits or total export figures). In contrast, there does not seem to be any quantitative target related to farmer incomes, or farmer profits per unit of land planted with pyrethrum.

\footnotetext{
${ }^{181}$ Field observation October 7, 2011 during SOPYRWA's 'farmers' day' event, Musanze District.
} 
It was noted in Chapter Three that some of the choices of 'approved crops' under the regional crop specialization programme appear to have been made in order to ensure that Rwandan agro-processing facilities do not continue to operate under-capacity but can purchase significant quantities of Rwandan production to become more profitable. This was the case in the maize sector, for example; and it also seems to be true for the pyrethrum sector. The SOPYRWA factory is capable of processing 3,000 tons of flowers annually but in 2011 it received only about a third of that (Anonymous, 2011a. In order to become more profitable, the firm is seeking to put 2000 ha of land under pyrethrum

production in Gishwati, Western Province (Anonymous, 2011a) and wants to 'expand pyrethrum plantations by encouraging farmers from the districts of Gicumbi, Rutsiro, Karongi Nyamasheke and Nyamagabe', according to an interview by the General Manager of SOPYRWA (Majyambere, 2011).

\section{Tensions between Governmental and Disciplinary Technologies}

The media coverage of the pyrethrum sector in the pro-government Rwandan media emphasizes the uptake of new technologies, such as improved seedstock and fertilizers (Gasore, 2013; Anonymous, 2011a; Mukombozi, 2012); there are also references to a need to encourage a 'savings culture' amongst farmers (Majyambere, 2011) which echoes broader ideas of mindset change, and mention of positive farmer responses to improved prices (Anonymous, 2011b). These are elements of the composite image of 
the modern farmer, and these governmental approaches been supplemented through some incentive based systems, such as the annual 'Farmers' Days'.

Through the Pyramid project, the government and donors communicate health 'messages' and attempt to encourage pyrethrum farmers to reduce the size of their families. The use of community theatre and radio programmes, and the 'interpenetration of themes' (Purdekova (2012: 199) between activities (with agronomists lecturing on hygiene, and health workers preaching good governance) in order to promote behavioural change related to health and family planning as well as agricultural productivity was pioneered in the coffee sector. These approaches are consciously diffuse, both temporally and spatially. For example, through use of the 'life player' radio/recorder (see below) radio programmes, and local people's responses to them, can be recorded and re-played, and shared among different listener groups at multiple spaces and moments. Information dissemination is intended to achieve as much spatial and temporal coverage as possible. The use of 'peer educators' (based on a training-of-trainers' model, sometimes also referred to as the 'barefoot' extension model) ensures that the training infiltrates the social milieu, as well as the professional setting. In short, the system is based on a strategy of saturation of the target zone, reminiscent of the governmental strategies outlined by Foucault. This strategy of repetition and diffusion is necessary, in the words of a SOPYRWA manager, as: 'it's hard because they are illiterate: we have to tell them again and again' ${ }^{182}$

\footnotetext{
${ }^{182}$ Interview B of May 122011 with senior SOPYRWA staff, SOPYRWA factory, Ruhengeri town.
} 
These activities are framed, in the official SPREAD project discourse, as part of a broader effort to improve the welfare and well-being of farmer households. Agricultural technicians are trained in basic health education techniques, while health workers are placed on agricultural cooperative committees (PEPFAR, 212: 278). This is described as an, 'integrated approach to health and agribusiness' (ibid: 280). However, this model makes claims beyond the mere institutional benefits and efficiencies of 'integration'; there is an implied link between improved health, better family planning, and the material outcomes of coffee production (e.g. improved quantity and quality of coffee). In the words of SPREAD personnel: 'Good health guarantees better production; you can only produce when you are healthy'. ${ }^{183}$

However, the slogans for the SPREAD project subtly speak to the broader assumptions made in much of the Rwandan government discourse. These slogans include, for example, 'Good health for coffee development' and 'Let's work together for healthy families and strong cooperatives' (PEPFAR, 2012: 280). The terms development and strong cooperatives resonate with the broader message of national development put forward through multiple and interrelated platforms by the Rwandan state machinery: material improvements, 'good governance' and 'unity and reconciliation' are wound together in a coherent narrative. Care of the self, this narrative implies, is as much a duty for the purposes of national development as it is a rational strategy for individual benefit. Such a narrative, as discussed in Chapter Two accords with the theoretical literature on strategies of governmentality.

${ }^{183}$ SPREAD Project Health Programme coordinator, cited in Bucyensenge, 2011. 
This emphasis on the production of self-governing subjects is present in some of the discourse of SOPYRWA staff. For example, a SOPYRWA manager argued that:

Fragmentation of plots is a big challenge: so it means that [soil] fertility will reduce, even with all the good agricultural practices, they have to control population growth. We have a medical arm to sensitize them to control the population: to reduce the number of mouths to feed. ${ }^{184}$

Here, the population is self-governing to the extent that it controls its own fertility; at the same time, rather than framing health and family planning interventions as part of the public good, this SPREAD manager sees it as part of its own disciplinary operations, which are geared towards improving productivity. Of course, this statement, which echoes the national-level concerns with land scarcity, fragmentation of plots, and demographic growth (e.g. MINITERE, 2004; MINECOFIN, 2000) also includes a logic of containment. 'The population' here is defined as the population of the pyrethrum zone, implicitly fixed to the pyrethrum-producing land. The pyrethrum zone is seen as a distinct sphere, under the governance of SOPYRWA and its partners.

With the intensive 'development' interventions of the Pyramid Project (particularly in the areas of health and family planning) we see paradoxes analogous, in some ways, to those contradictions in government policy identified in other chapters (particularly Chapters Three and Five). On the one hand, the pro-government media seeks to create the impression that SOPYRWA has put in place sufficient financial conditions (such as

\footnotetext{
${ }^{184}$ Interview B of May 122011 with senior SOPYRWA staff, SOPYRWA factory, Ruhengeri town.
} 
prompt payments for pyrethrum, and access to credit) that allow and encourage pyrethrum farmers to 'develop' themselves, in ways clearly associated with the idea of the 'self-governing subject'. For example, an 'advertorial' in a Rwandan newspaper mentions, '...the excellent terms that Horizon offers [the farmers], encouraging them to work harder, save for the future, feed their families better, send children to school and so on... Which farmer wouldn't work hard given such an enabling environment?' (Anonymous, 2011b)

Nevertheless, the idea of the 'farmer as rational development actor' model is undermined in the pyrethrum zone by the intense and comprehensive nature of intervention by the various actors. The mechanics of coercion are currently recognizable as disciplinary technologies, which operate largely at the level of the individual household, and which rely heavily on constant case-by-case monitoring, and enforcement through the threat and use of punishments.

Through its Geographic Information System (GIS) component, the Pyramid Project has collected and digitized various data on the pyrethrum zone, and has created maps detailing the locations of cooperative members' fields, the size of their landholdings, and similar information (Pyramid Project, 2011). This effort has seemingly been delayed by the departure of the SOPYRWA manager of the GIS project component, and the effects of this activity are hence not yet clear. It potentially represents an extension of existing disciplinary technologies. 
We might ask, if the 'excellent terms' that SOPYRWA offer are sufficient to encourage the farmers to take on the behaviours of 'good citizens', why is it necessary to conduct such intensive training and sensitization? If the 'enabling environment' is so positive, then why must such intense disciplinary technologies be implemented to force farmers to increase production?

One of these interventions, in particular, resulted in events that illustrate some of the tensions between the RPF's parallel trajectories of control, on the one hand, and subjectification through governmental strategies on the other hand. In 2011, Lifeline Radio attempted to distribute the 'lifeplayer' radio to pyrethrum farmers in the project area. The lifeplayer is a state-of-the art technology that incorporates a microphone, a memory card that can be used with other IT devices, a solar panel, cellphone charger, and other functions. As mentioned above, this technology represents a key node in a governmental network intended to saturate the pyrethrum area with 'messages' regarding health, family planning, good cooperative management practices, and other issues. Radios would be distributed to a 'guardian' of the devices who would make it available for group listening activities.

It appears that SOPYRWA was uncomfortable with farmers in the area having access to such technology. According to internal project documents, 'The unique product capable of connecting even the remotest farmers to radio and internet information also raised concerns among SOPYRWA owners. As a result, the new radio distribution was halted' (Pyramid Project, 2011. Emphasis added). The document says nothing about the reasons 
for concern, but we note that it was the owners of SOPYRWA - the RPF -that raised the issue. It took over a year of negotiations before the lifeplayers (with their functionality deliberately limited) could be distributed to farmer listening groups with the permission of the authorities. This episode says much about the limitations of the RPF vision for creating a new Rwandan subject; or, at least, suggests that the military see this governmental project as incomplete. The local population, in the eyes of the owners of SOPYRWA, are not fit to be trusted with versatile, networked information technologies. This is a significant realization in the context of the government of Rwanda's vision of creating a 'knowledge economy' through massive investments in information technology, and the broader dependence of the Rwandan development model upon a New Rwandan subject.

These events also provide an insight into the relationship between SOPYRWA and the various international partners that contribute to the governmental functions of the pyrethrum-extraction system. SOPYRWA was able to unilaterally block a project activity for a full year, and then acquiesced to the distribution only under certain conditions. Clearly, relationships between the various state, corporate and non-governmental actors in the pyrethrum zone are characterized by negotiation rather than donor imposition. 


\section{Land Tenure Tensions}

The tensions between discipline and governmentality also play out in terms of the land tenure system in the pyrethrum zone. The national land registration process led to the emergence of social and legal-administrative tensions over the nature of the landholdings in the area ${ }^{185}$. According to local land committee staff who were involved in the demarcation and registration of landholdings in parts of Kinigi sector, SOPYRWA claimed ownership of all the land under its institutional control. However, the National Land Centre (NLC) staff conducting the registration exercise, backed by NLC decisionmakers in Kigali, refused to register the land under the name of SOPYRWA. NLC staff communicated the same discourse of 'ownership' of the land by the local householders, and use of the land to access credit from financial institutions, that was disseminated throughout the country. According to local citizens; 'The Land Centre people said, "now, the land is for you"' ${ }^{186}$ At the same time, local authorities and SOPYRWA continued to emphasize in public meetings that the policy of compulsory pyrethrum cultivation would continue, no matter how the land was to be registered. Indeed, these two seemingly contradictory discourses were sometimes presented simultaneously, as SOPYRWA staff were often invited to speak during the 'sensitization' sessions of the National Land Centre staff. ${ }^{187}$

\footnotetext{
${ }^{185}$ As noted in Chapter Three, the land regularisation process, as it was officially called, involved 'awareness-raising' campaigns which disseminated the notion that Rwandan citizens would become land owners through registration of land claims. However, the land tenure system is one of leasehold, with the state claiming ultimate ownership of land. Many farmers were unpleasantly surprised to realize that they are now leaseholders rather than title-holders (i.e. absolute owners of land).

${ }^{186}$ Interview A of October 82011 with member of cell land committee in Kinigi Sector; Ruhengeri town

${ }^{187}$ interview I of October 62011 with local mediator (member of abunzi), Kinigi sector.
} 
There is some evidence that the land registration process, by raising expectation of 'land ownership' by the population, also raised the willingness of farmers to resist SOPYRWA's policies. A member of a cell land committee stated that the number of people trying to resist the pyrethrum policy had increased since the land registration process started. ${ }^{188}$ Respondents also mentioned a specific case mentioned of a man who, 'refused to weed the fields of pyrethrum, saying that now the land was for him, because he had the [leasehold] document ${ }^{\prime 189}$ This man was fined and had his land cultivated by SOPYRWA. In 2012, the population of in the pyrethrum-producing zones of Kinigi received word that definitive land leases were available for them to pick up at the local administrative offices. ${ }^{190}$ According to those working in the land registration programme, the leases included household members as the leaseholders, but listed SOPYRWA as amongst those having an interest in the land. The children of the householders were not listed in the leases as having an interest in the land. Under Rwandan law, those listed in the lease as having an interest in land (normally the spouse and/or children of the leaseholder) must provide written permission before land can be sold, rented or otherwise transacted. Importantly, the leases also stipulated amongst the 'conditions' of lease, that pyrethrum should be grown upon $40 \%$ of each parcel. The same sources reported that a similar system had been used to register the land of those living in tea-growing areas, and working as out-growers for tea plantations. These leasehold documents, which protect the user rights of the land-users and allow for market transactions of

\footnotetext{
188 Interview A of October 82011 with member of cell land committee in Kinigi Sector; Ruhengeri town

189 Interview E of October 62011 with cell land committee member, Kinigi Sector.

190 Phone interview with personnel involved in land registration, Musanze District, $18^{\text {th }}$ June 2012.
} 
land, nevertheless give SOPYRWA a veto over such market transactions. As such, they embody the tensions between disciplinary and governmental modes of agricultural development in Rwanda.

National Radio reported that many local people were unhappy with the arrangement specified in the leases. ${ }^{191}$ Many people were reportedly surprised to be registered as 'leaseholders' rather than landholders. One local person interviewed on the radio stated that the government had 'taken our land' ${ }^{192}$ while another argued: 'If the government wants to cultivate our land, it is free to hire workers to farm on our land, instead of using the population, who do not profit' ${ }^{193}$

These reactions are not unique to the pyrethrum area, as people in different parts of the country have expressed similar views, and many have declined to collect their lease documents from the collection points (Karake, 2012). The particular concerns and struggles of pyrethrum farmers in Kinigi regarding conditions attached to land 'rights' are therefore a microcosm of broader patterns across Rwanda.

\section{Farmer Perceptions of the Pyrethrum Production and Marketing System}

The changes to SOPYRWA over recent years have led to some improvements - as mentioned previously, the price of pyrethrum per kilo has increased since 2008; farmers say that they are almost always paid on time, compared to the period before 2009 ,

\footnotetext{
${ }^{191}$ Programme broadcast on Radio Flash FM (Kigali), 21st October 2012. Translated from the original Kinyarwanda.

192 Ibid.

${ }^{193}$ Ibid.
} 
when payment was often seriously delayed; cooperatives provide a little credit to farmers when they need it.

However, despite these benefits and improvements, the structural injustices in the sector remain, and are so fundamental, that these improvements hardly seem to figure into the calculations of farmers regarding the pros and cons of pyrethrum production. None of the pyrethrum farmers interviewed during the course of fieldwork gave a positive assessment of pyrethrum as a crop. Even a President of a pyrethrum cooperative, who by necessity works closely with SOPYRWA, recognized that pyrethrum is not an economically viable crop for farmers: 'If you estimate the benefits and the losses involved in growing pyrethrum, it's not sufficient, taking into account the investments that the farmer has to make'. ${ }^{194}$ A President of a different pyrethrum cooperative acknowledged that, 'we work for very little. ${ }^{, 195}$ The reluctance amongst farmers to plant pyrethrum is acknowledged even by SOPYRWA, who admitted that; 'If you gave them priority [to make decisions], they would just grow something to eat: potatoes' ${ }^{196}$ However, close examination of the SOPYRWA staff-member's statement reveals the kind of bias against smallholder farmers discussed in previous chapters. He characterizes potatoes as 'something to eat', implying that the population of the pyrethrum zone prefers to cling to subsistence rather than move into more commercial activities. This is a fallacy. It is not the fact that pyrethrum is a commercial crop that bothers farmers: it is the fact that it does not pay as well as other crops.

\footnotetext{
${ }^{194}$ Interview D of May 32011 with cooperative President, Kinigi Sector.

195 Interview A of May 72011 with President of a pyrethrum cooperative, Ruhengeri town.

196 Interview B of May 122011 with senior SOPYRWA staff, SOPYRWA factory, Ruhengeri town.
} 
In addition to the opportunity costs that pyrethrum represents - with households losing significant amounts of potential earnings every year -the social impacts of forced pyrethrum cultivation are also severe.

The original 'paysannat' landholdings of 2 hectares are now occupied by extended families related to the original household that signed lease agreements with SOPYRWA in the 1960s. These households have to negotiate the labour and land requirements of pyrethrum production within these 2 ha parcels between themselves. ${ }^{197}$ This sometimes results in tensions, particularly when some family members are suspected of using personal connections or bribes to influence the delegates and reduce their own share of the burden of pyrethrum production. ${ }^{198}$ Households who have small parcels of land are forced, in some years, to devote their entire landholding to pyrethrum, making it very difficult for them to access food during that period. ${ }^{199}$ Local people recalled instances where arguments amongst neighbouring families have ended with physical violence being used, resulting in machete wounds in some cases. ${ }^{200}$

Delegates are also at risk of reprisals from disgruntled farmers, as mentioned above. For example, a delegate had his foodcrops uprooted in his fields in Kaguhu cellule, Kinigi Sector, in early October 2011, and the same delegate was also physically attacked. ${ }^{201}$ Such events reportedly happen 'every year'. ${ }^{202}$

\footnotetext{
${ }^{197}$ Interview C of $4^{\text {th }}$ May 2011.with farmer, Kinigi Sector.

${ }^{198}$ Interview A of October 92011 with member of cell land committee in Kinigi Sector.

${ }^{199}$ Interview A of October 82011 with member of cell land committee in Kinigi Sector.

${ }^{200}$ Interview A of $9^{\text {th }}$ October 2011 with member of cell land committee in Kinigi Sector.

${ }^{201}$ Ibid.

202 Ibid.
} 
The local 'conciliators' (abunzi) who are legally empowered to mediate disputes, have been forbidden by local authorities from mediating disputes relating to pyrethrum. ${ }^{203}$ According to the abunzi, this policy has been in place for many years, but was reiterated most recently in a meeting at the Kinigi sector office in August $2011 .^{204}$

This demonstrates the levels of power enjoyed by SOPYRWA, which calls upon local authorities to assist with disputes and issues such as fines imposed on farmers who break SOPYRWA's rules. To some extent, the state services available to other Rwandan citizens have been suspended inside the pyrethrum zone.

\section{Strategies of Resistance}

Given the levels of resentment amongst farmers towards the pyrethrum production system, it is unsurprising that they attempt to invest as little as possible in pyrethrum cultivation. Local people have a suite of tactics to avoid following the directives of SOPYRWA regarding planting, weeding, and harvesting.

A few people have attempted to use quite direct means to oppose SOPYRWA's directives. For example, one man planted eucalyptus trees. When in August 2011 the delegates cut down the trees he had planted to grow pyrethrum, he decided to uproot

\footnotetext{
${ }^{203}$ The Organic law $n^{\circ} 02 / 2010$ of 09/06/2010 which forms the legal basis for the abunzi institution states that abunzi have particular responsibilities for mediating disputes related to removing or displacing land and plot boundaries; any kind of destruction or damage to crops. On the other hand, the law does stipulate that abunzi should not hear cases involving commercial contractual obligation. Given the fact that most of the current landusers in the pyrethrum zone are not the original leaseholders and hence have no formal contract with SOPYRWA, disputes between farmers and SOPYRWA exist in a legal grey area.

${ }^{204}$ Interview C of October 52011 with local mediator (member of the abunzi), Kinigi Sector.
} 
the pyrethrum. He was arrested and, according to local people, spent almost two weeks in the local police station. ${ }^{205}$ Respondents provided several other such examples.

However, because of the imbalance of power between farmers, SOPYRWA and the local authorities, most farmers avoid direct acts of resistance to the pyrethrum regime imposed upon them. Instead, many households use various forms of trickery, footdragging and/or corruption. While these rarely allow households to neglect pyrethrum cultivation completely, they often allow the household to keep the investments of labour to a manageable level. Though there is a very real possibility of punishment for these actions - ranging from fines to confiscation of land - interviews with farmers and SOPYRWA delegates reveal a systematic calculation of risks versus rewards involved in the farmers' decision-making processes. This phenomenon is reminiscent of efforts by smallholder farmers in Kirehe District to continue planting their preferred choice of foodcrops instead of maize, the government-approved crop (see the following chapter).

In Kinigi, despite very intense monitoring of their fields, farmers have a number of strategies that they can employ. In order to avoid planting, farmers often pretend to have health or family problems, and may bribe the delegate to support their claim. According to a delegate of SOPYRWA; 'Ssome people try to avoid planting it - until the planting season is passed - then they say 'oh the season is passed, I will have to grow

\footnotetext{
${ }^{205}$ Interview A of October 92011 with member of cell land committee in Kinigi Sector, Ruhengeri town.
} 
other crops'. If the delegates uncover these tricks, they uproot the plants and give fines. $^{206}$

Many farmers also attempt to plant pyrethrum in the rockiest, least fertile areas of their landholdings. ${ }^{207}$ Farmers may also try to plant in out-of-way corners of their fields, that are inconvenient for the delegates to visit and therefore easier to neglect. However this is a difficult strategy to maintain over multiple seasons without bribing delegates, as SOPYRWA insists that pyrethrum is rotated between different fields each season.

Farmers often try to lie about the amount of land under cultivation. However, delegates know the area well and fields tend to be separated into standard dimensions, with noticeable field boundaries (rocks, bushes, particular species of grasses) that are difficult to erase. ${ }^{208}$ This is therefore difficult to achieve.

Much easier is resistance through omission: failing to keep up with weeding schedules, for example. Because fields are rotated regularly, pyrethrum fields almost always have some seed potatoes under the soil, which the delegates insist should be uprooted. If they can, pyrethrum farmers allow the potatoes to mature, at the expense of the pyrethrum crop.

The final form of resistance identified is the covert sale of their land. This is a risky strategy as it is specifically prohibited by SOPYRWA, and those buying land secretly are at risk of losing it. Normally, those leaving the area sell the land to relatives, who if

\footnotetext{
${ }^{206}$ Interview C of May 62011 with SOPYRWA delegate, Kinigi Sector.

${ }^{207}$ Phone interview with development expert for an NGO working in the pyrethrum area, August 302012.

${ }^{208}$ Interview B of May 62011 with farmer, Kinigi Sector. For example, fields are often maintained at a size of $20 \mathrm{~m} \times 20 \mathrm{~m}$, a size that is popular for land leasing.
} 
challenged by the authorities or SOPYRWA can attempt to convince them that they are merely managing the land, temporarily. Such sales seem to be fairly common: respondents cited 2 cases from the same cellule in December 2010, for example. ${ }^{209}$ However, sales are made more difficult by disagreements within families over which piece of land can be sold, and for how much. Because land is managed by SOPYRWA in terms of the original paysannat 2 hectare blocks, rather than individual household parcels, families also have to manage the land in a communal manner. In the words of a member of the abunzi; 'No-one can say that the land belongs to them, but only to the family'. ${ }^{210}$ This limits the capacity of individuals to sell their land and leave. ${ }^{211}$

In summary, the strategies of resistance practiced by farmers represent a minor, if persistent, obstacle to SOPYRWA's production system. Production figures released by the Pyramid Project, as well as the comments of local farmers, suggest that the policing of the pyrethrum fields by the delegates has become more intense and effective in recent years, rendering such micro-practices of resistance more difficult. However, while the impacts on production may be minor, we should not underestimate the broader implications of ongoing resistance. The determination of some local people to cultivate as little pyrethrum as possible, despite the very high chances of being found out and sanctioned, is a sign that they refuse to accept the conditions imposed upon them. The ongoing resistance against the disciplinary technologies employed by SOPYRWA, and the negative social impacts of the pyrethrum production system, were concisely

\footnotetext{
209 Interview A of October 62011 with Cell land officer, Kinigi Sector

210 Interview $\mathrm{G}$ of October 62011 with local mediator (member of the abunzi), Kinigi Sector.

${ }^{211}$ Interview F of October 62011 with cell land committee member, Kinigi Sector.
} 
summarized by a local respondent, who stated that, 'there is a war [over] pyrethrum'. ${ }^{212}$ Such language is echoed by maize farmers in Kirehe, as will be described in the following chapter.

\section{Coercion as Philanthropy: Development and Discipline}

The owner of SOPYRWA, as mentioned earlier, is Horizon Inc. This firm was created as an 'investment arm' of the military, the Rwanda Defence Forces (Booth and GoloobaMutebi, 2011). Like Crystal Ventures (formerly Tri-star) this corporation is associated directly with the RPF and its finances are extremely opaque. Rather than a 'parastatal', then, Horizon is best described as a 'party-statal' which mingles its finances and objectives with those of the ruling party, rather than the state as a whole (Gokgur, 2012). It has been noted that the resources of such companies 'may well be used to fund the RPF's extensive intelligence network and other more hidden enterprises' (USAID, 2011a). According to experts on processes of privatization, 'no publicly available data exist on their legal status, exact shareholding structure, assets, accumulation of economic rent or profits, allocation of operating surplus to investment and social obligations; and their borrowings from the financial sector and payback rate' (Gogkur, 2012).

Booth and Golooba-Mutebi (2011), within a broader argument in favour of the 'development state' model, argue that Horizon Inc and other similar corporations play

\footnotetext{
${ }^{212}$ Interview D of October 62011 with cell land committee member , Kinigi Sector.
} 
an important role, along the lines of those played by 'venture capital' enterprises in expanding some sectors of the economy, taking on risks that private corporations are unwilling to take. They argue that the general commitment of the government of Rwanda - and particularly President Kagame - to the 'public good', and particularly the official stance against corruption, means that Horizon Inc's profits are likely to be ploughed back into the development of the country. More than this, they put forward the view that Horizon Inc has 'strategic social objectives'. They suggest that SOPYRWA has a positive impact not only on incomes but, implicitly, on the socio-political situation in Musanze and neighbouring Districts:

The intervention in pyrethrum was necessary to avert the collapse of a privatised parastatal [SOPYRWA] which would have had harmful employment and smallholder income effects in the still politically fragile mountain region of the North-West. (Booth and Golooba-Mutebi, 2011)

My research suggests that rather than having harmful effects on smallholder incomes, the collapse of SOPYRWA would have allowed smallholder farmers in the pyrethrum zone switch from loss-making pyrethrum to other crops, with positive impacts on incomes. Based on the comments of smallholder farmers during fieldwork the policies of SOPYRWA only contribute to political tensions in Musanze District. 


\section{Conclusion}

Households in the pyrethrum zone are extremely bitter about their obligation, under SOPYRWA's rules, to grow pyrethrum. According to respondents, pyrethrum is only for 'those with no other means to live'. One respondent stated bluntly that, 'no-one wants to grow pyrethrum ${ }^{213}$. The younger generation, in particular, does not want to grow pyrethrum. Three young men were summoned to the sector offices to explain themselves after they called pyrethrum cultivation 'slavery'. They fled the region, fearing punishment. Local people see themselves as part of a larger machine, as 'instruments of SOPYRWA.' ${ }^{214}$

Respondents use of the term 'worker' echoes popular discourse amongst maize farmers in Kirehe (see Chapter Nine) and reinforces the popular sense that they exist, at least in the eyes of SOPYRWA, not as independent, self-governing subjects, but primarily as a part of an integrated system for the extraction of profits from the area.

Several respondents compared the current regime of pyrethrum cultivation to slavery. ${ }^{215}$ It should be noted that terms such as slavery or serfdom are extremely politically sensitive in Rwanda, due to the history of forced labour during the precolonial and colonial periods, and the ways in which this narrative of exploitation was adapted (and arguably exaggerated) and deployed by those advocating genocide in

\footnotetext{
${ }^{213}$ Interview A of October 62011 with member of cell land committee in Kinigi Sector; Ruhengeri town. ${ }^{214}$ Interview F of October 62011 with cell land committee member, Kinigi Sector.

${ }^{215}$ Interview A of 29 April 2011, Kinigi Sector; Interview D of May 12011 with pyrethrum farmer, Kinigi Sector; Interview F of $4^{\text {th }}$ May 2011 with pyrethrum farmer, Kinigi Sector; Focus Group discussion A of $18^{\text {th }}$ February 2013, Kinigi Sector.
} 
1994 (see e.g. Des Forges, 1999). ${ }^{216}$ These ideas of 'slavery' are also found in some farmer narratives in Kirehe regarding maize production, as will be described in Chapter Nine.

The structural conditions under which pyrethrum is produced in northern Rwanda are a particularly stark example of a broader pattern experienced under the CIP. Indeed, some local people are aware of this. One member of a land committee said that:

I have come to realise that after having the official documents for land, the whole country will become like the farmers of pyrethrum, for the following reasons: the certificate that we will have is for leasing [not ownership]; the population doesn't have the right to cultivate its choice of crops; you will not have the right to sell the land without paying taxes, fees, etc. ${ }^{217}$

The involvement of donors such as USAID in a private-public partnership along with a completely opaque 'party-statal' such as Horizon Inc, in the name of 'improving smallholder livelihoods', says much about the close relationship between the US government and the RPF. The legitimacy that the pyrethrum model enjoys (demonstrated by USAID assistance; and policy publications such as Booth and GoloobaMutebi, 2011) suggests that other forms of problematic state-imposed contract farming are likely in the future.

\footnotetext{
${ }^{216}$ As will be explained in more detail in Chapter Eight, concepts of servitude in Rwanda are bound up with the historical relations between Hutu and Tutsi. In the late pre-colonial period and especially the colonial era, exploitative relations between the rulers and the ruled took on increasingly socio-ethnic character, with Tutsi largely exempt from oppressive labour requirements (Newbury, 1988).

${ }^{217}$ Interview H of October 62011 with cell land committee member, Kinigi Sector.
} 
The identification of the 'pyrethrum zone' as a distinct form of territoriality in Rwanda allows us to build on discussions of 'enclave extraction' (Ferguson, 2006: 203) which are often 'transnational spaces' due to their profound links with international capital (Ferguson and Gupta, 2002). The pyrethrum zone represents an enclave of extraction, in which local people are subjected to particular governance systems, crafted to enable and sustain extraction, that differ from those in other parts of the country. Unlike many enclaves, there is little in the way of physical infrastructure to demarcate the boundaries of the 'enclave'. Instead, the infrastructure largely comprises the delegates, and the disciplinary systems are plugged directly into the governance software and legal architecture of the state (the local administrative and land tenure system). The population in the pyrethrum zone lives under different life conditions than communities in surrounding areas.

There is an interplay of governmental and disciplinary strategies employed in the area. In some cases, such as the GIS capacity-building intervention implemented by the Pyramid Project, the international actors expand the disciplinary toolbox available to SOPYRWA; in other cases, such as the lifeplayer distribution, international organizations are acting in support of a more governmental approach. The disciplinary and governmental approaches can, of course, be deployed in complementary ways; but they contain the seeds of possible tension and dissent, as emerging 'self-governing subjects' start to test the limits of the form of subjectivity selected for them. As explained in Chapter Three, the 2005 Land Law was described by the government as the basis of a liberal, market-oriented land tenure regime, which raised citizen expectations regarding 
the commercial opportunities and security of tenure that might result. However, the reality is that the land tenure regime is embedded within disciplinary technologies. Farmers interviewed for this case study recognised this and argue that the model of citizenship which results from the interventions of government, donor and commercial actors in the pyrethrum zone is a limited one, focused on the supply of labour in the interest of Horizon Inc and its corporate partners. The forms of agricultural production that farmers are forced to follow, in the context of extreme land tenure insecurity, result in a variation on the dynamic of proletarianization. This notion of citizenship is based not on an entrepreneurial model that might be associated with greater heterogeneity in the agricultural sector, but rather the consolidation of spatial and institutional homogenization, standardisation and coercion associated with authoritarian high modernism. In contrast to the arguments in Scott (1998), however, this outcome is not an unintended consequence of interventions meant to improve the human condition' (Scott, 1998: 342) but is rather a foreseeable consequence of systems put in place to maximise profits. Claims by the various actors involved that such interventions are primarily intended to increase farmer incomes are rhetorical, and linked to the perpetuation of the Rwandan 'success story' narrative mentioned previously, with its key components of entrepreneurship and liberalization.

The improvements to the disciplinary mechanisms associated with this particular enclave of extraction represent the reconfiguration of ideas of territory and citizenship. Rights and responsibilities associated with citizenship are not extended universally but are reconfigured to enhance processes of extraction. 
The ruling party (and especially its military core), in the form of SOPYRWA, influence state mechanisms - the local imihigo, for example - in essence colonizing aspects of the state system. Some state functions, such as the abunzi dispute-resolution mechanism discussed above, have been deactivated regarding pyrethrum production. SOPYRWA, and the various international corporate, nongovernmental and governmental entities, combine to form an enclave of governance which is both transnational and sovereign. It is transnational because it is fundamentally based on the export economy, and permeated by a liberal discourse of education and self-governance which underpin the governmental strategies. The ruling party exercises control over the profits of pyrethrum (through ownership of the processing system, for example) and dominates the broader vision of 'development'. The constellation of discipline and governmentality in the pyrethrum zone suggests a redefinition or reconfiguration of the state's aims and responsibilities, in conjunction with various strategic partners in its political and commercial activities. As mentioned previously, analysis of dynamics of homogenization depend upon the chosen scale of analysis: this standardised approach to production within the pyrethrum zone represents a force for homogeneity when viewed at the level of the entire pyrethrum zone; however, from a broader geographical scale, this is a highly context-specific set of practices which represents a specific 'space of governance' within Rwanda. 


\section{Chapter Eight: Maize Production in Mahama Sector, Kirehe District}

\section{Introduction}

In contrast to the circumscribed area of resource extraction described in Chapter Six on pyrethrum production in Kinigi sector (Musanze District), this chapter describes systems of agricultural transformation across a more extensive area, less densely populated, and less amenable to commercial crop production due to agro-climatic conditions. These structural conditions have implications in terms of the feasibility of various disciplinary and governmental technologies. Despite these conditions, Kirehe District has managed to consolidate a greater proportion of land than most Districts, and ensure that the majority of households purchase fertilizer. The district had experienced extensive villagization, in contrast to other districts such as Musanze. Kirehe was also selected to be one of eight different districts for the 'pilot' phase of the Crop Improvement Programme (CIP), in Season A of 2007-8 (OECD/WTO, 2011).

The population density of Kirehe district is 286 people/square $\mathrm{km}$, compared to a national average of 416 people/ square km (NISR, 2012b). This reflects the agroecological conditions, which are much less favourable than better-watered Districts such as Musanze, and which have typically necessitated more extensive, rather than intensive, farming techniques. This chapter will describe the ways in which the CIP was implemented in Mahama sector during the pilot phase, and how the CIP system has since been modified to include greater private sector involvement. This private sector involvement does not equate to a straightforward 'liberalization' of the maize sector, as will be described. I then document the various forms of coercion used to force farmers 
to grow maize in preference to more popular staples, and to purchase fertilizer, and the particular ways in which the coordination of state agencies forms what one Rwandan policy-maker has termed a 'connectedness machinery' (Nsanzabaganwa, 2012: 142) well-suited to disciplinary activities. However, I also cite evidence that the authorities have not used all the sanctions available to them in order to improve compliance with the policy. The chapter then examines the total yields of maize which have resulted from the policy, and looks at the actions of farmers who are unhappy with the policy. Rather than positioning the actions of smallholders as 'responses' or 'resistance', I use a more Foucauldian perspective in order to recognise a nascent form of subjectivity which includes elements of the government of Rwanda's entrepreneurial vision, but is explicitly intended to subvert the disciplinary functions of the state.

\section{Background}

\section{Historical Background}

During the pre-colonial and colonial periods, large parts of the eastern region were reserved as pasture for the King's cattle, and population densities were low. During the colonial period, long-term labor migration to neighbouring Uganda or Tanzania was a strategy pursued by many farmers in the region in order to escape regimes of political and economic control that were perceived as exploitative (Newbury, 1988: 211-212).

Following independence, the East was officially opened up for migration. During the period 1962-1976, Kibungo Province saw relatively modest levels of migration, including by Tutsi, who left their areas of origin due to the risks of ethnically-targeted attacks in 
1962-3, and 1973 (Jefremovas, 2004). Throughout the late 1970s, in-migration to Kibungo Province accelerated rapidly, due to increasing scarcity of land across Rwanda. Jefremovas (2004) argues that by the 1980s, little vacant land remained in Kibungo to accommodate newcomers. She contends that there was competition for land between Tutsi inhabitants who had settled there during the 1960s and 1970s, and more recentlyarrived Hutu migrants.

During the genocide, Kibungo Province, which had a relatively high proportion of Tutsi inhabitants, was the scene of a particularly large number of attacks and murders (Jefremovas, 2004), and it was especially socio-politically tense in the immediate postgenocide period (Refugees International, 1996).

Following the genocide, in the late 1990s, the government of Rwanda constructed many planned villages (imidugudu) in Kibungo Province, which was the site of resettlement of many 'old case' refugees.

In the late 2000s, Tanzania expelled a large number of people of Rwandan origin (many of whom claimed Tanzanian citizenship) from Western Tanzania (Human Rights Watch, 2007). Many of these people were resettled in Kirehe District. Like other recent migrants, they were directed to settle in planned villages (imidugudu). More generally, cross-border activities persist. There have been numerous arrests in Kirehe for smuggling of fertilizer, prohibited drugs, alcohol, and other goods across the Tanzanian border (see e.g. RNP, 2012a) which is described as 'porous' (Rwembeho, 2010a) 


\section{Agro-Ecological Characteristics of Kirehe District}

Kirehe District is one of the driest in the country: areas in the east receive on average less than $900 \mathrm{~mm}$ of rain per year (Verdoodt, A. and Van Ranst, 2003, cited in Van Houdt, 2006). The average for Rwanda is $1,250 \mathrm{~mm}$ per annum (GWP, 2012).

The District is also one of the hottest in the country: Eastern parts of the District see average temperatures of more than 21 degrees Celsius (C) (MINAGRI, 2012a) while the national average is 19C (MINAGRI, 2012a). The District is divided into two agroecological zones in some analytical models: the Eastern Plateau zone, and the Eastern Savannah zone (ibid). Others categorise it as a single zone, the Eastern semi-arid agropastoral zone (FEWSNET, 2011a). Classifications of the 'actual capability' of the

District for agriculture - based on assessments of soil type, temperature, and rainfall regimes - suggest that there is much differentiation across the District, with some parts able to support crops only through 'careful' or 'very careful management' and other parts suitable only for pasture (FEWSNET, 2011a).

\section{The Agricultural Reform in Kirehe}

\section{Governmentality and Discourse}

The agricultural reform in Kirehe, as elsewhere in Rwanda, is framed by the government as a matter of modernisation and the facilitation of entrepreneurship, involving voluntary attitudinal change amongst farmers. Poor yields and poverty in the District have been blamed on the previous unwillingness of farmers to adopt more 'modern' 
techniques and crops. For example, the pro-government New Times decried 'farmer's ignorance and traditional attitude' in the District (Rwembeho, 2010b), and claimed that: 'The quantity and quality of maize produced in the district had been low for a long time, mainly due to people's negative attitude towards the crop' (Rwembeho, 2010b).

Likewise, officials of the Rwanda Agriculture Board (RAB) blamed low use of fertilizer on 'farmers' ignorance' (Rwembeho \& Uwamariya, 2012), while MINAGRI claims that larger, consolidated fields are 'more rational' than customary landholding and cultivation patterns (MINAGRI, 2013). In line with this conceptual model, leaders in Kirehe District used various means to encourage and 'facilitate' a shift in farmers' behaviour. According to some observers, the mere demonstration of 'modern' methods made some farmers change their behaviour:

Farmers and local leaders confirmed that it took them a demonstration garden and some computing device to show to farmers tangible results that would resolve them to adopt the change introduced by CIP. Ever since, maize cultivation and crop rotation were implemented without any resistance (Nsanzabaganwa, 2011: 46)

In addition to demonstration fields, the government selected Abajyanama b'Ubuhinzi ('farmer counsellors') as role-models for other farmers (Nsanzabaganwa, 2012: 165). These were part of a broad strategy of assisting farmers to acquire knowledge through 'training, demonstrations and learning by doing' (Nsanzabaganwa, 2011: 49). Such a strategy included government- 
organized trade fairs, presented by the local authorities as an 'opportunity [for farmers] to exchange ideas and re-think their farming methods' (Rwembeho \& Uwamariya, 2012). One informant mentioned the importance of what he called 'hot words', a term we can perhaps translate loosely as 'buzz words':

Public meetings were organized, at the level of the imidugudu, the sector, and the cellule, to convince the population of the importance of the agricultural reform. This awareness-raising [sensibilization] was based on the interests of the people in the convincing 'hot words' that the population would receive free fertilizer, bank credits, international and local markets [for their produce]. Awareness-raising regarding joining a cooperative was also done at the level of the community... ${ }^{218}$

In addition, post-harvest storage facilities have been constructed in order to 'facilitate' farmers to improve their production and marketing of maize (Anonymous, 2011). More recently, efforts have been made to introduce crop insurance (Mangula, 2012). In general, emphasis is placed on the abilities to farmers to make choices, as active, selfgoverning individuals: 'Farmers were encouraged to pool their resources as cooperatives, take advantages of economies of scale in procurement of inputs, utilizing extension services, bargaining for better prices and acquiring of crop insurance services' (Odooboo, 2010). Here then, the state is presented as enacting governmental strategies, acting at the level of the population rather than the individual (Foucault, 2004: 21), and 'guaranteeing and ensuring circulations' in the farming sector (ibid: 29), through

218 Interview F of May 30 2011, Munini cellule, Mahama Sector. 
'allowing the development of ever-widening circuits' (Foucault, 2004: 45) of capital, commodities, and expertise. Particularly following a successful maize harvest in 2010, Kirehe has been held up as an example of behavioural change in the farming sector, despite initial resistance by farmers (Nsanzabaganwa, 2012: 164-5).

Despite the official emphasis on voluntary behavioural change as a result of broadly governmental strategies, both the natural environment and the local population proved highly 'resistant' to the agricultural policy. In the face of frequent low crop yields and various 'everyday forms of resistance', the Rwandan state broadly kept to its blueprint for commercial maize production while relying on technical fixes, using disciplinary technologies, and quashing dissent. While these elements broadly match the 'seeing like a state model', close attention to the strategies of the local authorities in reveal a certain measure of flexibility, as well as (or perhaps, because of) an inability to fully control the counter-strategies of local households. In addition, the agricultural reform provides members of the local government with both legal and illegal sources of profit, while government investment in maize-milling factories means that the state has an interest in generating supply for these corporations, which currently operate below capacity. These elements suggest that it is not only the high modernist 'vision' of agricultural transformation, but also motives of private and state capital accumulation that lie behind the continued efforts to grow maize on a commercial scale in Kirehe. 


\section{The CIP System for Maize Cultivation in Kirehe District}

There are five priority crops grown in Kirehe District: coffee, pineapples, maize, rice, and bananas. These are not all grown in each sector: different sectors specialize in a few of these crops. ${ }^{219}$ In $2007-8$, seven of the District's twelve sectors specialized in maize. ${ }^{220}$ In Mahama sector, the fieldwork site, almost all of the emphasis of the CIP is placed on maize cultivation.

In Kirehe, according to official data, 17,000 Ha (about a third of the total 53,000 Ha of arable land) was consolidated in 2010 , which increased to $36,900 \mathrm{Ha}$ ( $70 \%$ of all arable land) in 2011 and 39,000Ha (almost three-quarters of arable land) projected to be consolidated in $2012 .{ }^{221}$ These figures are well beyond the national average of $19 \%, 37 \%$ and $48 \%$ respectively (Nsanzabaganwa, 2012: 46) although, as will be discussed below, they need to be treated with some caution.

While the authorities have managed to put a significant area under land use consolidation, this process of simplifying agricultural systems has frequently proven counter-productive, as the human, climatic and agro-ecological context has proven to be too complex and variable for the survival of such a simple and unadaptive model.

\section{The 'Pilot Phase' for the CIP: 2007-2008}

The first attempts to implement the CIP in Kirehe District were characterized by logistical, administrative, and planning problems. Those who have studied the

\footnotetext{
${ }^{219}$ Interview A of June 12011 with Kirehe District Agronomist.

${ }^{220}$ Murenge, Nyamugali, Mahama, Nasho, Mpanga, Kigarama and Musazo sectors.

${ }^{221}$ These figures are for all CIP crops, not just maize, and hence do not correspond to the figures for maize provided later in the chapter.
} 
economics of regional crop specialization have recommended a cautious approach of piloting and phasing-in, based on sufficient detailed household-level data, due to the rapidity and depth of the likely impacts on household livelihoods as well as national level food prices and other aspects of the macro-economy (Wickramasinghe and Weinberger, 2013; Pottier, 1999: 172; Hitayezu, 1993)

However, in Rwanda the crop specialization policy was launched very soon after the agricultural policy was finalized, and local authorities in Kirehe seemed very poorly prepared for the policy. Though this was described as a 'pilot' phase, it was launched across the District and had widespread effects.

The first attempt to introduce maize specialization in Kirehe District was in late 2007, with the aim of planting maize in September (season A). Some awareness-raising activities were carried out in the months prior to September, through the radio, sector level agronomists, and NGO projects. However, many people were only informed of the specific details of the crop specialization policy as late as September 2007, immediately before the planting season. ${ }^{222}$

The process of 'consultation' with local people does not seem to have been as participative as described in government policy documents. A farmer remembered Provincial Governor Mutsindashyaka's statements during a public meeting in September 2007: 'He said, "anyone who dares to grow sorghum, they will have enormous problems". And then the Governor closed the meeting, saying, "I don't want to hear any

\footnotetext{
${ }^{222}$ Interview A of February 162008 with farmer from Mahama sector, Kibungo town.
} 
questions. That is the policy." Then the meeting finished' ${ }^{223}$ This model of one-way communication was the norm, not the exception. ${ }^{224}$

According to District authorities, about 12,000 ha of maize were planted across the District under the CIP (Asiimwe, 2008a). Farmers were obliged to collect governmentapproved maize seed (supplied free) and fertilizers (for which farmers signed a credit agreement) from cellule offices. Seeds are Situka variety, imported from Tanzania (Rwembeho, 2012), which are able to produce high yields under drought conditions (CIMMYT, 2013).

In late 2007, a drought threatened the maize harvest in large parts of Kirehe district. The army oversaw the use of unpaid community labour to water some of the crop using a military lorry. Farmers were ordered to first pour water on fields along the main road. ${ }^{225}$ According to a local state employee:

The population started to ask, "why are we watering only these fields along the roadside? Why don't we water our fields further away - the sun shines there too, not only here, along the road!" The [military] captain said, "we're going to water the maize here, because this is where the authorities will pass." The people insisted, "but what about our fields?" The Captain replied, "the authorities won't go there, far from the road." Some people refused to

\footnotetext{
${ }^{223}$ Interview A of February 17, 2008 with farmer from Mwoga cellule, Mahama sector.

${ }^{224}$ Interview F of May 31 2011, Mwoga cellule, Mahama Sector

${ }^{225}$ Interview A of February 202008 with member of Rwandan NGO, Mwoga cellule, Mahama sector, Kirehe District.
} 
continue irrigating. The Captain beat some of them. And since that time, those people weren't seen in a good light by the authorities. ${ }^{226}$

The emphasis on fields along the road suggests that the military wanted primarily to create an 'image' of success, rather than saving as much of the crop as possible, based on a scientifically-based assessment of need. Once these roadside fields had been covered, similar efforts to water the maize crop took place across the sector, and seem to have involved considerable effort and cost on the part of the authorities as well as investments of unpaid labour by local citizens ${ }^{227}$ (Asiimwe, 2008a).

The district experienced rain in early 2008, which, in conjunction with the efforts to water the fields, saved a quarter of the projected 50,000 tonnes. However, by harvest time, the authorities had yet to announce how, where and when the maize could be sold. In the meantime, local people had been warned not to sell maize. The authorities attempted to control the transport of maize, by searching bags and vehicles on the roads. ${ }^{228}$ Farmers were faced with problems of maize storage while they waited for the authorities to tell them how the maize would be sold. ${ }^{229}$ Maize was stored in people's houses, where it is vulnerable to insect infestation. In its desire to achieve maximum production of maize, the state neglected to examine the local capacities for storage: a

\footnotetext{
${ }^{226}$ Interview B of February 202008 with a member of the Rwandan security services.

227 Interview E of May 30 2011, Munini cellule

${ }^{228}$ Interview A of February 21, 2008 with farmer from Mwoga umudugudu, Mwoga cellule, Mahama sector

${ }^{229}$ Maize requires larger storage areas than sorghum or other crops, and farmers do not usually store significant amounts.
} 
policy simplification and blindness to local context reminiscent of those described by Scott (1998).

The government attempted to find buyers and regulate maize prices. The official minimum price in Kirehe was set at 115 Rwandan Francs (FRW), of which the farmers had to pay back about 30 FRW per kilo to pay for seeds and fertilizers (Asiimwe, 2008b). It was difficult for the government to enforce the minimum price, as several informants received less (as little as $80 \mathrm{RWF} / \mathrm{kg}$ ) for maize in $2008 .{ }^{230}$ According to local agricultural experts, this is not unusual: maize prices are often so low that the price of production cannot be recovered. For example, the Executive Director of the national farmers' union, Imbaraga, estimated that maize costs $140 \mathrm{RWF} / \mathrm{kg}$ to produce, but it often sells for $120 \mathrm{RWF} / \mathrm{kg}$ (Twizeyimana, 2010). ${ }^{231}$ Other estimates of production costs are lower, at $97 \mathrm{RWF} / \mathrm{kg}$ (Van der Laan, 2011, citing MINAGRI and USAID sources), but this is still high compared to Rwanda's neighbours such as Uganda and Tanzania (Van der Laan, 2011).

MINAGRI admitted that the speed of initial implementation of the CIP led to problems:

The misunderstanding of the programme has in some cases led to questionable agricultural practices. The lack of information management may be due to the speed at which the policy was developed and implemented owing to the need to get ahead of the growing season, which

\footnotetext{
${ }^{230}$ Interviews A and D of June 1, 2011 with farmers, Mwoga cellule, Mahama Sector

${ }^{231}$ Of course, costs vary across the country because of different market values of labour, and different costs for inputs (especially because of high transport costs in some areas).
} 
led to poor explanation of the programme at the local level (Republic of Rwanda/United Nations, 2007)

However, while the 'delivery mechanisms' of the CIP have since been reconfigured, through the introduction of private sector agents, the overall dynamics of the programme have not changed. Moreover, the problems in Kirehe stem not only from technical limitations of the CIP, but from the limitations imposed by climate. For these reasons, the programme has continued to be extremely problematic, from the perspectives of local farmers, and increasingly, local government.

\section{Private Actors and Public-Private Partnerships within the Maize sector}

In 2009, the state brought a private corporation into the district CIP system, in line with the government's stated aim of commercializing the farming sector and moving to a facilitating, enabling role. Entreprise Nkubili Alfred \& Sons (ENAS) became involved in the CIP in Kirehe in 2009. It has at least four roles within the agricultural reform: distributor of fertilizers and seeds; provider of extension services; manager of (commercial) post-harvest storage facilities; and farmer in its own right. Alfred Nkubili is a large-scale commercial farmer with a 150 hectare ranch, coffee plantation, and coffee processing plant in Nasho sector of Kirehe District (Rwembeho, 2010b). ENAS recruited 23 extension agents from the region in the areas where land use had been consolidated (IFDC/CATALIST, 2010). Three private traders equipped with motorbikes have also been 
recruited by ENAS and the state in an initiative which is completely CIP-driven, rather than demand-based. Each trader receives 10 RWF/kg of fertilizer distributed and works in collaboration with the imidugudu leadership (IFDC/CATALIST, 2010). The traders, and ENAS more generally, buy fertilizer on credit at a subsidised rate ( $50 \%$ of cost) from the government. ENAS then has to repay the government when it receives payments from farmers (Mugisha, 2012).

The private profit motive as a mechanism for stimulating public policy implementation is not restricted to ENAS. The local authorities are also paid to ensure that the fertilizer is 'effectively applied' (IFDC/CATALIST, 2010) which means, in practice, that it is used for maize. Local authorities at the umudugudu level receive 4 RWF per kg of fertilizer applied to maize (IFDC/ CATALIST, 2010: 30). This arrangement means that both the local authorities and ENAS have financial incentives to sell as much fertilizer to farmers as they can. From this perspective, the forced fertilizer distribution described by farmers seems to be not only intended to enable the district to meet state targets for maize production, but also to generate private profits. As the sole commercial supplier of fertilizer in the district, with the coercive power of the state supporting it, and a network of extension agents (legitimized by the state), ENAS is in a position to sell significant quantities of fertilizer to farmers, whether they want it or not. This puts the firm in a clear conflict of interest regarding extension work: rather than providing demandresponsive advice to farmers - as they would be expected to, in order to support an 'entrepreneurship' model of farming - agronomists working for ENAS focus very heavily on maize, especially the use of fertilizers. Even extremely land-poor or landless 
households were obliged to purchase fertilizer on credit. ${ }^{232}$ Perhaps this is why fertilizer consumption in Kirehe is almost double the national average (NISR, 2012c:27).

Because fertilizer is supplied on credit, it is difficult for ENAS to recuperate the money owed to it by farmers. For 2012 season A, only $58 \%$ of fertilizer loans had been repaid by farmers (Ishimwe, 2012). In previous years, when the maize harvest has been particularly bad, the local government has allowed farmers in drought-hit sectors to write-off fertilizer debts; although ENAS has reportedly argued strongly against this. ${ }^{233}$ This is not surprising, given that ENAS is apparently lending to farmers at its own risk (IFDC, 2010: 30). I have no information on how the outstanding debts between ENAS and the government have been handled in such cases. Disagreements exist between local authorities and ENAS, but have not resulted in the collapse of the system. As such, they are indicative of the articulation of elements of the agricultural policy dispositif, rather than a completely 'independent' non-state actor (to use one alternative interpretation) or an actor who has been completely subsumed within state architecture (to use a competing interpretation).

As mentioned above, ENAS is also involved in post-harvest storage. With funding from USAID, five large facilities for grains storage were constructed in 2011, to be managed by ENAS on a for-profit basis, using a warrantage system, which ensures that farmers

\footnotetext{
${ }^{232}$ Such households were categorised together by umudugudu leaders into groups of five or so, with each group buying a $50 \mathrm{~kg}$ bag.

${ }^{233}$ Phone interview with local respondent, June $17^{\text {th }} 2011$, details withheld to protect the identity of the respondent.
} 
don't have to sell at the time of harvest, when maize prices are low. ${ }^{234}$ ENAS is also working with actors such as USAID, MINAGRI and the World Food Programme to find markets for maize, through for example World Food Programme's Purchase for Progress (P4P) programme, and to train cooperative leaders in post-harvest handling and business skills (Kanyesigye, 2011). It is possible that these activities and markets will represent opportunities for farmers to profit from maize, at least in some years.

However, ENAS's involvement in storing and 'finding a market' for the produce puts the maize commodity chain further under the control of this single company. The broader structural issue of control by one actor over multiple aspects of the commodity chain raises questions regarding conflict of interest and the possibility of collusion and de facto monopoly. These risks are multiplied by the very clear patterns of coercion within the maize sector in Kirehe.

\section{Illegal and Covert Systems of Private Accumulation within the Maize Sector}

In addition to the legal, government sanctioned revenue streams (to local authorities and ENAS) which benefit from the coercive role of the state, illegal and covert forms of profit have also emerged. There are at least three of these.

\footnotetext{
${ }^{234}$ Farmers are paid a proportion of the value of maize upon depositing it in the store (through a commercial low-interest loan, distributed through the cooperatives). The maize is only sold when a market is found at a pre-agreed price. At the time of sale, farmers receive the balance, and pay the interest on the loan as well as storage fees. For an existing warrantage system in Nyagatare, Eastern Rwanda, farmers sold their maize for $139 \mathrm{RWF} / \mathrm{kilo}$, receiving a net income of $120 \mathrm{RWF} / \mathrm{kg}$ once they had paid off the 18.9 RWF interest and storage fees (van der Laan, 2011). This is clearly beneficial, in a context of fluctuating prices that can hit as low as $80 \mathrm{RWF} /$ kilo for parts of the year.
} 
The first example was reported by local media sources. Maize milling companies, including Mukamira millers, had set up a basket fund to purchase maize from cooperatives from Eastern Province at 120 RWF/kg (Rwembeho, 2012). However in practice, some $90 \%$ of the 100,000 tonnes of maize purchased through this arrangement was purchased from Uganda, at a price of just $80 \mathrm{RWF} / \mathrm{kg}$. The Executive Sector of Mahama Sector, Alphonse Karambizi, was arrested in January 2012 on suspicion of involvement in the scheme (Rwembeho, 2012). However, according to local administrators, he was later released without charge, and the blame was placed on cooperative leaders. ${ }^{235}$ Cooperative leaders have been selected by local authorities and do not generally enjoy local support or legitimacy, which makes collusion between the authorities and cooperative leaders particularly likely.

The second illegal profit-making enterprise to emerge within the agricultural reform is linked to the lack of competition within commodity chains mentioned above, which increases risks of collusion and price-fixing, as has occurred in the fertilizer sector in Rwanda (IFDC/CATALIST, 2010). During auctions for fertilizer contracts, the ten bidders involved created a cartel, limiting entrance to newer or smaller firms (IFDC/CATALIST, 2010: 13). While technical improvements can limit the extent of such collusion, it demonstrates the risks involved in putting a small number of powerful actors in control of multiple elements of a commodity chain, particularly when those actors are not accountable to their constituents (as is often the case for cooperatives).

${ }^{235}$ Interview with local administrator, details withheld to provide anonymity, $14^{\text {th }}$ February 2013 
Most importantly from a theoretical perspective, fieldwork revealed the existence of an organized black market in fertilizers, with the covert involvement of at least some members of the local administration and security forces. Those officials who are involved are paid a percentage of the proceeds. ${ }^{236}$ This large-scale operation, which used vehicles to transport fertilizer out of the district at night, was broken-up by police in early-mid 2011. When fertilizer is heavily subsidized by the government, such smuggling rings are very likely to emerge, particularly in order to profit from trafficking the fertilizer to neighbouring countries where fertilizer is only available at full market price (RNP, 2012b). When many farmers are forced to accept fertilizers, such operations are particularly likely. The phenomenon may also be linked to local-level administrators (particularly those at umudugudu level, who are unpaid) becoming disenchanted with the maize policy and increasingly sympathetic to their farming neighbours. This concept will be discussed in more detail below.

\section{Outcomes: Maize Harvests in Kirehe, 2007-2013}

At the national level, maize harvests have increased dramatically and fairly steadily since the introduction of the CIP, in terms of total productivity and yields per hectare. The graphs below present government figures. Official government figures tend to be higher than FAO equivalents, and may be 'inflated' (van der Laan, 2011:4); for example,

${ }^{236}$ Interview D of $8^{\text {th }}$ June 2011, Mwoga cellule, Mahama Sector 
Government of Rwanda figures were 18\% higher than FAO for 2007 and $2008 .^{237}$

Nevertheless, the overall trend of improvement is clear (see Figures Three and Four).

Figure Three: Area under Maize Production (ha) and Total Maize Production (kg)

\section{Trends in Maize Output}

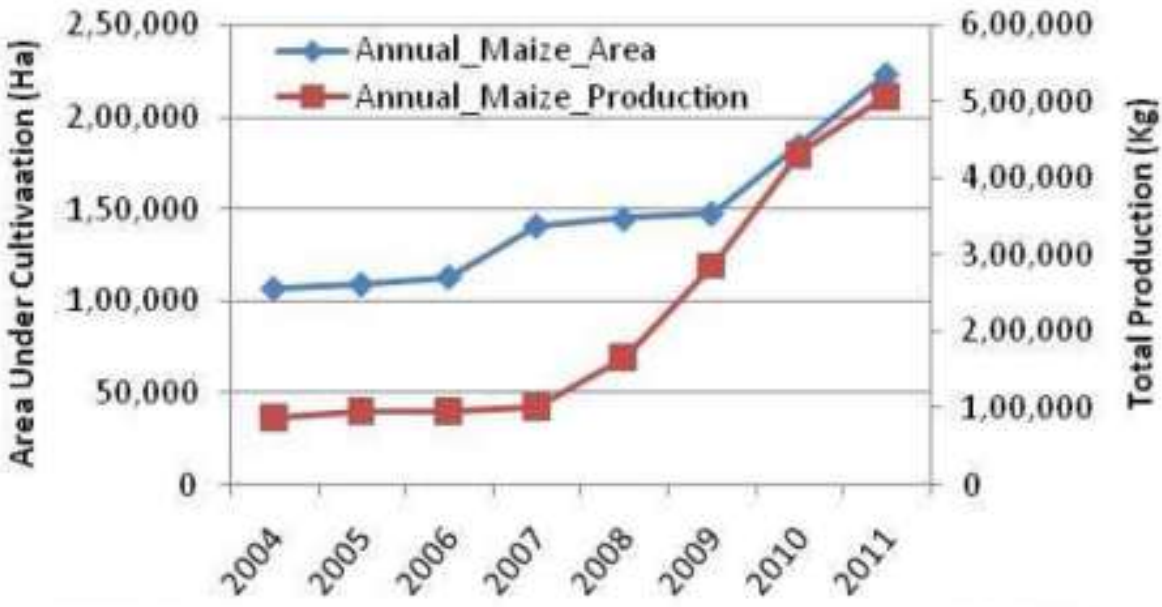

Source: Kathiresan 2012: 13

${ }^{237}$ The government claims total maize production of 102,447 metric tonnes $(\mathrm{mt})$ for 2007 and $166,853 \mathrm{mt}$ for 2008 (MINAGRI, 2010d). FAO reports 84,007 mt for 2007 and 136,819 mt for 2008 (FAO, 2013). There are significant issues regarding the reliability of agricultural data in Rwanda (Donovan, 2008), which are largely pre-harvest estimates (NISR, 2012e), with estimated volume levels generally higher than actual harvest (ibid). 
Figure Four: Area under Maize Production (ha) and Average National Maize Yield

(kg/ha)

\section{Trends in Maize Output}

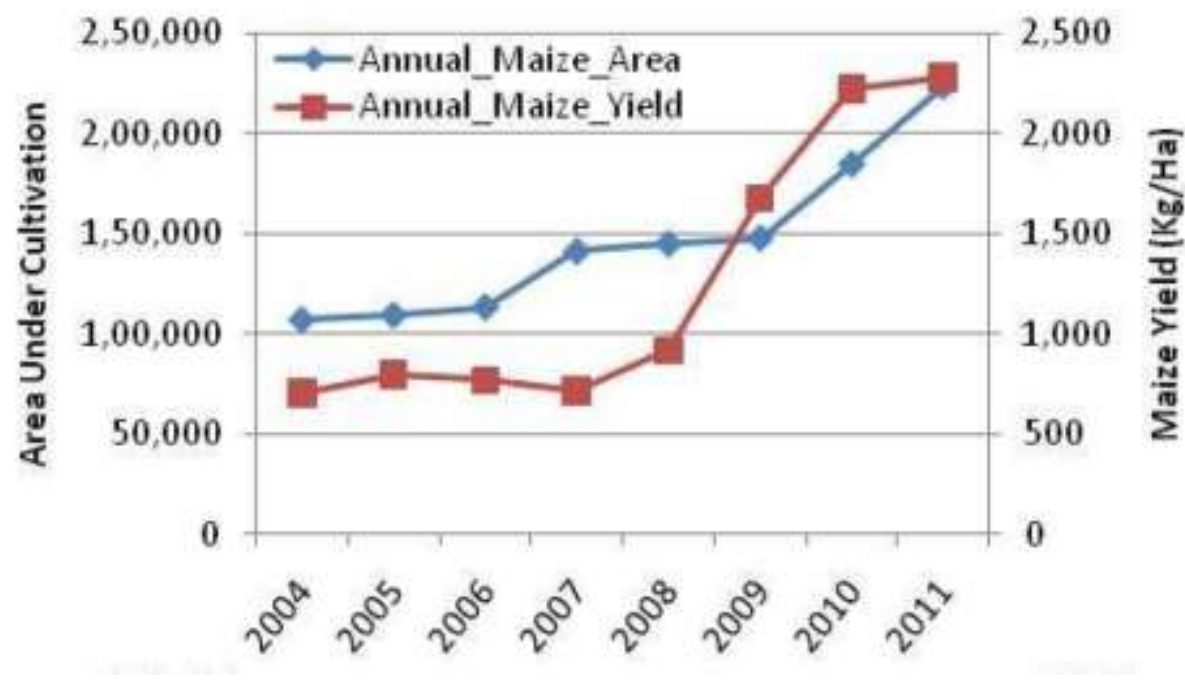

Source: Kathiresan, 2012:13

Notwithstanding this aggregate increase, eastern parts of the District, which are vulnerable to drought episodes, have seen peaks and troughs in production. This illustrates the importance of a disaggregated analysis of the impacts of agricultural reform, which would reveal significant temporal, geographical and agro-ecological differences. The following chronological overview of yields is based on the statements of District administrators reported in the pro-government media, as well as official government figures. ${ }^{238}$ The figures illustrate the highly uncertain nature of maize production in Kirehe District. It should be remembered that significant differentiation is

\footnotetext{
${ }^{238}$ It should be remembered that local leaders are under pressure to achieve imihigo targets and are often unwilling to provide the higher-levels of government with bad news (Sommers, 2012), further complicating the validity of data. These figures provided may therefore represent over-estimates rather than underestimates.
} 
also likely within the District, though I was unable to gather official sector-or cellulelevel data.

In the $2007-8$ season A, approximately 12,500 tonnes of maize were produced (Asiimwe, $2008 \mathrm{~b})$ on $12,000 \mathrm{ha}$. This represents an average yield of 1.04 tonnes/ha.

In 2008-9 season A, Kirehe District expanded the area under maize production to from 12,000 to 17,000 ha but only produced 30,000 tonnes of maize (Mugoya, 2010). This represents an average yield of 1.76 tonnes/ha.

For the $2009-2010$ season A, approximately 50,000 ha was produced on 17,000 hectares (Twizeyimana, 2010; Rwembeho, 2010e). This represents a yield of 2.9 tonnes/ha. Along with similar successes for other crops, this contributed to an increase in calorific intake per capita. Per capita calorific intake across the District was double the minimum required for basic food security (Odooboo, 2012). ${ }^{239}$

In 2010-11 Season A farmers harvested only 8,844 tonnes (District of Kirehe, 2011a) due to drought (FEWSNET, 2011b) and insect infestations (Rwembeho, 2010). Assuming that

\footnotetext{
${ }^{239}$ However, the relatively high costs of maize production - in comparison with sorghum, for example mean that even when the harvest is relatively good, profitability is still contingent on market prices. Although the 2009-10 harvest was good, the abundance of maize meant that prices dropped from 250 $\mathrm{RWF} / \mathrm{kg}$ (in 2009) to just $80 \mathrm{RWF} / \mathrm{kg}$ (in 2010), which is below the cost of production (Rwembeho, 2010d). As mentioned above, the government and donors are attempting to address this through post-harvest storage interventions.
} 
all of the targeted 25,000 hectares was planted, ${ }^{240}$ this represents a yield of just 0.35 tonnes/ha (Rwembeho, 2011b).

In 2011-12, harvests were better: according to the district administration, a total of 22,630 hectares were put under maize cultivation at yields of $3.7 \mathrm{t}$ per hectare (District of Kirehe, 2011b), which indicates that the total harvest was more than 83,000 tonnes.

In 2012-13 Season A, short rains were below average in the eastern parts of Rwanda, particularly in five sectors of Kirehe-Nyamugali, Kigarama, Mahama, Mpanga, and Nasho-which resulted losses of 60 to 80 percent of crop production (FEWSNET, 2013a and 2013c). As a result, the study area moved from a 'food secure' category to a 'stressed' category (FEWSNET, 2013b). ${ }^{241}$ Farmers reported serious losses to the maize harvest, and in March 2013, maize prices were 35\% higher than for March 2013, signalling scarcity (FEWSNET, 2013b). Detailed information for Kirehe is not yet available on the District website or in the Rwandan media. Assuming, (based on FEWSNET, 2013a and 2013c), that 70\% of the maize crop was lost, this would represent an average yield/ha of $1.05 \mathrm{mt} / \mathrm{ha}$.

\footnotetext{
${ }^{240}$ The imihigo report does not indicate whether the target of 25,000 ha of maize was achieved (District of Kirehe, 2012a).

${ }^{241}$ The FESNET system uses a 5-point categorization system to rank food insecurity, from 1 (none/minimal) to 5 (catastrophe/famine). The 'stressed' category is rank 2.
} 
Figure Five: Maize Yields per Hectare, Kirehe District, 2007-2012

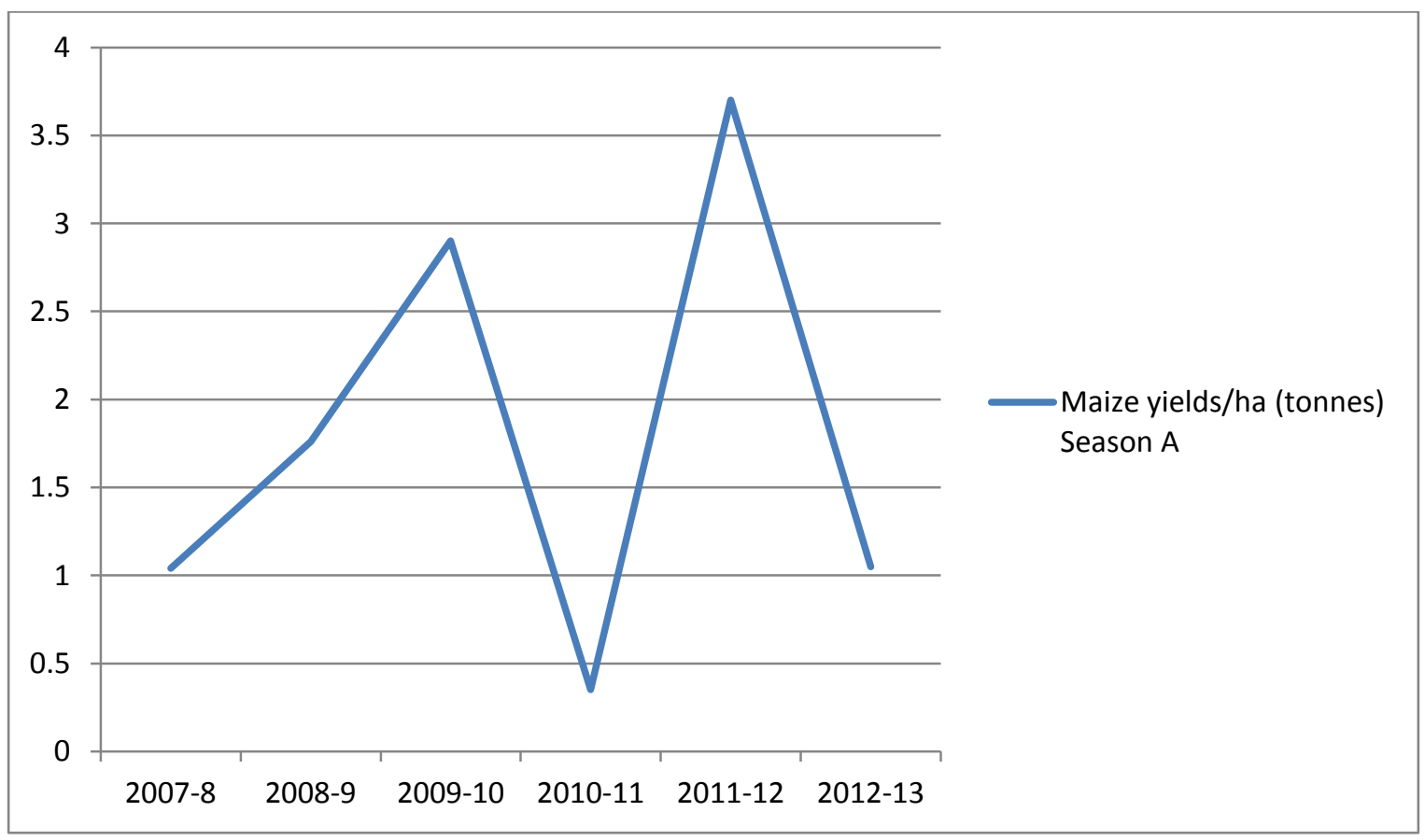

Sources: Asiimwe, 2008b; District of Kirehe, 2011a; District of Kirehe, 2011b; FEWSNET, 2013a and 2013c; Mugoya, 2010; Rwembeho, 2010e; Rwembeho, 2011b; Twizeyimana, 2010.

*Note: 2012-13 figures are estimated

It can be seen from Figure Five above that maize production is often far below the reported national average of 2.5 tonnes/ha. The data reflects the findings of independent agricultural experts, that 'maize production in Kirehe faces periodic rainfall deficits, and is highly risky' (IFDC/CATALIST, 2010: 31).

Given the likely effects of climate change, maize harvests will probably become even more erratic in future (Cairns et al, 2012). Official government documents have also 
recognised that due to the likely effects of climate change, 'suitability of maize as a crop is forecast to drop by $15 \%$ or more by $2020^{\prime}$ in Eastern Africa (Government of Rwanda 2011: 8, cited in Gebauer, 2012).The present-day impacts of climate change are accepted by local officials: 'I am convinced that climate change is really problematic in our sector... ${ }^{242}$

It is important to note that the history of cultivation in the area, as well as agroecological and climatic assessments by the government and international agencies, demonstrate that even prior to the destabilizing effects of climate change, maize cultivation in the lowland area of Kirehe has been extremely risky. To some extent then, the authorities have been using climate change as an excuse for the failures of a policy which was not appropriate to the climatic conditions. One respondent reported that: 'they [authorities] say to us that it's not the state [to blame]; it's a problem of climate change'. ${ }^{243}$

\section{Government Responses to Farmer Resistance}

Due to losses to the maize crop, logistical problems during the pilot phase of the CIP, low levels of legitimacy of cooperatives, and the logistical and marketing problems, most farmers preferred to revert to their original cultivation strategies

\footnotetext{
${ }^{242}$ Interview with local official, February 14 2013, Mahama Sector, details withheld to protect anonymity.

${ }^{243}$ Focus group discussion A of February 142013 with 5 women.
} 
in the following years. The various forms of 'resistance', and their degrees of success, will be discussed further below.

In response to smallholder resistance, the authorities continued their 'sensitization' strategies, such as public speeches encouraging maize production. As previously, these were not a dialogue, but a one-way flow of instructions, 'no criticism, no other speeches, no negotiation': ${ }^{244}$.When farmers did dare to openly criticise or disagree with the policy, some were punished, mostly through fines. Others were given a stark choice:

These speeches are repeated at the public meetings... One day a woman asked that her condition doesn't allow her to cultivate maize, which has grown many times without any harvest. The authorities told her that one must respect the state system, someone who doesn't accept it must go to other regions where the system is different from ours. ${ }^{245}$

In other cases, farmers were allowed to ask questions, and the authorities, like those in the pyrethrum-growing areas of Musanze district (see Chapter Seven) linked the production of government-approved crops with a patriotic duty:

There are some who ask why state forces the people to grow only maize. The response of the state, represented by the local authorities is to ask the population to be patient [in the face of] the problems encountered, it is

\footnotetext{
${ }^{244}$ Interviews A and F of October 13 2011, Saruhembe cellule.

245 Interview F of October 13 2011, Saruhembe cellule. A similar story was told in interview M of 31st May 2011, Mwoga cellule
} 
necessary to build the country, and will also be beneficial - one must have patriotic love. ${ }^{246}$

In addition, 'building the country' is particularly associated with exports:

During the meetings the authorities say that the state wants us to farm in order to export the agricultural products outside of the country, at the moment Rwanda doesn't have production to export outside. ${ }^{247}$

Another respondent, a local outreach worker for a state programme, mentioned that:

The state policy is to teach and educate the population to grow crops which are used at the international level; it gives the example of Tanzania which exports its products to foreign countries, such as maize flour, vegetable oil, and other industrial products. ${ }^{248}$

Here, the authorities are explicitly linking the idea of economic development with national macro-economic development, rather than local community-level profits. Many local farmers have seized upon this in their own analyses of the motives and structures behind the agricultural reform, as will be described further below.

The local government also stepped up sanctions against those found deviating from the agricultural policy. In Foucauldian terms, these sanctions represent what he calls the approach of 'law', associated with the absolute claims to power of the sovereign: the

\footnotetext{
${ }^{246}$ Interview G of October 14 2011, Kamomba cellule

247 Interview F of October 15 2011, Mwoga cellule

${ }^{248}$ Interview M of May 312011 with woman in her 30’s, Mwoga cellule
} 
power to prohibit and punish (Foucault, 2004: 4). Sanctions included the use of fines, typically of 5,000-20,000 RWF. This is a very significant amount: almost half (48\%) of the population of Kirehe lives below the poverty line of RWF 118,000 per year (NISR, 2012c: 5). Those who could or would not pay fertilizer debts were detained in local police stations for several days, or had household possessions - bicycles or goats- seized by the Local Defence Forces. ${ }^{249}$ Other sanctions include the uprooting of any crops which are not permitted under the regional crop specialization policy, or which have been intercropped. ${ }^{250}$ In a few cases, farmers were beaten, including by members of the local administration.

These sanctions have often been described by government officials and journalists as the actions of 'overzealous administrators', using their own initiative to fulfil government targets (Nsanzimana, 2013). Similar kinds of sanctions have been used all across the country (Rwagahigi, 2012; Nsanzabaganwa, 2011: 46). Rather than ad hoc tactics used by a few administrators, such sanctions are common enough to be identified as a major part of the local authorities' strategy for implementing the reform. $^{251}$

\footnotetext{
249 Local Defence Forces are paramilitary units under the control of local authorities. Interview D of October 11 2011, Munini cellule; and interview D of October 13 2011, Saruhembe cellule.

${ }^{250}$ Interview A of October 13 2011, Surahembe cellule; interview C of October 11, 2011, Mwoga cellule; interview B of June 20 2011, cellule Nyamugali, Mahama Sector; Interview D of June 17, 2011, cellule Kawombo, sector Mahama; Group discussion F of 1 Feb 17, 2013, Mwoga cellule; Group discussion D of $15^{\text {th }}$ Feb 2013, Mwoga cellule; Interview A of $13^{\text {th }}$ October 2011, Saruhembe Cellule, and several others.

${ }^{251}$ Even in the coffee sector, which is under considerable international scrutiny due to the heavy involvement of USAID and non-governmental actors in various liberalization programmes, there are indications of the coercive paradigm (Boudreaux \& Ahluwalia 2009, Kwibuka, 2008).
} 


\section{The Rwandan State 'Connectedness Machinery'}

The former Rwandan Minister of Trade and Industry, Monique Nsanzabaganwa, has written about agricultural reform in Kirehe as part of a PhD dissertation in economics (Nsanzabaganwa, 2012). Because she is 'close to the ruling Rwanda Patriotic Front' (US Embassy, Kigali, 2009) and a former cabinet member, it is a very useful source through which to understand the links between RPF governmentality and agricultural reform in Kirehe.

Nsanzabaganwa highlights the role of what she calls 'social change managers' in her conceptual framework (the 'connectedness model'), who can, 'raise consciousness, inspire and enlighten the community members' (Nsanzabaganwa, 2012: 106). As such, they can be seen as part of a broader governmental goal of creating the ideal development subjects or, in the agricultural sector, modern farmers. In her Kirehe case study she mentions the, 'persuasion and confidence building performed by different players in the extension and mobilization circles' (Nsanzabaganwa, 2011: 49)

Close attention to her description of so-called 'Farmer counsellors' suggests that, rather than being valued for their inherent skills and knowledge, they are conceived of as instruments of state policy, rather than responsible actors in their own right: 'These farmers provided a good link between policy makers and the farmers. They were used as effective communication channels to coordinate the 
implementation of the season calendar (when to plant, when to apply fertilizers, etc.)' (Nsanzabaganwa, 2012: 165. Emphasis added)

In general though, social change managers receive less emphasis in her case study of agricultural reform in Kirehe District than institutional linkages between 'local government, service providers, inputs dealership and the security organs' (Nsanzabaganwa, 2012: 49). These linkages imply a disciplinary mode benefitting from close surveillance of the population. She refers to the development of a 'connectedness machinery' in Rwanda (Nsanzabaganwa, 2012: 142) and comments that the success of ENAS stems in part from its connections with the local authorities and the police. Other researchers have found that elsewhere in Rwanda, sector-level committees have been established to monitor and police land use consolidation practices (Gebauer, 2012), presumably in order to combine different elements of the state apparatus.

Nsanzabaganwa also argues that the resettlement pattern in the area, specifically the preponderance of state-planned villages (imidugudu), facilitated the quick consolidation of land use. She does not elaborate further, but the implication seems clear: the spatial organization of settlements made it easier for the authorities to monitor the population. Observers have long noted the potential of the planned village, with its grid-like layout and open vista (e.g. devoid of farming areas or forest groves within the village boundaries), to facilitate state surveillance of the inhabitants (Jackson, 1999). 
Local administrators also emphasised the importance of the settlement patterns. One stated simply that because the population lives in villages, 'the distribution of everything proposed arrives at the level of the farmers easily', ${ }^{252}$ while another went into more detail:

The agricultural reform in our sector is possible because the population lives together in villages [imidugudu]. That is how the agricultural reform is possible: the land is consolidated, the villages can have seeds, there is no problem with roads [to deliver the seeds], it is possible to 'have' the farmers during sensitization, without problems, and the system of storage, buying seeds and agricultural markets is easy. ${ }^{253}$

These descriptions, with their emphasis on the logistics, are reminiscent of the emphasis on efficiencies and 'grids of legibility' within Scott's (1998) model of the authoritarian state apparatus; as well as the spatial technologies of discipline described by Foucault. An umudugudu leader also described his responsibilities vis-à-vis the agricultural reform in terms of delivery of inputs, and leveling of sanctions: 'Our key activities are to facilitate the distribution of fertilizer, facilitate the distribution of seeds, facilitate the payment for fertilizer at the level of the

\footnotetext{
${ }^{252}$ Interview B of Feb 142013 with local agronomist, details withheld to protect anonymity.

${ }^{253}$ Interview B with local administrator, February 14 2013, details withheld to protect anonymity.
} 
household, and assist with levelling fines against those who violate the agricultural policy'. ${ }^{254}$

It is interesting that this same 'connectedness machinery' was remarked upon by some local respondents. The most visible sign of such integrated activities is the simultaneous coordination of several aspects of the state machinery in order to monitor and police maize production:

After this campaign on maize, the distribution of maize [seeds] was done, and fertilizer too, the soldiers, the LDF [local defence forces], the agronomists and the sector-level authorities, there were also some who came from Kigali, from the Ministry of Agriculture and Livestock, they came to see how the maize production was coming along. The Province authorities came too. $^{255}$

In addition, local people saw the cooperative structures as part of this 'machinery'. ${ }^{256}$ The majority of respondents felt that they were the creations of the administration, and that cooperative leaders had been appointed, rather than fairly elected. ${ }^{257}$ Some farmers refer to such institutions as 'ghost' cooperatives, which exist largely on paper due to the complete lack of involvement of the

\footnotetext{
254 Interview D of February 14 2013, Mwoga cellule.

255 Interview E of May 30 2011, Munini cellule, Mahama Sector.

${ }^{256}$ Interview H of February 14 2013, Mwoga cellule.

257 Interview F of May 31 2011, Mwoga cellule; Interviews A and C of $15^{\text {th }}$ February 2013, Mwoga cellule.
} 
farming population; ${ }^{258}$ alternatively they are called the 'sector' cooperatives, in a reference to the local administration that founded them. In line with their 'official' nature, cooperatives are seen as delivery systems for the CIP: 'The cooperative doesn't have any other activities except collaborating with the authorities to forcibly distribute the fertilizer to the people.' 259

In many cases, respondents in Kirehe stated that they had been 'forced' to join cooperatives and to pay the membership fees: ${ }^{260}$ As one put it, 'Concerning the cooperative, I have refused to be a member. But I have been warned that I must go elsewhere if I don't accept to be a member' ${ }^{261}$

Respondents also felt that there was a lack of transparency in the management of the cooperatives: ${ }^{262}$ For example, one noted: 'There are no annual assemblies, no regular meetings, we have no information regarding the cooperative's activities, all the authority is in the hands of the members of the cooperative committee'. ${ }^{263}$ Lack of transparency, and 'ownership' by members, are not unusual problems in the cooperative sector.

\footnotetext{
258 Interview H of February 15 2013, Mwoga cellule.

259 Interview A of May 31 2011, Munini cellule.

${ }^{260}$ Interview H of February 14 2013, Mwoga cellule.

${ }^{261}$ Interview E of May 31 2011, Munini cellule.

262 Interview F of May 31 2011, Mwoga cellule.

${ }^{263}$ Interview E of $8^{\text {th }}$ June 8 2011, Mwoga cellule.
} 
It is clear that the idea of voluntary 'behavioural change' towards a model of entrepreneurial self-governance associated with governmentality, which dominates much official discourse on the agricultural policy, is undermined by the frequent recourse by the state to prohibitions and sanctions. However, the strategies of the government cannot be reduced to simple coercion.

Less visible, but with significant effects, is the 'interpenetration of themes' (Purdekova, 2012: 199) mentioned in previous chapters. In Kirehe, for example, health education includes nutritional information which is framed in terms of the need to follow the CIP. ${ }^{264}$ The interconnectedness exists not just at the level of discourse but also in terms of active policing of citizen behaviour. One farmer commented that the authorities, 'mix up in all the areas the activities: agricultural, administrative, civil, security, and other hidden activities such as collecting fines, contributions, etc....265

This 'mixing up' occurs, for example, when citizens are prevented from accessing one kind of government service, or cooperative activity, because of their failure to satisfy the demands of other aspects of the 'connectedness machinery'. A farmer reported that, 'we rented the marsh... The local authorities are also found there [at the marshland] and they ask for health insurance contributions and other taxes

\footnotetext{
${ }^{264}$ Interview M of May 31 2011, Mwoga cellule.

265 Interview C of May 30 2011, Munini cellule, Mahama Sector.
} 
saying that if we cannot make the contributions, we will not have anywhere to cultivate. $^{266}$

We are reminded here of citizens in Musanze being denied access to administrative services because they had not paid for the (supposedly voluntary) health insurance scheme (see Chapter Six). Respondents in Kirehe also noted that the activities of the cooperatives 'were mixed up with those of the sector authorities' ${ }^{267}$, which is unsurprising given that many cooperatives were founded by the authorities. The 'connectedness machinery' in Kirehe is an attempt to create a totalizing state presence within public spaces and, as far as possible, private spaces as well.

Other researchers have noted such patterns of 'mixing' of different spheres, such as farmers being threatened with being 'kicked out' of cooperatives because of their perceived unwillingness to follow government guidelines on reconciliation (Thomson, 2009: 164). In an example from a rice cooperative, the cooperative leadership visits members' homes after members have been paid, in order to monitor household spending. If householders are perceived to have spent too much money on alcohol or other undesirable things, they may be publically sanctioned at the next general assembly (Ratcliffe, 2013). In addition, cooperative leaders monitor the hygiene of members' homes and bodies (ibid). In a different example, poor people receiving direct support under the Vision 2020 Umurenge Programme (VUP), who are meant to receive

\footnotetext{
${ }^{266}$ Interview G of May 31 2011, Mwoga cellule.

${ }^{267}$ Interview F of February 14 2013, Mwoga cellule.
} 
a sum of money each month, received the equivalent of 6 months of the support in the form of aluminium roofing sheets in order to help them to destroy their thatched houses and construct new homes (Berglund, 2012: 26). This was not their choice (they preferred payment in cash), and represents the 'interpenetration' of the government policy against thatched roofs (popularly known as the 'bye-bye Nyakatsi' campaign) and the VUP.

In Kirehe, the 'connectedness machinery' also includes the interpenetration of public and private roles. Umudugudu leaders receive payments for their role in the disciplinary aspects of the CIP (overseeing the correct application of fertilizer) while agricultural extension services, normally the reserve of the state and non-profit organizations (or private actors without a stake in commercial delivery of inputs), are provided by the same company that sells fertilizer. The connectedness is therefore operating not only at the levels of discourse, coordination of activities and exchange of information, but in a blurring of the lines between the public and private economic spheres.

\section{High Modernism or Developmentalist Macro-Economics?}

The commercial aspects of 'non-priority' crops such as sorghum have been downplayed by government officials. For example, a traditional staple in most parts of Rwanda, sorghum has been characterized in extremely negative terms by the Minister of Agriculture, who contended that: 'Sorghum has no commercial value, you cannot sell it anywhere' (Kalibata, cited in Kagire, 2012). In fact, sorghum is amongst the most 
commercialised of all crops in Rwanda, with $32 \%$ of all sorghum, on average, marketed (NISR, 2012d). Therefore, the position of the state regarding maize and sorghum production appear to be based on macro-economic calculations related to industrialization objectives, as described earlier, rather than assessments of local economic realities.

\section{Authoritarian High Modernism and Local Government 'Flexibility'}

Faced with overwhelming evidence that maize harvests in Kirehe tend to fluctuate wildly year-by-year, due to climatic factors, the Minister of Agriculture visited Kirehe in mid2011 and stated, 'Overdependence on rain fed agriculture has been our undoing' (Kalibata, cited in Rwembeho, 2011a). This is a striking admission. The government's response to the failure of maize harvests reveals a lot about its perceptions of both mankind and nature.

\section{The Technological Fix}

The government chose not to move away from maize in favour of more droughtresistant crops. The policy remains the same. Instead, it opted for a technological fix. Since the Minister's comments in 2011, a reservoir, a network of irrigation canals, water pumping machines and feeder roads have been constructed to provide some 500 ha of fields with water, at a total construction cost of 5billion RWF, more than US\$ 8 million (Umuhinzi, 2013). ${ }^{268}$ The District agricultural officer opined that irrigation represented 'a

\footnotetext{
${ }^{268}$ Interview A of February 14 2013, location withheld to protect anonymity.
} 
new era of agriculture revolution' (cited in Rwembeho, 2013). However, the impact of irrigation on the CIP (which was estimated at 39,000 hectares of consolidated land in 2012-2013) is questionable. Another question is the capacity of farmers to adopt the appropriate water-and soil-management approaches: initial research suggests that only a small proportion of farmers had done so (Liyama et al, 2011).

This approach is a striking example of a confidence in the transformative powers of technology, bordering on irrational faith, mentioned by Scott (1998). Rather than alter the policy to better suit the natural and social environment, the government has decided to invest massively in capital- and knowledge-intensive infrastructure. Of course, irrigation can and does play an important part in agriculture around the world, including in East Africa; the point is that in the short-medium term (at least) it can only complement rain-fed agriculture, not replace it. The idea that the agricultural economy of drought-prone parts of Rwanda can be guaranteed through irrigation technologies would seem to reflect, in Scott's words, 'a supreme self-confidence about continued linear progress...and, not least, and increasing control over nature (including human nature) commensurate with scientific understanding of natural laws' (1998: 89:90)

\section{Local Government 'Flexibility'}

There are important differences between the responses of the central and local government. As noted previously, the authoritarian high modernism model emphasises 
a binary differentiation between 'policy implementation' and 'resistance', which does not reflect some of the nuances in the implementation of the maize policy in Kirehe.

The first example of government 'flexibility' concerns an innovative deviation from the usual model of simply exhorting, or forcing, smallholders to plant maize according to the official government agricultural calendar. Faced with ambitious targets for land consolidation, as well as significant resistance from farmers, the Mahama sector authorities made an agreement with the administration of a nearby TIG camp to bring a number of TIG workers, locally known as Tigistes, to perform agricultural work on consenting farmers' fields. The strategy was first used in 2010 and again in 2012. ${ }^{269}$ TIG labour would be paid for by each household after the harvest. According to farmers, the presence of the Tigistes had not been previously announced, and the project seemed ad hoc in nature. ${ }^{270}$ Many declined, either unsure of whether the maize harvest would justify the expense, or suspicious of the motives behind the strategy. ${ }^{271}$ When the maize harvest was disappointing the TIG administration did not return to claim payments from the farmers. $^{272}$

This strategy is significant as a local response to a policy challenge imposed by central government. The local administration is not merely a mechanical

\footnotetext{
${ }^{269}$ Interview A of February 142013 with local agronomist, Kirehe District, (exact location withheld to provide anonymity); Interview A of February 15, Mwoga cellule; phone interview with person involved in the agricultural sector in Kirehe District in an official capacity (identity withheld to provide anonymity), August 172012.

${ }^{270}$ Interview H of February 16 2013, Mwoga cellule

${ }^{271}$ Ibid.

${ }^{272}$ Various interviews of $15^{\text {th }}$ and $16^{\text {th }}$ February 2013, Mwoga cellule.
} 
'implementation system' but a set of actors with a certain degree of autonomy and agency, within the bounds of the policy targets imposed upon it. The use of 'unfree' labour; rather than wage-labour, also suggests that expediency was the primary motivation, rather than local economic benefit.

A broader discussion of the notion of 'flexibility' is pertinent to the research questions. Local administrators in the District have recognised the failings of the policy, acknowledging for example that targets for land consolidation imposed by central government are unrealistically high (Nsanzabaganwa, 2011: 46). Indeed, in response to huge losses in the 2010-11 season, the Governor of Eastern Province stated that: 'when maize fails, we should be able to go for a different crop' (Rwembeho, 2011b), though this has not been followed by any official policy change.

According to some observers, the district has observed 'flexibility in implementing policies' (Nsanzabaganwa, 2012: 166), such as by allowing farmers to cultivate crops of their choice during season B. In another example, rather than completely banning intercropping, agronomists sometimes allowed farmers to mix crops such as maize and beans, but showed them how to do it 'correctly' (e.g. alternating rows of maize and beans, and maintaining a uniform distance between planting holes, etc.). It is difficult to say whether this 'flexibility' is a conscious strategy, or an attempt to be seen to be 'doing something' in the face of massive policy failure. A mid-level local administrator 
suggested the latter, saying simply that, 'the agricultural policy doesn't accept this system [intercropping], but people do it'. ${ }^{273}$

Clearly, the landscape of Kirehe - with its patches of green monocropped maize amidst larger mosaics of intercropped varieties - cannot simply be interpreted as a visual portrayal of the limits of state 'power'. There is give-and-take in the relationships between administrators and local people. There are significant differences of opinion between farmers and district-level state actors regarding power- when consent is given by the state, and when farmers achieve a fait accompli without state consent.

At the umudugudu level, and perhaps the cell level as well, administrators have become convinced that the maize policy is failing. Some local leaders were absolutely against the policy. One umudugudu leader said, 'Think how the population can live without their participation, forcing the population against their will... 99\% of the population doesn't have confidence in our government., ${ }^{274}$ Citing the maize failure, another umudugudu leader said that he was no longer participating in local government, because it is 'a system that I do not understand ${ }^{\prime 275}$ Farmers reported in 2013 that local administrators are doing less and less 'sensitization' around the CIP: '[the authorities] are ashamed to talk to the population... being scared that the population will revolt because their crops

\footnotetext{
${ }^{273}$ Interview B of February 142013 with local administrator, details withheld to protect anonymity.

274 Interview D of February 14 2013; location withheld to protect anonymity.

${ }^{275}$ Interview E of February 142013 with head of umudugudu,
} 
have been uprooted, the agricultural sensitization and mobilisation has been stopped'. ${ }^{276}$

\section{Farmer Perspectives and Responses}

Interviews suggest that it is the overall aims and structure of the CIP (and not only the 'technical' issues around markets, storage, etc.) that are of concern to smallholder farmers in Mahama sector.

The early experience of drought and crop loss represented a major disincentive for smallholders to invest in maize. This is not due to inherent 'conservatism' or an attachment to the 'economy of affection' associated with subsistence (contra Hyden, 1980). Indeed, all the respondents marketed part of their harvest: across the district, household sell an average of $23.1 \%$ of their total harvest (NISR, 2013: 28). This is actually above the national average figure of $20.9 \%$ (ibid.). Rather than a retreat into subsistence or attachment to 'tradition', this strategy represents an unwillingness to risk incurring debts for fertilizer and seeds, based on a realistic assessment of risks.

Farmers preferred to plant other crops, notably sorghum. Respondents provided many reasons for their continuing preference for sorghum. Most importantly, sorghum is highly drought-resistant (Sasaki \& Antonio, 2009), more so than maize (Groen, 2006). ${ }^{277}$ All the farmers interviewed confirmed that sorghum harvests had been consistently

\footnotetext{
${ }^{276}$ Interview F of February 17 2013, Mwoga cellule

277 Interview H of February 14 2013, Mwoga cellule
} 
reasonable or good, even during drought years. This was confirmed by agronomists. ${ }^{278}$ Farmers estimated that sorghum required a financial investment of about one fifth to one half that of maize. ${ }^{279}$ It is not unusual for farmers to sell assets, such as cattle, in order to pay for labor costs and other inputs during the maize season (see also Asiimwe, 2012)

Farmers in Mahama Sector generally preferred to continue intercropping rather than switching to monocropping and land use consolidation. Various crops, including cassava, several varieties of beans, maize, sorghum, bananas, sweet potato and groundnuts may be intercropped in various combinations. Again, respondents had detailed and rational explanations for this. For most respondents, intercropping was a drought-management strategy:

Two varieties are [grown] together. If there is a loss, the other [crop] works; if there is a good harvest, they are both productive. ${ }^{280}$

Respondents acknowledged that by intercropping, they reduced the absolute yield potential, but saw this as a worthwhile trade off in order to reduce risk, arguing that intercropping provided at least $70-90 \%$ of the maximum yield for each

\footnotetext{
${ }^{278}$ Interview A of February 142013 with local agronomist, Kirehe District, (exact location withheld to provide anonymity).

${ }^{279}$ The differences in estimates may stem from seed preferences (some farmers keep their own sorghum seeds to plant, others buy it) as well as different amounts of fertilizer applied (which is a factor of farmer preferences as well as soil characteristics) and the extent to which paid labour is used. Interviews $A$ and $D$ of May 31 2011, Munini cellule; Interview J of May 31 2011, Mwoga cellule; interview B of May 31 2011, cellule Munini.

${ }^{280}$ Interview A of June 18, 2011, Kawombo cellule, Mahama Sector.
} 
variety. ${ }^{281}$ As noted previously, scholarly research supports the popular view that intercropping, under certain circumstances, offers greater benefits that monocropping (Blarel et al. 1992, 252; cited in Pottier, 2006; Spio, 1996).

\section{Farmer Strategies of Resistance}

Given the sheer level of opposition, judging from interview responses of farmers and agronomists, as well as published sources (Nsanzabaganwa, 2012: 164-166), it proved impossible for the state to completely monitor farmer behaviour.

Knowing that they risked such punishments, during the main agricultural season $(A)$ local farmers used various strategies that we might identify as 'everyday forms of resistance'. These did not involve direct confrontation with the authorities, but efforts to continue to intercrop or plant non-approved crops without being detected by the authorities.

For example, local people planted non-approved crops in the furthest edges of their fields, where they were unlikely to be noticed by passing agronomists or authorities. ${ }^{282}$ People went to the fields after dark in order to plant the crops of their choice; ${ }^{283}$ in some cases they would uproot the maize they had planted previously and replace it with

\footnotetext{
${ }^{281}$ Interview A of February 16 2013, Mwoga cellule.

282 Interviews $C$ and $E$ of June 10 2011, Mwoga cellule.

283 Interview F of June 18 2011, Kamombo cellule, Mahama Sector.
} 
other crops, ${ }^{284}$ while in other cases they would covertly plant sorghum between the rows of maize. It should be remembered that average landholdings are larger in Kirehe than elsewhere, providing more space for farmers to hide their preferred crops, and representing more 'legwork' for those seeking to monitor farmer behaviour. In one atypical case, a farmer with a large landholding (and presumably ample financial savings or other income streams) decided in 2010 to switch from maize agriculture to silviculture. He did this specifically because he calculated that the authorities would not uproot the trees he had planted, as they were valuable. ${ }^{285}$

Some farmers travelled outside of Kirehe District in order to rent land in sectors where land use was not as closely controlled, or simply rented land in their own sector that was far from the watchful eyes of the authorities. ${ }^{286}$ In addition, several respondents said that they had rented out their agricultural land, rather than cultivate maize or take the risk of growing a crop that had not been approved by the government.

Households facing financial stress due to losses from maize sometimes choose to temporarily separate, which generally means that men in the household travel to seek work as a casual farm labourer, or informal opportunities in urban areas. ${ }^{287}$ Some households left the District completely, migrating elsewhere within Rwanda, or to Tanzania. This phenomenon is discussed in more detail further below.

\footnotetext{
${ }^{284}$ Interview I of October 14 2011, Kamombo cellule.

285 Interview C of June 14 2011, Saruhembe cellule, Mahama Sector; interview B of June 16 2011, Saruhembe cellule.

${ }^{286}$ Interview A of June 13 2011, Saruhembe cellule.

${ }^{287}$ Interview G of February 14 2013, Mwoga cellule; Interview C of February 15 2013, Mwoga cellule; Interview E of February 17 2013, Mwoga cellule.
} 
The population were warned by the authorities that selling the fertilizer (that they had been forced to purchase) was 'illegal'. Despite this, significant amounts of fertilizer were reportedly smuggled across the border to Tanzania (IFDC/CATALIST, 2010). Several farmers admitted having covertly sold fertilizer. In a context in which they are forced to buy fertilizer, and have suffered major financial losses due to poor maize harvest, selling fertilizer can be seen as either a form of indirect resistance to the CIP, or as a household financial survival mechanism.

Most of those involved in such covert activities perceive of them as rational economic choices. Respondents stated that they know there is a chance that their actions will be discovered. If the authorities discover the 'prohibited' crops, they may uproot them, issue a fine, or (occasionally) both. In many cases, the older male member of the household will travel out of the immediate area to seek casual farm-work during the period when the prohibited crops mature and become more visible. This tactic is intended to avoid family members being imprisoned, as it is considered unlikely that the authorities would imprison a woman, particularly one with children. Households using these strategies are gambling that they will not be discovered or, if they are, that the crop won't be uprooted and that fines will be less than the market value of the crop. Sometimes the gamble pays off. One farmer reported that, 'Last season (A) I mixed maize with beans. They asked me to uproot them. I refused, they fined me 7000 RWF. 
On 1 hectare, I didn't get any maize harvest, but I harvested 2 sacks of beans. I sold it for 50,000 RWF $^{288}$

In comparison with the covert strategies used during the main season (A), farmers were much more assertive during season B. In 2009, farmers simply refused en masse to grow maize during season B. Instead, they planted the crops of their preference, particularly sorghum. This has been interpreted by external actors as a 'misconception' by farmers, caused in part by lack of a 'clear planning system linking Seasons A and Seasons B' (IFDC/CATALIST, 2010: 31). Others have written that farmers were allowed to cultivate sorghum and maize in Season B (Nsanzabaganwa, 2012: 164), as part of a general 'flexibility in implementing policies' that is 'one of the guiding principles' of the district (Nsanzabaganwa, 2012: 166).

In contrast, respondents described this phenomenon as a conscious act of resistance against the CIP. They are well aware that the state wants them to plant CIP crops during season B. ${ }^{289}$ One man stated that, '[In] season B we cultivated sorghum by force, the state found the sorghum in the fields without knowing the story of how it grew there, because it's forbidden along with other $\mathrm{crops}^{\prime} .^{290}$

\footnotetext{
${ }^{288}$ Interview D of June 17 2011, Kamombo cellule.

289 Interview F of June 21 2011, cellule Cyanika; Interview B of June 16 2011, cellule Saruhembe; Interview A of May 29 2011, Munini cellule.

${ }^{290}$ Interview E of June 10 2011, Mwoga cellule.
} 
Occasionally, farmers have tried more direct methods to assert their right to make decisions over their land use, financial investments and labour. The authorities have not been sympathetic:

One day I tried to go against the policy of growing maize; in a meeting we asked to leave maize farming. We had the intention to go to the cellule office to explain ourselves. After arriving at the office, we repeated the same words that we pronounced in front of the community. We were fined 4,000 RWF and we two had to sign [a paper] saying that we would never again say these things in front of the community. ${ }^{291}$

\section{Emigration to neighbouring Countries and Migration within Rwanda}

Many farmers have chosen to leave the district. Some have covertly crossed the border into neighbouring Tanzania. A common strategy is for one family member to covertly cross the border in order to identify opportunities, while other family members remain behind. Sometime later, when land or employment opportunities have been secured, other family members leave as well. In cases where entire families migrate, houses and fields are sold covertly to friends or neighbours, who if asked will pretend to be temporarily looking after the property for the real owners.

Households often leave because they have accumulated significant debts, mainly due to maize production. In other cases, farmers have left the District not to avoid repayment

${ }^{291}$ Interview B of May 31 2011; location withheld to provide anonymity. 
of debt, but rather to escape state-imposed crop specialization. ${ }^{292}$ Informants said that people they know have left, 'in order to get away from the system of the state.' ${ }^{293}$

The numbers of people leaving appear to be quite significant. One farmer estimated, for example, that between July and August 2011, some 15 people left Mwoga cellule. ${ }^{294}$ Another man in a third cellule estimated that about $5 \%$ of the population of the cell had left. ${ }^{295}$ Another informant said that six people had left his umudugudu, while another man in a different village and cellule also said that six youth had left, destinations unknown. ${ }^{296}$ A woman claimed that a third of the local population has plans to leave the region. ${ }^{297}$ Another contended that, 'those people who stay here are those who don't have a place to go or the energy to go into exile' ${ }^{298}$

Local authorities have raised the issue of flight into exile, during community meetings. Respondents stated that authorities warned them that they would arrest those who sell property on behalf of households who have fled the country. ${ }^{299}$ While there is little in the media about such phenomena, reports of cross-border smuggling have mentioned the rise in the number of cases and the significance of 'illegal immigrants' (Rwembeho, 2010f).

\footnotetext{
292 Interviews A and E of October 12 2011, Mwoga cellule

293 Interview A of October 11 2011, Mwoga cellule

294 Interview B of October 11 2011, Mwoga cellule.

295 Interview J of October 142011 Kamomba cellule

${ }^{296}$ Interview B of October 12, 2011, Mwoga cellule; Interview B of October 13 2011, Saruhembe cellule.

297 Interview H of October 13 2011, Saruhembe cellule

298 Interview D of October 14 2011, Kamomba cellule

299 Interview C of October 11 2011, Mwoga cellule.
} 
Not all of those who have left have headed for Tanzania; others migrate within Rwanda.

Due to the political and legal sensitivities involved, and the secretive nature of the migration, it was not possible to collect precise information on how many of those leaving have chosen internal migration, or exile.

\section{Smallholder Farmer Discourses on Agricultural policy implementation}

The differences between official discourses of agricultural transformation in Kirehe and the statements of the majority of smallholder respondents are striking. The idea of state facilitation of entrepreneurial smallholder farming practices does not figure in the discourses of local people. Rather than the idea of new options and choices, the agricultural reform represents a curtailing of options.

In contrast to the stereotypes of 'negative attitudes', 'traditional attitudes' (Rwembeho, 2010b) and 'ignorance' (Rwembeho \& Uwamariya, 2012) farmer respondents did not simple reject maize out of a yearning for customary norms. Instead, they often provided precise economic information (including investments, yields, and market prices) on maize and other crops, such as sorghum. Based on this information, as well as their characterisations of each crop (drought-resistance, multi-functionality, marketability etc.) they listed the pros and cons of each. Almost without exception, respondents found maize too unreliable. 
Many respondents expressed frustration at the maize policy. Many farmers stated clearly that they wanted to be able to choose which crops to grow, and when. Rather than primarily framing this as a question of 'rights', or merely asserting that they knew best how to grow crops reliably and profitably, many farmers contextualized their role within the broader commodity chain. Some respondents mentioned instances of cooperative leaders embezzling money. ${ }^{300}$ One farmer argued, 'why arrest the population for 20,000 [i.e. for outstanding fertilizer debts] instead of arresting those who have embezzled millions? ?301 $^{301}$

Many respondents talked not only of the district system of fertilizer distribution, with the prominent role of the private sector, but also of the significance of maize for largescale agro-processing firms and for export, and the legal framework of land ownership. These responses can only be described as political economy analyses of the agricultural sector. Farmers say that they are relegated to a position as an 'instrument' of state policy. ${ }^{302}$ Typically, they see the true object of the maize policy to be the profitable operation of maize processing plants. ${ }^{303}$ Smallholders would seem to agree with Harvey (2005) that commercialization is associated with elite strategies of accumulation. One middle-aged woman argued that:

\footnotetext{
${ }^{300}$ Interview D of June 13 2011, Saruhembe cellule

301 Ibid.

302 Interview M of May 31 2011, Mwoga cellule; Interview A of May 19 2011, Nyamugali cellule.

${ }^{303}$ Interview E of February 15 2013, Mwoga cellule; Interview L of February 16 2013, Mwoga cellule.
} 
The authorities who push the maize crop have come to find that these industries will be in debt, and also the banks are asking for credit on their loans. Our analysis as farmers is that it is not the state that pressurizes us to cultivate maize, it is the industrialists who look for a supply to process into maize-flour. ${ }^{304}$

The discourse of the Ministry of Agriculture, together with the promises made by the NLTRP prior to land registration, reproduce an image of a landowning farmer, empowered to make changes to seek profit. However, many farmers pointed out that they had only leasehold rights. ${ }^{305}$ This comment was a common one heard in many interviews: 'They lied to us that they would give us rights to land, afterwards they changed, saying that land doesn't belong to the population but to the state, the state has to lease the land [to us] ${ }^{306}$

Seemingly embittered by the gap between these promises, and the expectations they engendered, many farmers argued that they were no longer autonomous farmers in any sense, but were rather 'workers for the state' ${ }^{307}$ A very high number of respondents

\footnotetext{
${ }^{304}$ Interview C of June 22 2011, Munini cellule.

${ }^{305}$ Interviews C and G of February 15 2013, Mwoga cellule.

${ }^{306}$ Interview A of October 11 2011, Mwoga cellule.

${ }^{307}$ Interview K of May 31 2011, Mwoga cellule.
} 
extended this analysis to argue that farming under current conditions in Kirehe amounts to 'modern slavery'. 308

This term was also mentioned by some pyrethrum farmers, as mentioned in the previous chapter. ${ }^{309}$ The term appeared frequently enough to suggest that it is a trope within community discourse. Within the context of Rwanda, such terms have particular historic resonance. The immediate pre-colonial and colonial eras have been characterised by many scholars as periods of intense state control and exploitation of rural labour by the monarchy and the colonial regime. As mentioned briefly in Chapter Five, those Rwandans who could not claim some connection to the powerful sociopolitical patrons that gained legitimacy from the King (the Mwami) would have to perform forced labour known as ubureetwa (Newbury, 1988: 141). Such menial labour included fetching water and cultivating the fields of the powerful - normally the local chief or subchief. ${ }^{310}$ If ubureetwa was not performed on demand, the rights to land of his or her family, which were guaranteed by the chiefs in the name of the Mwami, would be forfeit. From the mid- $19^{\text {th }}$ century onwards, when the categories of Tutsi and Hutu became rigid and codified within rigid power structures, it was only Hutu who had to perform ubureetwa. This was later formalized by the colonial administration's ethnic policies (Vansina, 2004:135). The Belgian colonial regime imposed conditions of forced

\footnotetext{
${ }^{308}$ Interviews B and E of October 13 2011, Saruhembe cellule; Interview J of February 16 2013, Mwoga cellule.

${ }^{309}$ Interview B of February 18 2013, Kinigi sector.

${ }^{310}$ In the pre-colonial and early colonial period, each community would be under the jurisdiction of three chiefs (the chief of the army, the chief of the pastures, and the chief of the fields). The Belgian colonial regime re-organized this system in 1928, so that each community was under a single sub-chief or chief (Reyntjens, 1987).
} 
agricultural production on the rural population from the late 1920s onwards (Newbury, 1988: 154). Chiefs were responsible for ensuring that quotas for coffee production were met, and they used the ubureetwa labour of the local Hutu population to meet those quotas, as well as to work on the chief's own private farms (Newbury, 1988: 142). Therefore, as the colonial regime consciously attempted to integrate the political authorities into the commercial authority, it deepened the inequalities associated with a precolonial form of forced labour. This history of exploitation has not been forgotten by Rwandans and was mobilized (often in an exaggerated form) for anti-Tutsi propaganda produced by Hutu extremists, particularly in the months leading up to the 1994 genocide. Extremists drew upon a caricature of this exploitation, and universalised the role of individual Tutsi chiefs to suggest that all Tutsi were supremacists, bent on subordinating Hutu. Farmers' concerns about becoming 'instruments', 'workers', or 'slaves' should be understood within this complex matrix of history and propaganda.

Similarly to the pyrethrum case study, the relations between the state and local people over questions of agricultural reform were characterised by some farmers ${ }^{311}$ in terms of conflict: 'We have a war, combating and fighting against the state and its system of monoculture'. ${ }^{312}$ A respondent involved with the CIP in an official capacity was concerned that the implementation of the agricultural policy was going to bring a 'war' between the state and farmers. ${ }^{313}$ Others stated that the state was 'at war' those who

\footnotetext{
${ }^{311}$ Interview A of June 8 2011, Mwoga cellule

312 Interview D of June 18 2011, cellule KAWOMBO, sector MAHAMA.

${ }^{313}$ Phone interview with local respondent, June 17 2011, details withheld to protect the identity of the respondent.
} 
did not follow the policy: 'Those that are against the policy are taken as enemies who fight against the government' ${ }^{314}$ Others claimed that farmers refusing to follow the policy were treated as 'negationists' or 'divisionists' by the state. ${ }^{315}$ While I could not verify these claims, it suggests that farmers are accused of being 'against the state', which, as explained in the previous chapter, is implicitly, if indirectly, associated with genocide ideology. The combination of the 'slavery' trope, and the vocabulary of 'conflict', suggests that the agricultural policy is having profound effects, at least in some areas, on the relationships between the state and local people.

\section{Conclusion}

This chapter has highlighted several instances in which the government's over-riding faith in science appears to be driving policy (such as the investment in irrigation for maize) as well as the importance of 'legibility' of consolidated land for the blueprints of state programming. The case study therefore reflects some aspects of the 'authoritarian high modernism' model, despite the inclusion of commercial actors in agricultural extension and provision of agricultural inputs. One of the key findings of this Chapter is that commercialization of the maize sector in Mahama Sector, Kirehe District has involved the commercialization of some responsibilities of the local authorities, who

\footnotetext{
${ }^{314}$ Interview B of February 142013 with head of umudugudu, location withheld to protect anonymity.

${ }^{315}$ Interview F of February 14 2013, Mwoga cellule; Interview L of February 16, 2013, Mwoga cellule.
} 
receive payments when fertilizer is purchased and correctly applied by farmers. In addition, state functionaries have developed other, more covert, forms of incomegeneration, often at the expense of local farmers. The chapter suggests that commercialization of the maize sector is leading to an increasingly entrepreneurial cadre of local government workers, responding to the blurring of private and public interests. In contrast, farmers feel that their role, as citizen-producers within the contemporary Rwandan rural political economy, is reduced to a labour force. This conclusion is similar to that reached by many pyrethrum farmers, as described in Chapter Seven. In the pyrethrum-producing areas, the main characteristics that determined its uniqueness as a 'space of governance' was the extreme land tenure insecurity faced by farmers, as well as the monopoly enjoyed by the only pyrethrum processor in the country, SOPYRWA. The main characteristics that determine the uniqueness of Mahama sector as a 'space of governance' are the extent of villagization within planned settlements, which facilitates the disciplinary functions of the 'connectedness machinery' of government, and the commercialization of the fertilizer distribution system, which has likely made it even more coercive that in other parts of Rwanda. Compared to the pyrethrum zone described in Chapter Seven, where land confiscation can be easily accomplished by SOPYRWA and fields are patrolled by SOPYRWA delegates on an almost daily basis, the 'connectedness machinery' in Kirehe is more extensive, less centralized, and more clearly a dispositif of various actors.

While the 'authoritarian high modernism' model is useful, it tends, as discussed above, to rely upon an overly simple dichotomy between 'domination' and 'resistance'. 
Theories of governmentality enable us to move beyond the concept of 'resistance' in order to understand how particular modes of governance (by the state and other actors) result in the production of different kinds of subjects. The strength of Foucauldian theory is that it does not conceive of these subjects as purely a result of a one-way flow of power and influence, but of more complex exchanges between different actors.

Based on interviews, it seems that in the case of Mahama sector, Kirehe, the government has largely failed to achieve its stated intention to facilitate the emergence of the 'modern farmer', an assertive, entrepreneurial self-governing individual along the lines of the neoliberal 'rational actor'. However, several years of state insistence upon maize production in the face of almost universal smallholder opposition has led to the emergence of discourses and behaviours that can be associated with a particular kind of subject. Characterizing the state as interested only in the profit of elites, describing the relationship between the state and farmers as a 'war', perceiving of themselves as being pushed deeper and deeper into poverty by the continued insistence on maize, citizens in Mahama sector have engaged in a number of covert coping strategies. These go beyond 'everyday forms of resistance' and amount to radical reconfiguration of livelihood strategies.

One of the key characteristics of these new strategies is de-territorialization: poor local farmers are increasingly moving out of Kirehe District, either temporarily or permanently, as a family unit or as individuals. This de-territorialization is not only an act of desperation but also a conscious response to the legal and policy environment: 
emphasizing that they no longer have ownership rights to land, they say they have been reduced to proletariat status. They are making a conscious decision to disconnect themselves from particular parcels of land in Kirehe District. They implicitly see land as a commodity to be rented or purchased elsewhere, preferably in a lightly-regulated context rather than in Mahama where the maize policy is associated with labour dependencies which resonate with historical narratives of subjection and exploitation. Treating land as a commodity is of course part of the 'modern farmer' trope.

Other key characteristics of these new strategies are that they are covert and often illegal, and involve the collusion of local-level government officials. It is inconceivable that a household - particularly one living in a planned settlement - could sell its house and land without the umudugudu leaders coming to know of it very swiftly. Similarly, it is highly likely that umudugudu leaders, who are responsible for ensuring that fertilizer is applied on maize fields, are involved with the black market in fertilizer, at least at the level of being paid to keep quiet.

Ironically perhaps, the various strategies that the government uses to try to create 'modern farmers' - legal prohibitions, disciplinary measures, and investments in the milieu intended to encourage marketing of crops and circulation of expertise - have contributed to the creation of a local subject that is indeed 'self-governing' and assertive. Farmer livelihood strategies require considerable planning and adaptation to changing circumstances, which are the desired requisites of the neoliberal ideal subject. 
Because of the importance to this 'subject-type' of a flexible relationship to land and 'home', the title of 'mobile farmer' or 'fugitive farmer' is apt. The term 'fugitive' here refers both to the notion of fleeing state surveillance, and to the idea of a transient, conditional and sometimes short-lived relationship with particular pieces of land.

The governmentality lens allows us to recognise that that new subject-forms are not entirely created by the actions of the state; they are co-creations, involving the conscious effort of the smallholders themselves. Through reference to the inseparable relation between knowledge and power, we can see that the emerging discourses of conflict, oppression and servility (often based on what I have identified as a political economy analysis of the agricultural sector) represent not only 'mere words' but have power-effects as well, de-legitimising the state and justifying these new forms of household behaviour. Farmers do not reject 'markets' or 'commercialization' but rather the specific configuration of state support for some actors; and controls on the assets of others. Statements such as 'the population works by itself, without the help of the state $^{316}$ reflect a notion that local people have to help themselves, becoming selfgoverning subjects.

It is important to note also that such subject-forms do not emerge from nowhere. The historical analysis at the start of this chapter suggests that suspicion towards the central state, and certain behaviours - such as cross-border movements, smuggling, and internal migration - have strong precedents in the region. The new livelihood strategies

\footnotetext{
${ }^{316}$ Interview H of February 16 2013, Mwoga cellule
} 
such as 'mobile farming' or 'fugitive farming' therefore emerge from a specific space of governance, with its particular geo-political, agro-ecological, and socio-political characteristics. 


\section{Chapter Nine: Conclusion}

In English there is the saying about a carrot and a stick. Sometimes they give you a carrot but then later this carrot becomes a stick which they use to beat you up... They keep using it as a tool of control and management. (Kagame, 2012)

As noted in Chapter Four, President Kagame has criticised the international aid and justice architecture for moving between governmental and disciplinary forms of power, using the 'carrot and stick' metaphor. Similarly, the agricultural intensification architecture within Rwanda can be seen as a discourse of incentive-based development which seeks to achieve a degree of citizen consent, along governmental lines; which is paralleled by a range of disciplinary technologies employing the 'stick' of coercion. However, as we have seen, the simultaneous use of disciplinary and governmental strategies is not necessarily part of a masterplan or blueprint, but is rather loosely coordinated and based in part upon contingency. Moreover the agricultural reform is designed and implemented by multiple state and non-state actors, within a context often (wrongly) described as 'liberalization' of the sector.

Therefore, as discussed in Chapter One, my research questions are: 
What effects does the increased involvement of commercial non-state actors in the agricultural sector have on the processes of spatial and institutional homogenisation, standardisation, and coercion associated with authoritarian high modernism? Given the historically close association between projects of state-building (broadly defined) and processes of commodification and commercialization, how do discourses and practices of (neo)liberalism in the agricultural sector intersect with state efforts to mould ideas of citizenship, development, and governance, within specific geo-spatial contexts?

My research has provided the following answers to these questions. As argued in the three case studies presented in Chapters Six-Eight, the increased involvement of nonstate actors has tended to reinforce processes of spatial and institutional homogenisation, standardisation, and coercion associated with authoritarian high modernism. The commercial objectives of non-state actors have become incorporated within state-administered governance technologies (such as imihigo performance contracts) which are both homogenizing and coercive in nature, while the introduction of private profit-making mechanisms into state-directed systems of distribution of fertilizer, for example, have provided material incentives for state and non-state actors to use coercive measures to increase sales. In some circumstances, such as in the pyrethrum sector, non-state actors have initiated activities which are associated more with a governmental mode of power than a disciplinary system, and hence are not associated with outright coercion. However, these governmental activities were 
conducted in parallel with a significant strengthening of coercive disciplinary technologies.

I have traced the ways in which projects of state-building in Rwanda (such as programmes operating under the banner of unity and reconciliation) have incorporated capitalist development objectives within them, which emphasise economic growth. As described in Chapter Five, the concept of successful development and post-genocide citizenship, as communicated by myriad government agencies, is comprised of subjection to state-imposed policies as well as capitalist profit-making along the rather neoliberal principles of entrepreneurship. I have also shown that production of agricultural commodities which are prioritised by the government is associated in state discourse with 'patriotism', while opposition to government policies on mono-culture (itself a mechanism of commercialization) and other state-imposed agricultural technologies is associated with sedition and hatred of the Rwandan nation itself.

Discourses and practices associated with liberalism and neoliberalism in the agricultural sector are part of broader attempts by the Rwandan state to create a new kind of Rwandan citizen, a 'model farmer' who is entrepreneurial in nature and also compliant towards state policy. Key elements of the 'model farmer' ideal are crop specialization, a willingness to seek credit in order to expand and intensify agricultural production, and a complete integration into agricultural commodity-chains that are prioritized by the government for consolidation and commercialization. The integration of farmers into priority commodity-chains is facilitated by the imihigo performance contracts and other systems which, as mentioned above, incorporate the demands of commercial actors 
(e.g. approximate tonnage of commodity to be purchased by a company) within governance systems explicitly designed to produce 'good citizens' and 'good governance'. Therefore there are clear links, in terms of both discursive and 'operational' or programmatic activities, between (neo)liberalism in the agricultural sector and state efforts to mould ideas of citizenship, development, and governance.

These relationships are more explicit in some geo-spatial contexts than others, and linkages take on different forms. I have identified certain areas, such as the pyrethrumproducing zone in northern Rwanda, in which the disciplinary aspects of governance are more evident than in other areas. This is because of the particular history of the area and, especially, the land tenure regime found there. In this area, the authorities attempt to produce a version of the 'model farmer' trope which has much less emphasis on entrepreneurship (because the disciplinary system in the area explicitly limits the commercial options open to farmers) and more emphasis on subjection to government policy and responsible self-governance in the spheres of health and family planning (e.g. improved management of individual health is discursively linked to increased agricultural production with cooperatives). In the pyrethrum zone, the ownership of SOPYRWA by the RPF shows that relationships between commercialization and governance should not simply be understood through the role of 'the state' but through the colonization of both state and non-state spheres by the ruling party. There are likely to be other identifiable spaces of governance in Rwanda, where administrative systems and understandings of citizenship are configured in particular ways to enhance the authorities' abilities to impose the agricultural policy. 
Having stated the conclusions of the dissertation in concise terms, I will now discuss them in more detail. The research has, first of all, shed light on how some of terms used by Scott (1998) may be understood. I have argued that understandings of heterogeneity and homogenization are dependent upon the politics of scale, which is a key concern of geographers and political economists. I have drawn attention, for example, to the ways in which the regional crop specialization programme, with its various priority crops, may not seem like a homogenizing technology when examined from a 'national' level perspective, but seems much more homogenizing when a local (cellule or sector-level) perspective is taken. For example, when the entire population of an administrative sector or cellule is coerced into cultivating one specific crop during a particular seasonsuch as maize in Mahama sector - this appears to be a 'homogenizing' dynamic, given the agro-ecological and climatic diversity (across space) and variability (over time) within such administrative units. Similarly, the Imihigo performance contract system, which is deployed by the government in order to entrench and enforce the crop specialization system and, in many cases, facilitate the involvement of commercial actors within the agricultural sector, is a recognizably homogenizing technology because of its reliance on a standard 'template' imposed by the central government.

The institutional analysis (Chapters Three-Five) and case studies (Chapters Six-Eight) provide numerous examples of commercial and/or non-state actors becoming increasingly incorporated into the architecture of the agricultural reform. Overwhelmingly, these non-state actors work through such systems of standardisation and homogenization. In some cases, non-state actors may declare their ultimate 
objective to be an increase in farmer incomes through agricultural intensification and commercialization. However, the examples discussed in this dissertation involve farmers' organizations, multinational corporations, and wealthy private agricultural entrepreneurs, benefitting financially from their alignment with state systems of standardisation which are often imposed through the use of coercion. Using the Foucauldian concept of the dispositif or apparatus to enhance Scott's model of authoritarian high modernism, I showed that the incorporation of commercial, nonstate actors within the dispositif of agricultural reform in Rwanda has resulted not in a 'liberalization' (understood as an expansion of economic and other options associated with a decrease in government regulation) but rather a deepening of the dynamic of standardisation when viewed from a micro-scale (e.g. the sector-level). In the case of farmers' organizations, their close association with the state enables them to benefit financially from sales of fertilizer, seeds and technical services to cooperatives which are in many cases composed not of volunteers but of farmers who are coerced into investing their time, money and assets into the cooperative. The involvement of farmers' organizations and other civil society organizations demonstrates that Scott's authoritarian high modernism model over-simplifies the potential range of relationships between the state and civil society groups. The 'prostrate' nature of civil society that he describes is evident in Rwanda - as some organizations have been attacked by the state to such a degree that they have completely collapsed or have become unable to advocate for policy changes - but more generally, civil society has been co-opted into playing important roles within the state-dominated dispositif. Farmers' organizations 
and other non-profit organizations have become more deeply entrenched in the agricultural dispositif because they have adopted a financial model partly based on commerce with farmers. By hitching this commerce to the crop specialization policy and other coercive aspects of government policy, these organizations can maximise their revenue from such activities. In the case of Rwandan companies that have won government contracts to distribute fertilizer in Kirehe, they profit from the coercive policies enforced by the local government, which have resulted in record fertilizer sales across the District. In the pyrethrum sector, a multinational pharmaceutical company has partnered with the world's largest development agency to support the intensification of systems of discipline and coercion. As a result, more pyrethrum is being produced, under highly standardised conditions enforced in part by 'cooperatives' established by the authorities and the party-statal pyrethrum processing company, SOPYRWA.

However, while the dissertation has detected a pattern of increased standardisation and coercion following the incorporation of commercial actors, it has also shown how the imposition of standard models of production (associated particularly with the Crop Intensification Programme) is mediated by particular socio-political structures found in the local setting. In the case of the agricultural policy entrepreneur who founded a cooperative in Musanze District, for example (Chapter Six), I described how the coercive and persuasive force of the cooperative depended not only on the support of the local authorities (upon which the policy entrepreneur could depend because of his personal ties to the local administration) but also on various local dynamics related to kinship and 
class. This shows how homogenous and standardised packages of agricultural intensification are not necessarily implemented or imposed in similar ways.

As noted in Chapter One, Scott argues that authoritarian high modernism is unlikely to occur within a 'liberal political economy' (1998: 101). The research presented here has shown that even though the government of Rwanda has incorporated neo-liberal policy tools into its administrative structures, this does not necessarily result in 'liberalization'. The agricultural sector, like the broader economy of Rwanda, is a complex mixture of policies and programmes associated with state intervention and RPF 'party statal' (Gokgur, 2012) monopoly of certain activities, as well as more neoliberal concepts such as cost-recovery and privatization. Therefore, the results of the research do not directly contradict Scott's assertion. Rather, they suggest that Scott's generalizations regarding markets and liberal political economy, including the idea that 'large-scale capitalism is just as much an agency for homogenization' as the state, (1998:8), require greater nuance. As Harvey (2005) and Ferguson (2009) point out, neoliberal practices never completely follow neoliberal doctrine; we might also speculate that systems of centralised governance within authoritarian regimes are likely to be influenced by the diverse approaches and actors (domestic, transnational and multilateral, capitalist and non-profit, etc.) that characterise rural 'development' in the contemporary period. Therefore, the complex nature of the Rwandan political economy is likely replicated in other 'hybrid' regimes (Levitsky \& Way, 2002). Another lesson from the Rwandan experience is that, particularly in the context of a Green Revolution model that is often 'state-driven' (Djurfeldt et al 2005b), capitalist corporations do not operate 
autonomously but within the limits imposed upon them by state policies and programmes. As elements of a state-dominated dispositif, they may attempt to influence government policy but will succeed only through negotiations which take place within a field of (often very unequal) power-relations. It is governance instruments like the imihigo, as well as profit-making models (such as the commercialization of service provision and input supply by farmers' organizations) that provide the incentives for heterogeneous collections of actors to function as a dispositif despite their differences and disagreements.

These actors within the dispositif are not only Rwandan, but also international, which required me to look briefly at the ways in which the Rwandan state interacted with the international development architecture. There are striking parallels between the characteristics of the modern farmer, and 'New Rwandan subject' more generally, and the ideal model of the aid recipient state under global networks of governmentality. Ideas associated with entrepreneurship, such as adaptability, assertiveness, and 'hard work', are part of the image of the state that the government of Rwanda seeks to communicate within international systems of governance calculus. For example, the ways in which performance contracts and other management technologies are discursively embedded by the government of Rwanda within a 'traditional' Rwandan context are communicated as a form of national adaptation and 'ownership' of global governance technologies. These are also the traits that government leaders, particularly Paul Kagame, emphasize as the core characteristics of the New Rwandan subject. 
The discursive creation of Rwanda as an 'ideal development state', framed within neoliberal conceptual frameworks of governance, is not the work of Rwanda alone. A variety of private corporate actors, academics, multilateral organizations, and bilateral agencies reproduce a narrative of development with entrepreneurial characteristics, as part of a Rwandan 'success story'. These narratives are often mutually constituted by Rwandan and foreign actors. For example, President Kagame and the government of Rwanda more generally provided the authors of the book Rwanda, Inc with access to individuals and information (Crisafulli \& Redmond, 2012:2) because it reinforces this image and President Kagame promotes the book during private meetings with journalists and others (Soudain, 2013). Those that disagree with the narrative that Rwanda follows a liberal development model of 'exemplary governance' (Soudain, 2013 citing Crisafulli \& Redmond, 2012) may be targeted by an active public relations campaign waged by the government or those allied with the government of Rwanda. ${ }^{317}$ The 'modern farmer' and 'New Rwandan citizen' subject-types feed into this narrative, and hence play important roles in the government of Rwanda's strategies within systems of international governmentality. In addition to systems of aid, these models also perform roles within commercial networks, attracting foreign direct investment to the country.

However, that is not to say that it these models of ideal citizenship are only intended to play those roles. The government may well be committed to creating this kind of

\footnotetext{
${ }^{317}$ The precise identity of those involved is rarely explained, though some are frequent contributors to pro-government newspapers such as the New Times. See e.g. Remaking Rwanda Blog (2013); Butamire (2011)
} 
Rwandan subject. However, at many junctures, the circulations of ideas, people, goods and services that are required for an innovative, adaptive, and self-governing population to emerge, are contained within disciplinary systems.

The close relationship between donors and the government of Rwanda, which includes substantial 'technical' assistance in drafting laws and policies, as well as regular information-sharing and joint decision-making, has strongly influenced the Rwandan legal and policy environment. However, there are many instances when the government of Rwanda has acted against donor preferences. Similarly, the incorporation of commercial actors within state-regulated commodity chains is not completely smooth. In the pyrethrum zone of Musanze District, for example, there is friction over the extent to which local farmers should be treated as 'responsible' development actors (such as debates between donors and SOPYRWA over distribution of the 'Lifeplayer' technology,) which can be understood as tensions between disciplinary and governmental approaches. In Kirehe, the introduction of private profit-making streams into statesubsidised agricultural programme implementation has led to friction between corporate actors and local administrators over issues such as cost-recovery for fertilizers.

As described in Chapter Five, the concept of successful development and post-genocide citizenship, as communicated by myriad government agencies, is comprised of subjection to state-imposed policies as well as capitalist profit-making along the rather neoliberal principles of entrepreneurship. The efforts of the Rwandan state to promote 
an entrepreneurial model of agricultural development, through various arts of government broadly identified as governmental (the construction of physical market infrastructure, diffusion of ideas of 'innovation' and development by various state and non-state actors, dissemination of commodity price information, etc.) have been largely embedded within a state-controlled discursive, legal, policy, and institutional architecture that is designed for sovereign and disciplinary modes of power. Moreover, the use of ambitious targets, and disciplinary measures against those local administrators who fail to achieve them, encourages direct state intervention and processes of 'containment', rather than 'circulation' associated with governmental strategies. This is not unexpected, given Foucault's insistence on the ways in which the sovereign, disciplinary and governmental modes of power are all used in contemporary societies. The extent of intervention in the agricultural sector, while extreme, is not unique, as demonstrated by Polanyi's work on the state-engineered emergence of capitalism in Europe, for example (Polanyi, 2001: 56).

Scott (1998) provides various example of domination by the state, involving the use of fines, the deliberate weakening and silencing of civil society, and other means. However, he does not fully theorize the types of technologies of domination. Using Foucault's discussion of sovereign power, discipline and governmentality, we are able to differentiate between methods of 'domination' that seek to control individuals, and those that operate at the level of the population, in order to attempt to create new 'species life' (Duffield 2009, citing Foucault). We are also able to link the use of these 
tools by the state with the intensification of the influence of markets, and private actors more generally.

\section{Governmentality, Markets, and Spaces of Governance}

Rwanda's apparent decision to avoid large-scale private land acquisition (a 'corporate land grab') on the hills of Rwanda and encourage a combination of direct acquisition of smaller parcels, as well as significant use of out-grower (contract farming) relations would seem to militate against an 'enclave' model of agricultural production. However, the use of imihigo contacts in order to provide incentives for private sector investment means that these out-grower relations are restricted to citizens within particular administrative boundaries, who produce specific crops within a system of disciplinary technologies.

Particular spaces of governance are emerging, and are likely to become more distinct over time, particularly if there is increased corporate or parastatal penetration of rural production systems. In the Rwandan case, the particular nature of discrete spaces of governance tend to emerge as a consequence of the government's willingness to tailor the rights and obligations associated with citizenship to particular state goals. For example, in the pyrethrum zone, farmers are denied access to local dispute resolution mechanisms. The particular land-tenure system, the relatively manageable size of the pyrethrum zone and the 'dense' nature of the disciplinary machinery, has meant that 
farmers have difficulties avoiding detection by disciplinary systems. Those who refuse to abide by the policies of SOPRWA risk having their land seized.

Particular spaces of governance may be associated with slightly different ideas of citizenship and variations on the 'model farmer' concept. The ability of the government to adjust the idea of 'citizenship' comes from, firstly, the adoption of particular arts of government (many associated, broadly, with neoliberalism) and secondly from a 'moral' framing of notions of citizenship. A discourse around what constitutes 'good' citizenship has emerged, and has become embedded in subtle ways in the complex Rwandan administrative and non-state institutional context. The emphasis on the 'patriotic' nature of pyrethrum production, in parallel with a diffusion of a version of the 'model farmer' largely divested of the entrepreneurial aspects, creates a discursive model of citizenship that fits the highly disciplined environment of the pyrethrum zone. Therefore, the rights and responsibilities of sovereign citizens are being tailored by the state, in specific moments and geographic spaces, in order to more effectively harness them to the so called 'connectedness machinery' (Nsanzabaganwa, 2012: 142) that the government puts in place to drive 'development'. The state 'sees' citizens slightly differently depending on their location within particular spaces of governance, as well as their position within the processes of subjectification and socio-economic differentiation associated with the agricultural reform. These spaces of governance are therefore not purely imposed by the government, but are formed through interaction between various components of the state-dominated dispositif and farmer practices and discourses. 


\section{The 'Visible Foot' of the State}

These processes of socio-economic differentiation are associated with the concepts of primitive accumulation, and accumulation by dispossession. I used these concepts in Chapter Two, to link state-driven processes of commodification of rural livelihoods with the separation of small farmers from their land and other properties. The case studies included some examples of accumulation by dispossession. In the case study of a failed agricultural cooperative in Musanze district (Chapter Six), it was clear that the cooperative leadership had a strategy of accumulation by dispossession, which was possible because of the perceived power and coercive strategies of the cooperative President. The impacts of the coercive imposition of standard models of agricultural production by the cooperative leadership were associated with the socio-economic differentiation of the affected population, with some local people selling their land at below market rates, risking further impoverishment and eventual proletarianization.

However, processes of proletarianization are not only put in place through such direct acquisition of smallholder assets. As shown in Chapter Eight, coercion results in corporate actors and some local administrators siphoning value from the rural economy, at the expense of smallholders. More generally, the conditions imposed by the state on rural land-use force farmers to engage with commercial dynamics and push households into making investments. Such dynamics will accelerate processes of socio-economic differentiation. While the results will be largely seen as 'market transactions' (such as 
the distress sales of land documented in Chapter Eight) these are partly a result of the structural conditions imposed by the state.

My analysis of laws, policies, institutions, and discourses suggests that future processes of dispossession and proletarianization of smallholder farmers can only be partly understood through a traditional political economy approach: to be effective, such a methodology will have to be augmented by attention to issues of identity-formation and subjectification that I have introduced primarily through reference to the work of Michel Foucault.

The case studies, as well as the analysis of Rwanda's legal, policy and administrative systems, have shown that the government has made access to land, basic government services, credit, and shelter contingent upon each citizen's adherence to government policies. The experience of citizenship experienced by each individual will vary according to the ways in which they position themselves vis à vis the national project of reconciliation, economic development, and agricultural transformation. The extent to which citizens can perform the role of the ideal development subject within this national project conditions their access to land. The national development project, and the acceptable New Rwandan subject associated with it, is framed and controlled by the government, often using re-invented and re-purposed Kinyarwanda terminology. This form of subjectivity is consciously and explicitly separated from ethnic, regional, and similar identity markers. This means that there are few opportunities for older cultural 
claims to resources outside of the permitted discourses of development, reconciliation, and the like.

Access by citizens to the resources, services and opportunities supplied or monitored by the state are generally conditional on adherence to government-policed notions of good conduct. For example, even though the land registration process is recognizable as a governmental technology, involving the commodification and circulation of landholdings, continued access to land may in practice be conditional upon citizens following state agricultural policies, land use masterplans, and other systems of management and control. As noted above, government law-makers decided not to use the land law to provide state officials with the power to 'requisition' land held under leasehold if these systems are not followed. Nevertheless, local authorities have threatened to requisition land, in order to influence local behaviour.

Access to land in the marshlands and other areas of the state's domain is largely controlled by agricultural cooperatives. There is some evidence of access to such cooperatives being limited to citizens who are seen as exhibiting 'good conduct', defined through the discourses discussed earlier, which combine ideas of 'reconciliation' with subjection to state policies and willingness to be integrated into state-sanctioned commercial commodity chains. This is in addition to the fundamental economic demands (such as membership fees) imposed upon those wishing to join such cooperatives. As we have seen, these demands often result in the exclusion of the poorer segment of the population. 
Access to cooperatives more generally is a complex question, and the opportunities for access are highly dependent upon the specific area, purpose of the cooperative, and local socio-political context. For example, as we have seen in all three main case studies, local farmers are frequently forced to join cooperatives, especially those cooperatives involved in marketing the government's priority crops. However, those farmers who are forced to join in this way do not necessarily receive adequate information about the cooperative's management practices, financial situation, and other issues. While the cooperative institutional structure seems tailored, in part, to be highly legible to the state, many cooperatives are not legible to the population, but are on the contrary highly opaque.

Many cooperatives which are founded 'spontaneously' by local citizens, without the involvement of local authorities, may come under government scrutiny which limits their ability to gain formal cooperative status. For example, authorities may 'approve' (or disapprove) lists of members before permitting registration. Such vetting suggests strongly that those fulfilling the role of the 'modern farmer', and the willing development subject more generally, will be more likely to gain useful positions within cooperatives.

Access to basic government services is often restricted to those who have paid the health insurance fees, paid fertilizer debts, or fulfilled other aspects of 'good conduct' according to officials. This means that local authorities may refuse to provide administrative guidance in simple disputes, or refuse to write letters of recognition of 
residence (which are vital for those applying for identification documents or seeking to travel within Rwanda), for example. Denial of such basic services can greatly constrain farmer's opportunities in the social and economic spheres.

Access to credit, a key part of the entrepreneurial model, may also be conditional upon various factors. Access to commercial credit is linked to collateral, which means that for many farmers, access to land will determine access to credit. At the moment, only individuals or legally-recognisable groups able to demonstrate leasehold rights to very large areas of land (10 ha, in the Musanze example) are able to gain credit. Here again, the ability to fulfil the role of the 'modern farmer' and join a cooperative, subjecting oneself to the conditions placed upon agriculture by the state, may be key to accessing credit.

It can therefore be seen that depending on a variety of factors, including which space of governance a farmer is located in, the farmer's access to money, the way in which the farmer performs the role of the 'ideal development subject', and local variations in weather and pest infestations, each farmer will be affected differently by the various technologies of power deployed by the state. These technologies of power therefore drive processes of economic differentiation whereby some households become increasingly impoverished and are forced to drop-out from the farming sector, and others accumulate land and capital. It can therefore be seen that proletarianization associated with processes of agrarian transition is not only caused by accumulation by 
dispossession, but is mediated by state efforts at subjectification and the kinds of locallevel power dynamics described in the case study chapters.

\section{Farmers' Responses and Emerging Alternatives to the 'Model Farmer' Model}

In Chapters Six and Seven, I used Scott's model of 'resistance' to explain the activities of farmers in relation to government policies. In Chapter Eight, I was able to identify discursive and 'material' strategies employed by farmers which suggest the relevance of a more Foucauldian analysis. Faced with state crop specialization policies and discourses of entrepreneurship in a context of climatic uncertainty and generalized poverty, farmers in Kirehe, have, through discourse and various actions, legitimised the idea of a mobile, 'circulatory' livelihood which is only partially rooted in place. Circulation here is consciously intended to avoid being completely legible to state systems - such as when a 'household' reconfigures itself, with members dispersing across district or international borders without the knowledge of local leaders, or when households sell land clandestinely. While a reading of this phenomenon based on the 'everyday forms of resistance' model (Scott, 1985) would see this primarily as a reaction against the dominant development narrative of the government, signalling a lack of consent, attention to processes of subjectification suggests that it this phenomenon contains elements of the government narrative of entrepreneurship. Many farmers have achieved a 'strategic reversal' (Foucault, 1978: 131) by accepting some aspects of state discourse around land and labour, in order to enhance their own opportunities within 
the context of reform, for example treating land as a commodity and accessing it through market relations facilitated by the Land Law. While the state's discourse of the 'modern farmer' emphasises innovation, commerce, commodification and financialization, the systems of law and discipline are highly dependent upon households being fixed in space, and being legible to the state. The state promises and demands circulation, but practices containment.

In a strategic reversal, farmers in Kirehe (as well as in Musanze) have built a narrative in which the state systems instrumentalize them and reduce them to 'workers'. Some farmers in Kirehe have developed a counter-state discourse and a set of practices in which they embrace the ideas of commodification of land and the circulation of a workforce disconnected from ownership of land in a particular place. While this narrative is generally heard in situations where state agents are not present, and could therefore be interpreted as a series of 'private transcripts', the similarities between many of the statements made by individual farmers suggest that a shared narrative has emerged. While it is largely hidden from state view, it is not private but rather part of a 'shared' discussion. Rather than representing only a form of resistance, the emerging narrative of the 'instrument of the state' and the flexible, circulatory individual who avoids instrumentalization or 'slavery' represents a subject-type which is considered legitimate given the controlling nature of the state, and considered preferential to the former option. In Foucault's terms, this is a new 'species-type' emerging, a new kind of subject co-created by the state's narratives of entrepreneurship and the farmer's counter-narratives and livelihood strategies of dissent, dissembling, and re-circulation of 
inputs which the state attempts to fix in space (such as fertilizers). The discourse of struggle and 'conflict' between smallholder farmers and the state, involves a new subject-type whose engagement with place, institutions, and indeed the concept of citizenship, is highly conditional. Specifically, the attachment of this new subject-type to particular places and institutions is inversely proportionate to the intensity of the state's systems of law and discipline. The more the 'connectedness machine' attempts to make farmers legible to the state, according to this discourse, the more likely it is that the new subject-type will disconnect.

\section{Theoretical Contributions}

This dissertation has made several original contributions to academic literature on the critical political economy of rural change in the global South.

Firstly, by applying the authoritarian high modernism concept to a case study characterised (in contrast to those case studies featured in Scott, 1998) by a great degree of complexity, variation and the involvement of many non-state actors in a context incorporating elements of neoliberalism, I have identified both the limitations and the potentials of this concept. In order to effectively apply Scott's model to such a complex case, I have expanded and adapted his theoretical framework using insights from Foucault, Harvey and others in productive ways. In particular, the use of the Foucauldian dispositif idea and attention to the mechanisms through which commercial non-state actors are incorporated into state governance systems has allowed me to 
move beyond the idea of 'seeing like a state', or alternatively 'seeing like a company' (Ferguson, 2005) towards the possibility of 'seeing like a dispositif', or a heterogeneous network of actors. Such an approach is useful as it permits scholars to acknowledge the agency of the state while recognising a) that the state is complex and multi-faceted and b) that the state is not in complete control of the implementation of an overall masterplan or grand design.

Secondly, by bringing in a 'spaces of governance' approach to the theoretical framework, I have identified the ways in which commercial activities create enclaves of extraction and uneven development (echoing Ferguson, 2005) but have done this in ways which acknowledge not only the profit motives of commercial actors, but statebuilding activities which seek to create new kinds of citizens. ${ }^{318}$ While I am by no means the first academic to successfully link a post-structuralist concern for the politics of identity and processes of subjectification with a more materialist political economy approach, my research has made these links not only through recourse to discourse analysis, but through identification of specific institutions and mechanisms which concretely embody these links. For example, by identifying the imihigo performance contract as simultaneously a) an instrument that connects commercial actors to household-level commitments to agricultural production, and b) a mechanism to impose particular forms of subjectivity (such as the modern farmer ideal) on the population, I

\footnotetext{
${ }^{318}$ Ferguson (2005) bases his analysis on the idea that corporations categorise the world into 'useable' and 'unusable' zones. My use of 'spaces of governance' in Rwanda is rather different: I argue that the government is committed to making the whole territory 'usable', but reconfigures administrative systems and ideas of citizenship in particular spaces according to social, geographical, and other conditions.
} 
have successfully anchored my analysis of politics and discourse using a tangible materialist example.

Finally, I make an original contribution to the literature on Rwanda and critical poststructuralist literature by identifying the emergence of a new, explicitly counter-state identity trope in Kirehe. The particular novelty of my analysis is that it uses what are usually termed 'private transcripts' to identify what is clearly a pattern, and hence a discourse which is widely disseminated and 'shared' even if not made public (and hence available to the state). Private transcripts are usually seen as the binary opposite of public transcripts and hence associated with 'resistance', which implies the creation of a space outside of state-dominated power relations. In contrast, my understanding of the discourse created by these private, but widely-disseminated transcripts is that they incorporate elements of the state ideal subject model, and are hence not examples of 'resistance' but rather examples of a farmer trope co-created by the state and local farmers. I have called this farmer trope the 'mobile' or 'fugitive' farmer, who has a conditional relationship with land, home, and territory. Such an understanding of a cocreated subjectivity that incorporates elements of the state's ideal development subject as well as farmer notions of resistance does not rely on intentionality. Such a finding, in the context of a literature on Rwanda that overwhelmingly relies upon a binary model of domination and resistance, and in the context of a challenging fieldwork environment, represents a useful contribution to our understanding of citizen-state relations in authoritarian situations. 
Theoretical and Methodological Implications of the Research, and Recommendations for Future Research

These research findings have implications for academic interrogations of large-scale, government-led development projects.

The first implication is that the authoritarian high modernism model remains very relevant today, even in contexts like the Rwandan agricultural reform which involve multiple non-state actors and processes of commercialization often associated with 'liberalization'. Concepts such as legibility, standardization, homogenization and coercion are useful to analyzing ambitious large-scale programmes but are best applied in a critical context which recognises the diverse strategies and objectives of state and non-state actors, and which does not necessarily privilege such concepts over others. Moreover, as mentioned above, the concept of homogenization should be viewed from a multi-scalar perspective, as perceptions of heterogeneity are dependent upon the scale at which phenomena are analyzed.

In terms of methodological issues, the significant differences between the discourses of the government, donors, and other key actors on the agricultural reform, and the findings discussed in the case studies (for example, the important role of coercive technologies in the reform, which are not mentioned in official accounts), demonstrates the need for field-based methods of enquiry. As Scott amply demonstrates (1998), 
blueprints and narratives of large-scale policy coherence do not always reflect farmer's perspectives of policy implementation, and purely discourse-oriented work based on analysis of official documents is unable to uncover such dissonance.

The study of authoritarian states is an important stream of academic and policyoriented research. Several states in the global South, including Ethiopia, Rwanda, Singapore and Vietnam can be described as market-friendly authoritarian regimes, and many of these regimes receive significant international development funding as a result of their perceived ability to 'effectively' disburse aid to meet their ambitious development goals. Ethiopia, for example, received \$207 million of Canadian development assistance in 2012, more than any other country (Bhushan, 2013) and is also the biggest recipient of US and World Bank funding (Flores, 2013: 1). Despite its perceived successes, human rights organizations, civil society entities and academics have accused the Ethiopian government of restricting political expression, limiting economic competition, ignoring the 'development' preferences of households and communities, and using coercion to achieve development goals, especially in the rural context (Berhanu, 2012; Flores, 2013; Human Rights Watch, 2010). Within academia, there is contentious debate over both the nature of such regimes and how aid donors should respond to patterns of coercion. While many academics have warned of the potentially explosive, as well as oppressive, impacts of government policies in such states, some scholars argue that these regimes are examples of the 'developmental state', a governance model which can lead to positive development outcomes (Meyns and Musamba, 2010) and is 'more realistic than the standard 'good governance' 
alternative' (Booth and Golooba-Mutebi, 2011), which is a western model unsuited to much of the global South. So, Scott's authoritarian high modernism model is of great relevance today, particularly in the many cases where authoritarian regimes are involved in large scale, transformational 'development' programmes.

Nevertheless, Scott's focus on the state, almost to the exclusion of all other actors, seems anachronistic, while his focus on legibility and grids of analysis pays too little attention to processes of commodification and subjectification. Using Foucault's work to show how state projects also create new subjectivities is crucial in a context of ambitious transformative state programming. The example of the government of Rwanda, with its very explicit attempt to re-invent notions of citizenship in the aftermath of genocide, is a particularly clear example of the transformative process, but is by no means unique. Many countries, as mentioned in Chapter Two, have engaged in a comprehensive process of re-imagining following conflict or other forms of social rupture. In addition, the Foucauldian notion of the apparatus or dispositif has been very useful as a way of exploring the links between the state and other actors involved in strategies that are broadly envisaged as governmental. Likewise, the notion of systems of global governmentality is useful to our understanding of Rwandan government's engagement with international actors, though the dissertation suggests that the global governmentality architecture incorporates different actors and paradigms of 'development' unevenly and incompletely. 
A fruitful direction for further enquiry would be to focus on those international actors who are 'embedded' in the national-level governance mechanisms of aid recipient countries (such as donor personnel seconded to national agencies). This would provide more information on the ways in which dynamics associated with the 'governance state' (Harrison, 2004) manifest themselves within authoritarian contexts. While important work on such actors has been conducted (e.g. Mosse, 2005) it has largely focused on states that cannot be described as authoritarian.

Another potential question for future research into 'global governmentality' involves the direct negotiations between governments of the global South, for example over largescale acquisition of land, and especially the direct interstate negotiations involving governments, like China, which have a complex or ambivalent relationship to many of the international legal and normative mechanisms of the global governance architecture. How do such negotiations articulate with the broader global tools of 'good governance', particularly their disciplinary aspects?

The third major part of the theoretical framework is the accumulation by dispossession concept (Harvey, 2005: 159). While Chapter Six documented a classic form of accumulation by dispossession - sales of land below market prices due to the coercive pressure of socio-economic elites - the dissertation has also revealed other, less direct processes through which the assets of farming households are appropriated by elites. For example, the political economy of maize production in Kirehe, which is characterised by farmers being forced to purchase fertilizer, being forced to plant maize, and being 
forced to sell it to certain buyers, results in gluts in maize production (and hence rapid price fluctuations) which are engineered through these imposed policies. Due to the linkages between elites in the maize commodity chain (with ENAS company, for example, playing multiple roles within the commodity chain, involving conflicts of interest) such elites are able to benefit from such engineered fluctuations in maize prices, as well as from the black market in fertilizer. By controlling both the supply of inputs and the purchase of harvest, politically-connected economic elites involved with multiple levels of the maize commodity chain are in essence profiting at the expense of farmers, who have invested their assets in maize production (purchasing fertiliser, paying for farm labour, etc.) and have taken risks in planting maize in a risky agroecological context. Without such processes of coercion, farmers would make different decisions regarding maize production with the result that farmer behaviour, and maize prices, would be less predictable (and hence profitable for those in positions of power within the maize sector). Due to the combination of coercion and conflicts-of-interest, there has been elite capture of key elements of the maize commodity chain which results in the transfer of assets from farmers to politically-connected economic elites. This situation implies that scholars should take a broader approach to accumulation by dispossession, focussing on multiple actors and multiple elements of commodity chains, rather than focusing only on seizure or distress sales of land, for example. There is a need for an approach which could accurately trace the financial aspects of a particular commodity, at all levels of the commodity chain, to calculate the specific amounts of money involved in such processes of elite accumulation. 
When land is considered as the main element of accumulation by dispossession, it should not only be conceived of in terms of landholding, but also in terms of access to land (such as marshland) through cooperatives, in which case the issues of subjectification (described above) become significant as processes through which access to land is mediated. Those not performing the 'model farmer' role may be denied membership of cooperatives. Furthermore, the membership fees and other financial requirements of continued membership of cooperatives may prove an obstacle to poor people seeking to maintain access to land. Farmers may lose access to land and become part of a landless workforce dependent on casual farm labour, not through 'land grabbing' but through financial or politico-ideological marginalization. In order to understand such dynamics, a materialist political economy approach should therefore be combined with a more post-structuralist conceptual framework which can engage with issues of identity politics. 


\section{Appendix One: Comparative Value of Pyrethrum and Potato Crops}

On a hectare, anything between $350 \mathrm{~kg}$ and $750 \mathrm{~kg}$ of fresh pyrethrum flowers can be grown (UNIDO, 1995; Hove, 2012), though SOPYRWA staff indicate that for 2010, typical yields were only about $250 \mathrm{~kg}$ (2010). This figure is supported by fieldwork, with many respondents reporting yields of $300 \mathrm{~kg} / \mathrm{ha}$. This means that per hectare, at a price of $1000 \mathrm{RWF} / \mathrm{kg}$ of dried flowers, a farmer will earn some $250,000 \mathrm{RWF}-300,000 \mathrm{RWF}$ (from which must be deducted the costs of fertilisers and operating costs).

On a hectare, about 10 tonnes of Irish potatoes can be grown in one season (this can rise to more than 19.5 tonnes with the application of fertilizers, or 34.5 tonnes with a combination of techniques and inputs (IDFC, 2012; Tindiwensi, 2011). ${ }^{319}$ In Musanze District, there are two potato seasons, meaning that, according to the literature, at least 20 tonnes can be grown per year. However, fieldwork suggests that farmers achieve lower yields than this (at around 5 tonnes/ha), possibly because of the rocky nature of some of the plots, or the wet and cold weather conditions. Market prices for potatoes vary according to the quality of the variety and national and regional availability. Values vary between $110 \mathrm{RWF} / \mathrm{kg}$ and $230 \mathrm{RWF} / \mathrm{kg} .{ }^{320}$ This means that the earnings from a hectare of land used for potatoes is between 2.2 million and 4.6 million RWF (using the

\footnotetext{
${ }^{319}$ This is a somewhat conservative figure; Rwandan agronomists in neighbouring Gisenyi claim that Irish potato yields of 19-35 tonnes/ha are possible (Tindiwensi, 2011).

${ }^{320}$ Nyesiga provides a price of 250 RWF/kg in Kigali. This has been adjusted to 230 RWF to reflect the costs of transport from Musanze to Kigali.
} 
average potato yield figures in the literature) or 1.1 million RWF and 2.3 million RWF (using farmer data).

According to these calculations, then, pyrethrum represents between $5 \%$ and $28 \%$ of the value of potatoes.

In reality, most farmers rotate potato production with other crops (e.g. growing potatoes during the main growing season and growing beans or maize during the shorter season). The value of these crops is generally lower than for potatoes. However, the general findings of these calculations remain valid. 


\section{References}

Abrahamsen, Rita. (2003) African Studies and the Postcolonial Challenge. African Affairs, 102(407): 189-210.

Abrahamsen, Rita. (2004) The power of partnerships in global governance. Third World Quarterly, 25(8): 1453-1467

Adamczyck, C. (2012) Independent Actors or Silent Agents: Where to go for Rwandan Civil Society?; in Campioni, M. and P. Noack . (eds). 60-75. Rwanda Fast Forward. Palgrave Macmillan.

Africa Research Institute (2009) Waiting for a Green Revolution. London: Africa Research Institute

African Rights (1995) Rwanda: death, despair and defiance. London: African Rights

Agaciro Development Fund (2013) Background. Accessed on April $22^{\text {nd }} 2013$ at https://www.agaciro.org/

Agricultural Extension and Advisory Services Worldwide (AEASW), (2012) Rwanda:

Ministry of Local Government (MINALOC). Accessed on January $18^{\text {th }} 2013$ at http://www.worldwide-extension.org/africa/rwanda/MINALOC 
van Asten, P.J.A. (2011) Agronomic and economic benefits of coffee-banana intercropping in Uganda's smallholder farming systems. Agricultural Systems 104: 326334

Akram-Lodhi, A. H. (2008) (Re)imagining Agrarian Relations? The World Development Report 2008: Agriculture for Development. Development and Change 39(6):1145-1161

Akram-Lodhi, A. H. and Cristóbal Kay (2010): Surveying the agrarian question (part 2): current debates and beyond, Journal of Peasant Studies, 37(2): 255-284

Amnesty International, (2010) Safer To Stay Silent: The chilling effect of Rwanda's laws on 'genocide ideology' and 'sectarianism'. London: Amnesty International

Anders, G. (2010) In the Shadow of Good Governance: An Ethnography of Civil Service Reform in Africa. Leiden/Boston: Brill Publishers

Anonymous, (2007) Progress Report on Integrated Development Program. September. Mimeo, on file with the author

Anonymous, (2010) Interview with Rwandan President Paul Kagame: 'We Are Far from Exhausting Our Potential'. Der Speigel. July 06, 2010. Accessed on January 17, 2013 at http://www.spiegel.de/international/world/interview-with-rwandan-president-paulkagame-we-are-far-from-exhausting-our-potential-a-704894.html 
Anonymous (2011) New Grain Storage Facilities to Benefit Kirehe Farmers. Igihe. Com.

August 31, 2011. Accessed online on January $13^{\text {th }} 2013$ at

http://en.igihe.com/news/new-grain-storage-facilities-to-benefit-kirehe.html

Anonymous (2011a) The Magical Plant. The Independent (Uganda), November 23, 2011.

Accessed on August 28th, 2012 at http://www.independent.co.ug/rwanda-

ed/rwanda/4916-the-magical-plant

Anonymous (2011b) Special supplement on HORIZON GROUP. Rwanda Focus (Kigali),

September 22, 2011. Accessed online on January 27, 2012 at

http://focus.rw/wp/special-supplement-on-horizon-group-3-2/

Anonymous (2011c) The Visit of Prime Minister in Rulindo District, Northern Province on

the $15^{\text {th }}$ and $17^{\text {th }}$ June 2011. Ruhengeri: Republic of Rwanda. Accessed online on

February $22^{\text {nd }} 2012$ at

http://www.northernprovince.gov.rw/fileadmin/templates/Documents/PM VISIT RULI

NDO DISTRICT.pdf

Anonymous (2012b) Rwanda: Private sector to join IRST for development of Rwandans.

Itezimbere. Accessed online on July $19^{\text {th }}, 2012$ at

http://itezimbere.com/2012/07/rwanda-private-sector-join-irst-development-

rwandans/

Ansoms, A. (2009) Faces of Rural Poverty in Contemporary Rwanda: Linking Livelihood

Profiles and Institutional Processes. PhD dissertation, University of Antwerp. 
Ansoms, A. (2011) The 'bitter fruit' of a new agrarian model: Large-scale land deals and local livelihoods in Rwanda. Paper presented at the International Conference on Global Land Grabbing, Institute of Development Studies, University of Sussex, 6-8 April

Ansoms, A. (2012). Modernizing the Marshes: Large-scale Cultivation and Local Desperation. Presentation at Conference on 'Rwanda from Below', University of Antwerp, 29-30 June

Ansoms, A., G. Cioffo, C. Huggins and Murison, J. (forthcoming) The reorganisation of rural space in Rwanda: Habitat concentration, land consolidation, and collective marshland cultivation, in Ansoms, A. and T. Hilhorst (eds) Land grabbing in the Great Lakes Region of Africa. Oxford: James Currey

Araghi, F. (2009) The Invisible Hand and the Visible Foot: Peasants, Dispossession and Globalization. In Akram-Lodhi , A. H. and C. Kay (eds) 111-147 Peasants and Globalization: Political Economy, Rural Transformation and the Agrarian Question. New York: Routledge.

Asiimwe, A. (2008) Get ready for stiff competition, mayor tells district leaders. The New Times (Kigali) January 9, 2008. Accessed online on December 16, 2013 at www.newtimes.co.rw/news/index.php?i=13404\&a=3406 
Asiimwe, B. (2008a) Few women in Kirehe use family planning methods. The New Times (Kigali) May 5, 2008. Accessed online on December 16, 2013 at www.newtimes.co.rw/news/index.php?a=6072\&i=13521

Asiimwe, B. (2008b) Kirehe sets maize prices as buyers complain. The New Times (Kigali). Note: In recent internet searches, the date of publication is stated as January 27, 2011. This is an error, as can be inferred from the mention from US Ambassador Arrieti in the article. Ambassador Arrieti left the Ambassadorial post in 2008. Accessed online on December 16, 2013 at http://www.newtimes.co.rw/news/views/article print.php?14129\&a=5842\&icon=P $\underline{\text { rint }}$

Asiimwe, B. (2012) Traders protest official maize prices. The New Times (Kigali) July 27, 2012. Accessed online on December 16, 2013 at http://www.newtimes.co.rw/news/index.php?i=13512\&a=5865

Associates for Rural Development (ARD) (2008) Land Related Program Activities Completion Report. Washington: USAID

Bähre, E., and Lecocq, B. (2007) The Drama of Development: The Skirmishes Behind High Modernist Schemes in Africa. African Studies, 66(1): 1-8. 
Banque Rwandaise de Developpement (BRD) (2013) Vision, Mission \& Core Values.

Accessed online on April 4, 2013, at http://www.brd.rw/?Vision-Mission-Core

Barry, A., T. Osborne and Rose, N. (eds.) (1996) Foucault and Political Reason:

Liberalism, Neo-Liberalism, and Rationalities of Government, Chicago, IL: University of Chicago Press.

Bart, F. (1993) Montagnes d'Afrique, terres paysannes, le cas du Rwanda. Bordeaux : Presses Universitaires de Bordeaux

Bayart, J.-F., S. Ellis, and B. Hibou. (1999) Criminalization of the State in Africa.

Bloomington: Indiana University Press.

Bayart, Jean-François. (2009) The State in Africa: The Politics of the Belly. Second Edition. Cambridge: Polity.

BBC (2009) Rwanda forges ahead with IT goals. Accessed online on February $24^{\text {th }} 2012$ at http://news.bbc.co.uk/2/hi/programmes/click online/8285496.stm

Begley, L. (2012) The RPF control Everything! in Thomson, S., A. Ansoms and J. Murison, eds. (2012): 70-83. Emotional and Ethical Challenges for Field Research in Africa: The Story Behind the Findings. London: Palgrave Macmillan

Berhanu, K. (2012) The Political Economy of Agricultural Extension in Ethiopia: Economic Growth and Political Control. London: Future Agricultures Consortium 
Bernstein, H. (2009) 'The Peasantry' in Global Capitalism: Who, Where and Why? Socialist Register. 37: 25-51

Besançon, M. (2003) Good Governance Rankings: The Art of Measurement. Cambridge, MA. WPF Report 36.

Beswick, D. (2011) Genocide and the politics of exclusion: the case of the Batwa in Rwanda. Democratisation Special Issue, 18(2): 490-511

Bhushan, A. (2013) Forthcoming Aid Data. North-South Institute. Accessed online on September $12^{\text {th }}, 2013$ at http://cidpnsi.ca/blog/forthcoming-aid-data/

Bizoza, A. (2011) Farmers, Institutions and Land Conservation: Institutional Economic Analysis of Bench Terraces in The Highlands of Rwanda. PhD thesis, Wageningen University. Accessed online on July $2^{\text {nd }} 2013$ at http://edepot.wur.nl/169360

Booth, D. (2012) Development as a Collective Action Problem: Addressing the Real Challenges of African Governance. African Power and Politics Programme Working Paper. London: Overseas Development Institute

Booth, D. and F. Golooba-Mutebi (2011) Developmental patrimonialism? The case of Rwanda.. African Power and Politics Programme Working Paper. London: Overseas Development Institute

Booth, D. and F. Golooba-Mutebi, (2012) Policy for agriculture and horticulture in Rwanda: A different political economy? African Power and Politics Programme Working Paper. London: Overseas Development Institute 
Boudreaux, K. and P. Ahluwalia (2009) Cautiously Optimistic: Economic Liberalization and Reconciliation in Rwanda's Coffee Sector. Denver Journal of International Law and Policy 37 (2): 147-200.

Brass, T. (2007) How agrarian cooperatives fail: Lessons from 1970s Peru. Journal of Peasant Studies, 34(2): 240-287

Brockling, U., S. Krasmann and T. Lemke (2011) From Foucault's Lectures at the College de France to Studies of Governmentality, in Brockling, U., S. Krasmann and T. Lemke (eds): 1-35. Governmentality: Current Issues and Future Challenges. New York: Routledge.

Bucyensenge, J-P. (2010) Farmers to be sensitized on AIDS and family planning. The New Times (Kigali). October 25, 2010. Accessed on $28^{\text {th }}$ August 2012 at http://www.newtimes.co.rw/news/index.php?i=14424\&a=34988

Bugingo, I. and R. Interayamahanga (2010) A Study on the Development and Use of Governance Indicators in Rwanda. Kigali: Institute of Research and Dialogue for Peace

Buhura, P. (2011) Over 87,000 trained under Itorero. The New Times (Kigali) March 19, 2011. Accessed online on $28^{\text {th }}$ August 2012 at www.newtimes.co.rw/news/index.php?i=14569\&a=39360 
Burnet, J. E. (2008). Dense Citizenship: Producing Citizens and Performing National Unity in Post-Genocide Rwanda. Conference paper presented on the panel, "Political Parties and Subjectivity in Africa" sponsored by the Association for Africanist Anthropology and the Association for Political and Legal Anthropology at the American Anthropological Association Annual Meeting. San Francisco, CA. November 19.

Burnet, J.E. (2008b) The Injustice of Local Justice: Truth, Reconciliation, and Revenge in Rwanda. Genocide Studies and Prevention 3.2 (2008): 173-193

Butamire, P. (2011) "Remaking Rwanda" or "Wishing to deconstruct Rwanda"? Accessed online on $12^{\text {th }}$ October 2013, at http://butamire.wordpress.com

CAADP (2009) CAADP Pillar III Framework for Food Security. Midrand, South Africa: The African Union/New Partnership for Africa's Development

Cairns, J. E., K. Sonder; and P. H. Zaidi. (2012) Maize Production in a Changing Climate: Impacts, Adaptation, and Mitigation Strategies. Advances in Agronomy 114: 1-58

Cannon, P. (2005) Elusive Quest? The Political Economy of Reconciliation in Post Genocide Rwanda. Paper presented at the 14th Annual Africa/Diaspora Conference, Sacramento State Center for African Peace and Conflict Resolution. Accessed online in $16^{\text {th }}$ December 2013 at http://www.csus.edu/hhs/capcr/docs/2005\%20conference\%20proceedingspapers/patrick\%20cannon.pdf Chambers, R. (1983) Rural Development? Putting the Last First, London: IT Publications. 
Chayanov, A.V. (1966) The Theory of Peasant Economy. Manchester University Press Chemonics International Inc. (2002) Rwanda: Quality and Environmental Management Incentives for Agricultural Trade. Washington, DC: USAID

Clay, D. C., V. Kelly, E. Mpyisi, and Reardon, T. (2001) Input Use and Conservation Investments among Farm Households in Rwanda: Patterns and Determinants. East Lansing: Michigan State University, Department of Agricultural, Food, and Resource Economics

Commission Parlementaire ad hoc (2004) Rapport de la Commission Parlementaire ad hoc, crée en date du 20 janvier 2004 par le Parlement, Chambre des Députes pour Analyser en Profondeur les Tueries Perpétrées dans la Province de Gikongoro, Idéologie Génocidaire et Ceux qui la Propagent Partout au Rwanda, accepted by the Parliament, June 28, 2004. Kigali: Rwandan Parliament (unofficial translation from the official Kinyarwanda report)

Concern Worldwide (2011) Farming for Impact: a Case Study of Smallholder Agriculture in Rwanda. London: Concern Worldwide

Conway, G. (1997) The Doubly Green Revolution: Food for all in the 21st century. Ithaca: Cornell University Press.

Coronil, F. (2001) Smelling Like a Market, American Historical Review 106: 119-29 
Cowell, F. (2012) Participatory Rights in Rwanda: Genocide Ideology Laws and the Future of Political Space, in Campioni, M. and Noak, P. (eds): 45-59. Rwanda Fast Forward: Social, Economic, Military and Reconciliation Prospects. Palgrave Macmillan

Dagan, D. (2011) The Cleanest Place in Africa. Foreign Policy, 19th Oct 2011

Dahl, R. (1957) The concept of power, Behavioral Science, 2 (3): 201-215.

Dano, E. C. (2007) Unmasking the New Green Revolution in Africa: Motives, Players and Dynamics. Berlin: Church Development Service (EED)/ TWN/ African Centre for Biosafety Davis, (1989) Breeding for Intercrops: With Special Attention to Beans for Intercropping with Maize, in Waddington, S.R., A.F.E. Palmer and O.T. Edje (eds) Proceedings of a Workshop on Research Methods for Cereal/Legume Intercropping in Eastern and Southern Africa. Lilongwe, Malawi 23-27 January

De Lame, D. (2005) A Hill Among a Thousand: Transformations and Ruptures in Rural Rwanda. Madison: University of Wisconsin Press

De Lorenzo, M. (2008) The Rwandan Paradox: Is Rwanda a Model for an Africa beyond Aid? Washington, DC: American Enterprise Institute for Public Policy Research De Soto, H. (2000) The mystery of capital: why capitalism triumphs in the west and fails everywhere else. New York: Basic Books

De Vulpian, P. (2004). Rwanda, un Genocide oublié? Brussels: Editions Complexe. 
Dean, M. (1999) Governmentality: Power and Rule in Modern Society. London: Sage.

Death, C. (2011) Foucault and Africa: Governmentality, IR theory, and the limits of advanced liberalism. Paper presented at BISA Africa and International Studies Working Group Conference, Manchester, UK. 27 - 29 April

Des Forges, A. (1999) Leave None to Tell the Story: Genocide in Rwanda. New York: Human Rights Watch.

Desrosiers, M.-E. and S. Thomson (2011) Rhetorical legacies of leadership: projections of 'benevolent leadership' in pre- and post-genocide Rwanda, J. of Modern African Studies, 49 (3): $429-453$

Dillon, M. (1995) Sovereignty and Governmentality: From the Problematics of the "New World Order" to the Ethical Problematic of the World Order. Alternatives: Global, Local, Political. 20 (3): 323-368

District of Kirehe (2008) Kirehe District Performance Contract, 2008-9. Accessed online on April 7, 2008 at http://www.minaloc.gov.rw/spip.php?article115

District of Kirehe (2011a) Progress Report Of Performance Contracts Of Kirehe District For The Year 2010-2011. Accessed online on $12^{\text {th }}$ August 2012 via http://www.kirehe.gov.rw 
District of Kirehe (2011b) Kirehe District Performance Contract for the Fiscal Year $2012 / 2013$. Excel spreadsheet accessed online on January $30^{\text {th }}$ at http://www.kirehe.gov.rw/index.php?id=552

District of Kirehe (2012a) District Website. Accessed online on $12^{\text {th }}$ August 2012 at http://www.kirehe.gov.rw

District of Musanze (2011) Imihigo Y'akarere Ka Musanze Y'umwaka Wa 2010-2011. Accessed online on $12^{\text {th }}$ August 2012 via http://www.kirehe.gov.rw/index.php?id=552

Djurfeldt, G. and M. Jirstrom, (2005) The Puzzle of the Policy Shift - the Early Green Revolution in India, Indonesia and the Philippines, in Djurfeldt et al (2005a): 43-64

Djurfeldt, G., H. Holmen, M. Jirstrom and R. Larsson (2005a) The African Food Crisis: Lessons from the Asian Green Revolution. Wallingford: CABI Publishing

Djurfeldt, G., H. Holmen, M. Jirstrom and R. Larsson (2005b) African Food Crisis: the Relevance of Asian Experiences, in Djurfeldt et al (2005a): 1-8

Donovan, C. (2008) Agricultural Statistics in Rwanda: Key Aspects of Institutional Organization and Performance. East Lansing: Michigan State University

Duffield, M. (2007) Development, Security and Unending War. Cambridge: Polity Press 
Economist, the (2012) Congo and Rwanda: Stop messing each other up. The Economist.

Jul 3rd 2012. Accessed on $22^{\text {nd }}$ April 2013 at

http://www.economist.com/blogs/baobab/2012/07/congo-and-rwanda

Economist, the (2011) The hopeful continent Africa rising. The Economist. Dec 3rd 2011.

Accessed on $22^{\text {nd }}$ April 2013 at http://www.economist.com/node/21541015

Escobar, A. (1995) Encountering Development: the Making and Unmaking of the Third

World. Princeton, NJ: Princeton University Press

Ezeonu, I. (2003) Structural Adjustment and Stabilization in Sub-Saharan Africa, in Smith, M (ed.): 205-324 Globalizing Africa. Trenton, NJ and Asmara, Eritrea: Africa World Press

Fewsnet (2011) Livelihoods Zoning "Plus" Activity in Rwanda. Nairobi: FEWSNET/USAID.

Famine Early Warning Systems Network (FEWSNET) (2011a) RWANDA Food Security

Outlook July to December 2011. Nairobi: FEWSNET/USAID

Famine Early Warning Systems Network (FEWSNET) (2011b) RWANDA Food Security

Update. May/June 2011. Nairobi: FEWSNET/USAID

Famine Early Warning Systems Network (FEWSNET) (2013a) EAST AFRICA Seasonal

Monitor. March 2013. Nairobi: FEWSNET/USAID 
Famine Early Warning Systems Network (FEWSNET) (2013b) RWANDA Food Security

Outlook. April to September 2013. Nairobi: FEWSNET/USAID

Famine Early Warning Systems Network (FEWSNET) (2013c) RWANDA Food Security Update. February 2013. Nairobi: FEWSNET/USAID

FAO (1992) Maize in Human Nutrition. Rome: FAO

FAO (1995) Sorghum and Millets in Human Nutrition. Rome: FAO

FAO (2013) FAOSTAT Rwanda. Accessed online on $20^{\text {th }}$ May at http://193.43.36.162/home.aspx?c=RWA\&ta=184CFA010\&tr=9

Ferguson, J. (1990) The Anti-politics Machine: Development, Depoliticization and Bureaucratic Power in Lesotho. Minneapolis: University of Minnesota Press

Ferguson, J. (2005) Seeing Like an Oil Company: Space, Security, and Global Capital in Neoliberal Africa. American Anthropologist, 107 (3): 377-382

Flew, T. (2012) Michel Foucault's The Birth of Biopolitics and contemporary neoliberalism debates. Thesis Eleven 108(1): 44-65

Flores, L. (2013) Development Aid to Ethiopia: Overlooking Violence, Marginalization, and Political Repression. Oakland, CA: Oakland Institute 
Foucault, M. (1978) The History of Sexuality. Volume I: An Introduction. (R. Hurley trans.) London: Allen Lane

Foucault, M. (1980) The Confession of the Flesh, in Gordon, C. (ed): 194-228.

Power/Knowledge: Selected Interviews and Other Writings. New York: Pantheon Books.

Foucault, M. (1980a) [1977] Truth and Power, in Gordon, C. (ed): 109-133.

Power/Knowledge: Selected Interviews and Other Writings, 1972-1977. NY: Pantheon

Foucault, M. (1989) The Order of Things. (trans. unidentified) Brighton, Sussex, UK: Harvester Press

Foucault, M. (1990 [1978]) A History of Sexuality Vol. 1: An Introduction. (R. Hurley trans.) New York: Vintage Books

Foucault, M. (1991). The Foucault Effect: Studies in Governmentality. Graham Burchell, Colin Gordon, and Peter Miller, (eds.) Chicago: University of Chicago Press.

Foucault, M. (2003) [1966]) The Order of Things: an Archeology of the Human Sciences. (trans. unidentified) London: Routledge

Foucault, M. (2004a [1977-78]) Security, Territory, Population: Lectures at the College de France, 1977-1978. (D. Macey trans.) New York: Palgrave Macmillan

Foucault, M. (2004b) [1978-9] The Birth of Biopolitics: Lectures at the College de France, 1978-1979. (G. Burchell trans.) New York: Palgrave Macmillan

Foucault, M. (2007) Security, Territory, Population: Lectures at the Collège de France, 1977-78. (D. Macey trans.) Houndmills, Basingstoke: Palgrave MacMillan 
Foucault, M. (2008 [1978-9]) The Birth of Biopolitics: Lectures at the College de France, 1978-1979. (G. Burchell trans.) New York: Palgrave Macmillan

Fraser, N. (2003) From discipline to flexibilization? Rereading Foucault in the shadow of globalization, Constellations, 10(2): 160-171.

Freedman, S., Weinstein, H., Murphy, K.L. (2011) Teaching History in Post-Genocide Rwanda, In S. Straus, and L. Waldorf (Eds.): 297-315. Remaking Rwanda: State Building and Human Rights after Mass Violence. Madison: The University of Wisconsin Press.

Freire, P. (2007) [1970] Pedagogy of the Oppressed. New York: Continuum.

Fritz, V. and A. R. Menocal (2007) Understanding State-Building from a Political Economy Perspective. London: ODI

Frontline, (2005) Disappearances, Arrests, Threats, Intimidation and Co-option of Human Rights Defenders 2001 - 2004. Blackrock, Co. Dublin, Ireland

Gahene, A. (2009a) Residents irked by directive to cut down banana plantations, The New Times (Kigali), February 6, 2009. Accessed online on December 16, 2013 at http://www.newtimes.co.rw/news/views/article print.php?15201\&a=13102\&icon=Print

Gahene, A. (2009b) Residents reluctant to cut banana plants, The New Times (Kigali), February 23, 2009. Accessed online on December 16, 2013 at http://www.newtimes.co.rw/news/index.php?a=13585\&i=13815 
Gahiji (2013) Kamonyi Residents Educated About Heroes Day. News of Rwanda. January 31, 2013. Accessed on $22^{\text {nd }}$ February 2013 at http://newsofrwanda.com/ibikorwa/16912/rwanda-kamonyi-residents-educated-aboutheroes-day/

Gasore, B. (2013) Pyrethrum farmers fail to satisfy growing market demand. The New Times (Kigali), January 12, 2013. Accessed on $27^{\text {th }}$ January 2013 at http://www.newtimes.co.rw/news/index.php?a=62765\&i=15235

Gebauer, C. (2012) Agricultural Modernization in Rwanda: Effects of the Crop Intensification Program (CIP). German Research Foundation (DFG) Priority Programme 1448 'Adaptation and Creativity in Africa'. Accessed online on May $16^{\text {th }}$ at http://blog.spp1448.de/2012/09/agricultural-modernization-in-rwanda-effects-of-thecrop-intensification-program-cip/

Geertz, C. (1993) Thick Description: Toward an Interpretive Theory of Culture, in The Interpretation of Cultures: Selected Essays. New York: Basic Books, 1973. 3-30.

GeoSAS, (2012) Rwanda Consultation Report. African Gender, Climate Change and Agriculture Support Program (Gccasp). Addis Ababa: African Union.

GIEWS/FAO (2010) GIEWS Country Brief: Rwanda. 25-March-2010 
Global Water Partnership (GWP)(2012) Rwanda. Accessed online on $12^{\text {th }}$ August 2012 at http://www.gwp.org/en/WACDEP/IMPLEMENTATION/Where/Rwanda/

Gokgur, N. (2012) Rwanda's Party-Statals: Are they contributing or impeding development? Presentation at Conference on Rethinking State, Economy and Society: Political settlements and transformation potential of African States, IOB, Antwerp, Belgium, $27^{\text {th }}$ April

Gould, J. (2005) Timing, Scale and Style: Capacity as Governmentality in Tanzania, in Lewis, D. and Mosse, D. (eds) (2005): 61-84. The Aid Effect: Giving and Governing in International Development. Pluto Press

Gravel, P. (1965) Mixed Cultivation and Distribution of Crops in the Fields as Agricultural Techniques. Man, Vol. 65 (May - Jun.): 83-85

Gready, P. (2011) Beyond 'You're Either with us or Against Us": Civil Society and Policymaking in Post-genocide Rwanda, in Straus S. and Waldorf L. (eds.): 87-102. Remaking Rwanda. State Building and Human Rights after Mass Violence, Madison, University of Wisconsin Press

Groen, G. A. (2006). Evaluating Sorghum and Maize Germplasm For Post-Anthesis Drought Tolerance. Master's Thesis, Kansas State University Hakizimana, P. (2007) Rwanda agricultural extension services system: Operation and funding modalities. Director General/RADA. Presented at the UN-ECA EA-SRO, 11th 
Session of Intergovernmental Committee of Experts (ICE) Meeting, Bujumbura, Burundi, 16 to 19 April

Hansen, T. B. and F. Stepputat, (2001) States of Imagination: Ethnographic Explorations of the Post-Colonial State. Durham, NC: Duke University Press

Harding, C. (2011) Rwanda: New cassava flour plant to give farmers a ready market. How We Made it in Africa (website). $16^{\text {th }}$ April 2011. Accessed online on May $16^{\text {th }}$ at http://www.howwemadeitinafrica.com/rwanda-new-cassava-flour-plant-to-givefarmers-a-ready-market/9260/

Harrison, G. (2001) Post-conditionality politics and administrative reform: reflections of the cases of Uganda and Tanzania, Development and Change (32) 657-679.

Harrison, G. (2004) The World Bank And Africa: The Construction Of Governance States. New York and London: Routledge

Harrison, G. (2010) Neoliberal Africa: The Impact of Global Social Engineering. London: Zed Press

Harvey, D. (2005) A Brief History of Neoliberalism. New York: Oxford University Press Hasselskog, M. (2011) Social Engineering by the Rwandan State - in Line with and a Consequence of Development Aid. Paper for GCGD Conference on ‘Globalization and Development: Rethinking Interventions and Governance', November 22-23rd 
Havugimana, E. (2009) State Policies and Livelihoods: Rwandan Human Settlement Policy, Case Study of Ngera and Nyagahuru Villages. Gothenburg: School of Global Studies, University of Gothenburg

Hayman, R. (2009) Milking the Cow in Whitfield, L. The politics of aid: African strategies for dealing with donors. Oxford University Press

Hayman, R. (2011) Funding fraud? Donors and democracy in Rwanda, in Straus, S. and L. Waldorf (eds): 118-131. Remaking Rwanda: State Building and Human Rights after Mass Violence, University of Wisconsin Press Herbst, J. (1990) State Politics in Zimbabwe. Harare: University of Zimbabwe Press Herbst, J. (2000) States and Power in Africa. Princeton, NJ: Princeton University Press. Hilker, L. M. (2011) Young Rwandans' Narratives of the Past (and Present) in S. Straus, and L. Waldorf (Eds.): 316-330. Remaking Rwanda: State Building and Human Rights after Mass Violence, University of Wisconsin Press

Hitayezu, F. (1993) Farm Income Effects Of Regional Crop Specialization in Rwanda. Master's Thesis. McGill University: Department of Agricultural Economics.

Holden, J. (2012) Overcoming the Industrial Policy Taboo, in Campioni, M. And P. Noack (eds.) Rwanda Fast Forward: Social, Economic, Military and Reconciliation Prospects. Palgrave Macmillan

Holmen, H. (2005a) Spurts in Production - Africa's Limping Green Revolution, in Djurfeldt et al (2005a): 65-86 
Holmen, H. (2005b) The State and Agricultural Intensification in Sub-Saharan Africa, in Djurfeldt et al (2005a): 87-112

Holmes, G. (2013) Beyond 'pro' and 'anti': the dilemmas of post-conflict research. Times Higher Education, $28^{\text {th }}$ November. Accessed online on November $30^{\text {th }}$ at http://www.timeshighereducation.co.uk/features/must-academics-researchingauthoritarian-regimes-self-censor/2009275.fullarticle

Howard, A. and R.M. Shain (eds), 2004. The Spatial Factor in African History: The Relationship of the Social, Material, and Perceptual. Leiden/Boston: Brill Publishers Huggins, C. and H. Musahara (2004) Land Reform, Governance and the Environment: the Case of Rwanda. Paper Prepared for 4th Regional Session of the Global Biodiversity Forum (GBF) for Africa, White Sands Hotel and Resort, Dar es Salaam, Tanzania 9-11 June

Huggins, C. (2009a) Agriculture Policy and Local Grievances in Rural Rwanda: Growing Conflict? in Peace Review 21 (2)

Huggins, C. (2009b) Historical and contemporary land laws and their impact on indigenous peoples' land rights in Rwanda. London: Forest People's Program Huggins, C. (2010) Land, Identity and Power: Roots of Conflict in the Democratic Republic of Congo. London: International Alert 
Hughes, D. (2006) From Enslavement to Environmentalism: Politics on a Southern African Frontier. Washington, DC: University of Washington Press.

Human Rights Watch (2004) Rwanda: Parliament Seeks to Abolish Rights Group. Press Release. Washington DC: Human Rights Watch

Human Rights Watch (2001) Uprooting the Rural Poor, Washington, DC: Human Rights Watch

Human Rights Watch (2007) Human Rights Watch Letter to President Jakaya Mrisho Kikwete of Tanzania. Accessed online on $21^{\text {st }}$ February 2013 at http://www.hrw.org/news/2007/05/08/human-rights-watch-letter-president-jakayamrisho-kikwete-tanzania

Human Rights Watch (2010) Development without Freedom: How Aid Underwrites Repression in Ethiopia. Washington, DC: Human Rights Watch

Human Rights Watch (2011) Written evidence from Human Rights Watch: Working Effectively in Fragile and Conflict-Affected States: DRC and Rwanda. Report presented to the House of Commons International Development Committee, May. Accessed online on $19^{\text {th }}$ April 2013 at http://www.publications.parliament.uk/pa/cm201012/cmselect/cmintdev/1133/1133w e06.htm 
Human Rights Watch (2012) DR Congo: M23 Rebels Committing War Crimes. September 11, 2012. Accessed online on May $6^{\text {th }}, 2013$, at http://www.hrw.org/news/2012/09/11/dr-congo-m23-rebels-committing-war-crimes Hyden, G. (1980) Beyond Ujamaa in Tanzania: Underdevelopment and an Uncaptured Peasantry. Berkeley: University of California Press

IFDC (2011) Dutch Foreign Affairs Secretary of State Visits CATALIST's Field Activities in Rwanda. Accessed online on October $30^{\text {th }}$ at http://www.ifdc.org/Media Center/Press Releases/February 2011/Dutch Foreign Aff airs Secretary of State Visits CA/

IFDC/CATALIST, (2010) Crop Intensification Program (2008-2009) Evaluation Report. Muscle Shoals, Alabama: IFDC

IITA (2012) Banana can protect coffee from the effects of climate change. Press Release. Accessed online on May $16^{\text {th }}$ at http://www.iita.org/2012-press-releases/Lasset publisher/CxA7/content/banana-can-protect-coffee-from-the-effects-of-climatechange?redirect $=\% 2 F 2012$-press-releases\#.UZVmTLUsnSh

Ingelaere, B. (2007) Living the Transition: A Bottom-up Perspective on Rwanda's Political Transition. Discussion Paper 2007.06, Institute of Development Policy and Management. Antwerp: University of Antwerp.

Ingelaere, B. (2009) Do We Understand Life after Genocide? Working Paper 2009/2, Institute of Development Policy and Management. Antwerp: University of Antwerp 
Ingelaere, B. (2011) The Ruler's Drum and the People's Shout Accountability and Representation on Rwanda's Hills, in: Straus S. and Waldorf L. (eds.): 67-78 Remaking Rwanda. State Building and Human Rights after Mass Violence, Madison: University of Wisconsin Press.

Institute of Policy Analysis and Research (IPAR) -Rwanda (2011) East African Taxation Project: Rwanda Country Case Study. Kigali: IPAR

International Co-operative Alliance (2012) Co-operative Values, Identity and Principles. Accessed on $28^{\text {th }}$ August, 2012 at http://2012.coop/en/what-co-op/co-operative$\underline{\text { identity-values-principles }}$

International Maize and Wheat Improvement Centre (CIMMYT) (2013) Drought Tolerant Maize Varieties and Hybrids. Accessed online on January $30^{\text {th }}, 2013$, at http://dtma.cimmyt.org/index.php?option=com_content\&view=article\&id=83\&Itemid= 83

International Year of the Potato (2012) Official Website of the International Year of the Potato, 2008. Accessed on $18^{\text {th }}$ July, 2012 at http://www.potato2008.org/en/index.html Ishimwe, T. (2012) Rwf1bn yet to be recovered from fertiliser loans, Agric ministry. The New Times (Kigali) October 31, 2012. Accessed on $28^{\text {th }}$ August 2012 at http://www.newtimes.co.rw/news/index.php?a=60159\&i=15162 
Jackson, S. (1999) Relief, Improvement, Power: Motives and Motifs of Rwanda's Villagisation Policy. International Famine Centre. University College Cork, Ireland. Accessed online on February $2^{\text {nd }} 2012$ at http://www.ucc.ie/acad/sociology/rip/essays/rwanda.htm Jefremovas, V. (1997) Contested identities: power and the fictions of ethnicity, ethnography and history in Rwanda. Anthropologica 39 (1-2): 91-104

Jefremovas, V. (2004) Socioeconomic Conditions, Not Ethnic Hatred, Led to the Genocide, in Fisanick, C. (ed.): 29-39. The Rwanda Genocide, Farmington Hills/MI, Greenhaven Press

Jessop, B. (2002) Approaches to the Analysis of Civil Society and the State. Ritsumeikan Sansharonshu (Ritsumeikan Industrial Sociology Review), 37 (4): 251-269

Jones W., R. Soares de Oliveira and Verhoeven, H. (2013) Africa's illiberal state-builders. Working Paper 89. Oxford: Refugee Studies Centre, University of Oxford Joseph, J. (2010a). The limits of governmentality: Social theory and the international. European Journal of International Relations. 16(2) 223-246

Joseph, J. (2010b) Neoliberalism, Governmentality and the World Bank: Crisis, What Crisis? Paper presented at the annual meeting of the Theory vs. Policy? Connecting Scholars and Practitioners, New Orleans Hilton Riverside Hotel, The Loews New Orleans Hotel, New Orleans, LA, Feb 17 
Kagame, P. (2009) The Backbone of a New Rwanda; in Fairbanks, M., M. Fal, M. EscobarRose, and Hooper, E. (eds): 3-6. In the River they Swim: Essays from Around the World on Enterprise Solutions to Poverty. West Conshohocken, PA: Templeton Press

Kagame P. (2012a) Stop blaming Rwanda for the mess in DRC. The East African. August

17 2012. Accessed online on June $6^{\text {th }} 2013$ at

http://www.theeastafrican.co.ke/Rwanda/Opinion/Stop+blaming+Rwanda+for+the+me $\underline{\text { ss+in+DRC/-/1433246/1481588/-/p6wcqjz/-/index.html }}$

Kagame, P. (2012b) Kagame's Historic Speech in Parliament. News of Rwanda, October $6^{\text {th }} 2012$. Accessed on April $19^{\text {th }} 2013$ at http://www.newsofrwanda.com/abanyapolitiki/14227/rwanda-exclusive-kagameshistoric-speech-parliament/

Kagame, P. (2012c). HARDtalk Interview, BBC, London, July 12, 2012. Transcript accessed on January $21^{\text {st }} 2013$ at http://www.presidency.gov.rw/interviews/670-transcript-ofhardtalk-zeinab-badawi-interviewing-president-paul-kagame-

Kagire, E. (2012) Grow priority crops first, Kalibata advises farmers. The New Times (Kigali), January 4, 2012. Accessed online on $16^{\text {th }}$ December, 2013 at http://www.newtimes.co.rw/news/index.php?a=48751\&i=14860

Kalibata, Agnes M. (n.d.) 'Agriculture in a Changing World: Presentation by the Minister of State in change of Agriculture'. Kigali: MINAGRI 
Kanuma, S. (2012) Agaciro is about patriotism, not competition. Rwanda Focus.

September 24, 2012. Accessed online on $16^{\text {th }}$ December, 2013 at

http://focus.rw/wp/2012/09/agaciro-is-about-patriotism-not-competition/

Kanyesigye, F. (2011) Farmers learn post-harvest skills. The New Times (Kigali), February

24,2011 . Accessed online on July $19^{\text {th }}, 2012$ at

http://www.newtimes.co.rw/news/index.php?a=38630\&i=14546

Kanyumba, B. (2011) Imihigo y'Akarere ka Kirehe yaremejwe. Accessed online on July 18, 2012 at

http://www.orinfor.gov.rw/printmedia/news.php?type=rw\&volumeid=268\&cat=16\&sto $\underline{\text { ryid }=7441}$

Karake, E. (2012) Millions of land titles unclaimed. The New Times (Kigali), October 15, 2012. Accessed on $15^{\text {th }}$ October 2012 at http://www.newtimes.co.rw/news/index.php?i=15146\&a $=59542$

Karake, E. (2012) MPs urge Saccos to ease lending to farmers. The New Times (Kigali), October 15, 2012 Accessed online on December 16 ${ }^{\text {th }}, 2012$ at http://www.newtimes.co.rw/news/index.php?a=59552\&i=15146 Karangwa, J. (2010) Jetropha: a tree that worries Rwandan farmers. Radio Netherlands Website. Accessed on July 18, 2012 at http://www.rnw.nl/africa/article/jetropha-a-treeworries-rwandan-farmers 
Karinganire, E. (2012a) Private sector should embrace bio-fuel, says IRST boss. The

Rwanda Focus. Accessed on July 18, 2012 at http://focus.rw/wp/2012/04/privatesector-should-embrace-bio-fuel-says-irst-boss/

Karinganire, E. (2012b) IRST restructured to boost industrial development. The Rwanda Focus. Accessed on July 18, 2012 at http://focus.rw/wp/2012/05/irst-restructured-toboost-industrial-development/

Karinganire, E.D. (2012c) "Forced Agaciro contribution unacceptable" - Rwangombwa. Rwanda Focus. Monday, September 24th, 2012 Accessed online on April $12^{\text {th }} 2013$ at http://focus.rw/wp/2012/09/forced-agaciro-contribution-unacceptable-rwangombwa/

Kartas, M. and O. Jütersonke (2012) Urban Resilience in Situations of Chronic Violence: Case Study of Kigali, Rwanda. Centre on Conflict, Development and Peacebuilding (CCDP). Geneva: Graduate Institute of International and Development Studies

Karuhanga, J. (2013a) Legislators discuss Land Bill. The New Times (Kigali), January 18, 2013. Accessed on November 12, 2013 at http://www.newtimes.co.rw/news/index.php? $a=62963 \& i=15241$

Karuhanga, J. (2013b) Civil society wants land law that curbs conflict. The New Times (Kigali), January 18, 2013. Accessed on November 12, 2013 at http://www.newtimes.co.rw/news/index.php?a=63041\&i=15244 
Kathiresan, A. (2011) Strategies for Sustainable Crop Intensification in Rwanda. Shifting focus from producing enough to producing surplus. Kigali: MINAGRI

Kathiresan A. (2012), Farm Land Use consolidation in Rwanda, Assessment from the perspectives of Agriculture Sector. Kigali: MINAGRI

Kayisinga, J. C. (2012) Sustaining Partnership to enhance Rural Enterprises and Agribusiness Development. Powerpoint presentation accessed on $23^{\text {rd }}$ July 2012 at http://www.google.ca/url?sa=t\&rct=j\&q=\&esrc=s\&source=web\&cd=3\&ved=0CGEQFjAC \&url=http\%3A\%2F\%2Fwww.valuechains.org\%2Fdyn\%2Fbds\%2Fdocs\%2F803\%2FSPREAD\%2520PROJECT\%25202010.ppt\&e i=SQoOUL7qHqWJ6wH3qoGIDg\&usg=AFQjCNF25OjLKJlyYa hIFiXYN65ejOGHA

Killander, M. (2008) The African Peer Review Mechanism and Human Rights: The First Reviews and the Way Forward. Human Rights Quarterly 30 (1) 41-75

King, L. (2013) Seeing Like a Theorist, International Journal of Urban and Regional Research 37 (2): 804-814

Kinzer, S. (2008) A Thousand Hills: Rwanda's Rebirth and the Man Who Dreamed It. New Jersey: John Wiley \& Sons

Kopytoff, I. (1987) The African frontier: the reproduction of traditional African societies. Bloomington: Indiana University Press. 
Kwibuka, E. (2008) Country Must Enhance Traditional Ways of Milling Coffee Cherries to Improve Quality, The New Times (Kigali), September 1, 2008. Accessed online on December 16, 2013 at http://www.newtimes.co.rw/news/views/article print.php?14591\&a=9141\&icon=Print LandAC, (n.d.) Rwanda: Food Security and Land Governance Factsheet. Utrecht: IS Academy on Land Governance

Larner, W. and W. Walters (eds) (2002) Global Governmentality: Governing International Spaces. New York: Routledge

Larson, D.F., K. Otsuka, K. Kajisa, and Estudillo, J. (2010) Can Africa Replicate Asia's Green Revolution in Rice? Policy Research Working Paper 5478. Washington D.C.: World Bank.

Lavers, T. (2012) Patterns of agrarian transformation in Ethiopia: State-mediated commercialisation and the 'land grab'. The Journal of Peasant Studies 39 (3-4): 795-822

Lemke, T. (2001) 'The birth of bio-politics': Michel Foucault's lecture at the Collège de France on neo-liberal governmentality. Economy and Society, 30 (2): 190-207.

Lemke T. (2007) An indigestible meal? Foucault, governmentality and state theory. Distinktion Scandinavian Journal of Social Theory 15: 43-64.

Levitsky, S. and Lucan A. Way (2002) The Rise of Competitive Authoritarianism. Journal of Democracy 13, (2): 51-65 
Li, T. M. (2005) Beyond "the State" and Failed Schemes. American Anthropologist 107: 383-394.

Li, T. M. (2007a) The Will to Improve: Governmentality, Development, and the Practice of Politics. Durham, NC: Duke University Press

Li, T. M. (2007b) Governmentality. Anthropologica 49:275-281

Lischer, S. K. (2011) Civil war, genocide and political order in Rwanda: security implications of refugee return. Conflict, Security \& Development 11(3): 261-284

Lohmann, L. (2006) Carbon Trading - A Critical Conversation on Climate Change, Privatisation and Power. Development dialogue 48, September

Longman, T. (1995) Genocide and socio-political change: massacres in two Rwandan villages, Issue: A Journal of Opinion XXIII/2: 18-21

Longman, T. (2011) Limitations to Political Reform, in Straus S. and Waldorf L. (eds.) (2011): 25-47

Lowenheim, O. (2008) Examining the State: a Foucauldian perspective on international 'governance indicators'. Third World Quarterly, 29 (2): 255 - 274

Lukes, S. (1974) Power: A Radical View. London: Macmillan

Magnusson, W. (2011) Politics of Urbanism: Seeing Like a City. London and New York: Routledge 
Magnusson, W. (2008) Seeing Like a State, Seeing Like a City. Paper prepared for the 2008 Annual Meeting of the Canadian Political Science Association, University of British Columbia, Vancouver BC, 3 June

Majyambere, G. (2011a) Rwanda: Pyrethrum Exports Up. The New Times (Kigali), January 11, 2011. Accessed on August 18, 2012 at ttp://allafrica.com/stories/201101110331.html

Majyambere, G. (2011b) SOPYRWA challenges farmers on savings. The New Times (Kigali), August 3, 2011. Accessed on August 18, 2012 at http://www.newtimes.co.rw/news/index.php?i=14706\&a=43809 Mamdani, M. (2001) When Victims Become Killers: Colonialism, Nativism, and the Genocide in Rwanda. Princeton NJ: Princeton University Press

Mangula, G. (2012) Farmers Get Low-cost Crop Insurance Scheme. Igihe.com. $12^{\text {th }}$ October 2012. Accessed online on $21^{\text {st }}$ February at http://en.igihe.com/news/rwandafamers-get-low-cost-crop-insurance-scheme.html

Marx, K. (1967) Capital. Volume I. New York: International Publishers.

Marysse, S. ; Ansoms, A. ; Cassimon, D. (2006) The aid 'darlings' and 'orphans' of the Great Lakes region in Africa. Institute of Development Policy and Management Discussion paper 2006 - 10. Antwerp: University of Antwerp 
Matovu, G. (2011) New Participatory Instruments in Local Governance: Cases from Rwanda, South Africa, and Uganda. Paper Presented at the Commonwealth Local Government Research Colloquium Cardiff, United Kingdom, 13-15 March 2011

Mbembe, A. (2000) At the Edge of the World: Boundaries, Territoriality, and Sovereignty in Africa. Public Culture 12(1): 259-284.

Mbembe, A. (2001) On the Postcolony. London: University of California Press

McGreal, C. (2013) Is Kagame Africa's Lincoln or a tyrant exploiting Rwanda's tragic history? The Observer (London), Sunday 19 May 2013

Mellor, J. (2002) How Much Employment Can Rapid Agricultural Growth Generate? Sectoral Policies for Maximum Impact in Rwanda. Agricultural Policy Development Project Research Report No. 13. Washington, D.C.: USAID

Meyns, P. and C. Musamba (2010) The Developmental State in Africa: Problems and Prospects. Duisburg: Institute for Development and Peace. Duisburg and Essen: University of Duisburg-Essen

Mgbako, C. (2005) Ingando Solidarity Camps: Reconciliation and Political Indoctrination in Post-Genocide Rwanda. Harvard Human Rights Journal 18 (Spring): 201-224.

Millennium Challenge Corporation (MCC) (2008) \$24.7 Million MCC Threshold Program with Rwanda Signed. Accessed online on $17^{\text {th }}$ April 2013 at http://www.mcc.gov/pages/press/release/release-101508-rwanda 
Millennium Challenge Corporation (MCC) (2008) Rwanda Scorecard FY13. Accessed online on July $2^{\text {nd }}, 2013$, at http://www.mcc.gov/documents/scorecards/score-fy13rwanda.pdf

Miller, T. (2010) Michel Foucault, The Birth of Biopolitics: Lectures at the College de France, 1978-79. International Journal of Cultural Policy 16(1): 56-57.

Mills, G. (2010) Rwanda is No Singapore. The African.Org (Pretoria) Issue 8 Milz, M. (2011) The authoritarian face of the "Green Revolution": Rwanda capitulates to agribusiness. Montreal: GRAIN. Accessed online on February $2^{\text {nd }} 2012$ at http://www.grain.org/bulletin board/entries/4322-the-authoritarian-face-of-the-green$\underline{\text { revolution-rwanda-capitulates-to-agribusiness }}$

MINAGRI (1999) Avant Projet de Loi. Kigali: Republic of Rwanda MINAGRI (2004a) National Agricultural Policy. Kigali: Republic of Rwanda MINAGRI (2004b) Strategic Plan for Agricultural Transformation In Rwanda. Kigali: Republic of Rwanda MINAGRI (2008) Annual Report 2008. Kigali: Republic of Rwanda MINAGRI (2009a) National Agricultural Extension Strategy. Kigali: Republic of Rwanda 
MINAGRI (2009b) The Strategic Plan for the Transformation of Agriculture phase two (PSTAA II). Kigali: Republic of Rwanda

MINAGRI (2010a), Agriculture sector investment plan 2009 - 2012. Kigali: Republic of Rwanda

MINAGRI (2010b) Joint Agriculture Sector Review: Agriculture Sector Performance Report 2009/2010, Kigali: Republic of Rwanda

MINAGRI (2010c) Ministerial Order N¹4/11.30 Of 21/12/2010 Determining the Models of Land Consolidation And Its Productivity. Kigali: Republic of Rwanda

MINAGRI (2010d) Agricultural Statistics 2011-2009A. Kigali: Republic of Rwanda.

Accessed online on $20^{\text {th }}$ May at http://amis.minagri.gov.rw/content/statistique-agricole$\underline{2001-2009 a}$

MINAGRI (2010e) Agriculture Gender Strategy. Kigali: Republic of Rwanda MINAGRI (2012a) Agriculture in Rwand. Kigali: Republic of Rwanda. Accessed online on $12^{\text {th }}$ August 2012 at http://www.minagri.gov.rw/index.php?option=com content\&view=article\&id=173\%3A agriculture-in-rwanda\&catid=128\%3Aagriculture\&lang=en

MINAGRI (2012b) Farm Land Use Consolidation in Rwanda: Assessment from the Perspectives of Agriculture Sector. Kigali: Republic of Rwanda 
MINAGRI (2013) Crop Intensification Program (CIP). Kigali: Republic of Rwanda Accessed online on $16^{\text {th }}$ May at http://www.minagri.gov.rw/index.php?option=com content\&view=category\&layout=bl og\&id=177\&/temid=38\&lang=en

MINALOC and MINECOFIN (2002). Ubudehe to fight poverty. Kigali: Republic of Rwanda Ministry of Natural Resources (MINIRENA) (2011) Green Growth and Climate Resilience. National Strategy for Climate Change and Low Carbon Development. Kigali: Republic of Rwanda

Ministry of Finance and Economic Planning (MINECOFIN) (2000) Rwanda Vision 2020. Kigali: Republic of Rwanda

MINECOFIN (2007) Districts Imihigo Evaluations (January-September 2007). Ministry of Finance and Economic Planning, Kigali: Republic of Rwanda

Ministry of Infrastructure (2009) National Energy Policy and National Energy Strategy 2008-2012. Kigali: Republic of Rwanda.

Ministry of Lands, Environment, Forestry, Water and Mines (MINITERE) (2004) National Land Policy. Kigali: Republic of Rwanda

MINITERE (2005) Organic Law Determining the Use and Management of Land in Rwanda. Kigali: Republic of Rwanda 
Ministry of Trade and Industry (MINICOM) (2011) Rwanda National Export Strategy. Kigali: Republic of Rwanda

MINICOM (2012) Key Achievements 20120-11. Kigali: Republic of Rwanda. Accessed on June $23^{\text {rd }}, 2012$ at

http://41.74.172.18/t3 apps/minicom/index.php?id=85\&tx ttnews\%5btt news\%5d=69 \&cHash $=7377035567 \mathrm{cf} 748 \mathrm{bfe} 4 a 1 \mathrm{f} 6802 \mathrm{f} 25 \mathrm{e} 2 \mathrm{a}$

Ministry of Youth and ICT (2012) Rwanda ICT Sector Profile - 2012. Kigali: Republic of Rwanda

Mitchell, T. (1990) Everyday metaphors of power. Theory and Society 19 (5): 545-577

Mitchell, T. (1991) America's Egypt: Discourse of the Development Industry, Middle East Report, 169 (Mar. -Apr.): 18-34+36.

Moore, D. M. (2005) Suffering for Territory: Race, Place and Power in Zimbabwe.

Durham, NC: Duke University Press

Mosley, P. (2002) The African Green Revolution as a Pro-Poor Policy Instrument. J. Int.

Dev. 14: 695-724

Mugisha, I. (2012) Fertiliser distribution to be privatised. The New Times (Kigali), October 8, 2012. Accessed online on December 16, 2013 at http://www.newtimes.co.rw/news/index.php?a=59259\&i=15139 
Mugisha, S. (2010) Minister urges firm to speed up maize purchase. The New Times (Kigali), June 9, 2010. Accessed online on December 16, 2013 at http://www.newtimes.co.rw/news/index.php?a=30070\&i=14286

Mugoya, G. (2010) Kirehe District Sets Target of 60,000 Tons of Maize. The New Times (Kigali), September 29, 2010. Accessed online on December 16, 2013 at http://www.newtimes.co.rw/news/views/article print.php?14398\&a=34080\&icon=Print Mukombozi, B. (2008) Farmers complain over delayed seed, fertilizers. The New Times (Kigali), March 1, 2008. Accessed online on December 16, 2013 at http://www.newtimes.co.rw/news/index.php?a=34980\&i=14424

Mukombozi, B. (2009a) Consult locals over crop consolidation, The New Times (Kigali), October 7, 2009. Accessed online on December 16, 2013 at http://www.newtimes.co.rw/news/index.php?a=20834\&i=14041

Mukombozi, B. (2009b) Pyrethrum receives Rwf 500m boost. The New Times (Kigali), June 6,2009 . Accessed online on $19^{\text {th }}$ June 2012 at http://www.newtimes.co.rw/news/index.php?i=13918\&a=16365 Munyaneza, J. (2009) Grappling with Heroes' Day's biggest question. The New Times (Kigali), Feb 3, 2009. Accessed on $22^{\text {nd }}$ February 2013 at http://www.newtimes.co.rw/news/views/article print.php?15173\&a=13012\&icon=Prin 
Musahara, H. (2006) Improving Tenure Security for the Rural Poor: Rwanda-country case study. Kigali: FAO

Musahara, H. (2013) Perspectives on Cooperatives with Reference to Rwanda. Paper presented at a regional conference on 'Perspectives for cooperatives in Eastern Africa', organized by Friedrich-Ebert-Stiftung, October 2012, Kampala.

Musahara, H. and C. Huggins (2005) Land reform, land scarcity and post-conflict reconstruction: A Case Study of Rwanda, in Huggins, C. and J. Clover (eds) (2005): 269346. From the Ground Up: Land Rights, Conflict and Peace in Sub-Saharan Africa. Pretoria: Institute for Security Studies

Musoni, E. (2011) Africa can overcome food insecurity - Kagame. The New Times (Kigali), January 29, 2011. Accessed online on $19^{\text {th }}$ June 2012 at http://www.newtimes.co.rw/news/index.php?a=37862\&i=14520 Musoni, J. (2007) Rebuilding Trust in post-conflict situation through Civic Engagement: The Experience of Rwanda. Paper presented at the 7th Global Forum on Reinventing Government; Vienna, Austria: $27-29^{\text {th }}$ June

Mutisi, M. (2012) Local conflict resolution in Rwanda: The case of abunzi mediators in Mutisi, M. (ed): 41-74. Integrating Traditional and Modern Conflict Resolution: Experiences from selected cases in Eastern and the Horn of Africa. Africa Dialogue Monograph Series No. 2/2012 
Mwangi, W. (2006) The Social Relations of e-Government Diffusion in Developing Countries: The Case of Rwanda. Paper presented at the 2006 international conference on Digital government research, May 21-24, San Diego, California Mwesigye, E. (2007) Deliver or Resign, Local Leaders Told. The New Times (Kigali), November 26, 2007. Accessed on January $30^{\text {th }} 2013$ at http://www.newtimes.co.rw/news/index.php?a=2525\&i=1360

National Institute of Statistics of Rwanda (NISR) (2010) National Agricultural Survey 2008. Kigali: Republic of Rwanda NISR (2012a) EICV3 District Profile: Musanze. Kigali: Republic of Rwanda NISR (2012b) Population and Housing Census Provisional Results. Kigali: Republic of Rwanda.

Excel File, accessed on January $30^{\text {th }} 2013$ at http://www.statistics.gov.rw/publications/2012-population-and-housing-censusprovisional-results

NISR (2012c) EICV3 District Profile: Kirehe. Accessed online on $30^{\text {th }}$ January 2013 at http://www.statistics.gov.rw/publications/eicv-3-kirehe-district-profile NISR (2012d) EICV3 Thematic Report: Agriculture. Kigali: Republic of Rwanda 
NISR (2012e) The System of Agricultural Statistics in Rwanda (Improvement Action Plan). Kigali: Republic of Rwanda

NISR (2012f) Visa Instruction Manual. Kigali: Republic of Rwanda

NISR (2012g) The Third Integrated Household Living Conditions Survey (Eicv3). Kigali:

Republic of Rwanda

NISR (2013) Featured Indicators. Accessed on $21^{\text {st }}$ January 2013 at

http://www.statistics.gov.rw/indicators/featured

NURC (2012a) Mission and Vision. Accessed on $20^{\text {th }}$ August 2012 at

http://www.nurc.gov.rw/about-nurc/mission-vision.html

Newbury, C. (1988) The Cohesion of Oppression: Clientship and Ethnicity in Rwanda, 1860-. 1960. New York: Columbia University Press

Newbury, C. (1992) Rwanda: Recent Debates over Governance and Rural Development, in Hyden, G. and M. Bratton (eds.): 193-219. Governance and Politics in Africa. Boulder and London: Lynne Rienner

Newbury, C. (1995) Background to Genocide: Rwanda, in Issue: A Journal of Opinion, 23, (2): $12-17$

Newbury, C. (2011) High Modernism at the Ground Level, in Straus S. and Waldorf L. (eds.): 223-239. Remaking Rwanda: State Building and Human Rights after Mass Violence. Madison, University of Wisconsin Press 
Ngendahimana, L. (2012) Six Years of Transforming Rwanda. The New Times (Kigali),

October 10, 2012. Accessed on $31^{\text {st }}$ June 2013 at

http://www.newtimes.co.rw/news/index.php?i=15153\&v=247\&t=Six\%20Years\%20of\%2

OTransforming\%20Rwanda

Niringiye, A. and C. Ayebale (2012) Impact Evaluation of the Ubudehe Programme in Rwanda. Journal of Sustainable Development in Africa. 14 (3): 141-154

Nkuranga, T. and K. Wilcox (2013) Cooperative Performance Index: Field Results and Analysis. Kigali: USAID-Rwanda

Nsabimana, J. (2010) The Role Of Performance Contract (Imihigo) in The Transformation Of Agriculture in Rwanda. MsC Thesis: Wageningen University

Nsanzabaganwa, M. (2011) Captured for Success: How Private Actors Can Become Active Implementers of Development Policy. Paper presented at Stellenbosch University, 25 August 2011

Nsanzabaganwa, M. (2012) Uncertainty and private sector response to economic development policy in post-genocide Rwanda. PhD Dissertation. Department of Economics, Stellenbosch University

Nsanzimana, J-C. (2013) Farmers decry 'overzealous' local leaders. The Rwanda Focus. March $24^{\text {th }} 2013$. Accessed online on December $16^{\text {th }}, 2013$ at http://focus.rw/wp/2013/03/farmers-decry-overzealous-local-leaders/ 
Ntambara, F. (2007) Teach the population about the importance of intensive farming. The New Times (Kigali), October 16, 2007. Accessed on January 30, 2013 at http://www.newtimes.co.rw/news/index.php?a=1628\&i=1319

Ntambara, P. (2009) Nyamagabe on the Rise. The New Times (Kigali), August 14, 2009. Accessed online on December 16, 2013 at http://www.newtimes.co.rw/news/index.php?a=18733\&i=13987

Odooboo, K. (2010) Changing Lives: How MINAGRI is Transforming Agriculture. The New Times (Kigali), May 2, 2010. Accessed online on December 16, 2013 at http://www.newtimes.co.rw/news/index.php?a=6789\&i=14248

The Organisation for Economic Co-operation and Development (OECD) (2008) The Paris Declaration on Aid Effectiveness and the Accra Agenda for Action. Paris: OECD

OECD/WTO (2011) Support to the Agriculture Sector in Rwanda (2003-2010): European Union. Aid-for-Trade Case Study. Paris: OECD

Office of the Inspector General (2011) Audit of USAID/Rwanda's Agricultural Activities. Pretoria: USAID

Office of Tony Blair (2011) Africa Governance Initiative and the Republic of Rwanda establish innovative new partnership. Accessed online on February $26^{\text {th }} 2012$ at http://www.africagovernance.org/africa/news-entry/africa-governance initiative-andthe-government-of-rwanda-establish-innovat/ 
Olanyo, J. (2011) Rwanda soldiers kick out poverty. Igihe.com. Accessed on $12^{\text {th }}$ January 2013 at http://en.igihe.com/news/rwanda-soldiers-kick-out-poverty.html

Oluoch-Ojiwah, F. (2012) Agriculture tops 2011 investments as overall investments hit US\$598million. The New Times (Kigali), December 23, 2011. Accessed $18^{\text {th }}$ July 2012 at http://www.newtimes.co.rw/news/index.php?i=14848\&a=48404

Orth, R. (2001) Rwanda's Hutu Extremist Insurgency: An Eyewitness Perspective, Small Wars \& Insurgencies, 12: 76-109

OSSREA (2007) Rapid and Extensive Assessment of Performance Management Contracts - Imihigo. OSSREA Rwanda Chapter, Kigali. July 2007

ØSTERUD, O. (1976) The Class Quality of Peasantry: A Conceptual Exploration. Scandinavian Political Studies, 11: 35-50

Palmer, R. (2000) Recent Experiences of Civil Society Participation in Land Policy Planning in Rwanda and Malawi, Paper presented at International Conference on Agrarian Reform and Rural Development (ICARRD), Tagaytay City, Philippines, December 5-8

Patel, A. (2007) Stuffed and Starved: The Hidden Battle for the World Food System. Toronto: Harpercollins

Perelman, M. (2000) The Invention of Capitalism: Classical Political Economy and the Secret History of Primitive Accumulation. Durham, NC: Duke University Press 
Peter (2012) Non-existent cooperatives retard development - RCA. Itezimbere.com, February 5, 2012. Accessed online on February $24^{\text {th }} 2012$ at http://www.itezimbere.com/2012/02/rwanda-non-existent-cooperatives-retarddevelopment-rca/

Peters, Pauline (2004) Inequality and Social Conflict over Land in Africa, Journal of Agrarian Change 4(3): 269-314.

Plehwe, D., B. Walpen, and G. Neunhoffer (2006) (eds) Neoliberal Hegemony: A Global Critique. New York: Routledge

Polanyi, K. (2001) The Great Transformation: The Political and Economic Origins of Our Time. Boston: Beacon Press

Pottier, J. (1999) Anthropology of food: the social dynamics of food security. Cambridge: Polity Press

Pottier, J. (2002) Re-imagining Rwanda: conflict, survival and disinformation in the late twentieth century. Cambridge: Cambridge University Press

Pottier, J. (2006) Land Reform for Peace? Rwanda's 2005 Land Law in Context. Journal of Agrarian Change 6 (4): 509-37

Pottier, J. (2012) Reshaping Gender through Agricultural Reform: The Case of Rwanda. Paper presented at the Bhutan +10 Conference on Gender and Sustainable Mountain Development in a Changing World, Thimphu, Bhutan, 15-19 October 
Pottier, J. and A. Nkundabashaka, (1992) Intolerable Environments: Towards a cultural reading of agrarian practice and policy in Rwanda in Croll, E. and D. J. Parkin (eds): 146168. Bush Base, Forest Farm: Culture, Environment and Development. London: Routledge, 1992

Pritchard, M (2010) Land, power and peace: tenure systems and the formalization agenda in postgenocide Rwanda. Presentation at International Workshop on Collective Action, Property Rights, and Conflict in Natural Resources Management, June 28th to July 1st, Siem Reap, Cambodia. Accessed online at on $23^{\text {rd }}$ July 2012 at http://www.slideshare.net/capriaccount/land-power-and-peace-tenure-systems-andthe-formalization-agenda-in-postgenocide-rwanda

Pritchard, M. (2013) Land, power and peace: Tenure formalization, agricultural reform, and livelihood insecurity in rural Rwanda. Land Use Policy 30: 186- 196

Projet d'Appui au Système National de Vulgarisation Agricole (PASNVA) (2011) Etat Des Lieux Des Activites Du Projet PASNVA 2007-2010. Kigali: MINAGRI

Prunier, G. (1995) The Rwanda Crisis: History of a Genocide, 1959-1994. Fountain Publishers, Kampala

Prunier, G. (1998) The Rwandan Patriotic Front, in Clapham, C. (ed): 119-133. African Guerillas. Indiana University Press

Purdeková, A. (2011) 'Even if I am not here, there are so many eyes': surveillance and state reach in Rwanda. The Journal of Modern African Studies, 49: 475-497 
Purdekova, A. (2011b) Rwanda's Ingando camps: Liminality and the reproduction of power. University of Oxford. Refugee Studies Centre Working Paper No. 80

Purdekova, A. (2012a). Civic Education and Social Transformation in Post-Genocide Rwanda: Forging the Perfect Development Subjects, in Campioni, M. and Noak, P. (eds): 192-212. Rwanda Fast Forward: Social, Economic, Military and Reconciliation Prospects. Palgrave Macmillan

Purdekova, A. (2012b). Everyday Politics in Post Genocide Rwanda: A Micro Perspective on the Production of Disempowerment. Paper presented at Conference on 'Rwanda from below', 29-30 June 2012, Institute of Development Policy and Management, Antwerp, Belgium.

Pyramid Project (n.d.) Genesis and Accomplishments of the Pyramid Project. Butare: National University of Rwanda Rwanda Agriculture Board (RAB) (2013) A Two Days Workshop on Mycotoxin Contamination -Maize and Cassava in Rwanda, 05 May, 2013. Accessed online on May $16^{\text {th }}$ at http://rab.gov.rw/spip.php?article216

Rabasa, A. and J. E. Peters (2007) Dimensions of Ungovernability in Rabasa, A., S. Boraz, P. Chalk, K. Cragin, T. W. Karasik, J.D. P. Moroney ,K. A. O'Brien and Peters, J.E.: 8-18. Ungoverned territories: understanding and reducing terrorism risk. Santa Monica: RAND Corporation 
Ratcliffe, J. (2013) The (Post) Development of Rwandan Rice-Growers' Cooperatives. Master's Thesis: University of Ottawa

Reed, C. M. (1996) Exile, Reform, and the Rise of the Rwandan Patriotic Front. The Journal of Modern African Studies, 34 (3): 479-501

Remaking Rwanda Blog (2013) Accessed online on October $30^{\text {th }} 2013$ at: http://www.blogger.com/profile/03877014324031958318

Republic of Rwanda (2007) Law N 18/2007 of 19/04/2007 Relating To Expropriation in the Public Interest. Kigali: Republic of Rwanda

Republic of Rwanda, (2008). Joint Governance Assessment. Kigali: Republic of Rwanda Republic of Rwanda (2010) Ministerial Order N¹4/11.30 of 21/12/2010 Determining The Models Of Land Consolidation And Its Productivity. Kigali: Republic of Rwanda

Republic of Rwanda/United Nations (2007) Minutes of the XL Development Partners' Coordination Group Meeting, 15th November 2007. Accessed online on January 23, 2008 at www.devpartners.gov.rw

Research into Use (RIU) (2009) Prospects for increasing productivity, profitability and competitiveness of Maize in Nyagatare District, Eastern Province/Rwanda: Resolutions from the Maize Innovation Platform workshop held in Nyagatare 28-29 October 2009. Accessed online on 18th January 2013 at http://www.researchintouse.com/resources/riu09rw-maize-innovplatf.pdf 
Rettig, M. (2011) The Sovu Trials: the Impact of Genocide Justice on one Community, in Straus, S. and Waldorf, L. (eds) (2011): 194-209

Reyntjens, F. (1987) Chiefs and burgomasters in Rwanda: the unfinished quest for a bureaucracy. Journal of Legal Pluralism and Unofficial Law, 25-26: 71-97

Reyntjens, F. (2010) Constructing the Truth, Dealing with Dissent, Domesticating the World: Governance in Post-Genocide Rwanda. African Affairs, 110 (438): 1-34

Reyntjens, F. (2013) Political Governance in Post-Genocide Rwanda. Cambridge: Cambridge University Press

Richardson, J. (2013) How Monsanto Went From Selling Aspirin to Controlling Our Food Supply. Truth-Out News, accessed online on $22^{\text {nd }}$ April 2013 at http://www.truthout.org/news/item/15856-how-monsanto-went-from-selling-aspirin-to-controlling-ourfood-supply

Riungu, C. (2011) Rwanda: The Story of a Food Secure Nation. The East African (Nairobi), January 30th, 2011. Accessed online on December 17, 2013, at http://allafrica.com/stories/201101311486.html

Robbins, P. (2012). Political Ecology (2nd edition): Malden, MA: Blackwell

Roberts, N.C. and King, P. J. (1991) Policy Entrepreneurs: Their Activity Structure and Function in the Policy Process. Journal of Public Administration Research and Theory, 1(2): 147-175 
Robins, E. (1990) The Lesson of Rwanda's Agricultural Crisis, in Huss-Ashmore, R. and S. H. Katz (eds.): 245-268. African Food Systems in Crisis; Part Two: Contending with Change, New York: Gordon and Breach Science Publishers.

Robins, S. (2002) At the Limits of Spatial Governmentality: a Message from the Tip of Africa. Third World Quarterly, 23 (4): 665-689

Rockefeller Foundation (2013) Maize Network: Research into Use, Rwanda. Catalytic Innovations in African Agriculture Centennial Series. Accessed online on November $6^{\text {th }}$, 2013, at http://b.3cdn.net/rockefeller/8f06ae934a12606dc6 pxm6buyia.pdf

Ron-Balsera, M. (2011) Does the Human Capital Discourse Promote or Hinder the Right to Education? The Case of Girls, Orphans and Vulnerable Children in Rwanda. J. Int. Dev. 23: $274-287$

Rose, N. (1999). Powers of Freedom: Reframing Political Thought. Cambridge: Cambridge University Press

Ross, E. (2003) Malthusianism, Capitalist Agriculture, and the Fate of Peasants in the Making of the Modern World Food System, Review of Radical Political Economics, 35 (4): 437-461

Rurangwa, E. (2002) Perspective of Land Reform in Rwanda. Paper presented at FIG XXII International Congress, Washington D.C., 19-26 April. 
Rutherford, B. (2008) Conditional Belonging: Farm Workers and the Cultural Politics of Recognition in Zimbabwe. Development and Change 39(1): 73-99

Rwagahigi, M. (2012) Rwanda Governance Board calls for leniency from authorities in policy implementing. Hope Magazine (Kigali), May 24, 2012. Accessed online on December 17, 2013 at http://www.hope$\underline{\text { mag.com/news.php?option }=\text { Inews } \& \text { ca }=1 \& a=243}$

Rwanda Cooperatives Agency (2006) National Policy on Promotion of Cooperatives. Kigali: Republic of Rwanda

Rwanda Cooperatives Agency (2013) List of cooperatives. Database accessed on May $6^{\text {th }}$, 2013, at http://www.rca.gov.rw/wemis/registration/all.php?start=0

Rwanda Environmental Management Agency (REMA) (2009) Rwanda State of Environment and Outlook. Kigali: Rema/UNEP.

Rwanda Local Development Support Fund (RLDSF) (2013) District Potentialities Assessment for the Integrated and Self-Centered Local Economic Development: District of Musanze. Kigali: Republic of Rwanda

Rwanda National Police (RNP) (2012a) Police cordon and search operation in Kirehe districts [sic] arrests nine and seize narcotics. Accessed on $21^{\text {st }}$ February 2013 at 
http://police.gov.rw/content/police-cordon-and-search-operation-kirehe-districtsarrests-nine-and-seize-narcotics

Rwanda National Police (RNP) (2012b) Police, MINAGRI determined to fight fertilizer smuggling. Accessed online on May $15^{\text {th }} 2012$ at http://police.gov.rw/content/policeminagri-determined-fight-fertilizer-smuggling

Rwangombwa, J. (2012) Rwanda Can Be Proud of Its Economic Progress. Wall Street

Journal. February $10^{\text {th }}, 2010$. Accessed on $22^{\text {nd }}$ January 2013 at

http://online.wsj.com/article/SB10001424052970203824904577212704208216364.htm $\underline{1}$

Rwembeho, S. (2010) USAID awards dairy farmers. The New Times (Kigali), December 1, 2010. Accessed online on $19^{\text {th }}$ June 2012 at http://www.newtimes.co.rw/news/index.php?a=36178\&i=14461

Rwembeho, S. (2010a) Rwanda: Tanzania, Burundi Deport Suspected Fertiliser Smugglers. The New Times (Kigali) October 13, 2010. Accessed on $21^{\text {st }}$ February 2013 at http://allafrica.com/stories/201010130570.html

Rwembeho, S. (2010b) The farming revolution in Kirehe district. The New Times (Kigali), June 14,2010 . Accessed on $22^{\text {nd }}$ January 2013 at http://www.newtimes.co.rw/news/index.php?a=30212\&i=14291 
Rwembeho, S. (2010c) Pests destroy crops. The New Times (Kigali), December 30, 2010. Accessed online on $19^{\text {th }}$ June 2012 at http://www.newtimes.co.rw/news/index.php?a=24237\&i=14125

Rwembeho, S. (2010d) High agricultural production brings down maize prices. The New Times (Kigali), August 13, 2010. Accessed online on December 17, 2013 at http://www.newtimes.co.rw/news/index.php?a=32487\&i=14351

Rwembeho, S. (2010e) Kirehe to produce over 50,000 tonnes of maize. The New Times (Kigali), February 13, 2010. Accessed on January 30 2013 at http://www.newtimes.co.rw/news/index.php?a=25818\&i=14170

Rwembeho, S. (2010f) Burundian local leaders tour Kirehe. The New Times (Kigali), November 22, 2010. Accessed online on $22^{\text {nd }}$ February 2013 at http://www.newtimes.co.rw/news/index.php?i=14452\&a=35877

Rwembeho, S. (2011a) Farmers urged to embrace irrigation. The New Times (Kigali), August 28, 2011. Accessed online on December 17, 2013 at http://www.newtimes.co.rw/news/index.php?a=10168\&i=14731

Rwembeho, S. (2011b) Local leaders forecast food shortages in East. The New Times (Kigali), April 7, 2011. Accessed online on $19^{\text {th }}$ June 2012 at http://www.newtimes.co.rw/news/index.php?a=39930\&i=14588 
Rwembeho, S. (2012) Local leaders arrested in suspected maize scam. The New Times (Kigali), January 17, 2012 Accessed online on December 17, 2013 at http://www.newtimes.co.rw/news/index.php?a=49138\&i=14873

Rwembeho, S. (2013) New Dyke to Water Kirehe Farms. The New Times (Kigali), March 26, 2013. Accessed online on November $27^{\text {th }} 2013$ at http://allafrica.com/stories/201303270927.html

Rwembeho, S. and A. Niyonzima (2009) Kirehe targets bumper maize harvest this season. The New Times (Kigali), November 5, 2009. Accessed online on $11^{\text {th }}$ April 2013 at http://www.newtimes.co.rw/news/index.php?a=22115\&i=14070

Sagashya, D. and English, C. (2010) Designing and Establishing a Land Administration System for Rwanda: Technical and Economic Analysis; in Deininger, K., Augustinus, C. and S. Enemark (eds): 43-59. Innovations in Land Rights Recognition, Administration, and Governance. Washington, DC: World Bank

Salskov-Iversen, D., H. K. Hansen and S. Bislev (2000) Governmentality, Globalization, and Local Practice: Transformations of a Hegemonic Discourse. Alternatives: Global, Local, Political, 25(2) (Apr.-June): 183-222

Sasaki, T. and B. A. Antonio (2009) Plant genomics: Sorghum in sequence. Nature 457: $547-548$ 
Schattenberg, P. (2009) SC Johnson partners with Borlaug Institute, USAID to help Rwandan farmers. Press Release, June 3, 2009, Texas A \& M University. Accessed on $19^{\text {th }}$ July, 2012 at http://agnews.tamu.edu/showstory.php?id=1233

Schneider, L. (2007) High on Modernity? Explaining the Failings of Tanzanian Villagisation. African Studies, 66(1): 9-38

Schrader, T. and Wennink, B. (2010) Unleashing rural entrepreneurship in Rwanda: exploring options for innovating agricultural development cooperation. Amsterdam: Royal Tropical Institute (KIT)

Scott, J. (1985) Weapons of the Weak: Everyday Forms of Peasant Resistance. Yale University Press

Scott, J. (1998) Seeing Like a State: How Certain Schemes to Improve the Human Condition Have Failed New Haven: Yale University Press

Scott, J. (2010) James Scott on Agriculture as Politics, the Dangers of Standardization and Not Being Governed. Theory Talk \# 38. Göteborg, Sweden. Accessed online on $11^{\text {th }}$ April 2013 at http://www.isn.ethz.ch/isn/DigitalLibrary/Publications/Detail/?Ing=en\&id=155099

Sebarenzi, J. (2009) God Sleeps in Rwanda: A Journey of Transformation. New York: Simon and Schuster 
Sentama, E. (2009) Peacebuilding in post genocide Rwanda: Role of cooperatives in restoring interpersonal relationships PhD Thesis University of Gothenburg. Faculty of Social Sciences

Shanin, T. (1971) Peasants and Peasant Societies. Harmondsworth: Penguin

Shiva, V. (1991) The Green Revolution in the Punjab, The Ecologist, 21 (2): 57-60

Siri (2010) Rewarding Rwanda. Webpage. Accessed online on November 12, 2013 at http://sigriirwanda.wordpress.com/

Smith, A. (1759) The Theory of Moral Sentiments. London: A. Millar

Smith, D. (2013) US blocks military aid to Rwanda over alleged backing of M23 child soldiers. The Guardian, October 4, 2013. Accessed online on October 30, 2013 at http://www.theguardian.com/global-development/2013/oct/04/us-military-aidrwanda-m23-child-soldiers

Smith, D. (2012) Rwandan soldiers joined forces with Congo rebels, UN told. The Guardian (online edition), December 4, 2012. Accessed on January 29, 2012 at http://www.guardian.co.uk/world/2012/dec/04/rwandans-congo-rebels-un

Sommers, M. (2012) Stuck: Rwandan Youth and the Struggle for Adulthood. Athens, Georgia: University of Georgia Press 
SOPYRWA (2013) Farmer Relations. Webpage. Accessed on $21^{\text {st }}$ February 2013 at http://www.sopyrwa.com/cooperatives.php

Soudan, F. (2013) Rwanda was not created just for me - Kagame. The New Times (Kigali), May 25, 2013. Accessed online on April 4, 2013, at http://www.newtimes.co.rw/news/index.php?a=67249\&i=15368

Spio, K. (1996) Intercropping - The Hidden Revolution: A Solution to Land Scarcity and Household Food Security. Agrekon, 35 (4): 266-270

Stone, R., A. Temu, M. Kalisa, and Cabello, M. (2011) Rural and Agricultural Financial Services Strategy. Kigali: Ministry of Agriculture and Animal Resources and DFID Rwanda

Straus, S. (2006) The Order of Genocide: Race, Power, and War in Rwanda. Ithaca: Cornell University Press

Straus, S. and Waldorf, L. (2011) Seeing like a Post-Conflict State, in Straus, S. and Waldorf, L. (eds): 3-24

Swanson, B., J. Mutimba, P. Adedze, and O. Hixson. (2011). Comprehensive Assessment of Extension Services in Rwanda. Accessed on $18^{\text {th }}$ January 2013 at http://www.measextension.org/meas-offers/country studies/country-overview/rwanda

Takeshi, I., N. F. Rachman, and L. A. Savitri (2011) Naturalizing land dispossession: a policy Discourse analysis of the Merauke integrated food and energy estate. Paper presented at the International Conference on Global Land Grabbing, University of Sussex, 6-8 April. 
Taylor I. (2004) Hegemony, neoliberal 'good governance' and the International

Monetary Fund: a Gramscian perspective, in Boas, M. and D. McNeill (eds.): $124-137$.

Global Institutions and Development: Framing the World? New York: Routledge

Ten Hove, P. (2012) Exotic Technical Compendium. Technical Report. Accessed on $19^{\text {th }}$

June 2012 at

http://www.paultenhove.nl/ventura/engine.php?Cmd=see\&P site=352\&P self=10429\&

$\underline{\text { PMax }=\& P S k i p=M}$

Thomson, S. (2009) 'That is not what we authorised you to do...': Access and government interference in highly politicised research environments, in Sriram, C.L., J. C.

King, J. A. Mertus, O. Martín-Ortega and J. Herman (eds.): 108-124 Surviving Field

Research: Working in violent and difficult situations. London: Routledge

Thomson, S. (2010) Local Power Relations and Household Gender Dynamics: Assessing Rwanda's Claim to Universal HIV/AIDS Treatment in Context. Canadian Journal of African Studies. 44 (3): 552-578

Thomson, S. (2011) Reeducation for Reconciliation: Participant Observations, in Straus, S. and Waldorf, L. (eds) (2011): 331-342

Thomson, S. (2013) Book Review, Stuck: Rwandan Youth and the Struggle for Adulthood, by Marc Sommers, African Studies Review, 56 (1): 180-182

Tibrichu, H. and M. Buykusenge, (2009) Enterprise Network Mapping Study In Rwanda. Kigali: Care International/International Gorilla Conservation Program. 
Tindiwensi, M (2011) Residents want gov't to ban food exports. The New Times (Kigali), June 7, 2012. Accessed online on $19^{\text {th }}$ June 2012 at http://www.newtimes.co.rw/news/index.php?i=15016\&a=10136\&icon=Results\&id=2

Tindiwensi, M. (2008) Mitali wants professional farmers. The New Times (Kigali), February 8, 2008. Accessed online on December 17, 2013 at http://www.newtimes.co.rw/news/index.php?a=4060\&i=13435

Tizikara, C., D. Wilcock, and P.C. Habyarimana (2007) Needs Assessment and Action Plan for Improving Agricultural Research and Technology Transfer: Final Report. Kigali and Washington, D.C.: Republic of Rwanda and World Bank.

Twizeyimana, A. (2010) Rwanda: les agriculteurs produisent plus mais mangent plus mal, April 15, 2010. Accessed online on December 17, 2013 at http://www.syfia-grands$\underline{\text { lacs.info/index.php5?view=articles\&action=voir\&idArticle }=1737}$

U.S. President's Emergency Plan for AIDS Relief (PEPFAR), (2012). Rwanda Operational Plan Report, 2010. Washington DC: US Government.

Umuhinzi (2013) MINAGRI embarks on irrigation mechanization to maintain food security. Umuhinzi.com. Accessed online on May $13^{\text {th }} 2013$ at http://www.umuhinzi.com/2013/02/minagri-embarks-on-irrigation-mechanization-tomaintain-food-security/ 
Unido (1995) Technical Report: Survey of the World Pyrethrum Market and its Med-Term Tendency, Taking Account of New Competitors. Vienna: United Nations Industrial Development Organization.

United Nations Development Fund for Women (UNIFEM) (2010) Imihigo: Adapting a Traditional Accountability Mechanism to Improve Response to Gender-based Violence. Accessed online on April 19, 2010 at http://www.unifem.org/progress/2008/whoFS box1b.html United States Agency for International Development (USAID) (2011) Call for Proposals REQ-696-11-000044. Kigali: Acquisition and Assistance Office, USAID Rwanda United States Department of State (2010a) Rwanda. 2009 Country Reports on Human Rights Practices. Washington, D.C: United States Department of State. Accessed online on February $24^{\text {th }} 2012$ at http://www.state.gov/i/drl/rls/hrrpt/2009/af/135971.htm United States Department of State, (2010b) Statement by NSC Spokesman Hammer on Election in Rwanda. Washington, D.C: United States Department of State. Accessed online on February $24^{\text {th }} 2012$ at http://www.uspolicy.be/headline/statement-nscspokesman-hammer-election-rwanda

United States Department of State (2013) 2013 Investment Climate Statement. Washington, D.C.: Bureau of Economic and Business Affairs, United States Department of State 
US Embassy, Kigali (2009) Bio Report: Minister of Trade and Industry Monique Nsanzabaganwa. Internal cable. Accessed online on May $17^{\text {th }}$ at http://wikileaks.org/cable/2009/12/09KIGALI856.html

USAID (2010a) Partnering with USAID: A Guide for Companies. Washington, DC: USAID USAID (2010b) Alliances in Action: Rwandan Pyrethrum Value Chain Alliance. Kigali: USAID

USAID (2011) Rwanda FY 2011-2015 Feed the future multi-year strategy. Washington, DC: USAID

USAID (2011a) Turning from the Past to Face the Future: Negotiating the Transition to a Post-Genocide Rwanda. Washington, D.C.: USAID

Uvin, P. (2003) Wake up! Some Policy Proposals for the International Community in Rwanda. Unpublished article, June 2003. Accessed online on February $24^{\text {th }} 2012$ at http://ui04e.moit.tufts.edu/faculty/uvin/pdfs/reports/wakeup.pdf

Uvin, P. (1998) Aiding Genocide: the development enterprise in Rwanda. West Hartford, CT: Kumarian Press

van Asten, P.J.A., L.W.I. Wairegi, D. Mukasa and N.O. Uringi (2011) Agronomic and economic benefits of coffee-banana intercropping in Uganda's smallholder farming systems. Agricultural Systems 104: 326-334 
van der Laan J. (2011) 'Going Local': the Case of Minimex. Arnhem, the Netherlands: Agri-ProFocus

van der Ploeg, J. D. (2008) The New Peasantries: Struggles for Autonomy and Sustainability in an Era of Empire and Globalization. London: Earthscan

Van Houdt, N. (2006) On-Farm Assessment Of Banana Plant Density In Rwanda. Catholic University of Leuven: Master's Thesis.

Vandeginste, S. (2005) Rwanda, the World Bank, PRSP and Human Rights. L'Afrique des Grands Lacs, 2004-2005: 119-139

Veldman, M. and M. Lankhorst (2011) Socio-Economic Impact of Commercial Exploitation of Marshes in Rwanda: Cane sugar production in rural Kigali. RCN contribution to ILC Collaborative Research Project on Commercial Pressures on Land. Rome: International Land Coalition

Verdoodt, A. and Van Ranst (2003) A large-scale land suitability classification for Rwanda. Ghent: Ghent University, laboratory of soil science

Verwimp, F. (2002) Agricultural Policy, Crop Failure and the 'Ruriganiza' Famine (1989) in Southern Rwanda: a Prelude to Genocide? Center for Economic Studies Discussions Paper Series (DPS) 02.07. Leuven: Catholic University of Leuven Verwimp, P. (2003) "The one who refuses to work is harmful to society": Juvénal Habyarimana, 14 October, 1973. Working Paper of the Genocide Studies Program. New Haven, CT: Yale University 
Verwimp, P. (2006) Peasant Ideology and Genocide in Rwanda under Habyarimana. Working Paper of the Genocide Studies Program. New Haven, CT: Yale University Villa-Vicencio, C., P. Nantulya, and T. Savage. (2005) Building Nations: Transitional Justice in the African Great Lakes Region. Cape Town: Institute for Justice and Reconciliation

Waldorf, L. (2006) Mass Justice for Mass Atrocity: Rethinking Local Justice as Transitional Justice, Temple Law Review, 1(79): 1-87

Waldorf, L. (2011) Instrumentalising Genocide: the RPF's campaign against "genocide ideology'”, in Straus S. and L. Waldorf (eds): 48-66

Walters, W. P., Larner, W. (2004) Global Governmentality: Governing international spaces. London: Taylor \& Francis.

Waters, T. (2007) The Persistence of Subsistence Agriculture. Lanham, MD: Lexington Books

Watson, V. (2012) African urban fantasies: New generation urban 'master' plans, produced by international architectural and engineering firms. Distinguished Lecture Series, Oxford University, $5^{\text {th }}$ March 2013. Powerpoint presentation, accessed on November $27^{\text {th }} 2013$ at https://www.academia.edu/3568685/African Urban Fantasies Watts, M. (2008) Development and Governmentality. Singapore Journal of Tropical Geography, 24 (1): 6-34 
Wennink, B. and W. Heemskerk (2006) Farmers' organizations and agricultural innovation: Case studies from Benin, Rwanda and Tanzania. Amsterdam: Royal Tropical Institute (KIT)

Wickramasinghe, U. and K. Weinberger (2013) Smallholder Market Participation and Production Specialization. CAPSA Working Paper No. 107. Bogor, Indonesia: CAPSAESCAP

Williams, G., A. Duncan, P. Landell- Mills, S. Unsworth and T. Sheehy (2009) Carrying out a Joint Governance Assessment: Lessons from Rwanda. Policy Practice Brief 5. Brighton, UK: The Policy Practice Ltd.

Wongtschowski, M., J. Belt, W. Heemskerk, and D. Kahan (eds) (2013) The business of agricultural business services: Working with smallholders in Africa. Amsterdam: Royal Tropical Institute; Rome: Food and Agriculture Organization of the United Nations; and Arnhem: Agri-ProFocus

Wood, E. M. (2009) Peasants and the market imperative: the origins of capitalism, in Akram-Lodhi , A. H. and C. Kay (eds.): 37-56. Peasants and Globalization: Political Economy, Rural Transformation and the Agrarian Question. New York: Routledge Woodrow Wilson School Of Public and International Affairs, (2010) Interview with Fabien Majoro. Innovations for Successful Societies Project. Kigali: 27 May 2010 
Worby, E. (2000) ‘Discipline Without Oppression': Sequence, Timing and Marginality in Southern Rhodesia'S Post-War Development Regime. The Journal of African History, 41 (1): 101-125

Worby, E. (1998) Tyranny, parody, and ethnic polarity: ritual engagements with the state in northwestern Zimbabwe. Journal of Southern African Studies, 24 (3): 561-578

World Bank (2011) Rwanda Economic Update, Spring 2011: Seeds for Growth. Washington DC: World Bank.

World Bank (2013) Doing Business 2013: Smarter Regulations for Small and Medium-Size Enterprises. Washington D.C.: World Bank

World Bank Operations Evaluation Department (2004). Rwanda: Country Assistance Evaluation. Washington: World Bank

York, G. (2012) How a U.S. agency cleaned up Rwanda's genocide-stained image. Globe and Mail (Toronto) Jan. 31, 2012

Young, J. and E. Mendizabal (2009) Helping researchers become policy entrepreneurs. ODI Briefing Papers 53, September. London: Overseas Development Institute Zorbas, E. (2009) What does reconciliation after genocide mean? Public transcripts and hidden transcripts in post-genocide Rwanda. Journal of Genocide Research (2009), 11(1):

$127-147$ 
Zorbas, E. (2011) Aid Dependence and Policy Independence: Explaining the Rwandan

Paradox, in Straus S. and Waldorf L. (eds.): 103-117. Remaking Rwanda: State Building and Human Rights after Mass Violence, Madison, University of Wisconsin Press 